\title{
Revista Canaria de Ciencias Sociales
}

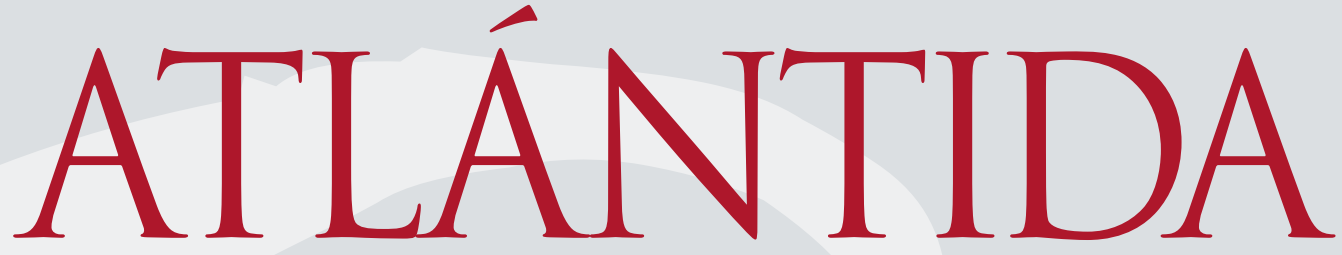

Universidad de La Laguna $11 \quad 2020$ 


\section{Revista}

ATLÁNTIDA 


\title{
Revista \\ ATLÁNTIDA
}

\author{
Revista Canaria de Ciencias Sociales \\ e-mail: alantida@ull.es \\ revistaatlantida@ull.es
}

DIRECTOR

Juan Salvador León Santana (jsleonsa@ull.edu.es) - Universidad de La Laguna

SUBDIRECTOR

Aníbal Mesa López (animelo@ull.edu.es) - Universidad de La Laguna

COMITÉ EDITORIAL

Sadio Ba Gning (Université Gaston Berger-Senegal), Alberto Báez García (Universidad de La Laguna-Espańa), Carmen Marina Barreto Vargas (Universidad de La Laguna-España), Celsa María Cáceres Rodríguez (Universidad de La Laguna-España), María Eugenia Cardenal de la Nuez (Universidad de Las Palmas de Gran Canaria-España), María Olga González Morales

(Universidad de La Laguna-España), Ramón Hernández Armas (Universidad de La Laguna-España), Rodrigo Fidel Hernández Borges (Universidad de La Laguna-España), María Verónica Elizabeth Moreira (Universidad de Buenos Aires-Argentina), Carmina Puig Cruells (Universitat Rovira i Virgili-España), Pablo Rodríguez González (Universidad de La Laguna-Espańa),

Carmen Rodríguez Wangüemert (Universidad de La Laguna-España).

\section{CONSEJO ASESOR}

Carmen Ascanio Sánchez (Universidad de La Laguna-Espańa), Ana Cano Ramírez (Universidad de Las Palmas de Gran Canaria-Espańa), Carla Cubillos Vega (Universidad Complutense de Madrid-Espańa), Rosa María Díaz Jiménez (Universidad Pablo de Olavide-España), David Fuentefría Rodríguez (Universidad de La Laguna-España), Genaro García Guzmán (Universidad Autónoma de Querétaro-México), Manuel Giovine (Universidad Nacional de Córdoba-Argentina), Manuel Eduardo González Ramallal (Universidad de La Laguna-España), Hugo Luna Soria (Universidad Autónoma de Querétaro-México), Blas José Martínez Gallardo (Universidad de Murcia-Espańa), Jesús Muyor Rodríguez (Universidad de Almería-Espańa), Sonia Plasencia Carrillo (Universidad de La Laguna-España), José Quevedo Abu-Tarbush (Universidad de La Laguna-España), Elizabeth Rahman (University of Oxford-United Kingdom), Javier Ramos Benítez (Universidad de La Laguna-España), Vanessa Rodríguez Breijo (Universidad de La Laguna-España), Alberto Jonay Rodríguez Darias (Universidad de La Laguna-España), Sarai Rodríguez González (Universidad de La Laguna-Espańa), María Elena Sánchez Jordán (Universidad de La Laguna-España).

\section{EDITA}

Servicio de Publicaciones de la Universidad de La Laguna Campus Central. 38200 La Laguna. Santa Cruz de Tenerife Tel.: 34922319198

DISEÑO EDITORIAL Jaime H. Vera Javier Torres/Luis C. Espinosa MAQUETACIÓN Y PREIMPRESIÓN Servicio de Publicaciones

DOI: https://doi.org/10.25145/j.atlantid.2020.11

ISSN: 2171-4924 (edición impresa) / ISSN: e-2530-853X (edición digital) Depósito Legal: TF 556/2010

Prohibida la reproducción total o parcial de esta obra sin permiso del editor. 


\section{Revista}

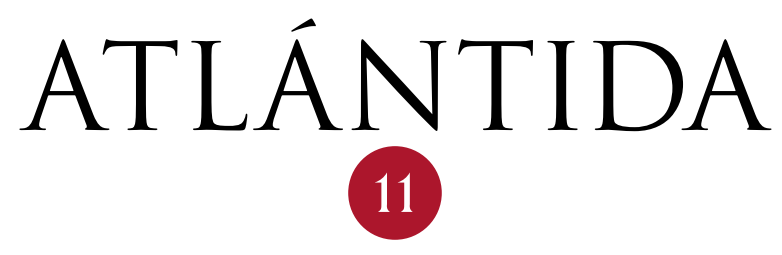

Servicio de Publicaciones

UNIVERSIDAD DE LA LAGUNA, 2020 
REVISTA Atlántida: Revista Canaria de Ciencias Sociales. N. ${ }^{\circ}$ (2009). -La Laguna: Servicio de Publicaciones de la Universidad de La Laguna, 2009-

Semestral

ISSN: 2171-4924

1. Ciencias sociales-Investigación-Publicaciones periódicas I. Universidad de La Laguna. Servicio de Publicaciones, ed.

3(05)

CSIC ISOCA

https://indices.csic.es/

\section{latindex}

http://www.latindex.unam.mx/

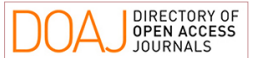

https://doaj.org/

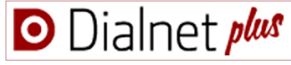

https://dialnet.unirioja.es/
MIAR

http://miar.ub.edu/

\section{NORMAS DE ENVÍO Y PUBLICACIÓN DE ARTÍCULOS}

Atlántida. Revista Canaria de Ciencias Sociales tiene por objeto difundir trabajos académicos inéditos en el ámbito de las ciencias sociales, siempre que su contenido contribuya al mejor conocimiento de la sociedad, la política, la cultura o la metodología de investigación social.

Antes de enviar un manuscrito para su evaluación, le rogamos que verifique que su contenido se ajusta a los objetivos expuestos. Los manuscritos fuera de este ámbito temático podrán ser rechazados sin que se proceda a su evaluación.

1. Los trabajos podrán presentarse, para su evaluación, en español, inglés o francés. Todos los artículos evaluados y aprobados se publicarán en la página web de la revista en el idioma presentado. Para los artículos escritos en inglés, las propias autoras y autores deben responsabilizarse de entregar su trabajo en un inglés adecuado. Se recomienda encarecidamente que, si el inglés no es su lengua materna, sus manuscritos sean revisados por una persona editora familiarizada con la escritura académica inglesa.

2. Atlántida acepta para su publicación los siguientes tipos de manuscritos:

a) Artículos: deberán ser trabajos de investigación originales, de carácter teórico o empírico, con un adecuado desarrollo teórico o analítico y tener el formato habitual de las revistas científicas especializadas.

b) Notas de investigación: deberán informar brevemente de hallazgos singulares, nuevas aportaciones, replicación de hallazgos o ańadidos a la literatura científica que justifiquen su publicación sin la extensión y desarrollo teóricos o el detalle analítico requerido a los artículos.

c) Ensayos bibliográficos: analizarán dos o más publicaciones recientes sobre el mismo tema; podrán tener notas a pie de página y referencias bibliográficas al final.

d) Crítica de libros: serán trabajos ensayísticos que analicen novedades editoriales de interés académico y científico.

e) Trabajos de investigación novel: trabajos de fin de máster o de fin de grado que han destacado por su calidad. Han de venir avalados por un informe docente.

f) Noticias de interés: breves textos dando cuenta de novedades relevantes.

3. Recepción de manuscritos: una vez que el artículo está preparado de acuerdo con las directrices establecidas, se enviará en formato Word (pudiéndose enviar archivos adicionales). El envío se realizará a través de la plataforma OJS, alojada en el servidor web de la Universidad de La Laguna. Una vez registrada/o como autora o autor en la plataforma OJS, deberán seguirse los pasos que allí se indican. Las dudas respecto al envío de trabajos podrán consultarse en las direcciones electrónicas ofrecidas en el apartado de contactos.

4. El envío de manuscritos presupone el conocimiento y aceptación de estas instrucciones, así como de las normas editoriales. 
5. El autor o la autora del envío o la persona remitente será la destinataria de todas las comunicaciones que emita el Consejo de Redacción de Atlántida. Revista Canaria de Ciencias Sociales. Esta persona se hará responsable, en el caso de que existan varios autores o autoras, de contactar con sus colaboradores/as y de facilitar la información necesaria, haciéndose responsable de los posibles conflictos sobre la autoría del manuscrito. Si se desea cambiar al destinatario/a de las comunicaciones, deberá solicitarse explícitamente.

6. Los trabajos han de ser inéditos en cualquier lengua. No obstante, la revista podrá aceptar textos publicados previamente siempre que su calidad y su pertinencia lo justifiquen. Se indicará en el artículo dónde ha sido publicado previamente. Será responsabilidad del autor/a informar sobre la situación de los derechos de autor. A efectos de lo estipulado en los artículos 138-143 de la Ley de Propiedad Intelectual respecto a las acciones y procedimientos que puedan emprenderse contra quien infrinja los derechos de propiedad intelectual, la publicación de un trabajo que atente contra dichos derechos será responsabilidad del autor/a.

7. El trabajo debe estar debidamente anonimizado, y esto incluye las propiedades del documento. Si bien es legítimo, se recomienda evitar la autocita excesiva.

8. Se adjuntará una breve nota biográfica del autor/a o autores, de no más de 150 palabras por cada persona. En cualquier caso, habrán de constar:

a) El nombre completo.

b) La filiación institucional, que se dará en orden decreciente; esto es, primero la institución general (entidad principal), seguido de la institución o instituciones subordinadas (departamentos, etc.) en el orden de dependencia orgánica que tengan. Se indicará la ciudad (aunque el nombre de la institución ya lo incluya) y el país. Se empleará el nombre completo y oficial de la institución.

c) Una dirección de correo electrónico.

d) Un teléfono de contacto.

El Consejo de Redacción de Atlántida. Revista Canaria de Ciencias Sociales se reserva el derecho de publicar un resumen de dicha nota biográfica conforme a los usos de las revistas especializadas.

9. En cuanto al formato del manuscrito se deberán tener en cuenta las siguientes indicaciones:

a) Los "artículos", los "trabajos de investigación novel» y las "notas de investigación" llevarán el título en español y luego en inglés (además del idioma original, si fuera diferente a estos). El título deberá reflejar el contenido del artículo o nota. No se recomienda emplear títulos con más de 10 palabras. Se podrán emplear subtítulos, pero en ningún caso incluirán abreviaturas.

b) Los trabajos irán precedidos de un breve resumen de entre 100 y 130 palabras, que tendrá una versión en español y otra en inglés (además del idioma original, si fuera diferente a estos), siendo todos de idéntico contenido. El resumen debe exponer con claridad la finalidad del estudio o investigación (objetivos), los procedimientos básicos (métodos), los principales hallazgos (resultados) y las conclusiones más relevantes, así como resaltar los aspectos nuevos e importantes del estudio.

c) Bajo el resumen se añadirán entre 3 y 5 palabras clave en español con su correspondiente traducción en inglés (además del idioma original, si fuera diferente a estos). A ser posible se usarán términos internacionalmente aceptados en las disciplinas de ciencias sociales.

d) Tras las palabras clave, se incluirá el texto del manuscrito propuesto que, en todo caso, habrá de atenerse a las siguientes características:

- Los «artículos» y "trabajos de investigación novel» tendrán una extensión máxima de 10000 palabras en total, incluyendo título, resúmenes, palabras clave, tablas, bibliografía y notas al pie.

- Las «notas de investigación» tendrán una extensión máxima de 5000 palabras en total, incluyendo título, resúmenes, palabras clave, tablas, bibliografía y notas al pie.

- Los «ensayos bibliográficos» tendrán una extensión máxima de 3500 palabras en total.

- Las «críticas de libros» tendrán una extensión máxima de 2500 palabras en total. En ellas se deberá especificar el autor, título, editorial, lugar y fecha de publicación de la obra analizada, así como el nombre, los apellidos y la dirección de contacto del autor de la crítica.

10. En lo que se refiere al estilo del texto del manuscrito que se envía, se debe:

a) Emplear un solo tipo y tamańo de letra: Times New Roman 12.

b) No justificar el texto.

c) No sangrar el comienzo de los párrafos. 
d) Todas las abreviaturas estarán descritas la primera vez que se mencionen.

e) Las notas irán a pie de página.

11. Todas las tablas y gráficos estarán numerados correctamente (números romanos para las tablas y números arábigos para los gráficos) y presentados en su ubicación correspondiente dentro del texto. Han de tener un título conciso que permita entender el contenido de la tabla o gráfico. Las imágenes habrán de enviarse en formato jpg, png o tiff, debiendo tener una resolución de 300 píxeles/pulgada, con un tamańo mínimo de $10 \mathrm{~cm}$ de ancho.

12. Todas las referencias de la bibliografía deben tener su correspondencia en el texto, así como toda manifestación expresada en el texto como perteneciente a otro autor/a debe tener su correspondencia en la bibliografía.

13. Las citas de libros y artículos en el texto se harán indicándose entre paréntesis el apellido del autor/a en minúsculas, seguido del año y página de la publicación, ej: (Bourdieu, 2000: 31). Si dos o más documentos tienen el mismo autor/a y año, se distinguirán entre sí con letras minúsculas a continuación del año y dentro del paréntesis, ej: (Coté, 1985a). Los documentos con dos autores/as se citan por sus primeros apellidos unidos por “y», ej: (Newton y Norris, 2000). Para los documentos con más de dos autores se abreviará la cita indicando solamente el apellido del primer autor seguido de et al.

14. Las referencias bibliográficas se pondrán al final del texto, siguiendo el orden alfabético de autores y según las siguientes formas establecidas:

a) En caso de autores múltiples: primer autor/a: apellido/inicial del nombre; restantes autores: apellido/inicial del nombre. Si no son más de tres autores/as hay que mencionarlos a todos; si son más de tres, hay que poner al primero y luego et al.

b) Año de publicación entre paréntesis.

c) Título del artículo o de un capítulo de un libro entre comillas y del libro en cursiva. El nombre de la revista también irá en cursiva.

d) Lugar de publicación, editorial o nombre de la revista, número y páginas que comprende.

Como referencia, se pueden citar los siguientes ejemplos ilustrativos:

* Referencias de libros:

a) Inglehart, R. (1997). Modernization and Postmodernization. Princeton: Princeton University Press.

b) Campbell, A. et al. (1960). The American Voter. New York: Wiley.

\section{* Referencias a capitulos de libros:}

Newton, K. y Norris, P. (2000). «Confidence in Public Institutions: Faith, Culture, or Performance?», en S. Pharr y R. Putnam (eds.), Disaffected Democracies: What's Troubling the Trilateral Countries? Princeton: Princeton University Press.

* Referencias a artículos de revistas:

Clarke, H.D., Dutt, N. y Kornberg, A. (1993). «The Political Economy of Attitudes toward Polity and Society in Western European Democracies». Journal of Politics, 55(4): 998-1021.

\section{* Referencias de Internet:}

Green, M., Krosnick, J.A. y Holbrook, A.L. (2001). «The Survey Response Process in Telephone and Face-to-Face Surveys: Differences in Respondent Satisficing and Social Desirability Response Bias», recuperado de http://www.clas.ufl.edu/users/kenwald/pos6757/spring02/tch62.pdf. Última consulta: 01/04/2011.

15. Los/as autores/as deben declarar, en su caso, soporte o financiación pública o privada de la investigación. 


\section{SUMARIO / CONTENTS}

\section{INTRODUCCIÓN / INTRODUCTION}

Discapacidad, diversidad y derechos humanos: apuntes para la reflexión y el debate / Disability, diversity and human rights: notes for reflection and discussion

Celsa Cáceres Rodríguez.

\section{ARTÍCULOS / PAPERS}

Una aproximación a la bioética de la diversidad funcional desde el deseo / An approach to the bioethics of functional diversity from desire

\section{Antonio Centeno Ortiz}

Documentar la sexualidad y la diversidad funcional. El sexo y los cuerpos diversos y no normativos como armas de empoderamiento y reivindicación política en Yes we fuck!, Jo també vull sexe! y Crip Camp / Document sexuality and functional diversity. Sex and diverse, non-regulatory bodies as weapons of empowerment and political vindication in Yes we fuck!, Jo també vull sexe! and Crip Camp

Hernando Carlos Gómez Prada y Marcos Bote Díaz.

Costa Rica: la situación de las personas con discapacidad en perspectiva histórica y actual / Costa Rica: the situation of people with disabilities in historical and current Perspective

$$
\text { Mariana Campos Vargas.. }
$$

Personas con discapacidad en cárceles. Reflexiones desde el trabajo social / People with disabilities in prisons. Reflections from Social Work

Clarisa Ramos Feijóo y Josefa Lorenzo García.

Inserción laboral del alumnado con discapacidad en la Universidad de Las Palmas de Gran Canaria (ULPGC) / Labour insertion of disabled students at the University of Las Palmas de Gran Canaria 


\section{INVESTIGACIÓN NOVEL / NOVEL INVESTIGATION}

La alteración de la salud del trabajador como factor de discriminación en las relaciones laborales: discapacidad y enfermedad / Altering workers' health as a factor of discrimination in employment relationships: disability and illness

Patricia Orlanda Rodríguez Padrón.

\section{MISCELÁNEA / MISCELLANY}

Dinámica y cautiva: la cultura material de la casa. Una mirada etnográfica sobre el habitar en Haedo, Provincia de Buenos Aires / Dynamic and captivating: the material culture of the house. An ethnographic glance of the way of inhabiting Haedo, Province of Buenos Aires

María Florencia Blanco Esmoris.

Cambios en la población de los municipios de hasta 5000 habitantes de España (2000-2019): una aproximación a la crisis demográfica en el territorio rural / Changes in the population of the municipalities with less than 5000 inhabitants in Spain (2000-2019): an approach to the demographic crisis in the rural territory

Xosé Elías Trabada Crende.

Multipartidismo parlamentario y pluripartidismo gubernamental. Vicisitudes del sistema de partidos del Estado español (2015-2020) / Parliamentary multipartidism and governmental pluripartidism. Vicissitudes of the party system of the Spanish State (2015-2020) 


\title{
INTRODUCCIÓN / INTRODUCTION
}

\section{DISCAPACIDAD, DIVERSIDAD Y DERECHOS HUMANOS: APUNTES PARA LA REFLEXIÓN Y EL DEBATE}

\author{
DISABILITY, DIVERSITY AND HUMAN RIGHTS: \\ NOTES FOR REFLECTION AND DISCUSSION
}

\author{
Celsa Cáceres Rodríguez \\ ccaceres@ull.edu.es
}

La discapacidad es un hecho inherente a la misma condición humana, complejo, heterogéneo y controvertido, de ahí la dificultad para lograr una definición unívoca y universal. Del mismo modo, la diversidad se puede entender de diferentes modos; no obstante, aceptamos que la diversidad es una de las principales características del ser humano y de su sexualidad. Por tanto, se puede decir que la diversidad humana está representada por 7500 millones de cuerpos diferentes, que piensan y sienten de maneras distintas. Así, asumimos que la diferencia es la sustancia de la individualidad, cada ser humano es único e irrepetible, al mismo tiempo que, tal y como hemos acordado en la Declaración Universal de los Derechos Humanos (DUDH) de 1948, nos reconocemos como iguales en dignidad y derechos.

La discapacidad puede ser explicada de modo distinto dependiendo de factores tales como el país de origen, el género, la edad, las ideologías políticas o creencias religiosas o la situación socioeconómica (OMS, 2011). Por consiguiente, las formas de abordar las «situaciones de menoscabo» (Casado, 1991: 51) a lo largo de la historia han estado marcadas por las ideas filosóficas, políticas y económicas de cada etapa que han configurado estructuras sociales diversas.

A lo largo de la historia, se pueden establecer dos ejes diferenciadores, uno sincrónico - propio de cada contexto cultural-y otro diacrónico que posibilita establecer grandes periodos históricos en el tratamiento social de las deficiencias (IOÉ y CIMOP, 1998).

En el eje sincrónico, las actitudes de apoyo o de rechazo hacia las personas que padecen menoscabo han coexistido y se han mezclado dando lugar a formas diferentes, en el seno de cada contexto sociocultural, de entender y afrontar la discapacidad. En el eje diacrónico, se ha pasado de un enfoque animista-religioso en el que las deficiencias eran resultado de poderes sobrenaturales o de castigos divinos 
a otro técnico-secularizado que concibe las deficiencias como el resultado de una enfermedad congénita o sobrevenida.

Con el desarrollo de la medicina y la concepción de las personas con discapacidad como poseedoras de derechos, han surgido diferentes modelos que proponen distintas explicaciones sobre las causas de la discapacidad. No obstante, la mayoría de ellas han coexistido a lo largo del tiempo y han sido asumidas por los contextos nacionales en distintos momentos.

En la literatura de la materia se pueden encontrar distintas propuestas sobre cuáles son los modelos teóricos para explicar la discapacidad (Casado, 1991; De Jong, 1979; Muyor, 2011; Smeltzer, 2007), generalmente usando distintos criterios de análisis y en ocasiones con variaciones, o matices, en la denominación. Una de ellas recoge nueve modelos distintos: el Tradicional (moral o religioso), el Médico, el Social Británico, el Minoritario Norteamericano, el Biopsicosocial (Modelo Clasificación Internacional del Funcionamiento), el Escandinavo (o relacional), el de Derechos Humanos, el Cultural y el Español de Diversidad Funcional (Pérez y Chhabra, 2019). Estos se podrían agrupar en dos grandes categorías: modelo médico (los dos primeros) y modelo social (con siete variantes).

De algún modo, esa agrupación simboliza los extremos de un continuo, que representa al mismo tiempo la evolución de la comprensión de la discapacidad y la tensión entre ambas concepciones. De forma sintética, el modelo médico asume que la discapacidad es la consecuencia de una enfermedad, o de determinada condición de salud, por lo que su intervención se centra en «reparar los fallos» que impiden llevar una vida «normal». Mientras el modelo social, con énfasis distintos según sus variantes, rechaza la noción de "funcionalidad normal» y considera que la discapacidad es una «construcción social». Sitúa las raíces de la «discapacidad» en las limitaciones de la sociedad para prestar servicios apropiados y para asegurar que las necesidades de todas las personas sean tenidas en cuenta dentro de la organización social (Palacios, 2008).

Visto así, parece lógico que el estudio de la discapacidad se aborde desde una doble perspectiva: la que muestra las opiniones y las vivencias de las propias personas con discapacidad (PCD) (perspectiva interna) y la que recoge las percepciones y análisis de quienes la observan desde fuera sin padecerla (perspectiva externa) (Acosta, 2003). La visión externa se puede asimilar con el abordaje del modelo médico que subyace a las clasificaciones internacionales de la Organización Mundial de la Salud (OMS), estas son las que mejor permiten su cuantificación y comparación. La visión interna se vincularía al modelo social y queda perfectamente representada en el eslogan que abandera el movimiento pro derechos de las personas con discapacidad: «Nada sobre nosotras sin nosotras». Además, en el marco de este modelo se inician los llamados «estudios sobre discapacidad» (Disability studies), con interesantes propuestas para el currículo académico de formación en las universidades (Verdugo, 2003: 1).

Sobre esta base, la Clasificación Internacional del Funcionamiento, de la Discapacidad y de la Salud (CIF) intenta integrar ambas concepciones en el Modelo Biopsicosocial (BPS) (OMS, 2001). En ese marco, la discapacidad se define como un término genérico que engloba deficiencias, limitaciones de actividad y restricciones 
para la participación. La discapacidad denota los aspectos negativos de la interacción entre personas con un problema de salud (como parálisis cerebral, síndrome de Down o depresión) y factores personales y ambientales (como actitudes negativas, transporte y edificios públicos inaccesibles y falta de apoyo social) (OMS, 2011). No obstante, para quienes la viven en primera persona, esta propuesta se percibe como insuficiente y no está logrando los cambios esperados; entre otras cuestiones, argumentan que la sociedad sigue pensando que el problema está en la persona (Lobato y Romanach, 2005).

De una u otra manera, los diferentes modelos han influido en las líneas de acción de la política sanitaria y social en distintos momentos y países. En los últimos años ha ido emergiendo, cada vez con más fuerza, la necesidad de abordar la relación entre discapacidad y derechos, de la que se hace eco el reciente Modelo de Derechos Humanos, que, en cierto modo, mejora al Modelo Social, en cuanto promueve la «igualdad transformadora» (Degener, 2016).

Este modelo se centra en la dignidad intrínseca del ser humano y después, pero solo en caso necesario, en las características médicas de la persona. Sitúa al individuo en el centro de todas las decisiones que le afectan y, lo que es aún más importante, sitúa el «problema» principal fuera de la persona, en la sociedad. En este modelo, el "problema» de la discapacidad se deriva de la falta de sensibilidad del Estado y la sociedad civil hacia la diferencia que representa esa condición. De ello se deduce que el Estado tiene la responsabilidad de hacer frente a los obstáculos creados socialmente a fin de garantizar el pleno respeto de la dignidad y la igualdad de derechos de todas las personas (Degener, 2016; Quinn y Degener, 2002: 20).

Entender que la discapacidad es una cuestión de derechos humanos (DD. HH.) implica asumir que las personas con discapacidad son objeto de discriminación por el simple hecho de serlo. Esto conlleva la responsabilidad de identificar la posible vulneración de derechos y promover los cambios necesarios en el sistema que la origina (Palacios, 2008). Esto es posible, si se toma el Enfoque Basado en los Derechos Humanos (Oficina del Alto Comisionado de las Naciones Unidas para los DD. HH., 2006), como una metodología útil que permite integrar la visión micro, que analiza las situaciones concretas de las personas e intenta darles respuesta; y la visión macro, que considera los derechos humanos como marco de referencia de las respuestas que deberían existir (disponibilidad, calidad, aceptabilidad y accesibilidad).

Desde la proclamación en 1948 de la DUDH, la discapacidad ha sido invisible en la legislación internacional sobre la materia (Quinn y Degener, 2002). Esto, junto con otros factores, condujo a la aprobación, por las Naciones Unidas en 2006, de la Convención sobre los Derechos de las Personas con Discapacidad (CDPD). Este instrumento pretende "promover, proteger y asegurar el goce pleno y en condiciones de igualdad de todos los derechos humanos y libertades fundamentales por todas las personas con discapacidad, y promover el respeto a su dignidad inherente» (OMS, 2011: 7).

La CDPD hay que entenderla como el resultado del largo camino recorrido por el movimiento asociativo, tanto de las personas afectadas como de sus familiares, en busca del reconocimiento de su dignidad y de sus derechos; el logro de su 
lucha para acceder a la plena ciudadanía. Sin duda, muestra un cambio importante en la comprensión de la discapacidad y en las respuestas a este hecho. También, está logrando que la sociedad entienda de un modo distinto a las personas con discapacidad y está afectando al modo de acercamiento a las mismas.

Para que la sociedad disponga de respuestas válidas que promuevan el avance en la mejora de las condiciones de vida de las personas con discapacidad, es fundamental la colaboración público-privada, representada en las múltiples alianzas que existen entre las administraciones públicas y organizaciones sin fin de lucro, de distinta naturaleza, vinculadas a la discapacidad.

En todo caso, no se puede olvidar que, en el enfoque de derechos humanos, el Estado sigue siendo el titular de obligaciones, lo que se concreta en el deber de promover y garantizar una oferta pública de servicios, amplia, solvente y suficiente (disponibilidad, calidad, aceptabilidad y accesibilidad). En cambio, las entidades sociales son titulares de responsabilidad, quedando su papel circunscrito a la participación para facilitar la tarea del primero. Naturalmente, esa participación tiene distintos grados y se presenta de diferente manera, en su mayoría estas organizaciones asumen la prestación directa de servicios financiados con fondos públicos, dejando en muchas ocasiones su papel de control (contrapeso de la labor pública) y de reivindicación en segundo plano, lo que a su vez puede comprometer el avance efectivo en materia de derechos humanos.

Con todo, se asume que la discapacidad forma parte de la condición humana: casi todas las personas sufrirán algún tipo de discapacidad transitoria o permanente en algún momento de su vida, y las que lleguen a la senilidad experimentarán dificultades crecientes de funcionamiento. La discapacidad es compleja, y las intervenciones para superar las desventajas asociadas a ella son múltiples, sistémicas y varían según el contexto (OMS, 2011: 7).

Sobre esa base, la diversidad representada por los 7500 millones de seres humanos que habitan el planeta conlleva que estos serían portadores potenciales de una discapacidad. A pesar de ello, de acuerdo con la idea «médica» de la misma, serían solo 1100 millones de personas las que actualmente ven limitada su vida cotidiana por la presencia de un déficit de funcionamiento.

Actualmente, la discapacidad ocupa un lugar destacado en la agenda política, en parte, como consecuencia de que los grupos de interés presionan para que el Estado asuma las obligaciones que se derivan de la CDPD.

Además, la discapacidad es un tema ampliamente estudiado por distintas disciplinas desde hace décadas; no obstante, aún siguen siendo muchas las preguntas sin respuesta. Vista la complejidad que entraña este tema y los retos que implica su abordaje científico, se podría decir que la transdisciplinariedad se convierte, casi, en una exigencia. Asimismo, se despliegan múltiples y variadas intervenciones profesionales que se pueden entender como intentos de transformar la realidad de las personas con discapacidad. Si ese es el objetivo, la intervención socioeducativa debería reconocer la diversidad y los mecanismos que la oprimen, ser metodológicamente nominalista -como recuerda Preciado (2019), no existen las verdades universales-, lo que conlleva un compromiso ético-político individual, con perspectiva de género y basado en el Enfoque de Derechos Humanos, que trate y nombre a cada ser 
humano (cuerpo con mente y alma) como quiera ser tratado superando las distinciones binarias del orden heteropatriarcal neoliberal imperante.

Este monográfico pretende, sobre todo, aportar elementos que contribuyan a la reflexión y estimulen el debate sobre algunas de las cuestiones actualmente en discusión. Los trabajos que presentamos a continuación se vinculan, de una u otra manera, a través de los derechos de las personas con discapacidad, analizando desde diferentes disciplinas distintas situaciones que los comprometen. Cada uno de ellos aporta algunas respuestas para viejas y nuevas cuestiones relacionadas con la discapacidad, la diversidad y los derechos humanos.

En primer lugar, hemos querido dar voz a las protagonistas principales, una visión interna vinculada al modelo de la diversidad funcional (Toboso, 2018), que propone desterrar el concepto de «capacidad». Desde esta postura, se discuten las grandes cuestiones sostenidas por las visiones externas, mayoritariamente ubicadas en el modelo médico-rehabilitador, que atraviesan la sociedad y se convierten en la «normalidad».

Antonio Centeno, activista del movimiento de vida independiente, escribe «Una aproximación a la bioética de la diversidad funcional desde el deseo», un texto revelador, distinto de los habituales textos académicos, en el que reflexiona desde su vivencia sobre cuestiones clave del debate actual en cuanto a la manera de abordar la diversidad humana, particularmente la de quienes «funcionan» de manera distinta a la «mayoría estadística».

En la primera parte, discute la pertinencia del uso del término «diversidad funcional» como medio para deconstruir las ideas profundamente arraigadas en la sociedad sobre la discapacidad, apunta la importancia que tiene el lenguaje en la construcción social de las ideas y los efectos que tiene en la comprensión de la diversidad humana. Reivindica el uso consciente del lenguaje en tanto instrumento político, que permite pasar de lo "políticamente correcto» a ser "políticos», postura que ofrece la oportunidad de observar la realidad, más allá de las dicotomías habituales en las que se sostienen los discursos mayoritarios, para aceptar verdaderamente la diversidad humana y sus implicaciones. No se trata, pues, de cambiar un término por otro, sino de comprender cómo se construye la realidad y decidir conscientemente desde dónde queremos participar de ella.

A continuación, plantea que la aceptación de la diversidad supone un motor de transformación social, en tanto el desarrollo de políticas inclusivas tendrá efectos positivos en toda la sociedad. Políticas que, de ser realmente inclusivas, contribuirán a la incorporación efectiva de las personas con diversidad funcional a los espacios comunitarios ordinarios, terminando así con la histórica segregación de quienes muestran cuerpos diferentes que funcionan de manera distinta. También, enuncia la importancia de disponer de asistencia personal, para él un «apoyo» sustantivo para la vida independiente. Sus argumentos parten de una comprensión de la autonomía que trasciende la «idea mitológica del individuo autosuficiente»; por consiguiente, 
lo importante es que las propias decisiones sean las que dirijan las acciones, de ahí la idea de «Otras Manos y Mis Decisiones» (OMMD).

Defiende que la asistencia sexual debería ser entendida como un apoyo más, un servicio más dentro de la asistencia personal, y, en todo caso, habría de articularse como un servicio específico. En esa línea, remata que la asistencia sexual debe ser un derecho, que permitiera reconocer a las personas con diversidad funcional como sujetos interdependientes con formas propias de autonomía. Esta controvertida demanda parece viable y puede encontrar encaje en el ordenamiento jurídico internacional y español, considerando el enfoque de derechos humanos como referencia fundamental (De Asís, 2017).

Asimismo, aborda dos cuestiones bioéticas clásicas, el aborto y la eutanasia. Desde su vivencia, defiende la ilegitimidad de usar el hecho diferencial de la discapacidad como argumento para legislar sobre el aborto, especialmente cuando este se despenaliza en varios supuestos relacionados con la potencial discapacidad del feto, y considera que ese tipo de legislación consagra y revalida el poder médico para decidir sobre qué vidas son dignas de ser vividas. Se muestra partidario de que el aborto, en tanto derecho humano, debe ser libre sin más explicaciones, reconociendo con ello el derecho de las mujeres a decidir sobre su propio cuerpo.

De forma similar, aborda la cuestión de la eutanasia, tomando como referencia el anteproyecto de ley española, denuncia como algo inaceptable que se señalen solo dos grupos humanos: los enfermos terminales y los gravemente discapacitados, como los «únicos» que "sufren de manera insoportable e irreversible». Cuestiona que solo esos grupos puedan padecer un sufrimiento insoportable y lo denuncia como un ejemplo más de la "política de la tolerancia», según la cual, ciertas vidas se toleran, pero no se valoran. En consecuencia, se muestra partidario de legislar el suicidio libre asistido como una alternativa para quienes, en consciencia, opten por este. Además, sugiere que la valoración del sufrimiento extremo, que lo justificaría, se extienda más allá de la medicina.

Antonio Centeno cierra su reflexión con una invitación a la esperanza para transitar hacia las que denomina "políticas del deseo», en las que propone que la política se articule desde las respuestas a la pregunta ¿qué quiero? como una vía para la responsabilización y el compromiso personal y social. Lo que supone, en primer lugar, un compromiso ético en torno al propio deseo y asegurarse de que efectivamente esos deseos sean de cada uno, en lugar de espejismos de lo que la sociedad estima que es una «vida buena y libre».

En definitiva, nos propone que abandonemos el discurso de las necesidades normativamente definidas y las sustituyamos por el discurso de los derechos humanos. Especialmente, el derecho a vivir la propia vida como cada cual decida, en los límites que libre y colectivamente se hayan dispuesto para ordenar la convivencia social. Ese sigue siendo el reto para transformar la sociedad actual en otra que sea verdaderamente inclusiva. 
En el artículo «Documentar la sexualidad y la diversidad funcional. El sexo y los cuerpos diversos y no normativos como armas de empoderamiento y reivindicación política en Yes we fuck!, Jo també vull sexe! y Crip Camp», Hernando Gómez y Marcos Bote nos presentan un análisis audiovisual sobre el tratamiento de la discapacidad en el cine. Concretamente hacen un estudio sobre tres documentales que se pueden entender como instrumentos al servicio del activismo; de hecho, uno ellos, Yes we fuck!, fue codirigido por Antonio Centeno, y, como dicen sus autores «tienen en común la visibilización del potencial político de los cuerpos en rebelión».

En este caso, también se puede observar una alianza entre las miradas externa e interna, la de los autores sobre los productos utilizados por las protagonistas para reivindicar sus derechos, especialmente el derecho a una vida sexual plena.

En la primera parte, realizan una introducción en torno a los mitos que existen sobre la sexualidad de las personas con discapacidad, que en parte surgen de la visión medicalizada que se tiene de la misma y en otra reproducen los tabúes que existen en torno a la sexualidad humana en general. De la misma manera que en el resto de cuestiones involucradas en la cuestión de la discapacidad, afortunadamente, se empieza a tratar la sexualidad como una cuestión de derechos humanos. No obstante, se espera un largo debate sobre la cuestión, pues a pesar de las numerosas actuaciones en esta materia lanzadas especialmente por las entidades sociales, todavía es incipiente la aceptación social de la plena ciudadanía de las personas con discapacidad.

El cine ha guiado la forma en que se percibe la discapacidad, presentando a las personas que tienen esta condición, bien enfatizando sus atributos más negativos, "los malvados y rencorosos tullidos», bien colocándolas en el papel de seres ingenuos e inofensivos incapaces de hacer nada por sí mismos, «los tontos bondadosos a quienes hay que proteger». Visto así, se detecta cierto paralelismo con la oscilación entre aceptación y rechazo que caracteriza el eje sincrónico de la discapacidad en la historia. Igualmente, esas dos representaciones se pueden relacionar con las explicaciones sobre el origen atribuido a la discapacidad: según sea el producto de una maldición o el resultado de una enfermedad, la rechazamos o la queremos.

En definitiva, si el cine es una forma de comprender cómo se muestra una sociedad y cómo comprende los hechos que se representan, se podría decir que este ha reproducido fielmente la forma en que se ha intentado explicar la discapacidad a lo largo del tiempo. Actualmente, empiezan a aparecer producciones que muestran una visión más realista de lo que significa la discapacidad y sus efectos en las personas. Tanto incorporando personajes que encarnan modelos positivos que desmontan algunos mitos como mostrando a las propias personas con discapacidad en un ejercicio de rebeldía contra el orden imperante, con el que reivindican igualdad de oportunidades y vivir de forma independiente con su particular idea de «autonomía con apoyo». En ese sentido, parece claro que el cine puede servir como instrumento de trasformación de la realidad social a través de los hechos reales que se muestran en los documentales como los analizados.

El eje central de reivindicación política que se muestra en los documentales analizados es el derecho a tener una vida sexual satisfactoria, uno más en la larga 
lucha por los derechos de ciudadanía de las personas con discapacidad, «invisibles» para la normativa internacional sobre derechos humanos (Quinn y Degener, 2002) hasta 2006. Sin embargo, este abordaje positivo de la cuestión no evita que se sigan produciendo situaciones de vulneración de derechos que afectan a la sexualidad y que muchas veces comprometen la autodeterminación, bien por no disponer de apoyos a la toma de decisiones, bien por no ser consultados sobre la intervención a realizar.

En todo caso, como se apuntó antes, el derecho a la asistencia sexual es un asunto controvertido, actualmente objeto de acalorados debates, más en las redes sociales y en la calle que en las instituciones. A pesar de que está por ver la conclusión de los mismos, no cabe duda de que si se acepta que el placer forma parte sustancial de la calidad de vida de los seres humanos habrá que encontrar las fórmulas para que ninguno quede excluido del mismo (por ejemplo, la propuesta de regulación de servicios específicos que formula Centeno usando la forma OMMD).

Además, queremos destacar el potencial del cine para dar voz a las minorías, constituyéndose en un canal para la expresión de su activismo, al mismo tiempo que es un instrumento contra la ignorancia en la que permanece sumergida la gran mayoría social frente a la discapacidad, en tanto puede trasmitir conocimiento informado y solvente sobre la diversidad, lo que se torna una base esencial para mejorar la tolerancia, ingrediente sustantivo de la convivencia respetuosa y saludable.

Gómez y Bote llevan a cabo un análisis subversivo que revierte las miradas tradicionales sobre la discapacidad con una perspectiva interdisciplinar, feminista y queer. Si bien los documentales están dirigidos a distintos públicos, los tres desafían las normas imperantes y retan los conocimientos/imaginarios colectivos para deconstruirlos, en pro de desvelar lo que hay de verdad tras los estereotipos profundamente arraigados sobre la sexualidad de las personas con discapacidad. Así, la evolución que se observa entre 2015 con Yes we fuck! y 2020 con Crip Camp muestra cómo, en solo cinco años, la sexualidad ha pasado de ser un tabú a una reivindicación lógica y plausible dentro del audiovisual.

Con todo, parece claro que el carácter político del documental, junto con su capacidad para crear contranarrativas, se desvela como un instrumento con un potencial inmenso al servicio del activismo de las personas con discapacidad, para poner de manifiesto las realidades que permanecen ocultas, no porque no se conozcan, sino porque han sido contadas desde perspectivas externas (o no situadas). $\mathrm{Si}$ el cine es capaz de construir y difundir mitos, quizás en las manos adecuadas pueda empezar a deconstruirlos.

En el trabajo «Costa Rica: la situación de las personas con discapacidad en perspectiva histórica y actual», Mariana Campos realiza un estudio de caso que ilustra, en un periodo muy amplio (1850-2020), la evolución que el tratamiento y la atención de la discapacidad ha tenido en la nación centroamericana, célebre por ser la «Suiza de Centroamérica» y caracterizada por su cultura de paz y por ser un ejemplo de defensa de los derechos humanos. 
Toma como punto de partida la noción de discapacidad como una parte de la diversidad humana, diversidad que es entendida y atendida de diferentes modos a lo largo de la historia en función del resultado de las interacciones entre los actores presentes en distintos momentos y contextos, lo que concuerda con la idea de la discapacidad como construcción sociocultural que evoluciona continuamente.

El trabajo utiliza fuentes secundarias como los datos censales, legislación, información sobre las instituciones y los organismos relacionados con la población con discapacidad. A partir de ellos, realiza un análisis con el que responde a cinco cuestiones básicas para describir la concepción y la respuesta a la discapacidad en Costa Rica: ¿qué normas estaban disponibles?, ¿cuántas personas con discapacidad había?, ¿qué servicios se ofrecieron?, ¿cómo se financiaron?, ¿desde qué instancia político-administrativa se gestionó la respuesta?

Retrata a la perfección la evolución de los distintos modos de comprender la discapacidad y la manera en que conviven los anteriores con los nuevos. La autora proporciona una perspectiva histórica que pone de manifiesto cómo la evolución de la comprensión de la discapacidad, de la población y de los actores ha ido dando lugar a formulaciones políticas distintas. En particular, se muestra el progreso de las políticas dirigidas a las personas con discapacidad y la influencia que las normas internacionales, especialmente de la legislación en materia de derechos humanos, han tenido en las mismas.

En la primera etapa (1850-1890), destaca que el primer antecedente de reconocimiento de discapacidad se sitúe en el ejército. Por una parte, se reservan puestos de trabajo concretos y, por otra, se garantiza protección económica cuando no pueden prestar servicios, prerrogativas que estuvieron vigentes hasta 1948, cuando se abolió el ejército. En cierto sentido, esta consideración alude a la forma de clasificación de la población en función de su aptitud para hacer determinadas tareas, al mismo tiempo que revela cierta forma de mutualismo al compensar a los encargados de mantener el orden y los servidores de la patria. De algún modo, se compensan los menoscabos sufridos en "acto de servicio público», dejando al margen de la protección al resto de personas con discapacidad. En todo caso, se trata de una práctica habitual en la llamada en la etapa final de la "Primera Revolución Moderna» (s. Xvi-finales del s. XIX), coherente con economías agrícolas (Aguado, 1995).

En la siguiente etapa (1890-1940), en los primeros intentos de contabilización, se incorpora el autodiagnóstico, es decir, quien completa el censo interpreta las indicaciones que se incluyen en el formulario y se "autoclasifica» en alguno de los supuestos posibles. Por una parte, resulta llamativo el porcentaje de personas «sordo-mudas» (39\%) frente al poco más del 1\% que se reconocen en el resto de los grupos (ciegos, enteramente impedidos, dementes e imbéciles), lo que podría ser una de las consecuencias derivadas del sesgo de autoclasificación (Malo, 2007). Y, por otra, es interesante observar cómo la nomenclatura de la época fija el estándar para clasificar a la población en la capacidad para ser autónoma en la vida cotidiana; de hecho, se asocian con «discapacidad» situaciones asimilables a las actuales «actividades de la vida diaria» (AVD).

Ya en el siglo Xxi, se pone en evidencia cómo, a pesar de la existencia de clasificaciones internacionales (OMS), el margen para la definición de las variables 
utilizadas en las operaciones estadísticas nacionales revela las dificultades para la comparación internacional, que se derivan de las diferencias en la forma de conceptualización y contabilización de la discapacidad (Jiménez y Huete, 2010). Ese es el caso del censo de 2011, en el que solo se toma en consideración la limitación, que es solo una parte de la propuesta que se recoge en la Clasificación Internacional del Funcionamiento, la Discapacidad y la Salud (CIF) (OMS, 2001).

En la actualidad está vigente la Ley de Igualdad de Oportunidades para las Personas con Discapacidad, aprobada en 1996, que se elaboró al amparo de la primera Clasificación Internacional de Deficiencias, Discapacidades y Minusvalías (CIDDM) aprobada por la OMS en 1980 (INSERSO, 1986). Esta clasificación propone un esquema lineal (enfermedad, deficiencia, discapacidad, minusvalía), claramente influenciado por la visión médica de la discapacidad imperante en ese momento. Sin embargo, Costa Rica se adelantó a los acontecimientos, dado que la norma se hace desde los principios de igualdad de oportunidades y en el marco de los derechos humanos. Además, en su elaboración se tuvieron en cuenta las percepciones y las expectativas de todos los actores implicados, lo que resulta un buen ejemplo de integración de las perspectivas interna y externa, al mismo tiempo que respeta el principio de participación, clave en el enfoque de derechos.

En cuanto a la cuantificación, los cambios en las variables para registrar la discapacidad, junto con los efectos del sesgo de autoclasificación, muestran una horquilla bastante amplia, del 5,35\% en 2000 al 18,2\% en 2018. Como consecuencia esperable de la aparición de nuevos marcos normativos y organismos de gestión, que sigue siendo centralizada, se aumentan y mejoran servicios. El Consejo Nacional de Personas con Discapacidad (CONAPDIS) sigue comandando la organización de las respuestas y la coordinación de los actores implicados en la mejora de las condiciones de vida de las personas con discapacidad «ticas».

Clarisa Ramos Feijóo y Josefa Lorenzo García nos presentan «Personas con discapacidad en cárceles. Reflexiones desde el trabajo social».

Un trabajo que trata de poner luz sobre la relación entre las personas con discapacidad intelectual (PCD-i) y el sistema penitenciario, una propuesta concreta que enuncia los aspectos a considerar, especialmente cómo se deberían plantear las actuaciones previas para lograr respuestas válidas que eviten el ingreso en prisión.

Aborda tanto la situación misma de privación de libertad como las actuaciones previas y posteriores a ella, centrándose en las razones que llevan a que finalmente algunas PCD-i terminen ingresando en prisión. Entre todas, destacan los fallos en los procesos de prevención, en general, entendidos como los mecanismos que deberían haber proporcionado apoyo para que tanto la persona con discapacidad como su familia y su entorno, hubiesen dispuesto de las herramientas para compensar los déficits y garantizar con ello un desarrollo ajustado a la situación.

En la realidad estudiada, emerge la relación entre discapacidad intelectual y enfermedad mental, un binomio que muestra una parte especialmente dura de la 
diversidad que encierra la escurridiza noción de discapacidad. En esta población, converge un mayor número de factores de exclusión que la convierte en un grupo especialmente afectado por la «discriminación múltiple» (Blázquez, 2013; Feria, 2013). Se trata de "casos complejos» que después de trayectorias erráticas en las que las respuestas no han sido eficaces, terminan privados de libertad, encontrando paradójicamente en las cárceles las primeras opciones de iniciar procesos de inclusión social. A eso se añade que se trata de un grupo minoritario dentro de la minoría ${ }^{1}$, con una vinculación muy débil o inexistente con las organizaciones sociales implicadas en la cuestión. Todo ello provoca, en cierto sentido, que "pasen desapercibidos» para los sistemas de protección social, especialmente en los servicios sociales.

Se trata de un estudio cualitativo, que busca potenciar las opciones para comprender mejor la realidad, descubrir los significados atribuidos por las protagonistas de los hechos estudiados, en aras del diseño de respuestas innovadoras. Lo hacen mediante la integración de los resultados de dos estudios previos y su contraste con los antecedentes teóricos. Así, abarcan en el proceso a las propias PCD-i, a los profesionales implicados en su atención, junto con otros actores de la comunidad y las familias.

Las autoras constatan que, efectivamente, las cárceles se convierten en recursos sociales cuando todos los anteriores, en el caso de haber existido, fracasan. La combinación que vincula discapacidad y pobreza, junto con la falta de habilidades sociales, la carencia de elementos que potencien la resiliencia familiar y la escasa tolerancia al estrés, se convierten en un "cóctel letal» que aumenta exponencialmente las probabilidades de que una PCD-i inmersa en esa realidad llegue a vivir situaciones de conflicto con la ley que terminen con su ingreso en prisión. Además, para muchas familias, la cárcel será entendida como «recurso alojativo alternativo seguro", en tanto pone fin a las situaciones de tensión vividas hasta ese momento en el hogar.

Asimismo, ponen en evidencia la necesidad de más y mejor capacitación de las personas que intervienen profesionalmente durante la aparición de las primeras situaciones "problemáticas». En algunos casos, las habilidades para afrontar el estrés que generan las conductas «desafiantes» de algunas PCD-i son escasas, lo que se ve agravado por la falta de interdisciplinariedad efectiva y por la parcelación en la atención social y sanitaria. Todo junto impide una visión integral de la situación y, por tanto, de las soluciones que se propongan.

La falta de atención específica a la enfermedad mental de las PCD-i y las intervenciones familiares insuficientes, con resultados fragmentados, por parte de los sistemas públicos de protección, especialmente salud y servicios sociales, contribuyen a la debilidad detectada en los procesos de prevención.

Por último, ponen de manifiesto un ejemplo más de alianza público-privada como marco para la asistencia a las PCD-i privadas de libertad. De hecho, los

${ }^{1}$ Son 1554 personas, frente a 1774 800, que representan el total de población activa con discapacidad (16-64 años). 
programas que actualmente están en vigor en España surgen de Plena Inclusión, que diseña, implementa y evalúa el programa de intervención con este grupo tan especial de PCD-i. En todo caso, señalan, el Estado (titular de obligaciones) debe proveer servicios que acompañen y asesoren a las familias desde el principio.

La superación de la realidad descubierta requiere creatividad y tiempo. La primera encuentra respuesta en el pluralismo metodológico y disciplinar que enriquezca los discursos habituales y ponga nuevas bases para diseñar soluciones innovadoras. Promover la implantación de procesos que eviten el fracaso personal por falta de apoyos adecuados es una responsabilidad colectiva, que incluye tanto a las profesiones presentes en los diferentes sistemas como a la comunidad y las entidades sociales; todas son titulares de responsabilidad. Asimismo, las soluciones deben arbitrarse desde la base y con la participación de todos, de ahí la necesidad de fortalecer el trabajo social comunitario. Lógicamente, para esto es necesario algún tiempo en el que se pueda ir transitando desde los modelos funcionalistas (médico-rehabilitador), en los que las opciones se restringen a encajar a la persona en la oferta disponible o excluirla del sistema, hacia la implantación del Modelo de Derechos Humanos en los servicios sociales, en el que, situada la persona en el centro del proceso y con la mirada puesta en los derechos, se proporcionen apoyos para el desarrollo de proyectos vitales libremente decididos.

Como marco general de las intervenciones profesionales, proponen el Modelo de Atención Integral Centrado en la Persona (MAICP). Los principios del MAICP se pueden relacionar directamente con los del Enfoque Basado en los Derechos Humanos, especialmente la participación, un factor central en ambos. Así, promover la participación activa, tanto de la propia PCD-i como de su familia, implica proveer apoyos adecuados para que logren conocer y comprender su propia realidad. En definitiva, se trata de articular la individualidad, la autonomía y la independencia, contando con su participación activa en el proceso y en la comunidad a la que pertenecen. Por tanto, se habrá de proporcionar cuidados coordinados, flexibles y continuos que potencien las cualidades de cada ser humano.

Cierra esta sección el artículo «Inserción laboral del alumnado con discapacidad en la Universidad de Las Palmas de Gran Canaria (ULPGC)», de Carmen Delia Díaz y Celsa Cáceres.

Se trata de un artículo que aborda el derecho a la educación (art. 24 de la CDPD), concretamente la situación de la inclusión en la educación superior y sus efectos en la incorporación laboral (art. 27 de la CDPD). Es un estudio exploratorio que analiza el caso de la ULPGC, que contribuye a incrementar los datos disponibles sobre esta cuestión, que, a su vez, pueden ser útiles para su comparación con otros similares. Asimismo, propone un nuevo marco metodológico para hacer analizar los efectos de la formación universitaria en el acceso al empleo.

Este trabajo, como los anteriores, toma como referencia el marco de los derechos humanos. Por un lado, recuerda el principio de la igualdad de oportunidades, 
según el cual las personas con discapacidad deberían disponer de apoyos adecuados para acceder y progresar en el sistema educativo, incluida la formación universitaria, lo que conlleva la responsabilidad directa de las universidades de proveer servicios dirigidos a proporcionarlos. Y, por otro, pone en evidencia que siguen siendo necesarios mecanismos para luchar contra la discriminación laboral que afecta a las personas con discapacidad, aun cuando logran finalizar con éxito estudios universitarios, en aras de eliminar las barreras que les impiden el acceso a empleos dignos y de calidad, en tanto estos se reconocen como el eje vertebrador para hacer efectivo el derecho a vivir de forma independiente (art. 19 de la CDPD).

En la primera parte, se aborda la situación de las personas con discapacidad en el mercado de trabajo, y se pone en evidencia la brecha estructural que existe en relación con la población sin discapacidad. En conjunto, 1 de cada 4 personas con discapacidad, tiene un empleo, frente a 2 de cada 3 en el resto de la población (tasa de empleo del $25,8 \%$ y el $65,9 \%$ respectivamente). Cabe destacar que Canarias es una de las comunidades autónomas con las tasas de participación laboral de personas con discapacidad más bajas de todo el Estado.

A continuación, ofrece una panorámica de la situación de las personas con discapacidad en el sistema universitario español, para centrarse en la descripción de los servicios de apoyo a la transición universidad-empleo que han puesto en marcha las universidades españolas como consecuencia del desarrollo del Espacio Europeo de Educación Superior (EEES). Una de las prácticas incorporadas en este proceso ha sido la sistematización de los resultados de la formación con énfasis en los relacionados con la inserción laboral de los egresados. Sin embargo, no se incorporan datos desagregados sobre la población con discapacidad que permitan análisis pormenorizados.

Para suplir esta carencia, se han llevado a cabo estudios específicos promovidos por distintas entidades, entre las que destaca la Fundación Universia, que se complementan con los realizados por el Observatorio Estatal de la Discapacidad (ODISMET) y con los promovidos por universidades concretas centrados en su alumnado. En conjunto, estos trabajos ponen en evidencia la baja tasa de personas con discapacidad en las universidades españolas. Los datos indican que solo hay un $1,5 \%$ de estudiantes con discapacidad, este porcentaje se incrementa hasta el 2,2\% si se consideran los jóvenes con discapacidad (16-24 años) que han completado estudios superiores. No obstante, aunque los datos son muy variables, si se observan considerando el tipo de discapacidad, en general, las personas con discapacidad intelectual son el grupo con menor presencia en las universidades.

Con el objetivo de observar los efectos de la educación superior en el acceso a un empleo, se lleva a cabo un análisis descriptivo y exploratorio, que incorpora como variable novedosa la noción de "empleo encajado», para determinar en qué medida los estudios universitarios facilitan el acceso a un empleo encuadrable en los tres primeros niveles de la Clasificación Nacional de Ocupaciones (CNO). Para ello, partiendo del emparejamiento de los registros académicos de la ULPGC y las bases de datos del Servicio Canario de Empleo, se construyeron las trayectorias laborales de las personas con discapacidad que egresaron de la ULPGC entre 2005-2010, lo que permitió observar la situación laboral a medio plazo. 
Entre los resultados que arroja el estudio, resulta destacable que el empleo encajado esté en torno al 50\%, siendo las personas con discapacidad visual las que lo logran en mayor medida. De manera complementaria, se alude a los posibles efectos que los servicios de apoyo a la inserción laboral de la ULPGC hayan podido tener en estos resultados. Esto se relaciona con la importancia de disponer, tal y como prevé el artículo 24 de la CDPD, de medidas de apoyo personalizadas y efectivas que fomenten al máximo el desarrollo académico y social, de cara a lograr las mayores cotas de inclusión educativa.

Concluye con una mirada al futuro, con la que se invita a otras universidades a suscribir convenios de colaboración con los servicios de empleo regionales, que permitan realizar estudios longitudinales, dirigidos a conocer con precisión los resultados de la formación universitaria de las personas con discapacidad en su incorporación laboral. Asimismo, estos resultados podrían ser de utilidad, tanto para la comparación entre las universidades españolas como para analizar los efectos de los diferentes tipos de servicios de apoyo a la transición universidad-empleo que se promueven en cada una de ellas.

Finaliza el monográfico con una aportación novel: «La alteración de la salud del trabajador como factor de discriminación en las relaciones laborales: discapacidad y enfermedad», realizado por Patricia Orlanda Rodríguez Padrón.

Se trata de un análisis enmarcado en el derecho del trabajo, en el que se explora la relación entre la alteración de la salud y la discapacidad, dos realidades de límites difusos, que comparten una frontera difícil de acotar en el complejo entramado de las relaciones laborales.

El eje central de este artículo es el bien conocido «derecho y deber de trabajar», sobre el que pivota la vida de los seres humanos, especialmente en el «norte capitalista", a pesar de que la realidad demuestra la escasez y la mala calidad del empleo disponible. La autora analiza distintos aspectos formales del empleo y va más allá de las personas con discapacidad, reconocidas legalmente como tales, para discutir si se debería flexibilizar este concepto y aplicar las medidas protectoras a las personas con enfermedades de cierto tipo.

Patricia Rodríguez argumenta que, actualmente, tanto la legislación española como la europea para la protección de las personas con discapacidad se basan en el modelo social. Si bien entiende que enfermedad y discapacidad son dos realidades distintas, sugiere que el concepto de discapacidad debería ser «unívoco y flexible». Así, afirma que las sentencias sobre algunos despidos por razón de enfermedad sientan las bases para que cuando esa tiene ciertas características (la duración de la misma y/o la presunción de larga duración) se apliquen las mismas medidas que las previstas para las personas con discapacidad. Especialmente, los ajustes razonables en el puesto de trabajo y la consideración de la discriminación por razón de discapacidad en los supuestos de despido, cuando este es consecuencia de cierto tipo de enfermedad. 
Con todo, cabe reflexionar sobre algunas de las aportaciones que hace este trabajo. En principio, merece la pena analizar si lo recogido en los artículos 9.2 y 49 de la Constitución espańola de 1978 es suficiente para afirmar que en la misma se «consolida» el modelo social de atención a la discapacidad.

Por otra parte, parece necesario profundizar en la estrecha relación entre discapacidad y enfermedad. La autora rescata el concepto de discapacidad de la CDPD, que es una versión del recogido en la CIF (OMS, 2001), según el cual el origen de la discapacidad es una determinada "condición de salud», lo que se podría asimilar con la enfermedad en tanto esta no es otra cosa que la «salud alterada»; habría que repensar si realmente enfermedades con determinadas condiciones deberían ser reconocidas como discapacidad según los procedimientos habituales, o bien, tal y como propone la autora, ser tratadas directamente como aquella en el ámbito de las relaciones laborales.

En cualquier caso, no se puede olvidar que el modelo biopsicosocial que promulgó y promueve la OMS entiende los aspectos físicos y psicológicos del ser humano como sustrato de la potencial discapacidad en el nivel orgánico y funcional. En pocas palabras, no se puede olvidar que la concepción de discapacidad, preeminente en la actualidad, se asienta y proviene del modelo médico, que se amplía para dar cabida a los factores contextuales, la participación y las actividades.

Queremos finalizar esta presentación expresando nuestro más sincero agradecimiento a las autoras y los autores que, a pesar de las vicisitudes de este extraño y complicado 2020, han estado disponibles y atentos a los requerimientos de la edición, haciendo posible la publicación de este monográfico sobre discapacidad, diversidad y derechos humanos. Igualmente, queremos mostrar nuestra gratitud al equipo editorial de la revista por haber estimado la oportunidad de publicar esta recopilación de artículos sobre una cuestión compleja y poliédrica como es la discapacidad, facilitando un espacio para el encuentro interdisciplinar que refleja la vigencia y el interés por este tema. En ese sentido, esperamos que esta modesta aportación pueda contribuir a alumbrar algunas de las sombras que aún quedan en determinadas zonas del planeta en el que cohabitan la discapacidad, la diversidad y los derechos humanos. 


\section{REFERENCIAS BIBLIOGRÁFICAS}

Acosta, V.M. (2003). «Un estudio de la sordera como construcción social: visiones externas versus visiones internas». Revista de logopedia, foniatría y audiología, 23(4): 178-194.

Aguado, A.L. (1995). Historia de las deficiencias. Madrid: Escuela Libre Editorial.

Blázquez, E.M. (2013). «Situación real de las mujeres efecto y/o consecuencia de la discriminación múltiple en el empleo. En especial la edad y la discapacidad», en J. Cabeza y F. Fernández (coords.) (2013), Politicas de empleo (215-230). Navarra: Thomson-Reuters Aranzadi, Universidad de Vigo y Ministerio de Economía y Competitividad.

Casado, D. (1991). Panorámica de la discapacidad. Barcelona: INTRESS.

Colectivo IOÉ y CIMOP (1998). Discapacidad y Trabajo en España. Madrid: Ministerio de Trabajo y Asuntos Sociales. Secretaría General de Asuntos Sociales. Instituto de Migraciones y Servicios Sociales.

De Asís, R. (2017). «¿Es la asistencia sexual un derecho?». Revista Española de Discapacidad, 5 (2): 7-18. Doi: https://doi.org/10.5569/2340-5104.05.02.01.

Degener, T. (2016). «Disability in Human Rights Context». Laws, 5 (3): 35, recuperado de https:// doi.org/10.3390/laws5030035. Última consulta: 30/09/20.

DeJong, G. (1979). «Independent living: from social movement to analytic paradigm». Archives of Physical Medicine and Rehabilitation, 60 (10): 435-446.

Feria, I.R. (2013). «La discriminación múltiple como reto de las políticas de empleo», en J. Cabeza y F. Fernández (coords.) (2013), Políticas de empleo (231-245). Navarra: Thomson-Reuters Aranzadi, Universidad de Vigo y Ministerio de Economía y Competitividad.

INSERSO (1986). Clasificación Internacional de Deficiencias, Discapacidades y Minusvalías. Madrid: INSERSO. (Orig. 1983).

Jiménez, A. y Huete, A. (2010). «Estadísticas y otros registros sobre discapacidad en España». Politica y Sociedad, 47, 1: 165-173.

Lobato, M. y Romanach, J. (2005). «Diversidad funcional, nuevo término para la lucha por la dignidad en la diversidad del ser humano", recuperado de http://www.forovidaindependiente. org/node/45. Última consulta: 30/09/20.

Malo, M.A. (2007). «La definición de la discapacidad en la investigación económica: Una reflexión necesaria sobre qué características debería cumplir». Estudios de Economía Aplicada, 25(2): 407-428.

Muyor, J. (2011). «La (con)ciencia del Trabajo Social en la discapacidad: Hacia un modelo de intervención social basado en derechos». Documentos de Trabajo Social, 49: 9-33, recuperado de https://www.researchgate.net/publication/329566915_La_con_ciencia_del_Trabajo_Social_en_la_discapacidad_Hacia_un_modelo_de_intervencion_social_basado_en_derechos. Última consulta: 30/09/20.

Oficina del Alto Comisionado de las Naciones Unidas para los DD. HH. (2006). Preguntas frecuentes sobre el enfoque de derechos humanos en la cooperación para el desarrollo. Nueva York y Ginebra: Naciones Unidas.

Organización Mundial de la Salud (OMS) (2001). Clasificación Internacional del Funcionamiento, las Discapacidades y la Salud. Ginebra: OMS (CD-ROM, multilingüe. Versión 1.0). 
Organización Mundial de la Salud (OMS) (2011). World Report on Disability, recuperado de https://www.who.int/disabilities/world_report/2011/report.pdf. Última consulta:30/09/20.

Palacios, A. (2008). El modelo social de discapacidad: orígenes, caracterización y plasmación en la Convención Internacional sobre los Derechos de las Personas con Discapacidad. Madrid: CINCA y CERMI.

Pérez, M.E. y Chhabra, G. (2019). «Modelos teóricos de discapacidad: un seguimiento del desarrollo histórico del concepto de discapacidad en las últimas cinco décadas». Revista Española de Discapacidad, 7 (I): 7-27. Doi: https://doi.org/10.5569/2340-5104.07.01.01.

Preciado, P.B. (2019). Un apartamento en Urano. Crónicas del cruce. Barcelona: Anagrama.

Quinn, G. y Degener, T. (2002). Derechos humanos y discapacidad. Uso actualy posibilidades futuras de los instrumentos de derechos humanos de las Naciones Unidas en el contexto de la discapacidad, recuperado de http://repositoriocdpd.net:8080/bitstream/handle/123456789/614/L_ QuinnG_DerechosHumanosDiscapacidad_2002.pdf?sequence=1. Última consulta: 30/09/20.

Smeltzer, S.C. (2007). «Improving the health and wellness of persons with disabilities: A call to action too important for nursing to ignore». Nurs Outlook, 55: 189-195.

Товоsо, М. (2018). «Diversidad funcional: hacia un nuevo paradigma en los estudios y en las políticas sobre discapacidad». Politica y Sociedad, 55(3): 783-804.

Verdugo, M.A. (2003). «La concepción de discapacidad en los modelos sociales», en Verdugo, M.A. y Jordán de Urríes, F.B. (coords.), Investigación, innovación y cambio: VJornadas Científicas de Investigación sobre personas con discapacidad: 235-247. Salamanca: Amarú. 

ARTÍCULOS / PAPERS 



\title{
UNA APROXIMACIÓN A LA BIOÉTICA DE LA DIVERSIDAD FUNCIONAL DESDE EL DESEO
}

\author{
Antonio Centeno Ortiz \\ antonio.centeno@gmail.com \\ Oficina de Vida Independiente
}

\section{RESUMEN}

Este trabajo expone algunas de las cuestiones que afectan directamente a la forma de comprender y abordar la realidad de las personas cuyo funcionamiento global difiere de los estándares generalmente aceptados como «normales». En la primera parte, se repasan las cuestiones que afectan al uso del lenguaje y su influencia en la representación cultural y simbólica de la discapacidad; a continuación, se exponen las consideraciones sobre la asistencia personal y sexual como base de una vida, efectivamente, independiente. En tercer lugar, se debaten dos cuestiones bioéticas clásicas, el aborto y la eutanasia, su relación con las políticas de la tolerancia y sus implicaciones en la vida de las personas con diversidad funcional. Por último, se exploran alternativas, para pasar de las políticas de la tolerancia a las "políticas del deseo».

Palabras clave: diversidad funcional, discapacidad, políticas del deseo.

AN APPROACH TO THE BIOETHICS

OF FUNCTIONAL DIVERSITY FROM DESIRE

\section{Abstract}

This work exposes some of the issues that directly affect the way of understanding and approaching the reality of people whose global functioning differs from the standards generally accepted as "normal." In the first part, the issues that affect the use of language and its influence on the cultural and symbolic representation of disability are reviewed; The following are the considerations on personal and sexual assistance as the basis of an effectively independent life. Third, two classic bioethical questions are debated, abortion and euthanasia, their relationship with the politics of tolerance and their implications in the lives of people with functional diversity. Finally, alternatives are explored, to move from the politics of tolerance to the "politics of desire."

KeYwORDs: functional diversity, disability, politics of desire. 


\section{LENGUAJE Y REPRESENTACIÓN CULTURAL MÁS ALLÁ DE LA NORMALIDAD}

He comido pan con aceite desde que tengo memoria, conozco bien las diferencias entre usar pan tostado o no, ponerle sal o tomate o ajo o una combinación de todo ello, aprecio los diversos matices de la variedad arbequina, la picual, etc. El pan con aceite es un paisaje sensorial que me acompaña desde la infancia, una realidad construida en lo cotidiano. En cambio, viajes interplanetarios no he hecho ninguno. Aun así, el cine, la televisión y la literatura han poblado mi mente de tantas imágenes e ideas sobre lo que es un viaje espacial que esa idea puede competir con el pan con aceite para hacerse un hueco en mis sueños, en mis pensamientos, en mi realidad. Y así es como construimos «lo real», el mundo se compone de unas entidades que surgen de la experiencia cotidiana y otras que se constituyen desde la cultura y los medios de comunicación.

Para la inmensa mayoría de la gente, la discapacidad es un viaje a Marte, algo de lo que no tienen ninguna experiencia real, cercana. Casi la totalidad de las personas que somos etiquetadas como «discapacitadas» seguimos viviendo en un universo paralelo de escuelas especiales, centros ocupacionales, centros de día, residencias, transporte especial, centros especiales de trabajo, etc., y/o encerradas en casa de mamá, a su cargo y sin apoyos, incluso cuando mamá ya pasa de los 80 . Sin convivencia es más difícil la empatía, y la cultura crea una «realidad de la discapacidad» absolutamente exotizada, alienígena, polarizada al extremo. Sólo se muestra al paria, un tipo desgraciado sin matices y filosuicida, que vende bien porque todo el mundo está encantado de no ser él y de poder mostrarse generoso ayudándole. O bien al gran héroe, capaz de lo inverosímil, una suerte de metamorfosis kafkiana a la inversa que resulta de lo más inspiradora para «los normales». Lo primero justifica la sobreprotección por encima de la libertad personal, como ocurre al encerrarnos en residencias. Lo segundo culpabiliza a la persona con diversidad funcional de su situación: si sufre no es por discriminación, sino porque no se ha esforzado lo suficiente.

En medio de estos extremos, la nada, un desierto ávido de que la cultura, el arte y los medios de comunicación elaboren un relato social mucho más rico y denso, una realidad de textura cercana a la que emerge de lo cotidiano, a la del pan con aceite.

Esta representación cultural de la diversidad funcional, sesgada, estereotipada y polarizada, incorpora también una mirada permanentemente infantilizadora y asexuante. Y claro, si se nos ve como niños se nos trata como tales. Se construye la idea de que ya estamos bien a cargo de las familias, de que esa dependencia es natural. Por eso es necesario sexualizar la diversidad funcional, para repolitizarla. En la medida en que nos visibilicemos como seres sexuados y sexuales, como cuerpos deseantes y deseables, será más difícil seguir pensándonos como niños, y si no somos niños no es natural depender de las familias. Esas situaciones de dependencia son una cuestión política sobre cómo nos organizamos colectivamente para hacer posibles todas las formas de autonomía, incluyendo la que consiste en hacer las tareas cotidianas con las manos de otra persona y nuestras propias decisiones. 


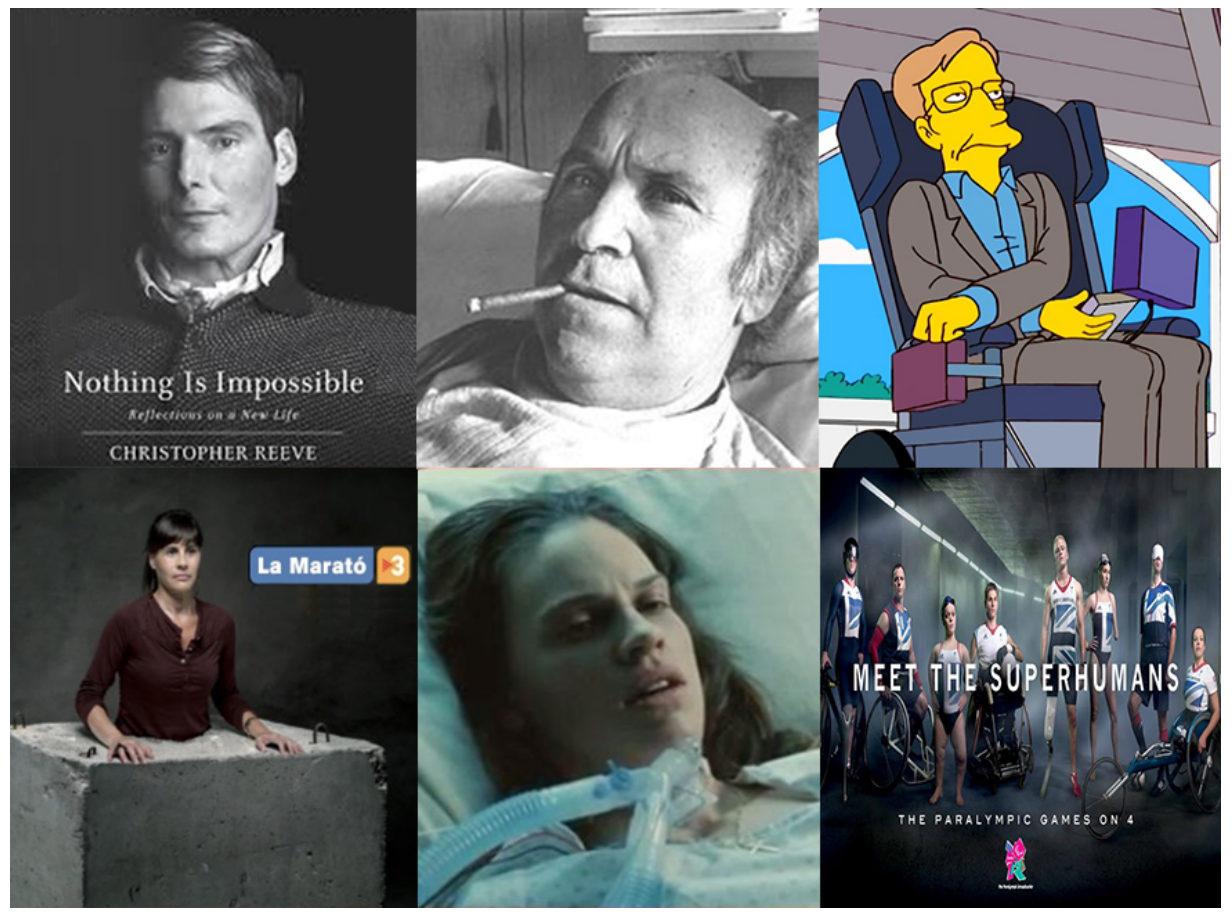

Imagen 1.

Esta forma de autonomía requiere de figuras de apoyo como la asistencia personal (AP) y la asistencia sexual (AS). Enseguida nos ocuparemos de analizar estos apoyos, pero antes de pasar al terreno de lo material conviene revisar dos aspectos clave del imaginario colectivo; el lenguaje y la idea de normalidad.

La construcción de una nueva realidad desde lo simbólico requiere prestar atención al lenguaje, en tanto que este orienta, condiciona e incluso conforma el propio pensamiento. En un ejercicio de realismo, desde el Movimiento de Vida Independiente hace más de una década que decidimos denunciar que el emperador va desnudo, que son falsas las dicotomías normal-anormal (porque todas somos diferentes), capaz-incapaz (porque la capacidad depende del entorno), dependiente-independiente (porque todas recibimos apoyos de y aportamos a la comunidad), y que, derrumbadas estas dicotomías, se revelan infinidad de maneras diferentes de ser, estar y hacer en el mundo. Sin embargo, aquellas que no satisfacen el mandato de productividad competitiva (y de reproducción obligatoria) son castigadas con una discriminación sistemática y sistémica. Por eso, decidimos nombrarnos a nosotras mismas como personas discriminadas por nuestras diferencias funcionales, o más sintéticamente personas con diversidad funcional. No es, pues, un intento de ser políticamente correctos, sino de ser políticos, de abandonar como eje de pensa- 


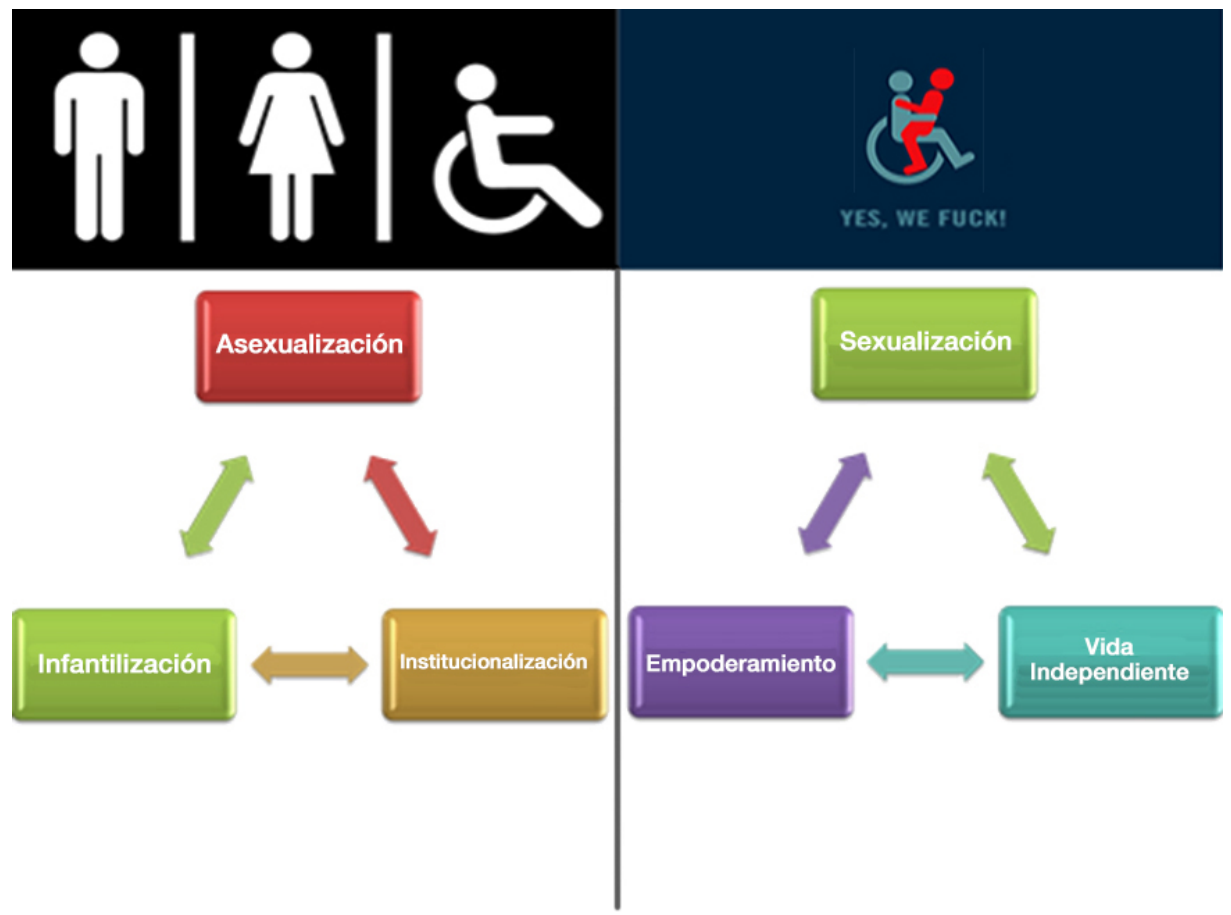

Imagen 2 .

miento las capacidades productivistas de individuos que compiten entre sí, aislados de la comunidad y estigmatizados por sus cuerpos defectuosos, para transitar hacia otro basado en la aceptación, valoración y gestión de las diferencias corporales en un marco de cooperación comunitaria. Es decir, pasar del marco de los infortunios personales al marco de la política.

Quizás, después de leer esto haya quien piense: «Ah, vale, ahora hay que decir diversidad funcional, me parece bien». Habría que ser cuidadosas con este tipo de actitudes, porque no se trata de «lo que hay que decir», sino de «lo que queremos decir». Resulta que la realidad no es algo dado, objetivo, asépticamente observable y describible, sino un constructo de nuestras decisiones personales y colectivas. Por ejemplo, imagine que usted (que seguramente se desplaza caminando) y yo (que lo hago en silla de ruedas) vamos a coger un tren de nuestros amigos de Renfe-Adif y este no tiene rampa sino escalones. Una manera de describir la situación sería: «Antonio no puede subir al tren porque sus piernas no funcionan bien, están mal». Para casi todo el mundo, a simple vista, un hecho obvio, irrefutable. Sin embargo, otra manera de mirar la misma escena podría ser: «A Antonio le impedimos subir al tren porque como comunidad aceptamos que la vía de acceso esté mal hecha». Ahora, y siempre, a usted, y sólo a usted, le toca decidir cuál es la realidad, dónde situamos 


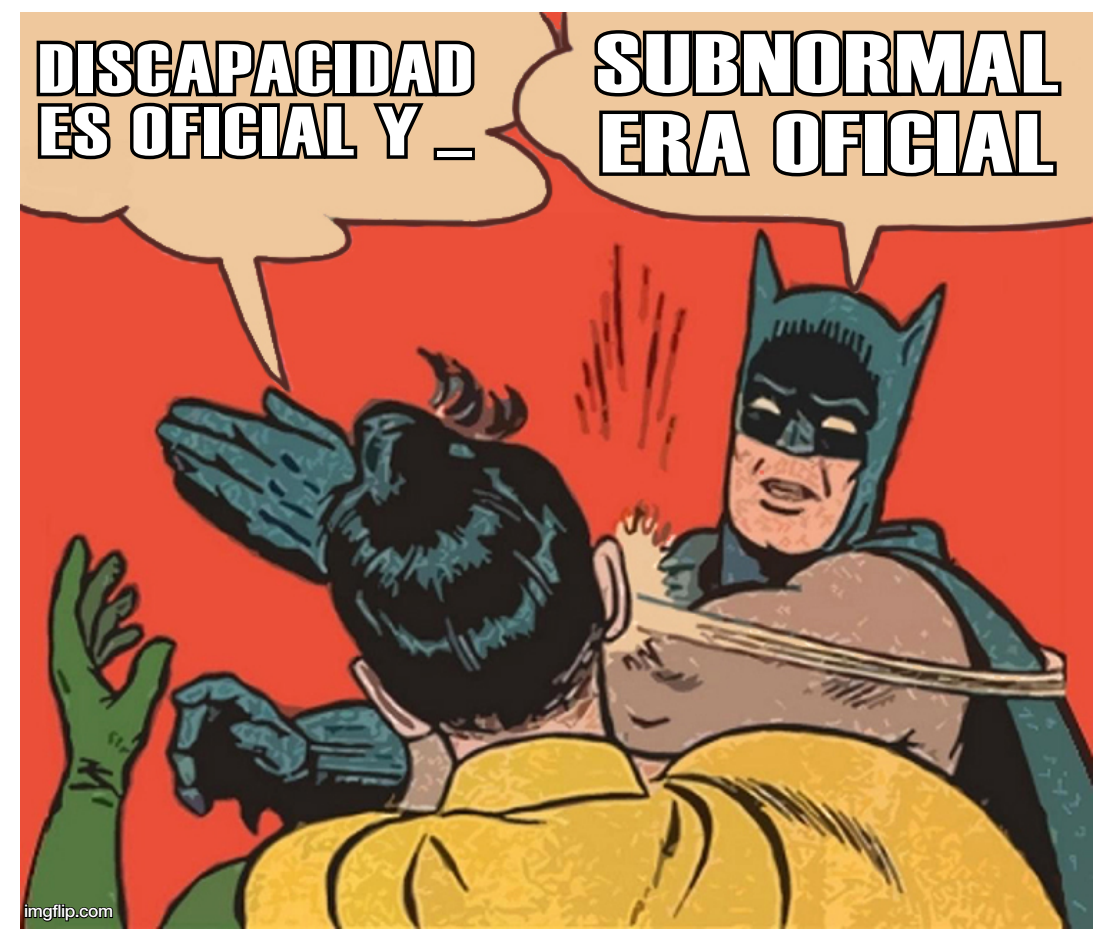

Imagen 3.

el problema y cómo de valiosas y respetables son o no las diferentes maneras de ser, estar y hacer en el mundo. El tejido social que surge de urdir políticamente esos hilos de decisiones personales conforma la realidad colectiva.

Sobre la «normalidad», lo primero que resulta significativo es que quizás sea la palabra más entrecomillada de la historia, probablemente porque responda a la idea más vacía (¿de qué nos informa?), deshabitada (¿quién es normal?), y violenta (sexismo, racismo, capacitismo...) que haya forjado el poder en su anhelo de controlar cuanto pueda amenazarlo. La decimos como sin querer decirla, a medio camino entre la desidia y la culpa por perpetuar estereotipos. Y es en esa dificultad donde merece la pena bucear para encontrar claves que nos permitan, por un lado, comprender cómo opera la idea de normalidad para preservar el poder y, por otro lado, explorar nuevas posibilidades de describir la realidad sin comillas, sin los prejuicios y mitologías que apuntalan dicho poder.

Existe un esquema opresor basado en la idea de normalidad que estructura diferentes formas de discriminación. Viene a ser algo así: 1) el mundo, el espacio de lo posible, se divide en dos únicas categorías excluyentes, esenciales e inmutables: lo normal y lo anormal, 2) se identifican las diferencias y las correspondientes a lo anormal son minusvaloradas, medicalizadas y estigmatizadas, 3) se naturaliza la 


\section{De la discapacidad a la diversidad funcional}

\section{Discapacidad}

- Normalidad

- Autosuficiencia

- Cuerpos defectuosos

Capacidad $\rightarrow$ Ciudadania $\rightarrow$ Dignidad

\section{Diversidad funcional}

- Diversidad

- Interdependencia

- Sociedad excluyente

Dignidad $\rightarrow$ Ciudadania $\rightarrow$ Capacidad

Imagen 4.

desigualdad social a partir de esas diferencias. Así funcionan el sexismo (hombre/ mujer), el capacitismo (capaz/incapaz) o el racismo (blanco/no blanco), por ejemplo.

Es fácil observar que estas dicotomías opresoras son de carácter mitológico, que no se ajustan a la realidad. Al sexismo se le atragantan los movimientos LBGTIQ, que han visibilizado la sexualidad como un continuo fluido mucho más allá de binarismos en la corporalidad, la identidad y la orientación. El capacitismo se tambalea desde que quienes habíamos sido catalogadas como inválidas o discapacitadas nos referimos a nuestra propia realidad como «diversidad funcional», poniendo de relieve que hay muchas maneras de ser, estar y hacer en el mundo y que algunas comportan una discriminación sistemática al interaccionar con un medio social pensado sólo para las maneras de funcionar afines a la idea de productividad. Más claro aún, si cabe, con el racismo, en tanto que la misma idea de "raza» ha sido vaciada de contenido desde los discursos de todas las ciencias y desde la vivencia, cada vez más significativa, de sociedades mestizas, multiculturales y multiétnicas a lo largo y ancho del planeta.

Sin embargo, a pesar de la contundencia de los saberes y las experiencias que certifican lo ineficaz, injusto y cruel que resulta un mundo pensado en términos de normalidad, el poder se resiste a abandonar este esquema opresor. Sigue necesitando que el sexismo garantice la reproducción, que el capacitismo optimice la productividad y que el racismo facilite el expolio internacional. Ante semejante tsunami de normalidad, sólo cabe resistir desde lo cotidiano y desde la cultura, haciendo de la diferencia una trinchera en la convivencia, poniendo en valor la anomalía como potencial creativo. No olvidemos que, como decía Foucault, el poder es un entramado de relaciones, es nuestra responsabilidad hacernos conscientes de los privilegios y las opresiones que nos construyen en relación con las demás para poder tejer vínculos desde la riqueza de la diversidad humana en todos sus aspectos. Pocos ámbitos como el del arte y la cultura para ello, donde siempre ha estado claro que 


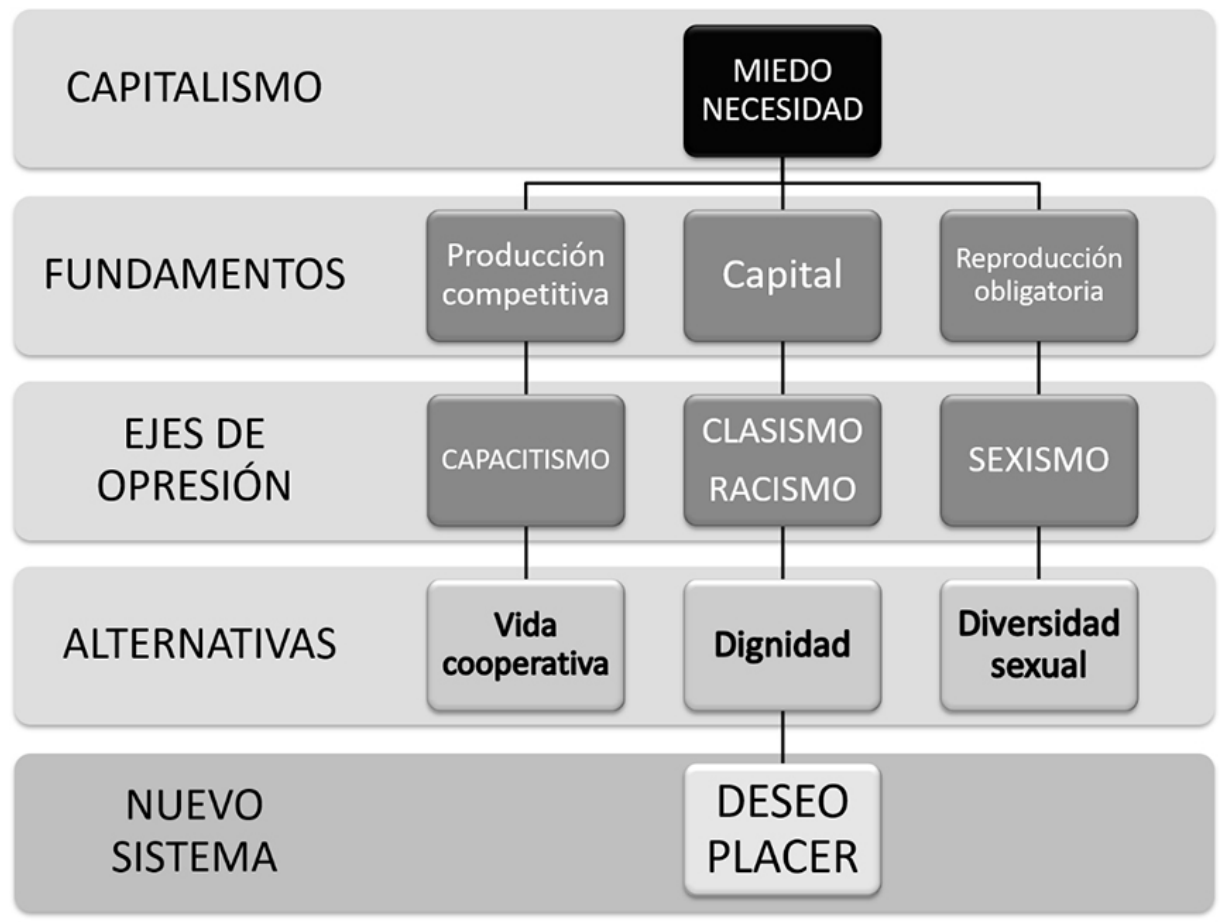

Imagen 5.

la homogeneidad es muerte. Resulta imprescindible, incluso urgente, recuperar el grito político y existencialista del punk: fuck normality!

\section{ASISTENCIA PERSONAL Y ASISTENCIA SEXUAL, LA MATERIALIDAD DE LA VIDA IN(TER)DEPENDIENTE}

Decíamos que la falta de apoyos materiales para la vida diaria, tales como la asistencia personal, la accesibilidad universal o la escuela inclusiva, por ejemplo, mantiene a las personas con diversidad funcional malviviendo en un universo paralelo, confinadas en residencias, escuelas especiales, centros especiales de empleo, centros ocupacionales, etc. Las buenas intenciones, los prejuicios y las inercias sociales nos aíslan y nos convierten en alienígenas para la mayoría de la población, que no tiene ningún tipo de interacción con la diversidad funcional. Esta segregación generalizada genera políticas del «todo sobre nosotras sin nosotras». Se impide la participación política de las personas con diversidad funcional y quienes dicen representarnos carecen de experiencia vital en cualquier aspecto relacionado con nuestra realidad. No es extraño que quieran creer que la de la diversidad funcional es una 
cuestión meramente técnica, pero ¿¿de qué sirve poner rampas en todas las discotecas si cuando entramos nadie quiere bailar con nosotras? Hay que entender que estamos ante una situación de discriminación y opresión generalizadas, poner en valor el lema del Movimiento de Vida Independiente de «Nada sobre nosotras sin nosotras» y, desde ahí, plantear que encerrarnos en instituciones o apoyar a las familias para que dependamos de ellas no es parte de la solución, sino parte del problema.

El capacitismo es caro, lo pagamos fundamentalmente las personas con diversidad funcional, pero la factura también alcanza al resto de la sociedad. Sabemos que incluir la diferencia en cualquier ámbito supone un motor de transformación social que lo mejora para todo el mundo, excluirla implica perder oportunidades para vivir mejor. Son claros ejemplos la escuela, que dispone de más y mejores herramientas pedagógicas para todo el alumnado; el transporte, que resulta más confortable y seguro para cualquiera; o la arquitectura y el urbanismo, que se convierten en más amigables para el conjunto de la población. Siendo grave esta pérdida de oportunidades para un mejor vivir, sobre todo teniendo en cuenta que cada vez viviremos más años y sobreviviremos a más enfermedades y accidentes, hay que señalar que el precio más alto lo pagamos en términos de género. Toda la industria de la discapacidad y la dependencia se sostiene sobre la base de los cuidados obligatorios por parte de las mujeres de la familia. Las vidas de ese ejército de esclavas no tienen valor, las hojas de cálculo de los poderes públicos dicen que ese trabajo es gratis. Cuando entendamos, como decía Machado, que es de necios confundir valor y precio, caeremos en la cuenta de que el capacitismo es insosteniblemente caro.

Es por todo ello por lo que resulta interesante el modelo de vida independiente, porque propone participación y convivencia. «Independencia» es un término histórico, que hace referencia no a hacer las cosas por nosotras mismas, sin apoyos, sino a tener toda la responsabilidad y libertad para gestionar los apoyos necesarios, evitando así las situaciones de dependencia. Es decir, hay un desplazamiento en la toma de decisiones, de la familia y los profesionales a la propia persona con diversidad funcional. Esto supone reconocer la propia autonomía como resultado de la interacción con los demás en iguales condiciones de responsabilidad y libertad, sin relaciones de dominación. En definitiva, estamos hablando de «interdependencia», aunque por razones históricas mantengamos la palabra «independencia». Es desde esta interdependencia desde la que resulta posible tanto la participación directa en la política como la convivencia. Necesitamos recuperar nuestros cuerpos y vidas para nosotras y dejar de ser extraterrestres para las demás.

A menudo, se intenta descalificar el paradigma de vida independiente tachándolo de elitista y económicamente insostenible. Hay que tener en cuenta que asumirse como oprimida y reclamar libertad requiere un empoderamiento que pasa por tener un cierto "passing» como "válidas", algo que casi siempre tiene que ver con privilegios de capacidad, clase, raza, género, etc. Nada nuevo bajo el sol, lo mismo que siempre ha ocurrido en cualquier otro movimiento de liberación. Lo importante es, desde esa conciencia de tener privilegios, articular un proceso político que sea para todas, coherente en la teoría y viable en la práctica. En este sentido, hay que entender que las personas con diversidad intelectual o mental toman sus propias decisiones a su manera, con los apoyos necesarios. Habitualmente, en colaboración con la persona 


\section{TOMIA DE DECISIONES}

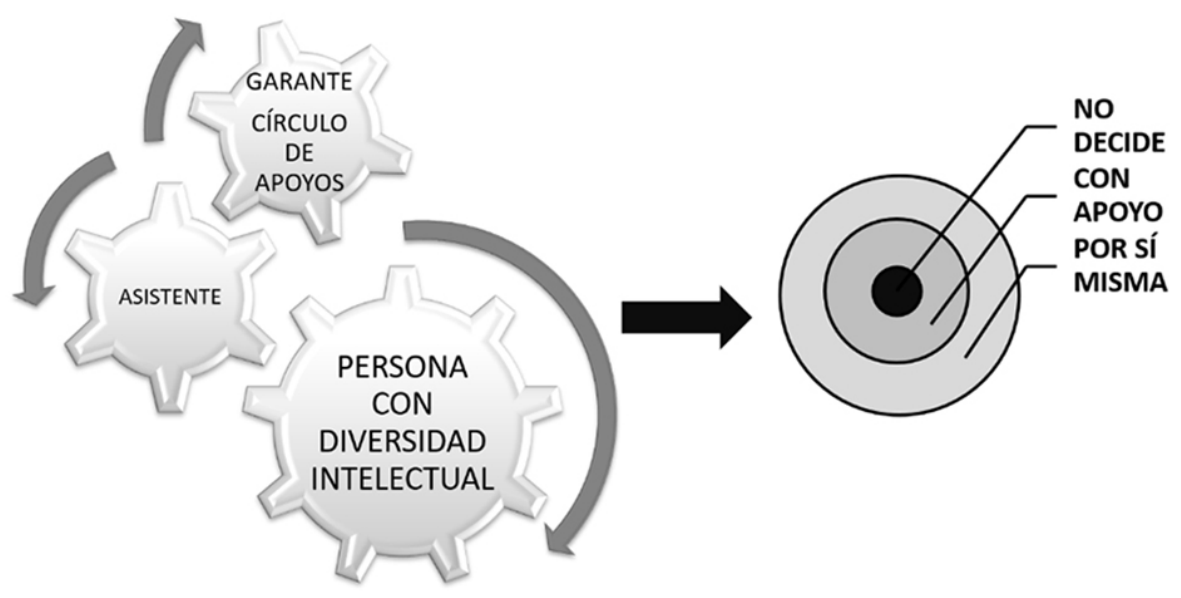

Imagen 6 .

garante y su círculo de apoyos, delimitan un mapa de toma de decisiones; qué pueden decidir por sí mismas, qué deciden con apoyo de sus asistentes y qué deciden mediante la interpretación de su voluntad. Así, cuando hablamos de decidir, queda implícito que nos referimos a que cada cual lo haga a su manera, el modelo de vida independiente también es para las personas con diversidad intelectual o mental.

En cuanto a la cuestión económica, todas las experiencias y estudios señalan que encerrarnos en instituciones es más caro que mantenernos en la comunidad con la asistencia personal necesaria. Algunos datos de los 12 años de experiencia en Barcelona ilustran este hecho general: asistencia personal $2800 € /$ mes de media, plaza residencial $3200 € / \mathrm{mes}$, SROI (Social Return of Investment) 3. Este último significa que por cada euro invertido en asistencia personal se genera un impacto social valorable en 3 euros. No nos encierran para economizar, nos encierran por principios. Y por negocio y corporativismo. A diferencia de los sistemas de salud, educación y pensiones, el sistema de autonomía personal es mayoritariamente privado (concertado o no). Incluso quienes no operan con ánimo de lucro tienen muchas nóminas que sostener, incluida la propia. Esta fue la jugada maestra de los poderes públicos, convertir a quienes reclamaban derechos en gestores de servicios que acaban siendo no un medio, sino un fin en sí mismos.

La falta de apoyos para la autonomía tiene que ver, también, con la idea misma de autonomía y dependencia. Veámoslo con un ejemplo que conozco bien. 
Tengo un certificado oficial que afirma que soy «dependiente en grado III». Para llegar a esa conclusión, un equipo multidisciplinar me hizo preguntas del estilo "¿puede beber por usted mismo?». Contesté que no, porque para beber mi asistente personal coloca el vaso en mis labios y lo inclina. Pero, en rigor, ¿puede alguien contestar afirmativamente? Detrás de ese vaso de agua hay miles de personas sosteniéndolo, se beba con las propias manos o con las del asistente personal; la diferencia entre 10000 manos y 10001 no debería ser significativa. La independencia es una fantasía, una ilusión óptica creada por un sistema social tan complejamente articulado para satisfacer las necesidades cotidianas de quienes funcionan de manera estándar que la tupida malla de productos y servicios que lo hacen posible queda invisibilizada por un uso y costumbre continuado que construye la idea mitológica del individuo autosuficiente. Todas dependemos de todas, todas aportamos a todas, nadie vive "por sí misma», la interdependencia es lo único real, es imposible ser sin las demás.

Lo que debería decir el certificado al que hacía referencia es que sufro una discriminación sistemática y sistémica (de grado x, si quieren) porque no se reconoce mi forma de autonomía, el mundo no está pensado para hacer las cosas a mi manera y esa falta de realismo para asumir la diversidad funcional de las personas es lo que transforma situaciones de interdependencia en dependencia. Mi forma de autonomía consiste en hacer las tareas cotidianas con Otras Manos y Mis Decisiones (OMMD). Por ejemplo, bebo con las manos de mi asistente personal (AP) sosteniendo el vaso y tomando yo todas las decisiones sobre esa acción (qué, cuándo, dónde, cómo, cuánto, etc.) Mi asistente no me da de beber, bebo a mi manera (OMMD). A veces, se ve más claro si el apoyo es tecnológico; cuando paseo lo estoy haciendo con el movimiento de la silla motorizada (ayuda tecnológica, AT) y mis propias decisiones (OMMD), la silla no me pasea. Puede parecer un juego de palabras banal, pero es la diferencia entre ser y vivir como un objeto o como un sujeto, nada menos. Beber con el apoyo de un asistente o pasear con una silla motorizada no son situaciones de dependencia, sino de autonomía OMMD en un entramado de interdependencias que se convierte en dependencia sólo si se me niegan esos apoyos.

El ejemplo de la silla sirve también para entender que «otras manos» es una metáfora que se refiere a cualquier apoyo externo, ya sea otro cuerpo, tecnología, un conjunto de indicaciones o un acompañamiento. Esto es importante para comprender que la OMMD es una forma de autonomía referida a cualquier tipo de diversidad funcional, ya sea física, intelectual o mental. En el caso de las personas con diversidad intelectual esas "manos» a veces son físicas, en otras ocasiones son indicaciones o acompañamiento, o bien todo a la vez. Al hablar de «las propias decisiones» hay que reconocer que existen diferentes maneras de tomarlas. Las personas con diversidad intelectual, con el apoyo de su círculo más cercano, las personas asistentes y la persona garante de que esos vínculos funcionen correctamente, diseñan un mapa dinámico sobre qué deciden por sí mismas, qué con acompañamiento y qué no deciden. Esa es su manera de tomar sus propias decisiones, más compleja que la de la mayoría, pero igual de humana, real y valiosa.

Dando una vuelta de tuerca más a la metáfora de "otras manos", parece claro que si las manos de un asistente personal tocan nuestros cuerpos con intención higiénica no hay ningún tipo de objeción social. Sin embargo, si durante un 


\section{FORMAS DE AUTONOMIÍA}

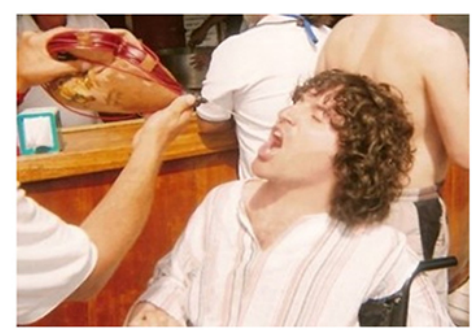

No me dan de beber. Bebo a mi manera, con las manos de mi AP $\mathrm{y}$ mis decisiones
La silla no me pasea. Paseo a mi manera, rodando con AT y mis decisiones
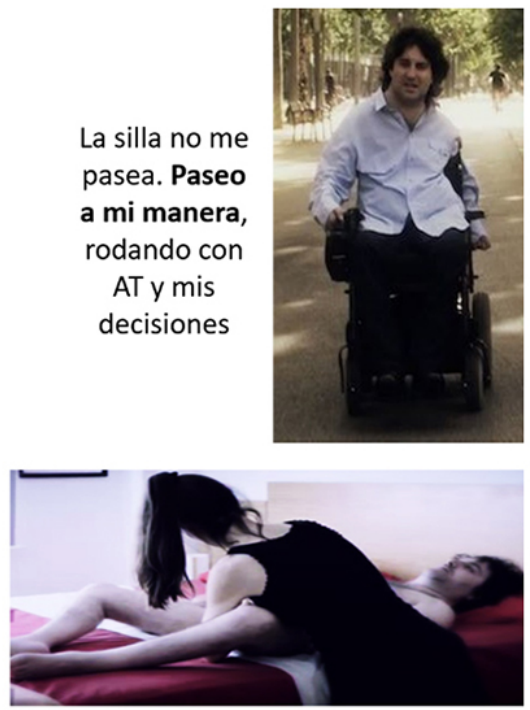

No me exploran ni me masturban. Me exploro y masturbo a mi manera, con las manos de mi AS y mis decisiones

Imagen 7.

solo segundo el objetivo fuese generar placer, entonces se encendería una polémica infinita en la que no poca gente aseguraría que nos precipitamos hacia el Apocalipsis. Es por eso por lo que cuando las tareas a realizar están directamente relacionadas con la sexualidad, la figura de apoyo para la forma de autonomía OMMD es otra, la asistencia sexual (AS). Resulta exactamente igual a la asistencia personal en cuanto a su justificación, su configuración como derecho y los roles que determina. Difiere en las acciones en las que se presta el apoyo, que son la autoexploración y el autoplacer, es decir, en el autoerotismo, que es lo que la mayoría desarrolla con la forma de autonomía mayoritaria (sus propias manos y decisiones). También es un apoyo para acceder sexualmente al cuerpo de otra persona (que no es el asistente). Esto último es habitual cuando dos personas con diversidad funcional necesitan apoyo para alcanzar determinadas posiciones o movimientos en sus prácticas sexuales. Por tanto, se trata de un trabajo sexual (por las tareas a realizar) y de uno de los recursos (como la asistencia personal o la interpretación de lengua signos, p.e.) que requiere la forma de autonomía OMMD para vivir como sujetos y no como objetos. En la misma línea de lo que hace décadas que los feminismos ya nos enseñaron, que sin recuperar el control, la responsabilidad y la libertad sobre nuestros cuerpos y sexualidades nunca recuperaremos nuestras vidas.

Igual que el asistente personal no es alguien con quien compartir tu vida cotidiana, sino que te apoya para que tengas una vida cotidiana propia y puedas 
compartirla con otras personas, el asistente sexual no es alguien con quien tener sexo, sino un apoyo para tener sexo con una misma y con otras personas. Se trata de un apoyo instrumental, ni educativo ni terapéutico, vinculado a una forma de autonomía minoritaria, que ni siquiera es la de todas las personas con diversidad funcional. Y, como todos los trabajos sexuales, tiene su propio marco, determinado fundamentalmente por los roles y prácticas posibles. En particular, no es tarea de la persona asistente excitar ni ser excitada, desnudarse, dar abrazos o besos o mantener prácticas sexuales con la persona asistida. La asistencia sexual es una herramienta clave, en tanto que permite romper la barrera de acceder sexualmente al propio cuerpo, pero no constituye ni la totalidad ni, en general, la parte más importante de nuestra vivencia de la sexualidad. Esta puede ser tan rica, intensa, subyugante, pobre, triste, ridícula o maravillosa como la de cualquiera, sea cual sea su forma de autonomía. Quizás no me crean, casi mejor que no me crean, anímense a comprobarlo por ustedes mismas.

Además del valor de la asistencia sexual como apoyo material concreto, hay que tener en cuenta la dimensión del valor simbólico de esta figura. En este sentido, intentar justificarla con mensajes del tipo «hay personas con diversidad funcional que sólo podrán vivir la sexualidad con estos servicios» valida y refuerza el estereotipo capacitista de la indeseabilidad de los cuerpos diversos y del estigma sobre las personas que hacen trabajo sexual. La asistencia sexual es una herramienta muy importante porque permite romper la barrera de relacionarse sexualmente con el propio cuerpo, de conocerlo y vivirlo también como fuente de placer. A partir de ahí, se hace posible que el vínculo con las demás incluya las dimensiones del deseo y del placer. La indeseabilidad no es exclusiva ni preponderante en ningún grupo humano, pero puede llegar a ser una profecía autocumplida si enseñamos que algunos deseos son inapropiados.

Estos discursos sobre la indeseabilidad de los cuerpos con diversidad funcional sustentan propuestas como la del presidente de Francia, Emmanuel Macron. Parte del lío que ha organizado Macron abriendo un proceso consultivo sobre la legalización de la asistencia sexual ${ }^{1}$ tiene que ver con que bajo el paraguas "asistencia sexual» se está colocando casi cualquier tipo de trabajo sexual que se dirija a las personas con diversidad funcional, y eso genera confusión porque hay propuestas y modelos muy diferentes entre sí. Lo que propone Macron, prácticas sexuales con las personas asistentes, es simple y llanamente prostitución especial y pretende justificarla en base a esa supuesta indeseabilidad. Hay quienes tienen problema con que sea prostitución, y hay quienes tenemos problema con que sea especial (igual que nos pasa con la escuela especial o el transporte especial). Lo que en el Movimiento de Vida Independiente entendemos por «asistencia sexual» no es ni prostitución ni especial, sino un apoyo específico relacionado con nuestra forma de autonomía.

\footnotetext{
${ }^{1}$ Asistencia Sexual (14 de febrero de 2020). Francia estudia legalizar la asistencia sexual. https://asistenciasexual.org/francia-estudia-legalizar-la-asistencia-sexual/.
} 


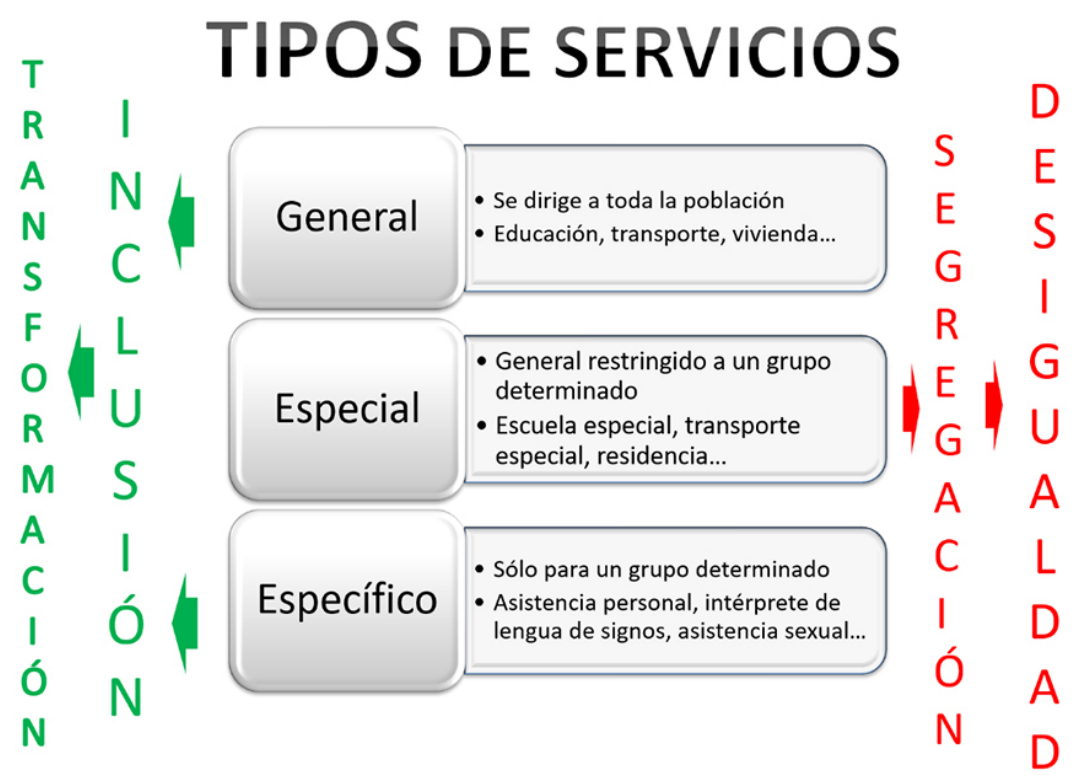

Imagen 8.

Cualquier propuesta sobre cómo debería ser un servicio de asistencia sexual tiene que incorporar lo que hemos aprendido a lo largo de décadas sobre cómo influye la estructura de los servicios sobre los procesos de inclusión y transformación social (ver imagen 8). Cuando un servicio general (es decir, que se dirige a toda la población) atiende a cualquiera, sean cuales sean sus diferencias respecto a lo habitual, el servicio resulta mejor para todo el mundo. Ejemplos claros de esto son el transporte, la educación, la arquitectura o el urbanismo. En cambio, cuando un servicio general en lugar de volverse inclusivo se segrega en un servicio especial para un grupo determinado, no contribuye a la transformación social general y, además, acaba dificultando la convivencia del grupo minoritario con el resto de población. Aquí también son claros los ejemplos ya citados. Por otro lado, también existen los servicios específicos (es decir, que no se dirigen a toda la población, sino sólo a aquellas personas con una determinada forma de autonomía) que se complementan y potencian con los servicios generales inclusivos. Ejemplos de estos servicios específicos son la AP, la AS, los intérpretes de lengua de signos, etc. En este sentido, los modelos de asistencia sexual en los que resulta posible pactar cualquier tipo de práctica sexual deberían encontrar encaje en una prostitución inclusiva, no en una prostitución especial. La propuesta del Movimiento de Vida Independiente se inscribe claramente en la idea de servicio específico.

Para entender las similitudes y diferencias de una figura profesional respecto de otras cercanas, es importante atender tanto a las tareas que se realizan como al rol 


\section{O5 AsistenciaseXuAl.ORG}

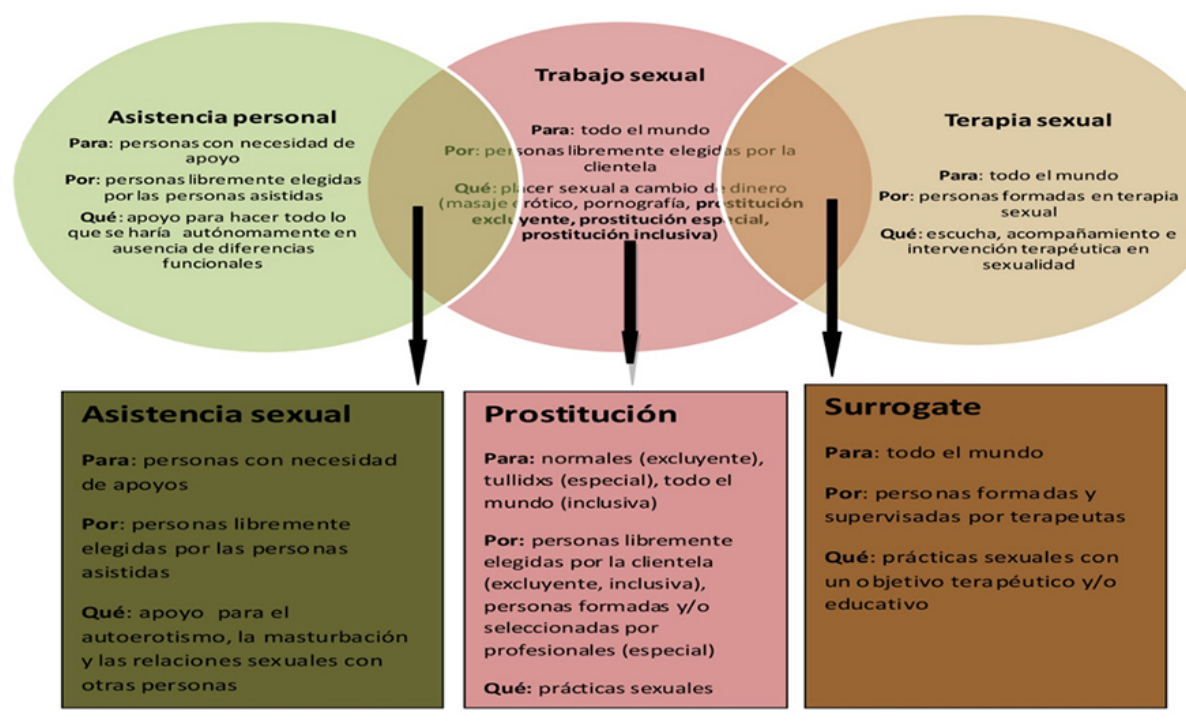

Imagen 9.

que se desarrolla realizándolas. Por ejemplo, aunque la acción sea la misma, resulta muy diferente ponerse un pantalón con un auxiliar de clínica, con un trabajador familiar, con un familiar o con un asistente personal. Mientras que con este último la persona con diversidad funcional se está poniendo el pantalón como un sujeto, a su manera, con sus propias decisiones, en el resto de situaciones es un objeto sobre el que actúa el conocimiento técnico y/o la buena voluntad. La definición de asistencia sexual que proponemos sitúa esta figura exactamente con el mismo rol que la asistencia personal y las tareas propias de los trabajos sexuales. Se trata, pues, de un terreno de intersección que genera una nueva figura. No está de más explicitar que entendemos por trabajo sexual cualquier intercambio libre de placer sexual por dinero. Dentro de esta definición caben multitud de trabajos sexuales, cada uno con su propio marco. No es lo mismo el estriptis que la pornografía, que el masaje erótico o la prostitución. Cada marco determina qué se puede esperar y qué no del servicio, tanto por parte de la persona trabajadora como por parte del cliente, y esto resulta fundamental para su buen funcionamiento. Por tanto, la asistencia sexual es un trabajo sexual con su propio marco, diferente de los otros trabajos sexuales, tal y como ocurre con cada uno de ellos.

En el cuadro (ver imagen 9), necesariamente sintético, pero con los conceptos ya desarrollados en los puntos anteriores, se intenta comprender mejor la AS ponién- 
dola en relación con otras figuras a partir de algunos elementos clave. La necesidad de distinguir cuál es el marco propio de la AS debe situarse en el terreno técnico y pragmático de clarificar las posibilidades y expectativas que ofrece tanto a la persona trabajadora como a la persona con diversidad funcional. Esto, además de ser fundamental para el buen desarrollo y funcionamiento de la figura, nos ayuda a distinguir entre qué constituye un derecho positivo (obligación de los poderes públicos de garantizarlo) y qué un derecho negativo (no se puede prohibir de manera arbitraria). Por otro lado, deberíamos evitar las distinciones basadas en valoraciones morales que muchas veces tienen que ver con los estereotipos sobre la diversidad funcional y con el estigma que pesa sobre los trabajos sexuales y las personas que los realizan.

Reconocer la asistencia sexual como un derecho supone reconocer a muchas personas con diversidad funcional como sujetos interdependientes con su propia forma de autonomía, rescatar esos cuerpos y esas vidas de un papel de objetos en manos expertas y bienintencionadas que nunca deberíamos haber asumido como algo natural, sino como el resultado de una mirada estrecha y triste, incapaz de reconocer el profundo valor humano de la infinidad de maneras de ser y estar en el mundo.

\section{ABORTO Y EUTANASIA, SI NO SON LIBRES NO ES MI REVOLUCIÓN}

Dos cuestiones bioéticas clásicas, el aborto y la eutanasia, ponen de relieve cómo las políticas de la tolerancia esconden un profundo desprecio por la diversidad funcional. En primer lugar, haríamos bien en no confundir la defensa del aborto libre con la defensa del aborto selectivo según las características corporales del feto. La postura más extendida en «ámbitos progresistas» viene a ser algo así como: «No, si yo estoy de acuerdo con el aborto libre, pero mientras no lo conseguimos me parece bien que haya un plazo diferente para malformaciones del feto». Este posicionamiento es, aparte de peligrosamente poco ético, ilegal. Veamos por qué.

Determinar plazos diferentes según alguna característica humana (sexo, etnia, diversidad funcional...) con el argumento de evitar sufrimiento a la futura persona o cargas al entorno familiar atenta contra la dignidad de las personas que ya viven esas realidades (como un servidor aquí o una mujer en la India). Nótese que el objeto de discriminación no es el feto, que no es un ser humano, sino las personas que tienen las características que pretenden justificar el aborto. En el mismo sentido, obsérvese que el sujeto discriminador no es la mujer que aborta, sino el texto legal que establece una minusvaloración de las vidas de las personas que poseen las características en cuestión.

En particular, no puede haber un plazo diferente por «malformación del feto». La Convención sobre los derechos de las personas con discapacidad ${ }^{2}$ forma parte del cuerpo jurídico español, y el Comité de la ONU que vela por su cumpli-

\footnotetext{
${ }^{2}$ https://www.un.org/disabilities/documents/convention/convoptprot-s.pdf.
} 


\begin{tabular}{|c|c|c|c|c|c|c|}
\hline & $\begin{array}{l}\text { Acceso } \\
\text { corporal }\end{array}$ & Vínculo & $\begin{array}{l}\text { Tipo de } \\
\text { servicio }\end{array}$ & $\begin{array}{c}\text { Rol } \\
\text { asistidx }\end{array}$ & $\begin{array}{l}\text { Prácticas } \\
\text { sexuales }\end{array}$ & Asistidxs \\
\hline Asistencia sexual & propio & trabajo & específico & jefx & masturbación & $\begin{array}{c}\text { necesidad de } \\
\text { apoyos }\end{array}$ \\
\hline $\begin{array}{c}\text { Acompañamiento } \\
\text { erótico }\end{array}$ & acompañante & $\begin{array}{c}\text { voluntariado } \\
?\end{array}$ & especial & $?$ & cualquiera & $\begin{array}{l}\text { diversidad } \\
\text { funcional }\end{array}$ \\
\hline $\begin{array}{l}\text { Prostitución } \\
\text { especial }\end{array}$ & prostitutx & trabajo & especial & clientx & cualquiera & $\begin{array}{l}\text { diversidad } \\
\text { funcional }\end{array}$ \\
\hline $\begin{array}{l}\text { Prostitución } \\
\text { inclusiva }\end{array}$ & prostitutx & trabajo & general & clientx & cualquiera & cualquiera \\
\hline Surrogate & Surrogate & trabajo & general & paciente & cualquiera & cualquiera \\
\hline $\begin{array}{l}\text { Eyaculación } \\
\text { asistida }\end{array}$ & Propio & voluntariado & especifico & paciente & masturbación & $\begin{array}{l}\text { Hombres con } \\
\text { necesidad de } \\
\text { apoyos }\end{array}$ \\
\hline
\end{tabular}

Imagen 10.

miento ya avisó a España ${ }^{3}$ en octubre de 2011 que debía corregir esa diferencia de plazos que se da en la actual ley. Nada dijo el Comité sobre si la corrección debía efectuarse eliminando todos los plazos, o elevando el plazo general a 22 semanas o eliminando el supuesto por "malformación del feto». Algo hay que hacer, pero no necesariamente lo que en su momento proponía el ministro.

Suele argumentarse que debe mantenerse el supuesto por «malformaciones del feto» porque si nace será una carga económica y emocional para la madre. Bueno, es posible, pero parece mejor camino luchar contra las causas sociales que convierten a un ser humano en una carga, en vez de demonizar alguna característica humana. Recordemos que los primeros en ser exterminados por la Alemania nazi ${ }^{4}$ fuimos las personas con diversidad funcional, y que la propaganda utilizada para buscar la aceptación social se basaba, entre otras cosas, en la carga que suponían esos ciudadanos indeseables. Tenemos que encontrar una manera de evitar "cargas insoportables» que no justifique y naturalice las causas sociales que, en muchas ocasiones, subyacen a esa percepción. También es habitual afirmar que debe mante-

${ }^{3}$ https://www.asociacionsolcom.org/files/documentos/Recomendaciones_ONU_Estado_ Espanol_sep_2011.pdf.

${ }^{4}$ http://www.elholocausto.net/parte03/0309.htm. 
nerse el supuesto por «malformaciones del feto» porque si nace sufrirá mucho. Otra vez nos movemos en terrenos pantanosos. Sé que genera rechazo hacer referencia a la propaganda nazi, pero es un hecho histórico que dicha propaganda se imbuía de autoridad científica para referirse a esas realidades como «vidas que no valen la pena ser vividas». No señalo ahí para acusar a nadie de nazi, sería profundamente injusto, sólo digo que la historia debería ser como mínimo una señal de alarma para reflexionar muy fino en estas cuestiones. Y no detecto esa reflexión.

Valga como ejemplo el exitoso artículo de El País «Nadie tiene derecho a obligar al sufrimiento». Después de un párrafo entero invistiéndose de autoridad científica, el autor deja ir una buena ristra de «terroríficas» afirmaciones y algunas inexactitudes. Especialmente significativo para mí es el parágrafo donde describe una de las situaciones de «sufrimiento más allá de lo inimaginable» en términos de "parálisis de ambas piernas. En los casos más graves, que desgraciadamente podrían ser la mayoría si la ley se modificase, el grado de parálisis será completo. Atrofia en estos casos de los músculos de los dos miembros inferiores con grandes deformaciones en los pies, piernas y también en la espalda, con desviaciones muy graves de la columna vertebral. Incontinencia completa de orina y de heces. Impotencia sexual completa». Un servidor, que es feliz como una lombriz, responde casi al milímetro a esa situación.

Así que, cuidado, alármense, pensemos, compartamos experiencias, no todo es como nos lo cuentan. Por otro lado, el artículo también hace referencia a situaciones como «la anencefalia (falta completa de desarrollo de los hemisferios cerebrales)", que sí me parecen claramente sin sentido alguno, tal y como ejemplifica El País en otro artículo sobre el caso de Gloria Muñoz y su hija Alba ${ }^{6}$. Por tanto, no digo que no haya realidades a intentar evitar, digo que no puede hacerse estigmatizando personas a base de naturalizar su presunta infelicidad porque eso ayuda a construir un imaginario colectivo sobre el que se han asentado y se asientan políticas nefastas para la dignidad de todas las personas.

Finalmente, el tercer argumento más popular afirma que debe mantenerse el supuesto por "malformaciones del feto" porque eso hace más libres a las mujeres para decidir sobre su propio cuerpo. La Conferencia Internacional sobre la Población y el Desarrollo (El Cairo, 1994) ${ }^{7}$ y la Cuarta Conferencia Mundial sobre la Mujer (Beijing, 1995) ${ }^{8}$ establecieron el derecho al aborto como un derecho humano en base al derecho a decidir sobre el propio cuerpo y el derecho a la salud. No es necesario

5 Esparza, J. (24 de julio de 2012). «Nadie tiene derecho a obligar al sufrimiento». El País https://elpais.com/sociedad/2012/07/24/actualidad/1343153808_906956.html.

${ }^{6}$ Sahuquillo, M.R. (25 de julio de 2012). «Si me quedase embarazada de otro bebé tan enfermo iría a abortar fuera». El Pais. https://elpais.com/sociedad/2012/07/25/actualidad/1343241210_620587. html.

${ }^{7}$ Naciones Unidas (1995). Informe de la Conferencia Internacional sobre la Población y el Desarrollo https://www.unfpa.org/sites/default/files/event-pdf/icpd_spa_2.pdf.

8 Naciones Unidas (1996). Informe de la Cuarta Conferencia Mundial sobre la Mujer. https:/www.un.org/womenwatch/daw/beijing/pdf/Beijing\%20full\%20report\%20S.pdf. 
(ni aconsejable) ningún otro argumento para defender la libertad total de las mujeres para ejercer su derecho al aborto. La cuestión es, cuando esa libertad total está secuestrada por una legislación como la actual que no respeta los derechos humanos, ¿’hace un «poquito libres» a las mujeres el supuesto de "malformación del feto»?

Parece que la impresión mayoritaria es que sí, y que mejor ese poquito que nada. En mi opinión, es un error gravísimo renunciar a lo establecido por el sistema de derechos humanos a cambio de un pedacito de "pseudolibertad" que consiste en que los médicos tengan la potestad de establecer una valoración suficientemente negativa de ciertas formas de vivir como para despenalizar el aborto. Así, ese pequeño trozo de pseudolibertad se construye validando el poder médico sobre el cuerpo de las mujeres y socavando la dignidad de las personas que ya viven las realidades que el estamento médico decide que no son dignas de ser vividas. ¿Es esta la mejor manera de que las mujeres lleguen a ejercer con total libertad sus derechos humanos? ¿Estamos construyendo libertad cuando acepta mos y reforzamos la medicalización de la vida humana como forma de opresión y dominación sobre quienes no encajen en el modelo utilitarista imperante? A mi modo de ver, la respuesta a ambas preguntas es no.

Si tenemos la conciencia de que algo, como el aborto libre, es un derecho humano no podemos aceptar que se viole dando por buenos cambalaches (como el aborto eugenésico) que validan y perpetúan esa vulneración, menos aún si tomamos conciencia de que ello quebranta también la dignidad de otras personas. Así no se construye libertad, sino situaciones de estigmatización, opresión y dominación de las mujeres y de las personas con diversidad funcional. Deberíamos recuperar la reivindicación del aborto libre como derecho humano vinculado al propio cuerpo y a la salud, y limpiar definitivamente esta lucha de otros argumentos bas$\operatorname{tardos}^{9}$ que lejos de ayudar a la causa la ensombrecen ${ }^{10}$ innecesaria y tétricamente.

En cuanto a la eutanasia, los razonamientos son análogos a los del aborto. Hay un consenso muy amplio respecto a la eutanasia pasiva, entendida como una buena praxis médica basada en el no encarnizamiento terapéutico y el acompañamiento en el proceso de morir, priorizando evitar el sufrimiento incluso cuando ello pueda acortar algo el tiempo de vida clínica. También hay bastante acuerdo social, aunque no tanto como en el caso anterior, en aceptar la eutanasia activa en pacientes aún no terminales pero cercanos a ese estadio, especialmente si han expresado claramente su voluntad al respecto mediante un documento de voluntades anticipadas. Ello permite rechazar tratamientos que podrían alargar considerablemente la vida clínica y recibir los cuidados necesarios para no sufrir dolor mientras las consecuencias del rechazo al tratamiento conducen a la muerte. La cuestión crítica es la eutanasia libre o suicidio asistido. Es decir, cuando la persona que solicita ayuda

9 Regás, R. (30 de julio de 2012). «Siniestra ley del aborto». El Mundo. https://www. elmundo.es/blogs/elmundo/ellas/2012/07/30/siniestra-ley-del-aborto.html.

10 Torres, D. (25 de julio de 2012). «Necesitamos tontos». Público. https://blogs.publico. es/davidtorres/2012/07/25/necesitamos-tontos/. 


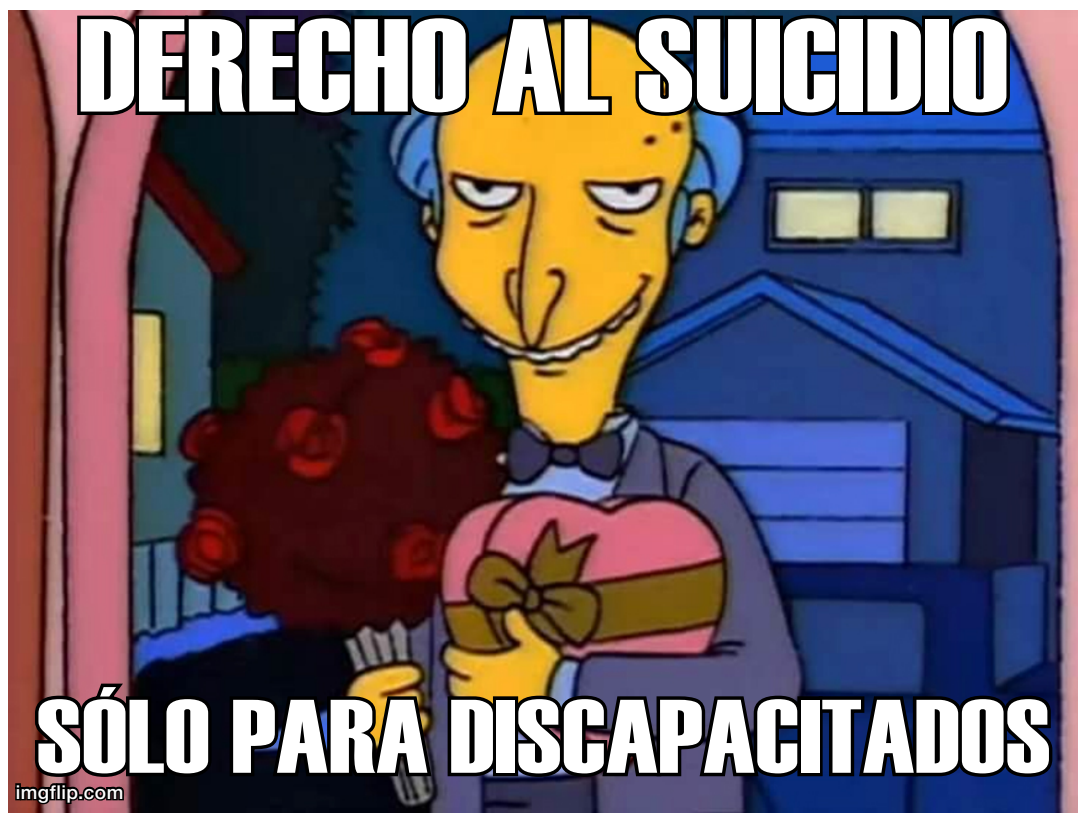

Imagen 11.

para morir como única vía para dejar de sufrir no se encuentra en un estado terminal o cercano a él.

Igual que pasa con el aborto, los problemas comienzan cuando, en lugar de aceptar un suicidio asistido libre, se pretende señalar a algunos grupos humanos como los únicos cuya mala vida permite despenalizar los apoyos necesarios para materializar la voluntad de la persona que los solicita. Un ejemplo paradigmático es el proyecto de ley de eutanasia del actual Gobierno de Espańa. El objetivo de la ley es loable y suscita, o debería suscitar, un consenso amplísimo: evitar el sufrimiento insoportable e irreversible. Lo que resulta inaceptable es que ese texto legal diga que dos (y sólo dos) grupos humanos sufren de manera insoportable e irreversible, a saber, los enfermos terminales y los gravemente discapacitados. ¿¿De verdad que ninguna persona sin discapacidad ni enfermedad terminal puede sufrir de manera insoportable e irreversible? Por supuesto que sí, sabemos que eso ocurre, luego la intención, o como mínimo el efecto, de semejante ley no sería acabar con dicho sufrimiento, sino señalar a los enfermos terminales y los gravemente discapacitados como únicos titulares de esa condición y, eventualmente, acabar con nosotras si damos consentimiento. Esta es la política de la tolerancia, no se nos obliga a morir, claro, pero se nos abre la puerta de salida exclusiva para nosotras. El resto de vidas son demasiado valiosas, son vidas no sólo toleradas, sino valoradas, celebradas, deseadas.

Por supuesto, cuando hablamos de suicidio asistido libre somos conscientes de que habrá que establecer mecanismos y protocolos que permitan asegurarse de 
que la persona conoce y dispone de todas las opciones que podrían revertir o hacer soportable su sufrimiento. Sería conveniente que la manera de acreditar el sufrimiento no estuviese sólo en manos del estamento médico, ni de ningún otro. El sufrimiento humano no es reductible a la mirada biomédica; filósofas, artistas, poetas o cómicas, por ejemplo, pueden penetrar en ese campo de conocimiento hasta lugares inaccesibles para la medicina. También habría que poner atención a que las herramientas de seguridad y acompańamiento necesarias no se conviertan en un tutelaje o una carrera de obstáculos insuperable. Finalmente, para cerrar la analogía con el aborto, nótese que quien discrimina no es la persona que decide suicidarse por tener ciertas características, sino el texto legal que informa de que esas formas de vida son tolerables, pero menos protegibles, menos valiosas que el resto.

\section{MÁS ALLÁ DE LA TOLERANCIA, POLÍTICAS DEL DESEO}

Vistas las nefastas consecuencias de las políticas de la tolerancia, necesitamos explorar posibilidades como, lo que podríamos denominar políticas del deseo. Para ilustrar la propuesta, recordemos que es habitual asistir al debate sobre si la asistencia sexual es un derecho o no. Quienes están en contra argumentan, entre otras cosas, que no es un derecho porque no responde a una necesidad. Se puede vivir sin placer sexual, dicen. Resulta una concepción del derecho como mínimo inquietante. Mi padre, que nació pobre en pleno fascismo, no fue nunca a la escuela. Así que sí, se puede vivir sin educación, pero ¿queremos vivir sin educación? Esta me parece la cuestión clave, hacer política desde el ¿qué necesito? o hacerla desde el ¿qué quiero? La política de la necesidad responde al miedo, en tanto que no se puede vivir sin tal cosa, y desresponsabiliza, ya que se presenta la necesidad como una ley natural externa a la persona. Por supuesto, el miedo puede ser encauzado socialmente y llegamos a ser tolerantes con lo innecesario, pero siempre será tratado como algo de menos valor, en ningún caso algo deseable. Quizás sea hora de activar la política del deseo, ¿qué quiero?, como una vía para la responsabilización y el compromiso personal y social.

Este hacer política desde el deseo requiere un compromiso ético en torno al propio deseo. En primer lugar, hay que asegurarse de que nuestros deseos sean nuestros. ¿Queremos que el centro de nuestras vidas sea acumular capital o queremos vivir con dignidad? Ninguna ley escrita nos obliga a ser productivas competitivamente contra las demás, ni tampoco a reproducirnos obligatoriamente. Pero lo hacemos, en primer lugar, por una falta de herramientas sociales alternativas a ese modo de vida, pero también porque lo deseamos, porque hemos aprendido que así son las buenas vidas, las vidas deseables. Resulta imprescindible construir una erótica de la dignidad, situarla en el centro de cualquier deseo que construyamos. Por otro lado, conviene cuestionarnos nuestra vivencia del deseo. A veces, pudiera parecer que el único sentido del deseo es convertirse en placer, aplicando en cada caso una serie de técnicas. Este sería un deseo muerto, repetitivo, incapaz de mover todo lo necesario para afrontar la complejidad de vivir. Necesitamos que sentir deseo sea 
una forma de placer, de manera que los segmentos inconexos que sitúan deseo y placer en sus extremos se conviertan en círculos virtuosos en los que deseo y placer se retroalimentan, se mantienen tan vivos como todo aquello a lo que tienen que dar respuesta.

Finalmente, necesitamos saber quiénes somos, con quién contamos para abrir experiencias en estas políticas del placer. De entrada, somos muchas las que compartimos la experiencia vital de haber sido machacadas por las políticas del miedo y su mitología normalizadora. Las mujeres, la comunidad LGBTQ+, las gordas, las locas, las racializadas, las personas con diversidad funcional, etc. Y quienes han vivido la breve ensoñación de la normalidad despertarán bruscamente cuando la edad, la enfermedad u otras circunstancias les expulsen de ese paraíso de plástico. Así que la alianza está abierta a cualquiera. Nuestras diferencias han sido patologizadas, estigmatizadas y parece que, como destino final, se nos reservan algunos huecos sociales en los que tolerarnos. Pocas cosas tan generadoras de un odio soterrado y camaleónico como esa tolerancia buenista. Sabemos que nada, salvo el deseo, es suficiente. Todo lo que no sea desearnos es asimilacionismo y abandono. Estamos aquí para transformar, lo queremos todo, exigimos deseo. 



\title{
DOCUMENTAR LA SEXUALIDAD Y LA DIVERSIDAD FUNCIONAL. EL SEXO Y LOS CUERPOS DIVERSOS Y NO NORMATIVOS COMO ARMAS DE EMPODERAMIENTO Y REIVINDICACIÓN POLÍTICA EN YES WE FUCK!, JO TAMBÉ VULL SEXE! Y CRIP CAMP
}

\author{
Hernando Carlos Gómez Prada y Marcos Bote Díaz \\ hergo22@hotmail.com_mbote@um.es
}

Universidad de Murcia

\section{RESUMEN}

El género documental es un cine subjetivo y reivindicativo que ha sido utilizado para prácticas activistas desde su creación, ampliando miradas, rompiendo tabúes y mostrando realidades diferentes, ricas y plurales. Los documentales Yes we fuck!, Jo també vull sexe! y Crip Camp tienen en común la visibilización del potencial político de los cuerpos en rebelión. En este artículo se realizará un estado de la cuestión acerca de la relación entre sexualidad y diversidad funcional para más adelante realizar un análisis audiovisual, con un enfoque cualitativo e interdisciplinar de los documentales seleccionados, poniendo especial énfasis en las transgresiones sociales que significa mostrar abiertamente las sexualidades y los cuerpos diversos. Entre los principales resultados, cabe destacar la forma en que el género documental aumenta el grado de empoderamiento personal y colectivo y termina convirtiéndose en un arma de reivindicación política.

Palabras clave: cine, documental, sexo, diversidad funcional, empoderamiento.

DOCUMENT SEXUALITY AND FUNCTIONAL DIVERSITY. SEX AND DIVERSE, NON-REGULATORY BODIES AS WEAPONS OF EMPOWERMENT AND POLITICAL VINDICATION IN YES WE FUCK!, JO TAMBÉ VULL SEXE! AND CRIP CAMP

\section{Abstract}

The documentary genre is a subjective and vindictive cinema that has been used for activist practices since its creation, broadening viewpoints, breaking taboos and showing different, rich and plural realities. The documentaries Yes we fuck!, Jo també vull sexe! and Crip Camp have in common the visibility of the political potential of bodies in rebellion. In this article, we will present a state of the art on the relationship between sexuality and functional diversity. We will then carry out an audiovisual analysis, with a qualitative and interdisciplinary approach, of the selected documentaries, placing special emphasis on the social transgressions that mean openly showing sexualities and diverse bodies. Among the main results, it is worth highlighting the way in which the documentary genre increases the degree of personal and collective empowerment and ends up becoming a weapon of political vindication.

Keywords: Film, Documentary, Sex, Functional Diversity, Empowerment. 


\section{INTRODUCCIÓN / MARCO TEÓRICO}

El asunto que nos aborda, sexualidad y discapacidad, se conforma, como se verá en las líneas siguientes, como un tabú profundamente incrustado en la socie$\mathrm{dad}^{2}$. Numerosos especialistas plantean que no se haya prestado atención a estudiar, en general, las demandas sociales de las personas con discapacidad, tratándolas siempre desde un paradigma mayoritariamente médico (Sandahl, 2003; McRuer, 2003). De este modo, aunque existe una revista científica desde 1978 titulada Sexuality and Disability, se trata de una publicación que aborda los aspectos médicos y psicológicos de la sexualidad en relación con la discapacidad. Un análisis de las publicaciones de esta revista entre 1996 y 2006 confirmaba esa percepción del cuerpo y la sexualidad de las personas con discapacidad ${ }^{3}$ como limitadas (Meinerz, 2010).

A pesar de los avances en la integración de las personas con discapacidad en la sociedad, la percepción social sobre su sexualidad permanece anclada en tabúes y prejuicios. Algunos autores han recogido (Shakespeare, 1998; Brodwin and Frederick, 2010) una serie de mitos y prejuicios sobre el binomio sexualidad/discapacidad que muestran claramente que existe un total desconocimiento por parte de la sociedad e, incluso, en algunos casos un alto grado de discriminación:

- Son asexuales o, en el mejor de los casos, sexualmente incompetentes. En cualquier caso, muestras de expresión sexual por su parte serían inadecuadas.

- No pueden ovular, menstruar, concebir ni dar a luz, tener orgasmos, erecciones, eyaculaciones ni fecundar.

- Si no están casados o en una relación estable es porque nadie los quiere (o no son atractivos), y no como fruto de una decisión personal de permanecer solteros o vivir solos.

- Si no tienen un/a hijo/a debe ser causa de profunda lástima, e igualmente nunca se puede deber a una elección propia.

- Cualquier persona no discapacitada que se case con alguien con diversidad funcional lo tiene que haber hecho por algún motivo sospechoso, nunca por amor.

- Si la pareja es también discapacitada, se han juntado precisamente por esa circunstancia, y no por otra cualidad que se pueda poseer. Cuando se escoge

${ }^{1}$ Centeno, Antonio. (2013): «La revolución de los cuerpos», en http://derechoshumanosya. org/la-revolucion-de-los-cuerpos/. (Consultado el 1/04/2020).

${ }^{2}$ Esta investigación se enmarca en el proyecto «Sexualidad y Diversidad Funcional (SEXFUN)» (Beca Leonardo a investigadores y creadores culturales/Fundación BBVA/2019).

3 A lo largo del artículo se utilizarán indistintamente los términos "personas con discapacidad» $\mathrm{y}$ «diversidad funcional», al no existir consenso sobre el término más adecuado para referirse a las personas que presentan condiciones físicas, intelectuales, sensoriales y emocionales diferentes a lo establecido como norma. 
a los de «su clase» el mundo de los no discapacitados se siente aliviado, hasta el momento en que deciden tener hijos, en cuyo caso se les considera irresponsables.

Estos postulados se enmarcan en el modelo médico rehabilitador, que aparece por primera vez a mediados del siglo xx. Un factor coadyuvante fue la simpatía que despertaban los veteranos de las guerras mundiales. No es hasta final del siglo pasado cuando la sociedad empieza a demostrar su preocupación por la identidad personal, imagen corporal y sexualidad humana como parte de la rehabilitación. En este sentido, el trabajo de Robinault Sex, society and the disabled puede considerarse un trabajo seminal sobre esta cuestión (Robinault, 1979; Cole \& Cole, 1993). Aproximadamente 15 años más tarde Monga (1995) llevaba a cabo un estado de la cuestión (o más bien, no estado de la cuestión, como acertadamente señalaron entonces algunos críticos) y reafirmaba los paradigmas del modelo rehabilitador, con importantes limitaciones que básicamente culpan a la enfermedad, y de forma adyacente al individuo, sin tener en cuenta el exosistema de creencias sociales y culturales que subyace en las concepciones médicas, sociales y políticas de tratamiento de la discapacidad. Todo ello, además, situado en una visión penecéntrica/ coitocéntrica de la sexualidad. Esta visión ha sido, desgraciadamente, la predominante durante la mayor parte de la historia, incluso con anterioridad a la rehabilitación, el paradigma de la institucionalización impuso severas medidas de control social llegando incluso a la esterilización eugenésica de las mujeres discapacitadas (Block, 2002; Fiduccia, 2000).

En las últimas décadas, este modelo biológico ha dado paso paulatinamente a lo que ha venido en denominarse el modelo social de la discapacidad. En este nuevo paradigma se tratan de integrar los componentes sociológicos y culturales de la diversidad funcional. En el caso concreto de la sexualidad, el modelo social se centra fundamentalmente en las limitaciones externas de la misma, sin perder en ningún momento de vista que la diversidad funcional, más allá de una condición médica, es un constructo social, como algunas investigaciones han puesto de manifiesto (Parchomiuk, 2012; Arnau, 2003). El modelo social de la diversidad, denominación acuñada por Mike Oliver en Reino Unido, se encuentra íntimamente ligado al movimiento de vida independiente, movimiento que desde mediados de los años 70 persigue la percepción de los sujetos con discapacidad funcional como ciudadanía de pleno derecho, así como la puesta en práctica de recursos como la accesibilidad universal y la asistencia personal autogestionada para que las personas con diversidad funcional puedan dirigir y controlar sus propias vidas (Arnau, 2005).

Cabe destacar cómo, a raíz del enfoque social de la discapacidad, el estudio sobre esta realidad ha comenzado a converger con otros campos de estudios, especialmente con el estudio del género y la orientación sexual. La crítica al modelo rehabilitador se suele enmarcar principalmente en la óptica foucaltiana. Especialmente desde los enfoques teóricos más críticos, como son la teoría queer y la teoría crip (Platero y Rosón, 2012; García-Santesmases, 2015). En este sentido, desde un enfoque paradigmático posestructuralista tanto la orientación sexual como la diversidad funcional son enmarcadas dentro de un paradigma crítico que cues- 
tiona el orden establecido social y culturalmente, así como él mismo es construido y naturalizado, incrustado en complejas relaciones culturales sociales y económicas y como esta construcción puede ser cambiada, especialmente a través de una economía social y política de la visibilidad (McRuer, 2006).

Esta visión culturalista del cuerpo no es exclusiva de los planteamientos más posmodernos provenientes de los estudios culturales, ya Marcel Mauss anticipa una visión culturalista del cuerpo frente a los mecanismos naturalistas (Mauss, 1968). Planteamientos que desde la antropología han tenido una continuidad en la obra de autores como Le Breton (2002) o Douglas (1988). Siendo abordado, también, desde un punto de vista de las relaciones de dominación y las lógicas de biopoder por autores como Foucault (1992) o Bourdieu (1977), que en el caso del territorio español permanecen muy presentes (Iañez, 2010).

Más recientemente, también se ha abordado el tema desde la perspectiva de los derechos humanos. Así, hay autores que formulan la necesidad de fortalecer los sistemas de salud para que los sanitarios no muestren resistencia o encaren dilemas cuando traten a pacientes con discapacidad, siendo necesaria no sólo la formación, sino una socialización integral de respeto a la diversidad (Mall y Swartz, 2012). Se insiste en esta perspectiva también para las personas con discapacidad intelectual, caracterizada por un discurso de supresión de su sexualidad (Taylor, 2012). En el presente siglo, se comienza a abordar desde una perspectiva más integral la sexualidad de las personas con discapacidad, física o intelectual, poniendo el énfasis en su derecho a una vida sexual satisfactoria y en la dotación de herramientas para evitar el abuso y el asalto sexual tanto de adolescentes como de adultos (Greydanus et al., 2002). Aun así, recientemente seguimos encontrando intervenciones psicológicas basadas en esta concepción terapéutica (Dukes y McGuire, 2009; Healy et al., 2009).

En un esfuerzo por integrar la perspectiva de los derechos humanos, algunos autores han advertido sobre el peligro de centralizar la importancia del sexo frente a la amistad o la intimidad. En este sentido, algunos autores han sugerido la incorporación de la teoría del reconocimiento de Axel Honneth para conceptualizar la sexualidad en la agenda de los derechos de las personas con diversidad funcional (Shakespeare, 2000). De ahí la necesidad de pensar el modelo social de la discapacidad, o más bien repensar, pues durante la primera década del presente siglo el modelo continuaba reforzando la matriz heterosexual con una visión binaria del sexo, apostando por visiones dismodernistas de la sexualidad y la belleza (Rembis, 2010). Parece que aún, en la actualidad, se hace necesaria la articulación de una concepción de la discapacidad en la cultura mainstream a través del desarrollo de políticas sociales que hasta el momento se ha regido fundamentalmente por principios utilitarios y de igualdad libertaria de oportunidades (Shildrick, 2007). Es importante, en esta articulación, integrar el discurso del placer, fundamental para la calidad de vida de las personas con discapacidad (Tepper, 2000).

Dentro de la sexualidad de las personas con discapacidad se ha tornado controvertido el asunto del derecho a la asistencia sexual. Desde el punto de vista jurídico o ético el derecho a la asistencia sexual puede enmarcarse en la teoría de las necesidades, reconociéndose como parte de los derechos sexuales o incluso como el derecho a elegir una forma de vida (De Asís, 2017). 
El cine es un instrumento significativo para la comprensión de la realidad social y debido a su variedad temática es un importante exponente del imaginario social. Walter Benjamin (2003) define el cine como un artefacto cultural de dimensión colectiva que a partir de la reproducción técnica facilita el proceso de alienación sociocultural.

El cine, además de su función lúdica, tiene una función informativa, investigadora y pedagógica que ayuda a crear y transmitir actitudes y valores sociales y culturales. El mundo de la imagen, de la ficción, conecta a través de canales connotativos, y su persistencia determina su aceptación y aportación al imaginario popular (Mitry, 1989)

El cine puede considerarse un instrumento de representación de la sociedad y de las relaciones que en ella se desarrollan y un medio de comunicación de masas (Sorlin, 1977). A través del cine se muestra la diversidad de culturas, con sus pensamientos, modos de vida, costumbres, y nos ofrece la posibilidad de sumergirnos en ellas para "conocerlas, comprenderlas, aceptarlas y respetarlas, con la esperanza de lograr una convivencia donde imperen valores necesarios en la sociedad actual como, la tolerancia y la ciudadanía» (Alonso y Pereira, 2000: 129), pero, además, el cine ha servido de vehículo cultural de la violencia simbólica (Bourdieu, 1999) contra las personas con discapacidad y urge la necesidad de desentrañar sus mecanismos por los cuales estereotipa y discrimina a este colectivo, poniendo el cine en las manos de las personas con discapacidad o buscando miradas no discriminatorias sobre este colectivo.

En el objeto de estudio que nos ocupa, los géneros cinematográficos en los que se inscriben las obras marcan de manera definitoria su enfoque, de esta manera nos encontramos ante dos largos documentales cinematográficos y un reportaje documental televisivo, que debido a sus similitudes con el documental cinematográfico y al compartir muchos elementos dentro de sus estructuras, analizaremos como cine documental.

En el caso de Yes we fuck! (YWF), nos encontramos con una obra audiovisual que va más allá del documental y muestra de una manera conscientemente política actos sexuales, por lo que estaría, además, enmarcada dentro del género pornográfico, o más bien dentro del conocido como movimiento posporno (o postporno), un tipo de pornografía realizada desde una mirada revolucionaria que cuestiona la pornografía mainstream al mostrar cuerpos y prácticas sexuales y eróticas reales, diversas, no normativas y subversivas, siempre desde una referencia feminista o transfeminista.

Jo també vull sexe! (JTVS) pertenece al género documental de entrevistas y está centrado en mostrar la sexualidad de las personas con discapacidad de una manera didáctica y dando la voz a los protagonistas, además, el fin del documental es mostrar al público la figura de el/la asistente sexual. Nos encontramos ante un documental divulgativo dirigido a un público experto, no un público general, debido a que es emitido en un programa especializado. La emisión del documental coincide cronológicamente con el interés por parte de los medios de comunica- 
ción por la figura de el/la asistente; en ese año 2017, encontramos numerosas noticias que se hacen eco de la regulación en Suiza de la asistencia sexual y comienzan a plantearse su implantación en España. Este documental viene a dar voz a los/las asistentes y a las personas con discapacidad que utilizan estos servicios como un medio de visibilizar y abrir el debate social sobre su regularización.

Crip Camp (CC) es un documental híbrido de entrevistas y archivo donde el sexo es tratado de una manera transversal. Hemos decidido incluir este documental como un ejemplo de la evolución de la temática sexualidad y discapacidad en el audiovisual. El tratamiento de la sexualidad en este documental es muy similar al que se concede a la integración, la eliminación de barreras o la reivindicación política. Desde 2015 con YWF hasta 2020 con CC podremos analizar desde una perspectiva histórica cómo la sexualidad ha pasado de ser un tabú a una reivindicación lógica y plausible dentro del audiovisual. A través de una narración clásica y con el uso de flashbacks se narra la historia del campamento de verano donde se gestó el movimiento por los derechos civiles de las personas con diversidad funcional, asistimos a las vidas pasadas y actuales de eminentes activistas que hablan de su sexualidad de una manera desprejuiciada y sin tabúes, como una parte esencial de sus vidas desde que son adolescentes hasta que son ancianos, elaborando un discurso que entrelaza amor y sexualidad de una manera normativa y rompiendo con imágenes anteriores discriminatorias.

\section{ESTADO DE LA CUESTIÓN}

Mucha de la investigación inicial se ha llevado a cabo desde el punto de vista clínico; sin embargo, existen numerosas aproximaciones desde las ciencias sociales. Un estudio pionero es el llevado a cabo en Sudáfrica en 1992 por la académica discapacitada Shanaaz Majiet, quien condujo talleres para conocer la percepción social de las mujeres con discapacidad obteniendo imágenes negativas o de condescendencia (Majiet, 1992, 1996). Más tarde se comenzó a hacer investigación cualitativa, destaca particularmente el trabajo de Yoshida, Lee y Odette (1999) con grupos de discusión con mujeres con discapacidad física de diferentes grupos étnicos. La intersección de desigualdades ha ganado también fuerza en los estudios sobre sexualidad, destacando especialmente los estudios que enlazan los estudios de discapacidad con los estudios queer (Drummond y Brotman, 2014).

Muchos de los estudios de personas con discapacidad se han llevado a cabo a través de cuestionarios con personas con discapacidad, en algunos casos sobre autoconocimiento (Kijak, 2011, 2013), abuso sexual (Nosek et al., 2001), autoestima (Taleporos y McCabe, 2001; Taleporos et al., 2002) o necesidades sexuales (McCabe, 1999; McCabe et al., 2000). También se ha usado la observación participante en bailes para personas con discapacidad intelectual (Löfgren-Martenson, 2004).

Una buena parte de los estudios se ha centrado en conocer la opinión de otras personas, en ocasiones los padres (Isler et al., 2009), estudiantes universitarios (Franco et al., 2012; Parchomiuk, 2012), personal de la industria del ocio (Gilmore y Chambers, 2010), personal de servicios de planificación familiar (Anderson 
y Kitchin, 2000) y, por último, los estudios que han puesto de manifiesto la falta de formación en el colectivo sanitario (Kedde et al., 2012; Shindel et al., 2010 Valvano et al., 2014).

Otros estudios se han centrado en conocer las actitudes y el conocimiento hacia la sexualidad de las personas con discapacidad. Los resultados han mostrado la necesidad de aumentar la formación de los terapeutas en este sentido de forma que se muestren más cómodos al tratar asuntos sexuales con sus pacientes (Sakellariou y Simó, 2006; Kazukauskas y Lam, 2010).

Más recientemente han cobrado notoriedad los estudios usando la perspectiva narrativa. Destacan particularmente los escasos estudios centrados en la asexualidad, libremente elegida, de personas con discapacidad (Kim, 2011). Estudios pioneros sobre la asexualidad de personas autistas (Williams, 1994) contestan el modelo de normalización de la sexualidad de las personas con discapacidad. En el caso de la sexualidad de personas con trastornos del espectro autista también se ha hecho hincapié en la necesidad de adaptar la educación sexual para que los conocimientos sean más fácilmente adquiridos por las personas que experimentan esta condición (Koller, 2000).

En la misma línea de estudios narrativos también aparecieron estudios a principio de siglo sobre la fertilidad de mujeres con discapacidad (Block, 2000) o el impacto de la discapacidad en la masculinidad (Shakespeare, 1999, Tepper, 1999; Guldin, 2000; Sakellariou, 2006). Más recientemente los estudios narrativos, algunos de corte autobiográfico, han cobrado fuerza en la actualidad, centrándose en diferentes condiciones, como el autismo (Block et al., 2012), la discapacidad intelectual y la autodeterminación (Bernert, 2010) o la experiencia como familiar de una persona con discapacidad (Winges-Yanez, 2013). Más escasos, pero también interesantes, son aquellos estudios que han usado el análisis de contenido para aproximarse a la sexualidad de las personas discapacitadas a través de la pornografía (Overstreet, 2008).

En el caso de España, resulta especialmente atractiva la aproximación etnográfica de García-Santesmases y Branco de Castro (2016) en torno a la figura de la asistencia sexual, usando tanto observación participante como entrevistas en profundidad con trabajadoras sexuales, siendo este último grupo un colectivo del que apenas existen estudios sobre la cuestión (Sanders, 2007).

\section{El CiNe COMO REFLEJO DE LOS CAMBIOS SOCIALES}

Juan Cobos, en el prólogo de El cine del aislamiento. El discapacitado en la historia del cine (Norden, 1998: 9), nos advierte que «la forma en que se ha reflejado la discapacidad, en que el cine nos ha guiado en nuestra forma de verla y sentirla. El balance es muy negativo. Aquel que tenía un rasgo físico distintivo ha sido aprovechado para atribuirle maldades, perversidad, odio».

Enrique Martínez-Salanova Sánchez (Ledesma, 2009: 130) retoma la idea de la exclusión y la marginalidad, incidiendo en la necesidad de una visibilización positiva: 
Las personas discapacitadas siempre han estado representadas en el cine, y cada vez más, con mayor fuerza. No obstante, este lenguaje global ha tratado al discapacitado de forma desigual presentándolo, en una gran parte de la filmografía, tanto como ser marginal, deforme y malvado, como el bonachón incapaz de hacer daño a nadie. En el correr de los años, el cine ha avanzado en sus lenguajes promoviendo una figura del discapacitado cada vez más acorde con el sentido que tiene y aporta a la sociedad, tomando de la sociedad los modelos que ésta provee. Sin embargo, el peor maltrato que sufren los discapacitados en el cine es que no se les ve, salvo excepciones, como a cualquier persona.

Como podemos comprobar, la imagen que el cine suele transmitir de la discapacidad es frecuentemente una imagen llena de prejuicios y estereotipos que en escasas ocasiones se acercan a la vida real de estas personas.

Es importante incidir en la importancia capital de la imagen cinematográfica porque el cine que se produce en un país pasa a formar parte de la realidad social de ese país debido a que se construye dentro de una cultura determinada. Esta producción cinematográfica está influida culturalmente por el lugar donde se produce y es reflejo de su política, de su historia o costumbres. En el cine aparece la visión que la sociedad tiene de sí misma y del otro, la imagen cinematográfica es reflexiva, porque sus historias provienen de la sociedad y son un reflejo de ella. Debido a este poder de comunicación social, el estudio del cine y su influencia en los cambios de paradigmas puede llevarnos a conocer cómo se desarrolla una sociedad. Desde este punto de vista el análisis fílmico permite comprender, de cierta manera, el pensamiento y tiempo de la sociedad en la que se ha producido (Goldman, 1976).

Según Kracauer (Ethis, 2009: 53), «el cine puede ser estudiado como reflejo de la sociedad o como documental expresivo del mundo social» y es esta idea la que queremos reflejar en este trabajo, que además se centra en el género documental, un género que, como nos indica Sorlin, «traduce la realidad y donde se presenta lo visible o representable de la sociedad» (Ethis, 2009: 63). Además, al «visibilizar» a la sociedad, el cine se sitúa en el plano de lo cultural y lo social, convirtiéndose así en una herramienta muy útil para cambiar, transformar o denunciar esa sociedad.

Norden (1998), en su libro titulado El cine del aislamiento, detalla los distintos estereotipos con los que las personas con discapacidad han ido apareciendo a lo largo de la historia del cine: desventurado cómico, dulce inocente, vengador obsesivo, villano discapacitado, noble guerrero, santo sabio y ciudadano superestrella. Lamentablemente, algunas de estas visiones estereotipadas siguen apareciendo en la producción cinematográfica de nuestros días.

Garland-Thomson (McRuer, 2006: 171) clasifica cuatro maneras de mirar a la discapacidad: desde el asombro, desde lo sentimental, con lo exótico o transgresivo y la manera realista. La primera nos aleja del sujeto que es mirado, la segunda coloca al sujeto discapacitado en una posición inferior a través de la pena y la compasión del que mira, la tercera hace ver la discapacidad como algo extraño y, por último, la manera realista, que supone un acercamiento a la discapacidad que minimiza las diferencias entre el que observa y la persona discapacitada. Esta última manera sería la manera en la que el documental se acerca a la realidad de la discapacidad. El documental, mostrando la realidad de la discapacidad, nos alerta sobre 
cómo no es la discapacidad, sino la exclusión y la falta de empatía, la que más sufrimiento produce.

La necesidad visual del cine de crear estereotipos para poder comunicar ha logrado durante largo tiempo que la discapacidad haya estado vinculada a la medicina, el terror o la maldad, elaborando el discurso simplista y discriminatorio que ha sido reelaborado desde el documental, un género que logra llegar de una manera más honda y reflexiva al espectador. «El documental puede ser tanto un ensayo premeditado como una expresión lírica e impresionista, es el opuesto al entretenimiento de escape, a la negación de la realidad; por el contrario, está comprometido con la riqueza y la ambigüedad de la vida tal cual es» (Rabiger, 1992: 17). Como observa Breschand (2004: 4) acerca del documental:

Interrogar al cine partiendo de su faceta documental significa interrogarse sobre el estatuto de la realidad frente a la cámara, o la relación entre el filme y la realidad. Significa elegir un eje de reflexión, un eje que supone que el cine se reinventa a sí mismo cuando logra hacer visible algo que hasta entonces había permanecido inadvertido en nuestro mundo.

Además, el cine documental puede desarrollarse de manera diferente al ficcional, es más libre en sus códigos y, gracias a sus presupuestos más reducidos, tiene una mayor capacidad de crear contranarrativas (Chanan, 2007); el documental es político por naturaleza. «El cine documental intenta provocar sentimientos, modificar o fortalecer compromisos y proponer acciones impulsadas por creencias compartidas» (Nichols, 2007: 39).

Esta necesidad de reemplazar las interpretaciones sobre lo que significa tener discapacidad entendiendo estas como construcciones sociales es la principal reclamación que se le formula actualmente al cine y sólo el documental tiene la capacidad de adaptarse a estas urgentes y necesarias reclamaciones.

Mientras toma forma, dirige siempre la cámara hacia los terrenos social, histórico y antropológico, espacios dominados por el poder y la autoridad de manera más o menos explícita, y cuando se proyecta, se dirige al público de un modo distinto al que emplea la ficción. Las películas de este segundo tipo heredan los modelos narrativos del teatro burgués del siglo diecinueve y de la novela, aunque adaptados a las aspiraciones populistas de la ficción, y apelan a la vida emocional y sentimental de los espectadores, a su subjetividad, incluso cuando tratan de asuntos sociales, históricos o políticos. El documental, en cambio, se dirige al espectador en cuanto ciudadano, en cuanto miembro de un colectivo y elemento constitutivo del espacio público puesto que es un cine íntimamente ligado a la esfera social (Chanan, 2007: 94).

Crow apunta hacia la necesidad de cambiar la visión de la minusvalía que existe en el cine mainstream "por otras basadas en la propia experiencia de la minusvalía, en lugar de con lo que las minusvalías significan para las personas no discapacitadas» (1996: 235). Como nos advierte Esteban, «lo que hay que cambiar son las actitudes, las creencias, los valores, más que el cuerpo en sí» (2004: 33). 
Para un análisis más profundo sobre esta cuestión de la imagen de la discapacidad en el cine debemos destacar las investigaciones realizadas por Margarita Córdoba y Julio Cabero (2009), Cine y diversidad social. Instrumento práctico para la formación en valores; Olga María Alegre de la Rosa, La discapacidad en el cine (2003), y, por su especialización desde una perspectiva de género, el capítulo de Marta Senet Ramos (2015) Woman and disbility in Spanish Cinema (1979-2012), además de la obra fundacional de Martin Norden (1998) que hemos reseñado anteriormente El cine del aislamiento.

\section{METODOLOGÍA}

Siguiendo la definición propuesta por Casetti y Di Chio (1991: 17) podemos entender el análisis como «aquel conjunto de operaciones sobre un objeto determinado y consistente en su descomposición y en su sucesiva recomposición, con el fin de identificar mejor los componentes, la arquitectura, los movimientos, la dinámica, etc.». Nos disponemos en esta investigación a realizar un abordaje interpretativo de los tres filmes documentales mencionados en el objeto de estudio a través de una metodología propia.

Además, se vuelve necesario un análisis que evidencie la aportación subversiva y deconstructiva de estas obras documentales y que muestre que estas obras se contraponen a la mirada clásica, parcial y limitada de la representación tradicional, victimizante, discriminatoria y llena de prejuicios de las personas con discapacidad. Como advierte Colaizzi (1997: 41):

Un texto -cualquier texto- no puede ser simplemente mirado o visto; se tiene que
leer su arquitectura, las fuerzas y los modelos que lo rigen, descifrar los códigos,
que lo constituyen, a los que se sujeta o resiste; quiere decir darse cuenta de que
"veo" no quiere decir "comprendo", que toda representación, todo texto no es
mímesis de la realidad [...] sino escritura, in/scripción cultural, construcción, una
articulación de sentidos hecha a partir de coordenadas histórico/sociales concretas,
siempre ideológicamente orientadas, motivadas y conducidas a intereses concretos.

A partir de estos parámetros, con rigor metodológico, integrando diversas tradiciones disciplinarias en un análisis claramente interdisciplinario, pretendemos adentrarnos en la lectura de estos textos cinematográficos aportando una nueva mirada libre de tabúes y discriminación.

Nos encontramos ante una investigación de las imágenes culturales cinematográficas dominantes creadas dentro de los contextos de la sociedad, a la vez que ponen de relieve los valores sociales imperantes, y este será nuestro análisis; para ello, además de las herramientas metodológicas del análisis visual cinematográfico, utilizaremos como marco teórico y metodológico las teorías fílmicas feministas, los estudios de género y la teoría queer, indagando en la relación cine/género/sociedad y en «la impía alianza del feminismo, la semiótica y el cine» (De Lauretis, 1984: 13).

Realizamos este análisis convencidos, como destacan Zurian y Herrero (2014: 18), de que este tipo de análisis: 
realmente supone una metodología atravesada transversalmente por una gran variedad de campos de investigación intelectual y disciplinas: un sistema de análisis en constante diálogo, pues en cada momento del análisis se introducen variantes epistemológicas que posibilitan o pretenden posibilitar la mejor episteme, la que mejor puede ahondar en el análisis y extraer mejores datos alejados de una doxa personal e individual.

\section{Delimitación Del objeto de estudio}

En la búsqueda en la web de cine online Filmin, bajo el epígrafe Enfermedades y discapacidades podemos encontrar 186 títulos sobre este tema (2/04/20) mientras que, si hacemos una búsqueda cruzada con el tema sexo, podremos encontrar títulos como Hasta la Vista (2012), Vivir y otras ficciones (2017), Dora y la revolución sexual (2015). Nos encontramos, pues, ante un tema que interesa a la sociedad y que está siendo debatido también en las pantallas.

La selección de los documentales objeto de estudio se ha hecho siguiendo dos parámetros, uno por la forma novedosa de mostrar la intersección entre sexo y discapacidad y además hemos querido elegir obras de distintos años y con una separación cronológica importante para también poder realizar un estudio comparativo en el tratamiento del tabú sexual. Las tres obras seleccionadas muestran cada una a su manera el espíritu del momento en que han sido realizadas y, como veremos en nuestro análisis, son cada una la consecuencia de la siguiente y muestran el avance social en nuestro país respecto a la relación entre sexualidad y discapacidad.

AnÁlisis aUdiovisual

Yes we fuck! (2015)

Dirigido por Antonio Centeno y Raúl de la Morena

Nos encontramos ante un documental que, a través de seis historias, en palabras de Teresa de Lauretis, trata de construir «otro horizonte discursivo, otra forma de pensar lo sexual» (1991: 4). Este documental no es novedoso sólo en el fondo, sino también en la forma, y podríamos calificarlo de documental híbrido debido a que ha ido extendiendo un nuevo relato hipertextual, a través de diversos medios y plataformas (web, redes sociales) con participación de distintos usuarios y asociaciones, creando una comunidad donde el nexo es la exploración de la sexualidad en personas con diversidad funcional. Lo que al principio se concibió como un documento audiovisual con una clara intención política, didáctica y visibilizadora ha seguido creciendo y se ha convertido en un movimiento social bajo el que se presentan nuevas obras y se siguen abriendo nuevas vías de visibilización. Kuhn (1991: 87) nos urge de la necesidad de "hacer visible lo invisible» y los autores de este documental han seguido esta máxima feminista a la hora de plantear su trabajo, desmontando tabúes y mostrando y explorando cuerpos no normativos, rom- 
piendo el orden sexogenérico dominante, el régimen heterosexual (Wittig, 2006) e incluso en la difusión de esta obra han sido rompedores y subversivos, pues el 12 de abril de 2018 se comenzó a distribuir gratuitamente el documental con la intención de convertirse en una "herramienta útil en las manos de cualquiera para abrir debates sobre la diversidad y la sexualidad» ${ }^{4}$.

El propio Centeno (O’Hara, 2013) lo explica así:

El documental quiere visualizar, principalmente, el sexo entre personas con diversidad funcional y generar así un nuevo e integrador imaginario colectivo donde tod@s, sin complejos, sin censuras, sin leyes, podamos disfrutar del sexo.

La complejidad de este documental rompedor estriba en cómo muestra el sexo y lo que la diversidad funcional puede aportar a la sexualidad humana. Rompe con la concepción de la sexualidad basada en el coito y plantea otras formas de vivir y sentir la sexualidad, poniendo como ejemplos a los cuerpos diversos, explorando los límites de la sexualidad y del cuerpo. Los protagonistas del documental se muestran orgullosos frente a la cámara y utilizan sus cuerpos diversos como armas empoderantes, abriendo un debate sobre las lógicas de exclusión/inclusión de la mirada y utilizando el cuerpo como una herramienta de liberación.

El sexo se presenta como «juego, diversión, experimentación, política» (min. 9:51) o como «diversidad, imaginación, placer-saber» (min. 10:01). Dando la libertad y la palabra a aquellos a los que se les niega su sexualidad descubrimos que las fronteras y los límites son construcciones sociales, como nos explican en el documental: «Para mí el sexo es un espacio de creación, un espacio en el que me siento libre de poder experimentar [...], aunque tampoco sabría definir dónde empieza y dónde acaba el sexo» (min. 34:54).

Centrándonos en su contenido pornográfico, Gubern (2005: 16) hace hincapié en el carácter didáctico de la pornografía:

Valorada en su calidad de escuela de técnicas eróticas, quebrantadura de inhibiciones sexuales, desmitificadora del dogma monogámico, fuente de gratificación hedonista $\mathrm{y}$, muy especialmente, para los ancianos, enfermos, físicamente desfavorecidos, solitarios o socialmente marginados. El carácter didáctico de la pornografía parece difícilmente cuestionable (y las cortapisas censoras no hacen más que confirmarlo), de modo que no sería aventurado afirmar que la extensión social en las culturas occidentales de técnicas como la felación, el cunnilingus, la sodomía, etc., deba bastante a la didáctica de la escuela pornográfica.

Sin embargo, esta obra rompe con el porno mainstream, muestra lo que otros ocultan o maquillan, mira a la cámara de frente y convierte lo personal en algo político, haciendo de este documental una pieza didáctica de gran interés para romper

${ }^{4}$ Fuente: Facebook, perfil del documental Yes we fuck! Disponible en https://www.facebook.com/yeswfck/. Consultado el 10 de mayo de 2020. 
con los regímenes visuales normativos. Como argumenta Centeno (O'Hara, 2013): «Si queremos cambiar el imaginario colectivo, nada mejor que imágenes contundentes contextualizadas por la idea política que sustenta el proyecto YWF».

Además, debemos hacer hincapié en cuándo se presenta este documental: en el ańo 2015 la sexualidad de las personas con discapacidad seguía siendo un gran tabú y apenas había sido representada. En el documental podemos reseñar Almas con sexo (TVE, 2003) y en la ficción en el año 2012 se había presentado el filme Las sesiones de Ben Lewin, un retrato amable de la pérdida de virginidad del periodista y poeta tetrapléjico y con un pulmón de acero, Mark O’Brien; sin embargo, aunque este filme tuvo una gran repercusión al mostrar escenas de desnudos frontales e incluso penetraciones en la pantalla de cine, se trata de una visión edulcorada y donde, además, aparece la figura del cura, una representación institucional, de las que huye YWF. Al presentar en el documental a los personajes relacionándose fuera de espacios institucionales o medicalizados y plantear de una forma política las reivindicaciones del colectivo, politizando la sexualidad y la figura de el/la asistente sexual y creando alianzas con los feminismos y activismos LGTBI y queer, YWF realiza una mirada subversiva que inicia un camino que más adelante será tomado por otras producciones.

\section{Jo també vull sexe! (2016)}

\section{Dirigido por Montse Armengou y Ricard Belis}

«Tú pagas al médico para que te arregle la muela. Yo tengo que pagar para que toquen mi cuerpo. Yo estaba muy triste, muy deprimida. Y desde que hago esto, me siento muy bien, es como una terapia» (min. 19:56). Existen muchas maneras de explicar un concepto, pero la máxima «una imagen vale más que mil palabras» sigue muy vigente. Palacio (2011: 8-9), afirma que «los medios audiovisuales se han convertido en actores centrales de la sociedad y de la cultura contemporánea; a su vez, por su capacidad de llegar a un público muy vasto son capaces de transformar valores, hábitos y formas de interrelación en nuestras sociedades».

En el año 2016 la sociedad española comenzó a preguntarse sobre la figura $\mathrm{de} \mathrm{el/la} \mathrm{asistente} \mathrm{sexual,} \mathrm{un} \mathrm{debate} \mathrm{que} \mathrm{sigue} \mathrm{abierto,} \mathrm{pero} \mathrm{que} \mathrm{en} \mathrm{ese} \mathrm{momento,} \mathrm{con}$ los cambios legislativos en Europa, era una cuestión candente. Ya existían algunas obras audiovisuales donde aparecía esta figura como, por ejemplo, el documental One Life: For One Night Only (BBC, 2007) (que más tarde se convertiría en la road movie Hasta la vista (Geoffrey Enthoven, 2011), Scarlet Road (Catherine Scott, 2011) o la antes mencionada Las sesiones (Ben Lewin, 2012). Sin embargo, el impacto de YWF había sido tan profundo que terminó convirtiéndose en una referente, como podemos comprobar en el hecho de que aparece una de sus proyecciones en este documental.

«Ha habido madres que han masturbado a los hijos antes de buscarles una asistenta sexual. Yo lo respeto, pero para mí es anormal» (min. 6:50). La dificultad a la hora de abordar el espinoso tema de la asistencia sexual con tantas implicaciones morales y éticas toma una nueva y necesaria visión en este documental, que da la voz a sus protagonistas y ahonda en sus necesidades sexuales y de afecto. 
Como dice Sánchez Noriega, «los medios tienen mucha importancia en la socialización de normas, valores y expectativas de conducta» (1997: 149). Los medios, y especialmente el medio televisivo, están asumiendo un papel creciente como instrumentos socializadores en detrimento de los que comúnmente se denominan agentes tradicionales, como lo son la familia, la escuela y la Iglesia. "Los medios de masas audiovisuales e informáticos han sustituido a las instituciones que tradicionalmente habían llevado el peso del proceso socializador, instaurando nuevas formas de comunicación y de interpretación de la realidad» (Ferrés 2000: 40).

Este documental se presenta dentro del espacio Sense ficció (Sin ficción), un título que deja clara la intención del programa de mostrar la realidad y tomar el pulso a la sociedad con documentales de producción propia para la cadena TV-3.

A «Sense ficció», entenem el documental com una eina per ajudar a progressar la nostra societat. El periodisme que practiquem busca donar veu a les persones que normalment no en tenen i treure a la llum els conflictes, les polèmiques i les històries que se'ns han volgut ocultar ${ }^{5}$.

De esta manera subraya el equipo del programa la idea principal de «hacer visible lo invisible» a través del documental, lo que relaciona esta obra, además de por su temática, con YWF. Asimismo, al incluir el tema de la sexualidad y la discapacidad en este programa podemos ver hasta qué punto YWF había logrado calar en la sociedad y abrir el debate de la asistencia sexual. De nuevo observamos cómo las imágenes de cuerpos desnudos no normativos son utilizadas como armas empoderantes desde la pantalla; como afirma Sutton (2007), la resistencia y la protesta políticas van siempre acompañadas de un intenso compromiso corporal: hay que "poner el cuerpo" y JTVS apuesta por una reivindicación empoderante desde la corporalidad.

Las diferentes audiencias de YWF y JTVS hacen que el tratamiento del sexo sea muy diferente y muestran una evolución hacia una normatividad heterosexual que es comprensible por el medio donde se emite el documental; sin embargo, creemos que al existir una directora, la perspectiva de género se ha impuesto y resulta un documental muy igualitario y empoderante. Si bien es cierto que YWF da la voz a los colectivos sexuales más marginales, JTVS muestra a hombres y mujeres con discapacidad con iguales necesidades sexuales, lo que es un hecho importante para una televisión generalista.

5 Web Sense Ficció. Disponible online en https://www.ccma.cat/tv3/sense-ficcio/programa/ Consultado el 11 de mayo de 2020. «En "Sin ficción”, entendemos el documental como una herramienta para ayudar a progresar nuestra sociedad. El periodismo que practicamos busca dar voz a las personas que normalmente no tienen y sacar a la luz los conflictos, las polémicas y las historias que se nos han querido ocultar» (traducción de los autores). 


\section{Crip Camp: A Disabled Revolution (2020)}

Dirigido por James Lebrecht y Nicole Newnham

Comenzaremos este análisis llamando la atención sobre la traducción del título con el que se conoce este documental en España: Campamento maravilloso.

Una de las principales premisas del movimiento queer es rechazar las definiciones: «Nombrar es matar», defiende Marla Morris (Talburt y Steinberg, 2005: 48). La importancia de la semántica y la función del lenguaje es una de las aportaciones más importantes queer. Butler (2004), en Lenguaje, poder e identidad, se pregunta si hablar es actuar, ¿qué consecuencias se derivan de ello? y se plantea la función del lenguaje en la constitución de la subjetividad y su articulación con el poder. Es por eso por lo que no podemos dejar pasar como algo anecdótico, burdo o simplemente absurdo cómo se renombra (porque no es una traducción) este documental en Espańa.

La traducción sería Campamento lisiado: Una revolución de discapacidad. El nombre original del campamento es Campamento Jenet, así que debemos asumir que los productores del filme decidieron nombrar el documental en una clara alusión a la teoría queer y específicamente a la teoría crip. Al tomar el término crip (lisiado/tullido) como un emblema y autorreferenciarse, se disloca el lugar de poder desde el cual parte cuando se hace como insulto y así podemos observar cómo se desnaturaliza ese insulto y se utiliza el término como forma de rebelarse contra el poder; además, en el título original se utiliza la palabra revolución, con la importante carga semántica que supone de cambio, lucha y superación.

Sin embargo, en España también pensamos que de una manera consciente, el campamento de los lisiados o tullidos (entendido desde lo queer) se ha convertido en un campamento maravilla, una palabra que es descendiente por vía semiculta del latín mirabilia, plural neutro del adjetivo mirabilis «digno de admiración», convirtiendo una acción de protesta y subversión en un acto de que debe ser aprobado por los otros/as. Esta palabra nos remite a los términos con los que los adultos se comunican con los nińos/as para de forma condescendiente alabar sus logros, infantiliza los logros de esta comunidad y sensacionaliza el activismo realizado por estas personas.

En Screendaily ${ }^{6}$, Fionnuala Halligan aporta un dato importante sobre la obra, lo inesperado de sus consecuencias: «Una mirada reveladora e inspiradora al movimiento por los derechos de los discapacitados de los años 70 [...]. Su estructura es clásica, pero lo que presenta es inesperado».

El llamado «efecto mariposa» parece la premisa de este documental, porque la elección del campamento y la posibilidad de asistir cambia no sólo las vidas de sus campistas, sino de toda la sociedad americana. La premisa de cambio, de giro copernicano, estaba en la base de la reunión, como explica Larry Allison (EFE, 26 de marzo de 2020), director de aquel campamento.

${ }^{6}$ https://www.screendaily.com/reviews/crip-camp-sundance-review/5146381.article. 
Intentamos promover ahí un ambiente en el que los adolescentes pudieran ser adolescentes sin todas las etiquetas y estereotipos, lo cual fue un producto de esa era gracias a la experimentación social. Nos dimos cuenta de que el problema no venía de las personas con discapacidades sino de quienes no tenían discapacidad. Era nuestro problema así que nosotros debíamos cambiar.

Uno de los puntos de mayor interés del documental es el material grabado en el campamento por el colectivo People's Video Theater. Mostrar la América de 1971, dos ańos después de Woodstock, tiene algo de entrańable y sentimental, pero también de político, porque, con los años el movimiento hippie ha sido tildado por sectores conservadores como irresponsable o vago; sin embargo, las imágenes nos muestran cómo los responsables del campamento, «melenudos» hippies, tratan de manera innovadora y trabajan con jóvenes con parálisis cerebral o afectados por la polio, juegan al béisbol o les ayudan con sus dudas sexuales, propias de la adolescencia, siempre con eficacia y profesionalidad.

Hay que destacar que el campamento aparece como una isla de integración $\mathrm{y}$ respeto en una sociedad que trataba a las personas con discapacidad casi como a ciudadanos de segunda clase, y es aquí donde comienza lo inesperado, los campistas no quieren que al salir se acabe su sueño y deciden seguir su lucha.

Dentro de nuestro análisis hemos elegido este filme por la manera en que se trata la sexualidad. Tras YWF y JTVS, CC incide en la sexualidad como uno más de los temas que trata, la naturalidad con la que ya no es tabú referirse a la masturbación o al coito viene a romper con los discursos anteriores de una forma radical. Sin mostrar escenas sexuales o pornográficas, las declaraciones de los entrevistados, las imágenes de archivo y las actuales transmiten una sensación de superación que contribuyen decididamente a una visión más amplia de la sexualidad humana y a un nuevo paradigma a la hora de enfrentar la sexualidad en la discapacidad. Es muy llamativo cómo se utilizan las imágenes de archivo para, por ejemplo, mostrar cómo una pareja que se formó en el campamento entre dos personas con discapacidad intelectual sigue siendo pareja 49 años después, marcando un nuevo hito, el unir sexualidad con amor y compromiso. Si bien el sexo no es el elemento principal empoderante en este documental, podemos ver, sin embargo, un hecho muy importante por su invisibilidad en la sociedad y en el audiovisual, la supervivencia y la lucha. Al mostrar dos momentos separados temporalmente, CC presenta una imagen activa, positiva y empoderante de la diversidad funcional, mostrando a sus protagonistas como activistas comprometidos que logran convertir sus ideales en leyes, cambiando la sociedad, un hecho que en el audiovisual estaba siempre reservado a aquellas personas que no presentaban una discapacidad.

\section{RESULTADOS/CONCLUSIONES}

Somos seres sexuados desde el mismo momento que nacemos; sin embargo, durante demasiado tiempo a las personas con discapacidad se les ha negado su sexualidad, además de infantilizarlos. Esto, sumado al tabú inherente a la socie- 
dad hacia el sexo, ha articulado mitos y creencias que han victimizado y discriminado a las personas con discapacidad, negándoles el acceso a su derecho a una sexualidad plena.

El cine, como espejo de la sociedad, ha contribuido de manera fehaciente a esta discriminación elaborando estereotipos negativos respecto a la discapacidad y negando la sexualidad de este colectivo, ofreciendo imágenes distorsionadas o directamente discriminatorias durante un primer periodo para más tarde pasar a un discurso moralizante, de superación personal o infantilizante. Ha sido un largo proceso hasta que las personas con discapacidad han podido ponerse tras la cámara y contar su realidad o frente a ella en documentales que han mostrado que no sólo son personas sexuadas, sino que su manera de entender el sexo, no centrada en el coito, puede suponer la respuesta para los nuevos discursos sobre sexualidades diversas.

Durante este trabajo se ha detectado la carencia de una investigación comprehensiva sobre la sexualidad y la discapacidad y acerca de los factores culturales que influencian las actitudes de la sociedad hacia la sexualidad de las personas con diversidad funcional.

Recientemente en España se ha producido una mayor atención social, cobertura mediática, académica y política hacia este tema donde la figura de el/la asistente sexual ha sido clave. Creemos fundamental la presencia de la discapacidad en el cine, para concienciar, y también para inculcar valores como la integración y no discriminación; además, mostrar la sexualidad de las personas con discapacidad ayuda a romper con regímenes de imágenes normativos, respecto al cuerpo o la sexualidad, y esto ayuda a otras minorías a empoderarse y mostrarse en la pantalla.

Podemos asegurar que el camino emprendido por YWF ha llevado hacia un cambio de paradigma en la representación de la sexualidad de las personas con discapacidad en el cine, rompiendo el tabú de la representación de los cuerpos no normativos y abriendo las puertas para nuevas discusiones como el erotismo, las relaciones de pareja o el amor romántico, que estaban igualmente vetadas a las personas con discapacidad.

La visión subversiva y política de estas obras y sus fuertes reivindicaciones las convierten en herramientas didácticas muy útiles para el empoderamiento de las personas con discapacidad y suponen un cambio fundamental a la hora de mostrar el sexo en la pantalla, abriendo, además, el camino a cambios legislativos y políticos que incluyan la adopción de medidas de acción positiva orientadas a evitar o compensar las desventajas de una persona con discapacidad para participar plenamente en la vida política, económica, cultural y social y lograr una mayor igualdad de oportunidades y acabar con la discriminación a causa de su discapacidad, además de dotarlos de la ayudas necesarias para tener una sexualidad totalmente plena. 


\section{REFERENCIAS BIBLIOGRÁFICAS}

Alegre de la Rosa, O.M. (2003). La discapacidad en el cine. Barcelona: Octaedro.

Alonso, M. ${ }^{a}$ L. y Pereira, M. ${ }^{a}$ C. (2000). «El cine como medio-recurso para la educación en valores. Un enfoque teórico y tecnológico». Pedagogía social: Revista Interuniversitaria, (5): 127-148.

Anderson, P. y Kitchin, R. (2000). «Disability, space and sexuality: access to family planning services». Social science \& medicine, 51(8): 1163-1173.

Arnau Ripollés, M.S. (2005). «Otras voces de mujer: el feminismo de la diversidad funcional/ Other Women's Voices: The Feminism of Functional Diversity». Asparkia. Investigació feminista, (16): 15-26.

Arnau Ripollés, M.S. (2003). «Una Construcción Social de la Discapacidad: el Movimiento de Vida Independiente», en VIII Jornadas de Fomento de la Investigación de la Facultad de Ciencias Humanas y Sociales. Fórum de Recerca.

Asís, R. de (2017). «¿Es la asistencia sexual un derecho?». Revista Española de Discapacidad, 5(2): 7-18.

Benjamin, W. (2003). La obra de arte en la época de su reproductibilidad técnica. México: Itaca.

Bernert, D.J. (2011). «Sexuality and disability in the lives of women with intellectual disabilities». Sexuality and Disability, 29(2): 129-141.

BLock, P. (2002). «Sexuality, parenthood, and cognitive disability in Brazil». Sexuality and Disability, 20(1): 7-28.

Block, P. (2000). «Sexuality, fertility, and danger: Twentieth-century images of women with cognitive disabilities». Sexuality and Disability, 18(4): 239-254.

Block, P. et al. (2012). "Disability, Sexuality and Intimacy», en Pollard, N. and Sakellariou, D., Politics of occupation-Centred practice: Reflections on occupational engagement across cultures. New Jersey: John Wiley \& Sons. 162-179.

Bourdieu, P. (1999). Meditaciones pascalianas. Barcelona: Anagrama.

Bourdieu, P. (1977). «Remarques provisoires sur la perception sociale du corps». Actes de la Recherche en Sciences Sociales, 14: 51-54.

Breschand, J. (2004). El documental. La otra cara del cine. Barcelona: Paidós.

Brodwin, M.G. y Frederick, P.C. (2010). «Sexuality and societal beliefs regarding persons living with disabilities». Journal of Rehabilitation, 76(4), 37.

Carter Overstreet, L. (2008). «Splitting Sexuality and Disability: A Content Analysis and Case Study of Internet Pornography featuring a Female Wheelchair User». Thesis, Georgia State University.

Centeno, A. (2004). «Simbolismos y alianzas para una revuelta de los cuerpos». Educació Social. Revista de d'Intervenció Socioeducativo. (58): 101-118.

Chanan, M. (2007). «El documental y el espacio público». Archivos de la Filmoteca, 57-58(1): 68-99.

Cole, T.M. y Cole, S. (1993). «Sexuality, disability, and reproductive issues through the lifespan». Sexuality and Disability, 11(3): 189-205.

Cordoba Pérez, M. y Cabero Almenara, J. (2009). Cine y diversidad social. Instrumento práctico para la formación en valores. Sevilla: Editorial Mad.

Crow, L. (1996). «Nuestra vida en su totalidad: renovación del modelo social de Discapacidad», en Morris, J., Encuentros con desconocidas. Feminismo y discapacidad. Madrid: Narcea. 229-250 
De Lauretis, T. (1991). «Queertheory: lesbian and gay sexualities. An introduction». Differences. A Journal of Feminist Cultural Studies, 3(2): 3-17.

Douglas, M. (1988). Simbolos naturales: exploraciones en cosmología. Madrid: Alianza.

Drummond, J.D. y Brotman, S. (2014). «Intersecting and embodied identities: A queer woman's experience of disability and sexuality». Sexuality and Disability, 32(4): 533-549.

Dukes, E. y McGuire, B.E. (2009). «Enhancing capacity to make sexuality-related decisions in people with an intellectual disability». Journal of Intellectual Disability Research, 53(8): 727-734.

EFE (26/3/2020). “"Crip Camp”: el Woodstock de la discapacidad revisado por los Obama». La voz de Asturias, recuperado de https://www.lavozdeasturias.es/noticia/cultura/2020/03/26/ crip-camp-obama-discapacidad/0003_202003G26P479919.htm. Última consulta: $01 / 7 / 2020$.

Esteban, M. ${ }^{2}$ L. (2004). Antropología del cuerpo. Género, itinerarios corporales, identidad y cambio. Barcelona: Bellaterra.

Eтhis, E. (2009). Sociologie du cinéma et de ses publics. París: Édition Armand Colin.

Ferrés, J. (1996). Televisión subliminal. Socialización mediante comunicaciones inadvertidas. Barcelona: Paidós.

Fiduccia, B.W. (2000). "Current issues in sexuality and the disability movement». Sexuality and disability, 18(3): 167-174.

Foucault, M. (1992). Vigilar y castigar: nacimiento de la prisión. Madrid: Siglo XXI.

Franco, D.G., Cardoso, J. y Neto, I. (2012). «Attitudes towards affectivity and sexuality of people with intellectual disability». Sexuality and Disability, 30(3): 261-287.

García-SAntesmases, A. (2015). «El cuerpo en disputa: cuestionamientos a la identidad de género desde la diversidad funcional». Intersticios. Revista sociológica de pensamiento crítico, 9(1): 41-62.

García-Santesmases, A. y Branco de Castro, C. (2016). «Fantasmas y fantasías: controversias sobre la asistencia sexual para personas con diversidad funcional». Pedagogia $i$ Treball Social, 5(1): 3-33.

Gilmore, L. y Chambers, B. (2010). «Intellectual disability and sexuality: Attitudes of disability support staff and leisure industry employees». Journal of Intellectual and Developmental Disability, 35(1): 22-28.

Goldman, A. (1976). «Quelques problèmes de sociologie du cinéma». Sociologie et société, 8(1), abril. 71-80.

Greydanus, D.E., Rimsza, M.E. y Newhouse, P.A. (2002). «Adolescent sexuality and disability». Adolescent Medicine Clinics, 13(2): 223.

Gubern, R. (2005). La imagen pornográfica y otras perversiones ópticas. Madrid: Cátedra.

Guldin, A. (2000). Self-claiming sexuality: Mobility impaired people and American culture. Sexuality and Disability, 18(4), 233-238.

Healy, E. et al. (2009). «Sexuality and personal relationships for people with an intellectual disability. Part I: service-user perspectives». Journal of Intellectual Disability Research, 53(11): 905-912.

Iañez Domínguez, A. (2010). Prisioneros del cuerpo: la construcción social de la diversidad funcional. Madrid: Diversitas.

IsLER, A. et al. (2009). «A study on sexuality with the parents of adolescents with intellectual disability». Sexuality and Disability, 27(4): 229. 
Kazukauskas, K.A. y Lam, Ch.S. (2010). «Disability and sexuality: Knowledge, attitudes, and level of comfort among certified rehabilitation counselors». Rehabilitation Counseling Bulletin, 54(1): 15-25.

KEDDE, H. et al. (2012). «Sexual health problems and associated help-seeking behavior of people with physical disabilities and chronic diseases». Journal of sex \& marital therapy, 38(1): 63-78.

KIJAK, R. (2013). «The sexuality of adults with intellectual disability in Poland. Sexuality and disability", 31(2): 109-123.

KIJAK, R. (2011). «A desire for love: considerations on sexuality and sexual education of people with intellectual disability in Poland». Sexuality and disability, 29(1): 65-74.

KIм, E. (2011). «Asexuality in disability narratives». Sexualities, 14(4): 479-493.

Koller, R. (2000). «Sexuality and adolescents with autism». Sexuality and Disability, 18(2): 125-135.

Kunn, A. (1991). Cine de mujeres. Feminismo y cine. Madrid: Cátedra.

Le Breton, D. (2002). Antropología del cuerpo y modernidad. Buenos Aires: Nueva Visión.

Ledesma, J.A. (2009). La imagen social de las personas con discapacidad. Madrid: Ediciones Cinca.

LÖFgren-MÅtenson, L. (2004). «May I? About sexuality and love in the new generation with intellectual disabilities». Sexuality and Disability, 22(3): 197-207.

Majiet, S. (1996). «Sexuality and disability». Agenda, 12(28): 77-80.

MaLL, S. y Swartz, L. (2012). «Sexuality, disability and human rights: strengthening healthcare for disabled people». SAMJ: South African Medical Journal, 102(10): 792-793.

Mauss, M. (1968). «Les techniques du corps», en Mauss, M., Sociologie et anthropologie. París: PUF. 363-386.

Mauss, M. (2003). "As good as it goes. Queer Theory and Critical Disability». GLQ: A Journal of Lesbian and Gay Studies, 9(1-2): 79-105.

McCaвe, M. (1999). «Sexual knowledge, experience and feelings among people with disability». Sexuality and Disability, 17(2): 157-170.

McCabe, M., Cummins, R.A. y Deens, A. (2000). «Sexuality and quality of life among people with physical disability». Sexuality and Disability, 18(2): 115-123.

McRuer, R. (2006). Crip Theory: Cultural signs of Queerness and Disability. New York: New York University Press.

Meinerz, N.E. (2010). "Corpo e outras (de) limitaçóes sexuais: uma análise antropológica da revista Sexuality and Disability entre os anos de 1996 e 2006». Revista Brasileira de Ciências Sociais, 25(72): 117-178.

Mitry, J. (1989). Estética y psicología del cine. Madrid: Siglo XXI.

Monga, T. (1996). «Physical medicine and rehabilitation state of the arts review: Sexuality and disability». Journal of Sex Research, 33: 267-270.

Nichols, B. (2007). «Cuestiones de ética y cine documental». Archivos de la Filmoteca. 57-58(1): 29-45.

Norden, M.F. (1998). El cine del aislamiento. El discapacitado en la historia del cine. Madrid: Escuela Libre Editorial.

Nosek, M.A. et al. (2001). «Vulnerabilities for abuse among women with disabilities». Sexuality and Disability, 19(3): 177-189. 
Parchomiuk, M. (2012). «Specialists and sexuality of individuals with disability». Sexuality and Disability, 30(4), 407-419.

Platero M.R. y Rosón Villena, M. (2012). «De la 'parada de los monstruos' a los monstruos de lo cotidiano: la diversidad funcional y la sexualidad no normative». Feminismo/s, 19 (jun. 2012): $127-142$.

Rabiger, M. (2004). Directing the documentary. USA: Focal Press.

Rembis, M.A. (2010). «Beyond the binary: rethinking the social model of disabled sexuality». Sexuality and Disability, 28(1): 51-60.

Robinault, I.P. (1978). Sex, society, and the disabled. New York: Harper \& Row.

Sánchez Noriega, J.L. (1997). Crítica de la seducción mediática. Madrid: Tecnos.

Sakellariou, D. (2006). «If not the disability, then what? Barriers to reclaiming sexuality following spinal cord injury». Sexuality and disability, 24(2): 101-111.

Sakellariou, D. y Simó, S. (2006). «Sexuality and disability: A case of occupational injustice». British Journal of Occupational Therapy, 69(2): 69-76.

Samuels, E. (2003). «My body, my closet. Invisible Disability and the Limits of Coming-Out Discourse». GLQ: A Journal of Lesbian and Gay Studies, 9(1-2): 233-255.

SAndahl, C. (2003). «Queering the Crip or Cripping the Queer? Intersections of Queer and Crip Indentities in Solo Autobiographical Performance». GLQ: A Journal of Lesbian and Gay Studies, 9(1-2): 25-56.

SAnders, T. (2007). «The politics of sexual citizenship: commercial sex and disability». Disability \& Society, 22(5): 439-455.

Shakespeare, T. (2000). (1998). «Poder y prejuicio: los temas de género, sexualidad y discapacidad», en L. Barton (comp.) Discapacidady Sociedad. Madrid: Moratta, 205-299.

Shakespeare, T. (2000). «Disabled sexuality: Toward rights and recognition». Sexuality and disability, 18(3): 159-166.

Shakespeare, T. (1999). "The sexual politics of disabled masculinity». Sexuality and disability, 17(1): 53-64.

SHILDRICK, M. (2007). «Contested pleasures: The sociopolitical economy of disability and sexuality». Sexuality Research \& Social Policy, 4(1): 51-75.

SHindel, W. et al. (2010). «Medical student sexuality: How sexual experience and sexuality training impact US and Canadian medical student's comfort in dealing with patient's sexuality in clinical practice». Academic Medicine, 85(8): 1321-1330.

Senet Ramos, M. (2015). "Woman and disbility in Spanish Cinema (1979-2012)», en Cascajosa Virino, C. (ed.), A new gaze: Women creators of film and televisión in democratic Spain, Cambridge: Cambridge Scholar publising. 137-147.

Sorlin, P. (1977). Sociología del cine. La apertura para la historia de mañana. París: Aubier- Montaigne.

Sutton, B. (2007). «Poner el Cuerpo: Women's Embodiment and Political Resistance in Argentina». Latin American Politics and Society, 49(3): 129-162.

Talburt, S. y Steinberg, S.R. (eds.) (2005). Pensando queer. Sexualidad, cultura y educación. Barcelona: Graó.

Taleporos, G. y McCabe, M.P. (2001). «Physical disability and sexual esteem. Sexuality and Disability", 19(2): 131-148. 
Taleporos, G. y McCabe, M. (2002). «The Impact of Sexual Esteem, Body Esteem, and Sexual Satisfaction on Psychological Well-Being in People with Physical». Disability. Sexuality \& Disability, 20(3): 177-183.

Tepper, M.S. (2000). «Sexuality and disability: The missing discourse of Pleasure». Sexuality and disability, 18(4): 283-290.

Tepper, M.S. (1999). «Letting go of restrictive notions of manhood: Male sexuality, disability and chronic illness». Sexuality and Disability, 17(1): 37-52.

TAYLOR, M. (2012). «The $S$ words: Sexuality, sensuality, sexual expression and people with intellectual disability». Sexuality and Disability, 30(2): 237-245.

Valvano, A.K. et al. (2014). «Health professions students' perceptions of sexuality in patients with physical disability». Sexuality and Disability, 32(3): 413-427.

Williams, D. (1994). Somebody Somewhere: Breaking Free from the World of Autism. New York: Three Rivers Press.

Winges-Yanez, N. (2014). "Why all the talk about sex? An authoethnography identifying the troubling discourse of sexuality and intellectual disability». Sexuality and Disability, 32(1): 107-116.

Wittig, M. (2006). El pensamiento heterosexual y otros ensayos. Barcelona: Editorial Egales.

Yoshida, K., Li, A. y Odette, F. (1999). "Cross-cultural views of disability and sexuality: Experiences of a group of ethno-racial women with physical disabilities». Sexuality and Disability, 17(4): 321-337.

Zurian, F. y Herrero, B. (2014). «Los estudios de género y la teoría fílmica feminista como marco teórico y metodológico para la investigación en cultura audiovisual». Área Abierta, vol. 14(3): 6-21. 


\title{
COSTA RICA: LA SITUACIÓN DE LAS PERSONAS CON DISCAPACIDAD EN PERSPECTIVA HISTÓRICA Y ACTUAL
}

\author{
Mariana Campos Vargas \\ mariana.campos@ucr.ac.cr \\ Universidad de Costa Rica
}

\section{RESUMEN}

Esta investigación es un análisis de la situación de las personas con discapacidad en Costa Rica, tanto en el pasado como en el presente, a partir de los datos disponibles desde 1821 hasta el día de hoy. El estudio presenta la institucionalidad que se ha creado para la atención de ese sector de nuestra población. Las fuentes que se emplearán para ese propósito serán las siguientes: datos censales, normativa pasada y vigente e información sobre las instituciones y organismos relacionados con esa población. El principal hallazgo se refiere a la importancia de la trayectoria institucional previa en materia de discapacidad en el país, que hoy permite sostener los logros alcanzados, a pesar de la época de ajustes.

Palabras clave: Costa Rica, discapacidad, datos censales, normativas, organismos.

\section{COSTA RICA: THE SITUATION OF PEOPLE WITH DISABILITIES \\ IN HISTORICAL AND CURRENT PERSPECTIVE}

\section{Abstract}

This research is an analysis of the situation of people with disabilities in Costa Rica, in the past and present, based on the data available from 1821 to this day, referring to the institutional framework that has been created for the attention of this particular sector of the population. The sources that will be used for this purpose are going to be census data, past and current regulations and available information of the institutions and organism present about institutional structures and agencies concerning the situation of people with disabilities. The main discovery refers to the importance of the previous institutional path in the field of disability within the country, which today allows it to sustain the achievements, despite the adjustments period in the country.

KeYwords: Costa Rica, disability, census data, regulations, agencies. 


\section{INTRODUCCIÓN}

En este trabajo se aborda el estudio de factores del contexto nacional, así como de los actores de la sociedad civil y del Estado, que influyeron y determinaron la creación de instituciones para la atención de población con discapacidad en Costa Rica. De igual forma, se mencionan elementos del contexto internacional que favorecieron el surgimiento de esa institucionalidad, para ofrecer una perspectiva, tanto en el pasado como en el presente, acerca de la situación de ese segmento poblacional en el país.

En Costa Rica, las políticas sociales del Estado ${ }^{1}$ han tenido como componentes acciones de diversa naturaleza: complementaria (alimento, techo, cuidado), supletoria (sustitución permanente), rehabilitación social (capacitaria) y preventiva (evitar comportamiento específico), con el objetivo de eliminar circunstancias desventajosas y preservar instituciones básicas. Esas acciones y objetivos se han centrado en algunos de los segmentos más vulnerables de la población. Ese es el caso de los niños, las mujeres, los ancianos, grupos urbanos y rurales marginales y personas en condición de discapacidad.

En el país, posterior a la independencia (1821), se constató una trayectoria incipiente e inconexa de disposiciones y acciones, dirigidas a las personas con discapacidad, que se fue fortaleciendo y articulando muy lentamente a partir de la segunda mitad del siglo xIx.

En etapas más recientes, fue en el último tercio del siglo pasado cuando las distintas áreas de la política social en el país se fortalecieron a partir de la promulgación de la Ley n..$^{\circ} 7600$, «Ley de igualdad de oportunidades para las personas con discapacidad» $(1996)^{2}$, legislación que favoreció el reconocimiento social de los derechos de esa población y tuvo de referencia lineamientos en ese ámbito, establecidos por organismos internacionales como la Organización Mundial de la Salud (OMS) y la Organización de Naciones Unidas (ONU).

Por otra parte, en algunos de los censos y recuentos de la población del país y en diferentes épocas, la variable «discapacidad» fue incluida y sistematizada, -aunque desde distintas definiciones y metodologías-, lo que demuestra el interés por contar con datos cuantitativos de ese segmento poblacional, información que se consigna en este trabajo.

${ }^{1}$ Las políticas públicas se estructuran dentro del Estado, pero cristalizan a partir de planteamientos y necesidades de diversos grupos. El concepto de política pública se entiende como producto de la acción de distintos agentes, en este caso organismos internacionales, grupos políticos, sindicales, comunales, sectores de la población con discapacidad o que conviven con personas en esa condición, líderes políticos y el Estado. Este asume distintas funciones, por ejemplo, como garante de la legislación vigente en el ámbito público y privado o como regulador y definidor de la inversión social destinada a esa población. El enfoque analítico propuesto por el neoinstitucionalismo histórico resulta de utilidad en el análisis de políticas sociales (Farfán, 2007: 87-124). Sobre los regímenes de bienestar, un trabajo de interés es el de Juliana Martínez (Martínez, 2007).

${ }^{2}$ El documento contiene 85 artículos y un transitorio (La Gaceta n. $\left.{ }^{\circ} 102,1996\right)$. El reglamento de la Ley fue emitido en 1998 (Decreto Ejecutivo n. ${ }^{\circ}$ 26831, 1998). 
En esta investigación, el análisis de la situación de las personas con discapacidad en Costa Rica, tanto en el pasado como en el presente, se inserta en una periodización que tomó en cuenta el papel jugado por distintos actores: el Estado, las organizaciones sociales de diferente conformación e iniciativas individuales. El estudio tomó en cuenta distintas fuentes de información, entre estas publicaciones de época, documentación del Archivo Nacional de Costa Rica e información censal.

En este trabajo, se estima que la diversidad es consustancial al ser humano. Las personas en condición de discapacidad son un segmento de esa diversidad. No obstante, a través del tiempo y en distintos contextos, la forma en que el conjunto de la población define, percibe y se relaciona con ese grupo ha sido diferente porque sus características, intereses y necesidades son distintas, esto debido a la interrelación que se da entre sus condiciones (físicas, sensoriales, intelectuales, mentales) y su entorno social (limitación en la actividad y restricción para la participación). La discapacidad es, en parte, un fenómeno sociocultural. Su construcción deviene de la interacción de diversos actores en un contexto sociocultural determinado, donde fueron diseñados modelos de atención y se definieron y ejecutaron políticas públicas específicas.

\section{ALGUNAS DISPOSICIONES INCIPIENTES RELACIONADAS CON LA POBLACIÓN CON DISCAPACIDAD EN COSTA RICA (1850- 1890): REGISTRO, CONFINAMIENTO, PENSIÓN DE GUERRA}

La etapa inmediata a la independencia en Costa Rica (1821) llevó a una transición entre las características propias del desarrollo colonial y la construcción de una sociedad nueva.

En este trabajo se parte del año 1850 porque hay consenso entre los estudiosos acerca de que en el lapso comprendido entre 1830-1850 culminó el tránsito de la economía colonial al capitalismo agrario, por medio del desarrollo del cultivo del café, actividad que modificó la estructura social, acentuó la desigualdad entre distintos sectores y profundizó las diferencias culturales compartidas hasta ese entonces ${ }^{3}$. Además, de forma paralela, a partir de 1850 , se sentaron las bases de la centralización política, etapa en que el Estado estaba encabezado por un grupo de comerciantes y productores-exportadores de café; el poder se sustentaba en el Ejército y las finanzas estatales dependían del aguardiente y el tabaco, monopolios organizados desde la colonia.

A partir de esas primeras décadas de vida independiente, se registran algunas prácticas, disposiciones y la creación de algunas instituciones, que de manera directa o tangencial se relacionan con las personas con discapacidad. De seguido se citan algunos hitos que destacaron en el período en estudio.

\footnotetext{
${ }^{3}$ Se comparte la periodización y el argumento que utiliza Botey (2013: 3) para el caso que estudia.
} 
Desde fines del período colonial, una de las prácticas desarrolladas para controlar la lepra fue el confinamiento de las personas y su aislamiento de los espacios habitualmente poblados en las comunidades. En la etapa independiente, también fue común el levantamiento de listas con los nombres, el estado civil y la condición económica de las personas afectadas por esa enfermedad, además de la contribución con limosnas para sostener su alimentación.

$\mathrm{Al}$ igual que otras enfermedades, la lepra puede presentar secuelas, ese es el caso de la afectación de las terminaciones nerviosas de manos y pies y provocar ceguera, discapacidades que agudizaban la situación de los portadores de esa enfermedad.

El constante contagio de los pobladores llevó a que en 1833 se estableciera un lazareto (Malavassi, 1998). Ese fue un primer esfuerzo para subsanar de alguna manera las necesidades de las personas afectadas por ese mal y por las secuelas de discapacidad que provocó.

Otra disposición con incidencia en la situación de las personas con discapacidades tuvo lugar cuando se aprobó la ley de reorganización del Ejército en 1850, institución que se fortaleció en las décadas siguientes y se mantuvo vigente hasta 1948, cuando fue abolida.

Su estructura contempló el ejército permanente (fuerzas acuarteladas), el ejército de operaciones (individuos entre los 18 y 50 años físicamente aptos) y la guardia nacional, a la que pertenecían todas aquellas personas que por aspectos físicos no podían ingresar al ejército de operaciones. Además, ese subgrupo sustituía al ejército de operaciones en caso de que este saliera de campaña (González y Solís, 1989: 66). Como se constata, desde 1850, en el Ejército se hizo referencia a la población con discapacidad y a la posición que debía y podía ocupar en sus filas.

El Código Militar de 1850 mantuvo las Ordenanzas Generales del Ejército, emitidas por el rey Carlos III de España en el siglo XVIII, que contempló el funcionamiento del Monte Pío, que resultó en un tipo de pensión por vejez e invalidez para los oficiales del Ejército de Costa Rica. Ese beneficio se conservó en el Código Militar de 1871, previa constancia de la condición de discapacidad del funcionario (Código Militar, 1871: 18).

A fines del siglo xix y en los años posteriores, estuvo vigente la Ley de Organización General del Ejército de la República de Costa Rica (1898). Esa legislación estableció que los individuos con «mala constitución física o defectos orgánicos justificados por certificación de los respectivos cirujanos del Ejército [...] quedaban exentos del servicio militar». Además, dispuso que la persona debía poseer «aptitud militar», definida en esa ley como «la capacidad intelectual y la condición sana y robusta del cuerpo» (Ley 14, 1898: x y XI).

Esas disposiciones apelan a un concepto de salud enfocado en la «normalidad» de las estructuras corporales y funciones fisiológicas de las personas; por lo tanto, la discapacidad fue una variable que condicionó la posibilidad de esos individuos de participar en el Ejército.

El Cuerpo de Sanidad Militar, formado por los cirujanos del Ejército, fue la autoridad encargada de calificar la aptitud física de los sujetos y de informar en caso de pensión. 
En caso de que la persona quedara inhabilitada temporal o permanentemente, debía plantear una solicitud para el trámite de su pensión, con cargo al Tesoro Público, dirigida a la Secretaría de Guerra por medio del Estado Mayor, general o divisionario o comandantes de provincia, en cuyas oficinas se preparaban los expedientes y se levantaban las pruebas. La Secretaría resolvía las solicitudes de la tropa y las peticiones de los oficiales se enviaban al Congreso (Ley 14, 1898: XI). El beneficio fue otorgado de forma diferenciada para los oficiales e integrantes de las tropas, con respecto al plazo y al monto concedido.

La ley de 1898 también contempló la existencia de un «Cuerpo de Inválidos» en el Ejército, influencia de la legislación militar española de 1717. Los miembros de ese grupo eran militares «inutilizados» por su participación en eventos bélicos.

Los militares costarricenses, afectados en la Campaña Nacional 1856-1857 contra los filibusteros estadounidenses de William Walker, podían solicitar y recibir la indemnización por ese motivo, tal y como se constata en la documentación de la época (Guerra y Marina, 1862-1907).

El conjunto de disposiciones indicadas en la legislación militar mantuvo su vigencia durante largo tiempo, hasta que el Ejército fue abolido en 1948.

Con respecto al número de personas con discapacidad en el período en estudio, solo destaca el censo de $1864^{4}$, pues hizo referencia a la condición mental y física de los habitantes de Costa Rica.

En las instrucciones para llenar la casilla de esa boleta censal que refiere a calidad «física y mental» se indicó: Bajo la expresión de "enteramente impedidos" se entienden aquellos que hayan perdido el uso de cualquiera otro órgano principal p.e. [sic] ambos pies o ambas manos, y por esta razón no están aptos para ganar su subsistencia. Se comprenden en los "imbéciles" aquellos que carezcan de sus facultades intelectuales por debilidad de ellas (mentecatos y fatuos), y en los dementes aquellos que no tengan el uso de ellas por excesiva irritación» (Censo, 1864: XL).

El registro de la «calidad física» de las personas incluyó a ciegos, sordomudos y enteramente impedidos. En el caso de la "calidad mental», la clasificación fue la de «dementes» e «imbéciles». Esos criterios remiten a la deficiencia.

En 1864, un 1,21\% de la población total de Costa Rica presentó alguna de las discapacidades indicadas, siendo la condición más connotada la sordomudez (39\%).

En el ámbito institucional, al finalizar la etapa en estudio, en Costa Rica se estableció el Asilo de Insanos en 1890 (CCSS, 2002: 4), destinado a albergar enfermos mentales y financiado por la Lotería Nacional, una institución que puso en marcha un modelo de atención para ese segmento de la población, respaldado por la comunidad de médicos del país.

En la primera década de su funcionamiento, para entonces denominado Asilo Chapuí (1896), habían sido atendidas 814 personas y registrado algunos diagnósticos: esquizofrenia paranoica, demencia precoz, idiotismo y consumo excesivo de alcohol (Rodríguez, 1974: 16). Esos pacientes eran declarados en «estado de enaje-

\footnotetext{
${ }^{4}$ La población total de Costa Rica registrada en ese censo fue de 120499 personas.
} 
nación mental» por el médico de pueblo, mientras que la autoridad superior certificaba esa declaración para su internamiento.

En aquella época, el doctor Vicente Lachner, convencido de la necesidad de ese hospital, argumentó el aumento en la cifra de enfermos e hizo referencia a las causas de las enfermedades mentales, señalando: «... más de la mitad de las enfermedades mentales entre nosotros se debe a la defectuosa selección matrimonial, inmensa responsabilidad que pesa sobre los padres de familia» (Lachner, 1902: 187), con lo que hizo referencia a la endogamia.

Un balance de la legislación y la institucionalidad, citada entre 1850-1890, muestra inicialmente una gestión a nivel municipal. A partir de 1850, se encuentran disposiciones y acciones a nivel nacional, que tienen relación con el contexto de centralización política. Ese es el caso del Ejército como institución estratégica y, por otra parte, el censo de 1864, que dio cuenta de la cantidad y características de los pobladores del territorio de Costa Rica.

Al cierre de esa etapa se registra la creación de un asilo para enfermos mentales (1890), ubicado en la ciudad capital, que, al igual que el lazareto fundado en 1833, tenía como propósito principal el confinamiento de las personas.

En ese período, las personas con discapacidad fueron caracterizadas bajo el enfoque de deficiencias y fueron objeto de la caridad de los grupos religiosos, la filantropía, la exclusión social y el aislamiento, acorde con el modelo tradicional de la época. Sí cabe destacar que el personal del Ejército, en particular la oficialidad, recibió el beneficio de pensión por invalidez, un antecedente importante de la legislación, que se puso en marcha para el conjunto de la población en la segunda mitad del siglo xx.

\section{LAS PERSONAS CON DISCAPACIDAD EN EL CONTEXTO DEL RÉGIMEN LIBERAL DE BIENESTAR EN COSTA RICA (1890-1940): REGISTRAR, EXCLUIR, REHABILITAR}

El cierre del siglo xix y la nueva centuria marcaron algunos cambios con respecto a la etapa anterior. Las disposiciones y la institucionalidad, creada en seis décadas en el país, dan cuenta de la continuidad de la participación de distintos actores sociales e individuales, pero con influencia -en las disposiciones tomadasde organizaciones internacionales, y con la convicción de los hacedores de la política pública en Costa Rica de estar asumiendo una dirección «científica» para el destino del país.

Desde mediados del siglo XIX, en distintos países, hubo interés en promover «encuentros internacionales», dirigidos a controlar enfermedades contagiosas y epidémicas. Esa fue la trayectoria de las Conferencias Sanitarias 5 inicia-

${ }^{5}$ Las Conferencias Sanitarias Internacionales fueron catorce (1851-1938). Algunas repúblicas americanas como Argentina, Brasil y Uruguay (1887) firmaron convenciones sanitarias. La Pri- 
das en 1851 y los Convenios Sanitarios posteriores, que lograron institucionalizar la salud pública.

Después de 1919, al término de la Primera Guerra Mundial, un volumen importante de hombres quedó con discapacidades físicas y mentales, razón por la cual se establecieron principios de rehabilitación médica en distintos puntos de la geografía mundial. Además, se crearon asociaciones de civiles discapacitados por accidentes en el trabajo, como lo fue la Federación de mutilados del trabajo en Francia (1921).

Esas condiciones fueron el contexto para que la Sociedad de Naciones ${ }^{6}$ celebrara el primer congreso de la Sociedad Internacional de Asistencia al Inválido (1929), donde las recomendaciones fueron la profilaxis para eliminar las causas de las discapacidades físicas, la obligación de informar sobre el nacimiento de los nińos deformes y afectados de cualquier lesión que los invalidara, la elaboración de un censo y la creación de escuelas especiales para la instrucción cultural y profesional de esa población (Miangolarra et al., 2003).

Buena parte de esas disposiciones tuvieron influencia en las acciones implementadas en Costa Rica, en particular porque la élite política y profesional del país, donde destacaron abogados y médicos, tuvo como referente los parámetros del desarrollo social y científico foráneo.

En esa etapa de 1890 a 1940, en Costa Rica, la financiación por parte del Estado para cubrir los ámbitos correspondientes a la salud, la educación, la vivienda, los servicios sociales, el empleo y el ingreso mínimo denota un crecimiento. Al respecto se señala sobre esos gastos del Estado que «con altibajos, desde un punto de partida del 4\% del gasto público total, como promedio del decenio 1870-1879, hasta un 28\% del gasto público total, como promedio del decenio 1920-1929» (Viales, 2008: 1411).

En ese lapso se mantuvieron algunas disposiciones e instituciones para las personas con discapacidad, que surgieron en el período anterior y que incluso permanecen vigentes en la actualidad. Ese fue el caso del Asilo Chapuí, institución que hoy se denomina Hospital Nacional Psiquiátrico Manuel Antonio Chapuí, vigente con parámetros distintos a los que le dieron su origen, actualmente insertos dentro de un modelo de atención para la salud mental, que reconoce los derechos humanos, previstos en la declaración de 1948 y también lo establecido en la declaración de Caracas en 1991, sobre los derechos de las personas con enfermedad mental.

mera Conferencia Internacional Americana se llevó a cabo en 1889 en Washington y siguiendo una de sus resoluciones en la Convención Sanitaria Internacional (1902) se estableció la Oficina Sanitaria Internacional (1902-1923) pasando a denominarse en 1923 Oficina Sanitaria Panamericana para obtener su nombre actual: Organización Panamericana de la Salud OPS (1958). Costa Rica participó en 1924 en la sétima conferencia sanitaria panamericana, encargada del estudio y la aprobación del Código Sanitario Panamericano, que con varias enmiendas se mantiene vigente.

${ }^{6}$ La Sociedad de Naciones (1919-1946) tuvo como propósito establecer las bases de la paz y restablecer las relaciones internacionales bajo los principios de cooperación, arbitraje y seguridad. Costa Rica formó parte entre 1920 y 1925. 
Otra disposición que se mantuvo vigente hasta 1948 fue el otorgamiento de pensiones por invalidez a los funcionarios del Ejército costarricense, quienes estuvieron involucrados en distintos acontecimientos bélicos, algunos de corta duración y otros de gran magnitud.

Uno de los más destacados fue el golpe de Estado de 1917, con importantes repercusiones dada la relativa estabilidad política del país. También, el conflicto fronterizo con Panamá en los meses de febrero y marzo en 1921, que culminó con la mediación del Gobierno de Estados Unidos para detener las hostilidades.

En la década del cuarenta, se abrió un ciclo caracterizado por la reforma social, la confrontación, la desobediencia civil y una espiral de violencia, que culminó con la Guerra Civil de 1948, situación que tuvo como desenlace la llegada de una Junta al Gobierno y la abolición del Ejército.

En el período 1890-1940, todos los funcionarios del Ejército afectados por las asonadas militares y los eventos bélicos podían tramitar su solicitud de pensión por invalidez, aportando la documentación dispuesta para ese propósito. Ese fue el caso de los afectados en el conflicto armado con Panamá (Serie Congreso y Serie Guerra y Marina, 1921-1924), quienes mencionaron como afectación más común problemas en los miembros inferiores o su condición de invalidez.

Los beneficios recibidos por los militares eran por una fracción de su salario, sujeto a revisión de las autoridades respectivas (el médico), y las peticiones podían ser rechazadas. El trámite de pensión podía durar unos meses o extenderse como plazo máximo hasta por dos años.

En esa época, la condición de discapacidad se asoció con la deficiencia, condición que calificó al sujeto como inhabilitado para el trabajo por su situación de invalidez, concepto vigente en la legislación, las instituciones y actores sociales.

La ley de accidentes de trabajo de 1925 también marcó un hito en la historia costarricense, pero en aquellos años solo aseguró a un fragmento de los trabajadores. No obstante, será el inicio del actual Instituto Nacional de Seguros.

Una de las novedades en el período 1890-1940 fue el desarrollo de la Enseñanza Especial, favorecido por la articulación de las entidades que se ocupaban de los asuntos de salud y educación en el país.

A fines del siglo XIX, la reforma educativa promovió la centralización, secularización y actualización del sistema educativo a cargo de la Secretaría de Instrucción Pública (1885). De igual forma, para mejorar las condiciones de higiene y salud de la población costarricense, tuvieron importancia la Facultad de Medicina (18951940) y más adelante la Secretaría de Salubridad Pública (1922).

En esa etapa, esos dos ámbitos de la política pública se articularon y eso favoreció que el sistema educativo se constituyera en la base sobre la cual se estructuró la salud pública.

El resultado de ese vínculo favoreció la higienización en las escuelas, tarea que consistió en la revisión médica, el tratamiento dental y la higiene en la infancia (Palmer, 2009: 408). Ese esfuerzo conjunto propició la creación el Departamento Sanitario Escolar (1914) y el Reglamento del Cuerpo Médico Escolar e Inspección Médica e Higiénica de los establecimientos de Instrucción Pública. Esas dependencias tuvieron a cargo las labores de observar y registrar las particularidades de 
la población escolar costarricense en una cobertura de carácter nacional y uniformando los formularios médicos.

El estado sanitario de las escuelas y la salud de los estudiantes a cargo de esas instancias se vieron reforzados con la promulgación de la Ley sobre Protección de la Salud Pública (1923), que estableció la obligación de los jefes de Sanidad de hacer dos visitas anuales a las escuelas para inspeccionar su estado sanitario y la condición física e intelectual de los escolares, en caso de ausencia del médico escolar (Ley 52, 1923). En 1926 se emitió el Reglamento de Inspección Médica de las Escuelas, cuya aplicación pasó a estar a cargo de la nueva Subsecretaría de Higiene (Decreto Ejecutivo 2, 1926).

Esa Inspección Médica tuvo por objetivos la protección de los niños contra toda causa de enfermedad, el diagnóstico de enfermedades agudas o crónicas, el tratamiento para los niños pobres y la «observación de los escolares física o intelectualmente anormales» (Campos, 2015: 7).

El médico escolar sometía a los niños a un examen de su constitución física y mental. Completaba una tarjeta con información sobre datos antropométricos, medidas de agudeza visual y auditiva, examen de la boca, la faringe, la nariz, los dientes, la columna, el corazón, los pulmones. Además, registraba antecedentes hereditarios, familiares y el estado del desarrollo mental del niño.

En esa etapa, existió interés, de los médicos, intelectuales y pedagogos, por registrar los aspectos físicos, fisiológicos y mentales de la población escolar, tanto con el propósito de incidir científicamente en la disminución de las tasas de morbilidad y mortalidad infantil como también por la necesidad de mantener las bases de una ciudadanía «apta física y mentalmente» (Campos, 2015: 8).

Ese interés se mantuvo cuando se levantó el censo de población en el año $1927^{7}$, el primer censo del siglo xx, que incorporó la variable «condición mental y física». Ese registro mostró solo al 0,37\% de la población con alguna de las siguientes condiciones: sordera, ceguera, mudez y demencia. Ese resultado fue afectado tanto por la omisión calculada en el censo como por el diseño del ítem en la boleta y la negación en la declaración.

En 1927 la mayoría de los habitantes residían en la región central y ahí fue donde se ubicó la mayor parte de la población con discapacidad, en particular, en Cartago y Heredia. Las personas con sordera obtuvieron el mayor porcentaje, un 51\% con respecto a otras discapacidades (Campos, 2013: 23).

Algunos datos socioculturales y laborales constatan que del conjunto de la población del país que sí sabía leer y escribir en aquella época, un $0,2 \%$ presentó alguna discapacidad y, de quienes se declararon analfabetos, una cifra cercana al $1 \%$. Por otra parte, de la población inscrita en primaria un $0,2 \%$ presentó alguna discapacidad y, de quienes asistieron a la secundaria un $0,1 \%$ tuvo esa condición. Esos datos refieren la escasa incorporación de ese segmento al sistema educativo. Acerca

\footnotetext{
${ }^{7}$ El total de la población registrada en Costa Rica en ese año fue de 471524 personas.
} 
de las ocupaciones, alrededor de un 1\% de población con discapacidad se ubicó en el sector agrícola, de transporte o en el de personas sin oficio (Campos, 2013: 22-23).

Los registros escolares y la información censal dieron cuenta a los encargados de la política pública de las condiciones físicas y mentales de la población. No fue casual que, en el Código de la Infancia en 1932, se vislumbrara la necesidad de crear establecimientos para nińos «anormales» o con «debilidad mental» (Campos, 2015: 9).

A fines de esa década, con la creación del departamento de Higiene Mental en el Ministerio de Salubridad Pública, a cargo del doctor Fernando Quirós Madrigal (1907-1961) y, en especial, del profesor Fernando Centeno Güell (1908-1993), quedó claro el interés por fundar un centro para menores con discapacidades.

En 1940 Centeno Güell presentó al Poder Ejecutivo un proyecto para la creación de una sección de enseńanza especial del niño, propuesta acogida y que dio fundamento a la creación de la Escuela de Enseñanza Especial ese año. En el decreto se afirmó: «El Estado no debe permanecer indiferente a la suerte de estos niños, sino más bien procurar su mejoramiento de acuerdo con los recursos que indica la ciencia médica y la psicología» (Decreto Ejecutivo 10, 1940: 338).

En esa institución se siguieron tendencias en el aprendizaje provenientes de escuelas españolas, belgas, alemanas y estadounidenses, se trabajó con terapia ocupacional y se emplearon aparatos electrofónicos y procedimientos para la educación de la vista, el oído y el tacto (Campos, 2015: 15).

La deficiencia siguió presente como criterio en el modelo de atención, pero la Escuela de Enseñanza Especial, hoy Centro Nacional de Educación Especial Fernando Centeno Güell, planteó la rehabilitación para sus alumnos.

En el período en estudio, diversos grupos como el cuerpo de médicos, algunos órganos de gobierno, como la Secretaría de Instrucción Pública y la de Salubridad Pública, y algunos educadores abogaron por acciones y disposiciones, que mostraron la coexistencia en el tiempo del modelo de atención tradicional, centrado en el aislamiento y la exclusión, junto con el modelo médico-pedagógico, cuyos ejes fueron la rehabilitación y la integración.

\section{EL RÉGIMEN ESTATAL PROTECCIONISTA DE BIENESTAR Y LAS PERSONAS CON DISCAPACIDAD (1940-1985): REHABILITAR, PROTEGER, INTEGRAR}

En la etapa 1940-1980, el Estado costarricense profundizó su intervención en la prestación directa de servicios a la población, siendo las personas con discapacidad un grupo destinatario de esa asistencia. Además, el país contó con directrices promulgadas por organismos supranacionales en el ámbito de la discapacidad.

Una de las consecuencias sociopolíticas de las conflagraciones mundiales fue el surgimiento de órganos supranacionales para velar por un orden económico, social y político en los países. Desde allí emanaron directrices en diferentes ámbitos: salud, trabajo, educación, derecho y protección social. Otra consecuencia social de las dos guerras mundiales fue el gran volumen de población afectada por disca- 
pacidad y la dificultad para incorporarla al trabajo, razón por la cual se establecieron directrices en ese sentido, en especial en la rehabilitación. También los accidentes laborales movieron el interés por asociar a los afectados y llamar la atención de esos organismos, especialmente la ONU (1945), la Organización Internacional del Trabajo OIT (1946) y la OMS (1948).

Desde esos órganos, emanaron disposiciones universales y convenciones internacionales, que dieron a conocer derechos y deberes, protección y prevención, uniformaron conceptos, reglas, disposiciones y formas de atención que por ser inclusivas cubrieron a la población con discapacidad y fueron acogidas por Costa Rica. Entre estas, Declaración Universal de los Derechos Humanos (1948); Convención sobre derechos políticos de la mujer (1953), Convenio relativo a la discriminación en materia de empleo y ocupación (1960), Convención de los Derechos del Niño, 1989 (CONAPDIS, 2020).

En la década de 1950, esos organismos prestaron especial atención a las personas con deficiencias visuales en los países en desarrollo y recomendaron la exoneración de impuestos a los artículos de las personas invidentes, impulsaron la rehabilitación y fomentaron programas de rehabilitación en el mundo.

En el siguiente decenio, la ONU creó mecanismos de supervisión de los programas de rehabilitación en el mundo y en el artículo 19 inciso «d» de la Declaración sobre el Progreso y el Desarrollo Social (1969) hizo referencia a la prestación de servicios médicos, de seguridad y de bienestar social.

En los años setenta, se emitió la Declaración de los Derechos del Retrasado Mental (1971).

También, la ONU promovió la rehabilitación (1973), la eliminación de barreras físicas y arquitectónicas (1975), la Clasificación Internacional de Deficiencias, Discapacidades y Minusvalías (1980) y proclamó el Año Internacional de los Impedidos (1981).

Esa información muestra cambios en los conceptos para designar a ese segmento de la población, unos más restrictivos y otros un poco más inclusivos. Entre estos se encuentran retrasados, impedidos, inválidos, minusválidos, relacionados con los modelos de atención vigentes.

$\mathrm{La}$ incidencia de las disposiciones internacionales en Costa Rica se puede constatar durante la epidemia de poliomielitis (1953-1954). En esa ocasión, en el Hospital San Juan de Dios se estableció un pabellón de rehabilitación para niños, que contó con personal capacitado enviado por la OMS (Murillo, 1992: 71-72). En ese momento también se contó con el apoyo de médicos, fisioterapistas y técnicos en prótesis de varios países del continente, quienes contribuyeron con los ortopedistas nacionales.

Con posterioridad a esa epidemia, el doctor Humberto Araya impulsó la cooperación internacional para fortalecer la rehabilitación y, en consecuencia, la creación del Patronato Nacional de Rehabilitación (PANARE, 1966), instancia creada para la atención de ese grupo (Murillo, 1992: 72). Además, otros hospitales del país dieron el servicio de rehabilitación y fisioterapia, incluido el Hospital de Niños (1964).

Esas acciones se reforzaron con la fundación del Centro Nacional de Rehabilitación (CENARE, 1977), institución dedicada a la atención de personas con dis- 
capacidad neuromusculoesquelética, que formó parte de la Caja Costarricense de Seguro Social (CCSS) ${ }^{8}$.

Por otra parte, la Asociación Amigos del Ciego (1955) y el Patronato Nacional de Ciegos (PANACI, 1957) fueron instancias que nacieron para la protección, habilitación y rehabilitación de la persona con ceguera (Ley 2171, 1957).

La ampliación en la cobertura de escuelas de enseñanza especial ${ }^{9}$ fue reforzada en el período en estudio con la labor del Centro de Educación Especial Neuro-psiquiátrica Infantil (1968). En los años setenta, el Ministerio de Educación Pública desarrolló el programa de aulas diferenciadas (1974), luego llamadas aulas integradas (1979), que operaron como secciones en escuelas regulares (Murillo, 1992).

En 1973, el Consejo Nacional de Rehabilitación y Educación Especial (CNREE), hoy Consejo Nacional de Personas con Discapacidad (CONAPDIS, 2015), fue una instancia que atendió demandas de ese segmento, coordinó la colaboración de órganos no gubernamentales y de apoyo externo y hoy es la entidad rectora en materia de discapacidad.

Acerca del sistema de pensiones, la universalización del Seguro Social desde la década del setenta favoreció la ampliación en la asignación de pensiones denominadas de «invalidez» para las personas con discapacidad, sujetas a requisitos establecidos por la Caja Costarricense de Seguro Social.

Con respecto al recuento de población, cuando se levantaron los censos de los ańos 1950, 1963, 1973 y 1984, en todos se hizo referencia a las personas con discapacidad, pero los criterios fueron diferentes al clasificar a la población por inactividad (1950) o condición de actividad económica y, además, se llevó a cabo de forma agregada, tal y como se aprecia en la tabla I.

En esos registros, la discapacidad fue considerada como una condición que inhabilitaba para el trabajo, las personas eran catalogadas como inactivas económicamente y, además, clasificadas junto a otros grupos considerados inactivos: adultos mayores y niños. También eran considerados enfermos. Ese fue el caso de «los enfermos mentales». Además, fueron incluidas junto a segmentos marginales: mendigos, vagabundos y antisociales (Campos, 2013: 7).

Por otra parte, en el lapso comprendido entre 1950 y 1980, estuvo vigente la Clasificación Internacional de Enfermedades (CIE) emanada desde la OMS en diferentes revisiones. No fue hasta 1980 cuando ese ente aprobó el manual de la Clasificación Internacional de Deficiencias, Discapacidades y Minusvalías (CIDDM, 1980), donde definió la deficiencia como pérdida o anormalidad de una estructura o función psicológica, fisiológica o anatómica y la discapacidad como toda restricción o ausencia de capacidad de realizar una actividad debida a una deficiencia.

La vigencia de esas disposiciones internacionales explica, en parte, la asociación de la discapacidad con la enfermedad y con la deficiencia, aspectos que se

\footnotetext{
${ }^{8}$ Por aplicación de la Ley 5349 del 24 de setiembre de 1973 se hizo el traslado a la CCSS.

9 Se estableció con la Ley Fundamental de Educación (Ley 2160, 1957). El artículo 27 fue reformado con la Ley 7600 del 2 mayo de 1996.
} 


\begin{tabular}{|c|c|c|c|}
\hline \multicolumn{4}{|c|}{ TABLA I. CLASIFICACIÓN DE LA POBLACIÓN CON DISCAPACIDAD EN LOS CENSOS (1950-1984) } \\
\hline FECHA & VARIABLE & Categoría & DATO \\
\hline 1950 & $\begin{array}{l}\text { Población } \\
\text { económi- } \\
\text { camente } \\
\text { inactiva }\end{array}$ & $\begin{array}{l}\text { Otro estado: incluyó a personas retiradas por edad, incapaci- } \\
\text { dad, recluidas en un penal, en un asilo de caridad o enfer- } \\
\text { medades mentales, los que tenían ceguera o parálisis. }\end{array}$ & $2 \%$ de la PEI \\
\hline 1963 & \multirow{3}{*}{$\begin{array}{l}\text { Condición } \\
\text { de actividad } \\
\text { económica }\end{array}$} & $\begin{array}{l}\text { Desocupados. Incluyó estudiantes, personas en oficios } \\
\text { domésticos, pensionados, rentistas, internados en institucio- } \\
\text { nes, enfermos físicos y mentales. }\end{array}$ & $\begin{array}{l}\text { Los enfermos } \\
\text { físicos y mentales } \\
\text { representaron el } 1 \% \\
\text { de los registrados } \\
\text { como desocupados. }\end{array}$ \\
\hline 1973 & & $\begin{array}{l}\text { Otro. Incluyó personas con ceguera, parálisis, deficiencias } \\
\text { físicas, sin ocupación. Niños que terminaron la escuela, no } \\
\text { trabajaban, ni buscaban trabajo, personas mayores de } 65 \\
\text { ańos. También mendigos, vagabundos y antisociales. }\end{array}$ & $\begin{array}{l}\text { No se desagregó en } \\
\text { el censo. }\end{array}$ \\
\hline 1984 & & $\begin{array}{l}\text { Incluyó las anteriores registradas en el censo de 1973, más } \\
\text { los que estaban en la cárcel, convento, asilo y hospital. }\end{array}$ & $\begin{array}{l}\text { No se desagregó en } \\
\text { el censo. }\end{array}$ \\
\hline
\end{tabular}

Elaboración propia. Fuente: censos de población de Costa Rica 1950, 1963, $1973,1984$.

pueden observar en los criterios de clasificación empleados en los censos de población de Costa Rica entre 1950 y 1984.

En el transcurso del período en estudio, órganos estatales, civiles e internacionales estuvieron involucrados en la atención de la población con discapacidad. También participaron médicos, terapeutas, enfermeros, microbiólogos, trabajadores sociales, educadores y abogados, así como la misma población objeto de atención. Todos fueron actores responsables de prácticas, conceptos y políticas dirigidos a ese sector.

La trayectoria institucional reseñada muestra el énfasis en el modelo rehabilitador para la atención de las personas con discapacidad, un modelo que tuvo su origen en los mutilados de la Primera y la Segunda Guerra Mundial, donde la discapacidad radicó en el sujeto que tuvo un daño - una deficiencia- limitado en su capacidad y, por tanto, fue necesario restablecer y rehabilitar al individuo para integrarlo a la sociedad. Para eso fue preciso eliminar u ocultar la diferencia. Además, ese modelo propició políticas públicas de compensación, como la asistencia y la seguridad social. 


\section{LA SITUACIÓN DE LAS PERSONAS CON DISCAPACIDAD EN EL TRÁNSITO DEL RÉGIMEN ESTATAL-PROTECCIONISTA DE BIENESTAR A LA FASE DE AJUSTES (1985-SIGLO XXI): RECONOCIMIENTO, AUTONOMÍA, DERECHOS}

Hacia el último quinquenio del siglo xx, Costa Rica contó con directrices internacionales y legislación nacional, que concebían la discapacidad en tres dimensiones: deficiencia, limitación en la actividad y restricción en la participación e impulsaron un modelo social sustentado en la igualdad de oportunidades basada en derechos, autonomía, capacidad y respeto a la diversidad. Resulta un fenómeno complejo en la interacción entre el organismo humano y las características de la sociedad donde vive ${ }^{10}$. Con el modelo inclusivo de ciudadanía, se aseguraron garantías plenas de sus derechos (Blanco y Sánchez, 2006: 39-40). En ese desarrollo la coexistencia de modelos no fue una excepción.

De los años ochenta al siglo XXI, Costa Rica acogió varias disposiciones de la ONU, entre estas, principios para la protección de los enfermos mentales y la mejora de la atención de la salud mental (1991), la declaración del día 3 de diciembre como Día Internacional de las Personas con Discapacidad (1992) y Normas Uniformes sobre la Igualdad de Oportunidades para Personas con Discapacidad (1993). Esa última disposición fue la base para la cooperación técnica y económica, incorporando la perspectiva de los derechos humanos (Blanco y Sánchez, 2006: 40).

También lo dispuesto por la Organización de Estados Americanos (OEA) fue un esfuerzo regional para poner en marcha políticas en el área, enfatizando en los derechos humanos y la eliminación de la discriminación; un ejemplo fue el Programa de acción para el decenio de las Américas por los derechos y la dignidad de las personas con discapacidad (2006-2016), el cual quedó ratificado en Costa Rica (CONAPDIS, 2020).

En las últimas décadas del siglo xx en Costa Rica continuó la gestión del CNREE, que se vio acompañada de las disposiciones establecidas en los planes nacionales de gobierno y de la labor de la rectoría emanada de los ministerios e instituciones involucrados con la atención y demandas de la población con discapacidad.

La promulgación en Costa Rica de la Ley 7600 Ley de Igualdad de Oportunidades para las Personas con Discapacidad (1996) constituyó el marco legal para atender las necesidades de esa población y para la formulación de políticas públicas. Esa ley buscó la igualdad de oportunidades, la eliminación de la discriminación y propuso la inclusión, propiciando el acceso a la educación, al trabajo, a los servicios de salud, a los medios de transporte, información y comunicación, estableciendo reformas en códigos y leyes vigentes, por ejemplo, al Código Penal, Civil y de Familia, a la Ley Fundamental de Educación y Ley General de Salud (Ley 7600, 1996).

${ }^{10}$ La definición se encuentra en la página web de la Organización Mundial de la Salud OMS en temas de salud. 
La legislación del año 1996 y las directrices impulsadas desde los organismos internacionales en el último tercio del siglo xx fueron el marco apropiado para mejorar las condiciones para la población en condición de discapacidad en el nuevo siglo.

Las políticas nacionales en materia de discapacidad fueron articuladas en varios ejes: políticas para la institucionalidad, comprometidas con la población con discapacidad; políticas para la accesibilidad y la calidad de vida; políticas para la participación plena y para la investigación y cooperación. Sus principios fueron igualdad, no a la discriminación, participación, autonomía personal y accesibilidad. Esas políticas favorecieron la conformación de Comisiones Institucionales en Materia de Discapacidad (CIMAD), instancias que articularon el funcionamiento de las instituciones públicas.

La legislación posterior (tabla II) a la emisión de la Ley de Igualdad de Oportunidades dio cuenta de la aprobación de nuevos convenios internacionales, así como del fortalecimiento de la multiplicidad de ámbitos que garantizaron los principios antes citados, mediante las disposiciones emitidas a nivel nacional. En esa promulgación cabe destacar la creación del Consejo Nacional de Personas con Discapacidad (CONAPDIS, 2015), instancia rectora en la actualidad, que tuvo como antecedente al CNREE (1973). La denominación del ente rector en dos momentos distintos denota el cambio en el modelo de atención y en la definición de discapacidad.

\begin{tabular}{|c|c|c|}
\hline AÑo & LEY & Título de la Ley \\
\hline 1999 & 7948 & $\begin{array}{l}\text { Aprobación de la Convención Interamericana para la eliminación de todas } \\
\text { formas de discriminación contra las personas con discapacidad }\end{array}$ \\
\hline 2008 & 8661 & $\begin{array}{l}\text { Aprobación de la Convención sobre los Derechos de las personas con discapa- } \\
\text { cidad y su protocolo }\end{array}$ \\
\hline 2010 & 8822 & Creación de las Comisiones Municipales de discapacidad COMAD \\
\hline 2010 & 8862 & $\begin{array}{l}\text { Inclusión y protección laboral de las personas con discapacidad en el sector } \\
\text { público }\end{array}$ \\
\hline 2012 & 9049 & $\begin{array}{l}\text { Ley de reconocimiento de Lenguaje de Señas Costarricense LESCO como } \\
\text { lengua materna }\end{array}$ \\
\hline 2013 & 9171 & Creación de comisiones institucionales sobre accesibilidad y discapacidad CIAD \\
\hline 2015 & 9303 & Creación del Consejo Nacional de personas con discapacidad CONAPDIS \\
\hline 2016 & 9379 & Promoción de la Autonomía personal de las personas con discapacidad \\
\hline 2018 & 9616 & $\begin{array}{l}\text { Reforma Ley de Igualdad de Oportunidades para las Personas con Discapacidad } \\
\text { en sus artículos } 41 \text { y } 54\end{array}$ \\
\hline 2019 & 9697 & $\begin{array}{l}\text { Reforma artículo } 51 \text { de la Constitución Política para garantizar la protección } \\
\text { especial del Estado a las personas con discapacidad }\end{array}$ \\
\hline 2019 & 9714 & Adición del capítulo Viii, acceso a la justicia, al título II de la Ley n. ${ }^{\circ} 7600$ \\
\hline 2019 & 9739 & $\begin{array}{l}\text { Reformas para la inclusión al deporte y la recreación de las personas con dis- } \\
\text { capacidad }\end{array}$ \\
\hline
\end{tabular}




\begin{tabular}{ccl}
\hline 2019 & 9793 & $\begin{array}{l}\text { Reforma al Instituto del Deporte y Recreación (ICODER) y su Régimen Jurídico } \\
\text { y de Impuestos sobre Cigarrillos y Licores para Plan de Protección Social, para } \\
\text { la inclusión al deporte y la recreación de las personas con discapacidad }\end{array}$ \\
\hline 2020 & 9821 & $\begin{array}{l}\text { Otorgamiento de un segundo bono familiar de vivienda para personas con } \\
\text { discapacidad }\end{array}$ \\
\hline
\end{tabular}

Elaboración propia. Fuente: Costa Rica. Sistema Nacional de Legislación Vigente. Procuraduría General de la República.

Una aproximación a la situación reciente de la población en condición de discapacidad se plantea desde los datos que ofrecen los censos del país en los años 2000 y 2011.

Esos censos se localizan en una etapa de descenso drástico del crecimiento demográfico y después por una estabilidad relativa. Ello fue debido a un proceso relacionado con una baja en la tasa de natalidad y un descenso sostenido de la mortalidad, donde el envejecimiento demográfico y el aumento en la esperanza de vida son características en ese momento.

El contexto de envejecimiento demográfico, en el que ubican los registros del ańo 2000 y 2011, mostraron asociación con una mayor prevalencia de deficiencias y discapacidades. El subgrupo de población mayor de ochenta años se ha caracterizado por una mayor prevalencia de discapacidades físicas y mentales, retirados de la fuerza laboral, viudos y dependientes (Ramírez, 1998).

En el censo del $2000^{11}$, se incluyó un ítem sobre discapacidad. Ese hecho respondió a la necesidad de información del CNREE y a la ampliación de oportunidades según la Ley de Igualdad de Oportunidades para las personas con discapacidad en Costa Rica (1996).

Además, en ese censo se definió la discapacidad como cualquier deficiencia permanente, física, mental o sensorial, que dificulte a las personas realizar actividades cotidianas de manera independiente. Se estableció que las deficiencias podían ser de origen congénito (desde el nacimiento) o adquiridas (por enfermedad o accidente). Se registraron ceguera parcial o total, sordera parcial o total, retraso mental, parálisis y amputación, trastorno mental y otras ${ }^{12}$.

Esas categorías de clasificación fueron más amplias si se comparan con las usadas en otros registros, pero el concepto de discapacidad empleado se refirió solo a la deficiencia, definida como la pérdida o anormalidad de una estructura, función fisiológica, psicológica o anatómica, siguiendo lo dispuesto en la Clasificación Inter-

${ }^{11}$ La población total del país en ese año fue de 3810179 personas.

${ }^{12}$ La ceguera parcial o total y la sordera parcial o total consiste en la pérdida de la capacidad visual o auditiva respectivamente; el retardo mental resulta de las dificultades significativas en el funcionamiento intelectual y el aprendizaje de conceptos y actividades prácticas. Parálisis y amputación comprenden la pérdida, parálisis o dificultad de funcionamiento o movilidad de una o varias partes del cuerpo; trastorno mental es una enfermedad que provoca serios problemas de adaptación y comportamiento social de las personas. En «otras» discapacidades se incluyó la enfermedad pulmonar obstructiva crónica, la fibrosis quística, el labio leporino, la hemofilia, la mudez y la epilepsia (Censo, 2000). 
nacional de Deficiencias, Discapacidades y Minusvalías (CIDDM, 1980). Aunque la Ley 7600 (1996) consideró la discapacidad en relación con las deficiencias, con las limitaciones y con la restricción en la participación, esa definición no fue usada en el censo del año 2000.

En el año 2000, quienes presentaron algunas de las discapacidades indicadas en la boleta censal constituían el 5,35\% de la población; un 93\% se declararon sin ninguna discapacidad y un $1 \%$ fue declarada como ignorada. En esa fecha, las personas con discapacidad visual fueron quienes presentaron el mayor porcentaje con un 31\% (Campos, 2013: 8).

En relación con los grupos de edad, la población mayor de 60 años fue la que obtuvo el porcentaje más alto con un $21,6 \%$. La diferencia por sexos no fue significativa.

La distribución en el territorio nacional sí marcó diferencias. Las provincias de Puntarenas (7\%), Guanacaste $(6,2 \%)$ y Limón $(6,1 \%)$, provincias costeras y alejadas de la capital, fueron las que presentaron los porcentajes más altos. Las otras provincias se acercaron al promedio nacional de discapacidad (Campos, 2013: 12).

En esa fecha censal, la proporción de personas con discapacidad que sabía leer y escribir fue de un 5\%, mientras que las analfabetas constituían un 11,6\%. Con respecto al nivel de instrucción los individuos inscritos en primaria, representaron el 6,5\%, aunque también hubo acceso a otros niveles, pero en menor proporción (Campos, 2013: 22).

A fines del siglo $\mathrm{xx}$, la población con discapacidad que formó parte de la fuerza laboral estaba empleada en el sector agropecuario $(7,7 \%)$ y un $5 \%$ en oficios no calificados, lo que ubicó a esas personas, en un nivel bajo en el extremo de la estructura ocupacional.

Para el segmento poblacional en estudio, se observó una mayor proporción de discapacidad en mujeres como cabezas de hogar (10,3\%).

Sobre la estructura de los hogares de las personas con discapacidad, se constató que los hogares de tipo unipersonal representaron un 13\%, seguidos de los hogares colectivos (10,7\%), luego un $9,9 \%$ en los no conyugales y un $6,3 \%$ en los conyugales. Esos datos denotan la debilidad de los lazos de parentesco en esa población. Dentro de ese conjunto de hogares, se identificaron como más vulnerables los que estaban en condición de hacinamiento (7\%), donde la proporción de discapacidad fue de un $8 \%$ entre los encabezados por mujeres y de un $6 \%$ aquellos a cargo de hombres (Campos, 2013: 24).

El primer censo del siglo Xxi en Costa Rica tuvo lugar en el año $2011^{13}$. En esa ocasión, se contó con un módulo estándar dispuesto por la OMS -Grupo Washington-. En coordinación con el Instituto Nacional de Estadística y Censos INEC y el CNREE, se preparó el ítem sobre discapacidad.

Ese ítem mostró ocho alternativas de marcado múltiple. El encabezado ponía «Tiene alguna limitación permanente...» y las opciones fueron estas: ¿para ver aun

\footnotetext{
13 La población total registrada en ese censo fue de 4301712 personas.
} 
con los anteojos o lentes puestos?; ¿para oír?; ¿para hablar?; ¿para caminar o subir gradas?; ¿para utilizar brazos o manos?; ¿de tipo intelectual? (retardo, síndrome de Down, otros); ¿ ¿de tipo mental? (bipolar, esquizofrenia, otros), ninguna de las anteriores (INEC, 2011: 147).

Las opciones que se ofrecen en la boleta censal refieren al carácter permanente y a la limitación como la condición que define la discapacidad. Aunque se constata el uso de la herramienta Clasificación Internacional del Funcionamiento de la Discapacidad y la Salud (CIF, 2001) emitida por la OMS, una propuesta que incorpora el ámbito social y no solo el médico sanitario, en la boleta del censo del 2011 en Costa Rica se enfatizó solo en la limitación.

Los datos de ese censo (Pérez, 2012) fueron procesados por el CNREE. En este trabajo se destacarán algunos de esos resultados. El primer dato que mostró ese estudio denotó que la discapacidad más significativa en la población, tanto en las personas que tienen discapacidad (41,7\%) como a nivel nacional $(5,8 \%)$, fue la visual. Ese resultado incluyó a personas ciegas, pero también a aquellas con baja visión que, aun con lentes o anteojos, es manifiesta la limitación visual. En segundo lugar, se ubicó la limitación de movimiento con un $23,3 \%$ en las personas con discapacidades y un 1,6\% en la población total del país. La limitación para oír ocupó el tercer lugar con un $11,7 \%$ en las personas con discapacidad y un $0,7 \%$ en el total de las personas del país (Pérez, 2012: 5).

Con respecto al aseguramiento de la población en edad laboral (18 a 65 años), en ese estudio del CNREE, se sustentó que entre un $41 \%$ y un $75 \%$ de personas con discapacidad eran asegurados por un familiar o tienen un seguro o pensión para su manutención. Además, en el estudio se demuestra la condición de asalariado(a), cuyo porcentaje estuvo entre un 5\% y 30\% (Pérez, 2012: 7).

Los datos ofrecidos por la fuente de información consultada señalan que un $46,4 \%$ de la población con discapacidad en edades entre 18 y 65 años estaba trabajando o buscaba trabajo.

Con respecto a la asistencia a un centro educativo, los datos de la fuente señalada indican que un $74,6 \%$ de los niños y niñas con discapacidad asistían a uno, pero solamente un $57,6 \%$ de adolescentes estaban en secundaria, mientras que a la Universidad solo asistían el 24,8\% de los que tenían edades entre los 18 y 25 años.

Acerca de las condiciones de tenencia de la vivienda, esos datos indican que la posesión de casa propia en las personas con discapacidad fue mayoritaria $(76,72 \%)$. De ese $76,72 \%$, un $68,37 \%$ es casa totalmente pagada y el resto (apenas un $8,35 \%$ ) es propia, pero aún la están pagando. El 12,63\% de las personas con discapacidad viven en casas alquiladas. También se registró que 6675 personas con discapacidad viven en precarios ( $1,47 \%$ de la población total con discapacidad) y 5033 personas con discapacidad viven en viviendas colectivas, que pueden ser hospicios, albergues, cárceles o conventos. Según los datos del censo 2011, un 54,7\% de la población con discapacidad vive en viviendas cuya condición es buena; un $32,1 \%$ es regular, y un 12,0\% fue considerada mala (Pérez, 2012: 15-16).

Respecto a la población adulta mayor, los datos refieren que existían 311712 personas mayores de 65 años. De ellas, 127346 presentaban al menos una discapacidad. Eso representa aproximadamente un 3\% de la población total. Pero en la 
población de 65 años o más, es de aproximadamente 40,85\%. Además, solo el 40\% recibe pensión o trabaja por cuenta propia. De la población pensionista, el 51,2\% está asegurada por el Estado, lo que podría indicar una condición económica baja para la subsistencia (Pérez, 2012: 20).

Los resultados de los censos del 2000 y el 2011 con respecto al predominio de la discapacidad visual en el conjunto de la población llevaron al desarrollo de estudios que denotaron como causas principales de esa situación la catarata no operada y la retinopatía diabética (Acevedo et al., 2016: 1-37).

Los resultados generales de la primera encuesta nacional de discapacidad llevada a cabo en Costa Rica en el año 2018 y publicada en el 2019 refieren distintos aspectos de la situación actual de la población con discapacidad (INEC y CONAPDIS, 2019).

De acuerdo con esos datos, correspondientes al total de personas de 18 ańos y más del país, un 18,2\% estaban en condición de discapacidad, de los cuales, un $14,4 \%$ tenían una condición severa y un 3,8\% leve.

El contraste entre las distintas regiones del país destacó a tres de ellas con los valores más altos en discapacidad: el Pacífico Central, con un 24\%, seguido de la zona Brunca, en el sur del territorio de Costa Rica, con un 22,5\%; y la zona Chorotega, correspondiente a la totalidad de la provincia de Guanacaste, con un 21,6\%. Las diferencias también se observan en la ubicación de las personas con discapacidad por zona urbana $(74,1 \%)$ y rural $(25,9 \%)$.

Por otra parte, el 99, 6\% de la población con discapacidad lee y escribe, pero el 95,5\% no recibió apoyo educativo, de equipo o psicopedagogía. Con respecto a la educación formal, el 7,4\% no tenían ningún nivel de instrucción, un 19,6\% no tenía la primaria completa y solo el $17 \%$ había alcanzado la educación superior.

La condición de actividad mostró al 56,4\% fuera de la fuerza de trabajo, situación relacionada con la salud $(50,4 \%)$, con el hecho de que no les daban trabajo por distintas razones $(22,8 \%)$ o porque no querían trabajar $(16,2 \%)$. Quienes tuvieron trabajo tenían una ocupación calificada media el 50,2\%, un $26,1 \%$ con una ocupación calificada alta y un $23,4 \%$ en trabajos no calificados. El $58,1 \%$ eran asalariados y un $35,4 \%$ eran trabajadores por cuenta propia e independiente.

Otra fuente de información sobre la situación reciente de las personas con discapacidad la ofrece el Boletín Discapacidad en Acción de la Defensoría de los habitantes en Costa Rica, en el cual se mencionan 450 denuncias por vulneración de derechos en 2019. Un 68\% corresponden al impedimento de acceso a la seguridad social, debido a que esas personas lo solicitan mediante el régimen no contributivo, situación asociada con las condiciones sociolaborales de ese grupo (Defensoría de los habitantes, 2020).

Con respecto a los estudios sobre discapacidad en el país, se constata un predominio desde el área de Educación. En los trabajos finales de graduación en la Universidad de Costa Rica (2017-2020) también se hace investigación desde áreas como Derecho y Trabajo Social.

Un balance de la etapa en estudio 1980-2020 muestra que la institucionalidad creada en las etapas previas, así como las disposiciones y la firma de convenciones internacionales, fueron esenciales para mantener condiciones relativamente 
buenas para las personas con discapacidad en el país, a pesar de que, en los años recientes, Costa Rica atraviesa por una etapa de ajustes, que limita las posibilidades y la calidad en la prestación de servicios en el ámbito de la salud, la educación, el empleo, la vivienda, pensiones e ingreso para el conjunto de la población del país.

\section{CONCLUSIONES}

Las gestiones, disposiciones y el surgimiento de instituciones para las personas con discapacidad en Costa Rica fueron iniciativas que partieron de actores individuales y sociales desde el nivel local, estatal, civil, religioso e internacional, donde fue común el predominio de unos sobre otros y la coexistencia de estos. Igualmente, se contó con la participación de médicos, terapeutas, enfermeros, educadores y abogados y la misma población objeto de atención, lo que fortaleció las políticas hacia ese sector.

En el transcurso del período en estudio, los avances en salud y educación, así como el diagnóstico precoz, integral y multidisciplinario, y la protección en los accidentes de trabajo, fueron aspectos importantes para la atención de la población con discapacidad.

Dentro de las conquistas para ese sector, se pueden citar un sistema de atención en salud especializado, bajo el amparo de la seguridad social; un sistema de educación dentro de los marcos del sistema nacional; un régimen de pensiones; una legislación y normativa para garantizar los derechos de la población con discapacidad.

Desde el siglo XIX y hasta el presente, los diferentes actores que intervinieron en la atención para la población con discapacidad configuraron cuatro modelos: el modelo tradicional donde las personas recibieron la denominación de lisiados, impedidos y se constituyeron en sujetos de susceptibilidad de asistencia, caridad, protección y cuidado. El segundo modelo fue el de rehabilitación, donde la atención se centró en la intervención profesional de especialistas para restablecer capacidades en el individuo. El siguiente modelo se ha llamado de autonomía personal, con equiparación de oportunidades y facilitador del entorno físico y social. El último modelo toma en cuenta la inclusión y los derechos para ese grupo. Los distintos conceptos y modelos de atención calaron tanto en la comunidad de profesionales ligados a la atención del grupo con discapacidad como en la política pública del país en esa etapa.

Los entes rectores, el CNREE (1973) y CONAPDIS (2015), han tenido la responsabilidad de promover y fiscalizar el cumplimiento de los derechos de la población con discapacidad para favorecer su inclusión social, bajo el amparo de disposiciones internacionales y de la legislación nacional. 


\section{REFERENCIAS BIBLIOGRÁFICAS}

Acevedo, R. et al. (2016). «Estimación de la prevalencia de enfermedades asociadas a ceguera prevenible y discapacidad visual Costa Rica 2015». San José, C.R.: EDNASSS-CCSS, recuperado de https://repositorio.binasss.sa.cr/repositorio/handle/20.500.11764/626. Última consulta: $9 / 08 / 2020$.

Archivo Nacional de Costa Rica. Serie Congreso y Serie Guerra y Marina (1862-1907/1921 y 1948).

Blanco, E. y Sánchez, A. (2006). «Enfoque de la discapacidad en los organismos internacionales». Revista del Ministerio de Trabajo y Asuntos Sociales 65, recuperado de https://sid.usal.es/ idocs/F8/ART9501/Est03.pdf. Última consulta: 9/08/2020.

Bотеу, A. (2013). Los actores sociales y la construcción de las politicas de salud del Estado Liberal en Costa Rica (1850-1940). Tesis (Sistema de Estudios de Posgrado). Universidad de Costa Rica.

Campos, M. (2013). «La población con discapacidad en los censos de población del siglo xx en Costa Rica». Población y Salud en Mesoamérica, 11 (1): 1-43, recuperado de https://www.redalyc. org/articulo.oa?id=44628565001. Última consulta: 9/08/2020.

Campos, M. (2015). «Los primeros pasos hacia la enseñanza especial en Costa Rica». Revista Actualidades Educativas en Educación, 15 (1), recuperado de https://revistas.ucr.ac.cr/index.php/ aie/article/view/17726. Última consulta: 9/08/2020.

Caja Costarricense de Seguro Social (2002). Hospital Nacional Psiquiátrico. Memoria.

Censo de población de Costa Rica, 1864, recuperado de http://www.ccp.ucr.ac.cr/bvp/censos/1864/1864c06-cr.pdf. Última consulta: 04/04/2020.

Censos de población de Costa Rica 1927, 1950, 1963, 1973, 1984, 2000, recuperado de http:// www.ccp.ucr.ac.cr. Última consulta: 04/04/2020.

Código Militar de la República de Costa Rica 1871, recuperado de http://www.asamblea.go.cr/ sd/Otras_publicaciones/C\%C3\%B3digo\%20Militar\%20de\%20Costa\%20Rica\%201871. pdf. Última consulta: 04/04/2020

CONAPDIS e INEC. ENCUESTA NACIONAL SOBRE DISCAPACIDAD 2019, recuperado de https://www. inec.cr/sites/default/files/documetos-biblioteca-virtual/reenadis2018.pdf. Última consulta: $9 / 08 / 2020$.

Decreto Ejecutivo 2, 1926. Reglamento de Inspección Médica de las Escuelas.

Decreto Ejecutivo 26831 del 23 de marzo de 1998. Reglamento de la Ley 7600.

Defensoría de los habitantes. Boletín Discapacidad en Acción, recuperado de http://www.dhr. go.cr/informacion_relevante/revistas/Dis-capacidad.aspx. Última consulta: 9/08/2020.

FARfán, G. (2007). «El nuevo institucionalismo histórico y las políticas sociales». POLIS 3, (1): 87124, recuperado de http://www.scielo.org.mx/pdf/polis/v3n1/v3n1a5.pdf. Última consulta: 04/04/2020.

González, C. y Solís, E. (1989). El ejército en Costa Rica: Poder politico y poder militar 1870-1890. Tesis. Universidad de Costa Rica.

Lachner, V. (1902). «Apuntes de higiene pública, organizaciones, instituciones y profesiones relacionadas con ese ramo". Revista de Costa Rica en el siglo XIX, tomo I. 
Ley 14. Ley de organización del Ejército, 1898 (1978). Tipografía Nacional, Centro de Investigaciones Históricas de América Central. Repositorio Carlos Meléndez. Versión digital, recuperado de http://repositorios.cihac.fcs.ucr.ac.cr/cmelendez/handle/123456789/84. Última consulta:

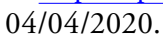

Ley 61. Ley constitutiva de la Escuela de Enseñanza Especial del 15 de marzo de 1944.

Ley 2171 del 30 de octubre de 1957. Ley del Patronato Nacional de Ciegos. Sistema Costarricense de Información Jurídica, recuperado de http://www.pgrweb.go.cr/scij/Busqueda/Normativa/ Normas/nrm_texto_completo.aspx?param1=NRTC\&nValor1=1\&nValor2=38462\&nValor3=40550\&param2=1\&strTipM=TC\&lResultado=3\&strSim=simp. Última consulta: $04 / 04 / 2020$.

Ley 2160 del 25 de Setiembre de 1957. Ley Fundamental de Educación. Sistema Costarricense de Información Jurídica, recuperado de http://www.pgr.go.cr/scij/index_pgr.asp. Última consulta: 04/04/2020.

Ley 5347 del 11 de noviembre de 1973. Ley de creación del CNREE. Sistema Costarricense de Información Jurídica, recuperado de http://www.pgrweb.go.cr/scij/Busqueda/Normativa/Normas/nrm_norma.aspx?param $1=$ NRM\&nValor1=1\&nValor2=10613\&nValor3=100851\&strTipM=FN. Última consulta: 04/04/2020.

LeY 52 del 12 de MARzo De 1923. Ley de protección de la salud pública. Sistema Costarricense de Información Jurídica, recuperado de http://www.pgrweb.go.cr/scij/Busqueda/Normativa/ Normas/nrm_texto_completo.aspx?param1=NRTC\&nValor1=1\&nValor2 $=31262 \& \mathrm{nVa}$ lor3=32975\&param2=1\&strTipM=TC\&lResultado=1\&strSim=simp. Última consulta: $04 / 04 / 2020$.

Ley 7600. Ley de Igualdad de Oportunidades para las personas con discapacidad. La Gaceta 102 del 29 de mayo de 1996.

Malavassi, A. (1998). «Cotidianidad marginal. La lúgubre y frugal vida al interior del lazareto general del Estado de Costa Rica (1833-1850)». Revista de Historia, 38, recuperado de https://www. revistas.una.ac.cr/index.php/historia/article/view/2032. Última consulta: 04/04/2020.

Martínez, J. (2007). Regímenes del bienestar en América Latina. Fundación Carolina, recuperado de https://www.fundacioncarolina.es/wp-content/uploads/2014/08/DT11.pdf. Última consulta: 04/04/2020.

Miangolarra, J. et al., (2003). Rehabilitación Clínica Integral. Funcionamiento y discapacidad. Barcelona: Masson.

Murillo, S. (1992). Evolución histórica conceptual y práctica de la rehabilitación en Costa Rica (19401990). Tesis SEP. Universidad de Costa Rica.

Organización Mundial de la Salud (OMS). Temas de salud, recuperado de https://www.who. int/topics/disabilities/es/. Última consulta: 04/04/2020.

Pérez, A. (2012). Resultados relevantes de discapacidad: Censo 2011. CNREE, recuperado de http:// www.conapdis.go.cr/documentacion/estadisticas/Analisis\%20datos\%20censo\%202011\%20 discapacidad.pdf. Última consulta: 04/04/2020.

Ramírez, O. (1998). Factores determinantes de los arreglos de convivencia de la población adulta mayor. Tesis. Universidad de Costa Rica.

Rodríguez, M. (1991). Reseña Histórica. Hospital Nacional Siquiátrico Manuel Antonio Chapuí y Torres, recuperado de https://www.google.es/url?sa=t\&rct=j\&q=\&esrc=s\&source=web\&c$\mathrm{d}=\& \mathrm{cad}=$ rja\&uact=8\&ved=2ahUKEwjTpY_Dy_XsAhUz8uAKHVq7C7UQFjABegQI- 
BBAC\&url=https\%3A\%2F\%2Fwww.binasss.sa.cr\%2Fbibliotecas\%2Fbhp\%2Ftextos\%2Frhistoricahnp.pdf\&usg=AOvVaw18NNENCWLPOZRuFIhUyunS. Última consulta: $04 / 04 / 2020$.

Sistema Costarricense de Información JurídiCa, recuperado de http://www.pgrweb.go.cr/scij/ Busqueda/Normativa/Normas/nrm_texto_completo.aspx?param1=NRTC\&nValor1=1\&nValor2=36711\&nValor3=38700\&param2=2\&strTipM=TC\&IResultado=13\&strSim=simp. Última consulta: 04/04/2020.

Viales, R. (2008). «Construcción, trayectoria y límites del régimen liberal en Costa Rica». Revista Diálogos, 9 Número especial. DOI 10.15517/DRE.V910.31245, recuperado de https:// revistas.ucr.ac.cr/index.php/dialogos/article/view/31245. Última consulta: 09/08/2020. 



\title{
PERSONAS CON DISCAPACIDAD EN CÁRCELES. REFLEXIONES DESDE EL TRABAJO SOCIAL
}

\author{
Clarisa Ramos Feijóo \\ clarisa.ramos@ua.es \\ Universidad de Alicante \\ Josefa Lorenzo García \\ fini.lorenzo@ua.es \\ Universidad de Alicante
}

\section{RESUMEN}

La presencia de personas con discapacidad intelectual y con enfermedad mental en el sistema penitenciario español es una realidad que interpela a la capacidad de prevención de los sistemas de protección social. El tema no ha sido suficientemente estudiado y sigue requiriendo estrategias innovadoras de intervención. Con el objetivo de realizar una propuesta de aspectos clave para la intervención en el área de personas con discapacidad intelectual y enfermedad mental en conflicto con la ley, desde el enfoque de derechos en el trabajo social, se ha llevado a cabo un análisis comparativo de las conclusiones de dos investigaciones previas y se han contrastado con la teoría. En conjunto, se propone que ante estas situaciones de «alta complejidad» puede ser útil el Modelo de Atención Integral y Centrado en la Persona. Palabras clave: discapacidad intelectual, inclusión, trabajo social, cárcel, modelo de atención integral y centrado en la persona.

\section{PEOPLE WITH DISABILITIES IN PRISONS. REFLECTIONS FROM SOCIAL WORK}

\section{Abstract}

The presence of people with intellectual disabilities and mental illnes in the Spanish prison system is a reality that challenges the prevention capacity of social protection systems. The subject has not been sufficiently studied and continues to require innovative intervention strategies. Whit the aim of making proposal of key aspects for intervention in the area of people with intellectual disabilities and mental illness in conflict with the law, from the perspective of rights in Social Work, a comparative analysis of the conclusions of two previous investigations and they have been contrasted with the theory. Overall, it is proposed that in these "highly complex" situations, the Person-Centered Comprehensive Attention Model may be useful.

KEYWORDs: Intellectual disability, inclusion, social work, prison, comprehensive and person-centred care model. 


\section{INTRODUCCIÓN Y ANTECEDENTES}

La presencia de personas con discapacidad intelectual y con enfermedad mental en el sistema penitenciario español es una realidad que se viene asumiendo desde distintos ámbitos de la intervención social en los últimos 30 años. Son varias las iniciativas enfocadas a su atención, destacando entre todas ellas la iniciada en el año 1995 desde FEAPS (hoy Plena Inclusión) con el apoyo en sus inicios del Real Patronato sobre Discapacidad. Los resultados de algunos estudios sobre el tema consideran que esta presencia en las cárceles interpela a los sistemas de protección social sobre la auténtica inclusión de las personas con discapacidad intelectual por la falta de recursos preventivos de las situaciones de conflicto con la ley. El objetivo del presente artículo es reflexionar a partir de las conclusiones de dos trabajos de investigación, sobre los aspectos claves para la intervención social con las personas con discapacidad intelectual y/o enfermedad mental, desde la perspectiva de la ética y el enfoque de derechos en el trabajo social.

Las investigaciones que fundamentan este artículo constituyen una línea dentro del trabajo social. Ambas corresponden a trabajos vinculados al campo de la discapacidad intelectual y la enfermedad mental en el entorno penal penitenciario. Sin embargo, su contenido no se basa exclusivamente en el análisis de la situación de reclusión, sino que la confronta con el papel de los sistemas de protección social y su actuación antes, durante y después del ingreso dentro del sistema penal penitenciario. La metodología se enriquece en el desarrollo de ambos trabajos, partiendo de un enfoque mixto cualitativo y cuantitativo, para pasar a profundizar en el segundo trabajo en un enfoque marcadamente cualitativo basado en el estudio de caso. De esta manera se aporta una mirada holística propia del trabajo social y que además se alinea con la idea de "comunidad de investigación» dado que se van abriendo vías a la construcción del conocimiento en trabajo social. La idea de vincularlas pone en acción el concepto de "comunidad» en la búsqueda de respuestas innovadoras y aplicadas a la problemática social. Ahonda en el concepto de análisis crítico de la praxis, dándole sentido a través de la reflexión teórica.

Las conclusiones de las dos investigaciones a las que haremos referencia en este artículo confluyen en la presentación del fenómeno de las personas con discapacidad intelectual dentro del sistema penal penitenciario español durante el período 2005-2015, recogiendo, a la vez, todos los antecedentes de la atención al colectivo en España. Comparten una mirada, como decíamos, en la que la persona es la protagonista de su proyecto vital y analizan de qué manera los sistemas de protección por un lado y la familia por el otro participan en la búsqueda o en el fracaso de la inclusión. Esta lectura se realiza desde el trabajo social y se concluye con un análisis desde el Modelo de Atención Integral y Centrado en la Persona como propuesta innovadora que dé respuesta a la alta complejidad de los problemas que se plantean.

En la primera investigación, cuyo resultado es la tesis doctoral La discapacidad intelectual en el ámbito penal penitenciario. Procesos de exclusión y de integracion social (Ramos-Feijóo, 2011), se analiza cómo las personas con discapacidad intelectual que pasan por el sistema penal penitenciario encuentran, en muchos casos por primera vez, el camino a la inclusión social, a través de su paso por la cárcel. Este hecho 
nos lleva a pensar en qué medida puede plantearse que muchas personas encuentran por primera vez un espacio para trabajar proyectos inclusivos en un entorno de máxima exclusión. Por ello decimos que este hecho cuestiona los itinerarios y procesos de intervención preventivos de los sistemas de protección en el período previo a la situación de conflicto con la ley. Se pone entonces el acento en la burocratización de los sistemas de protección social que están centrados en el recurso y no en las necesidades de las personas, hecho que dificulta responder adecuadamente, entre otros, al principio de individualización del trabajo social que luego vincularemos con el Modelo de Atención Integral y Centrado en la Persona (MAICP).

Así, nos situamos en la segunda investigación, que da como resultado la tesis doctoral El papel de las familias de las personas con discapacidad intelectual en los procesos de intervención social, ante la comisión de un delito. Una mirada desde el Trabajo Social (Lorenzo-García, 2015). A través de este trabajo de investigación se abordan los aspectos más relevantes de las historias familiares de personas que se encuentran internas en el Hospital Psiquiátrico Penitenciario de Fontcalent (Alicante). Por medio de sus historias vitales siguiendo la metodología de estudio de caso, se analizan la relación intrafamiliar y la que las familias desarrollan con los sistemas de protección social. De esta manera se pueden describir y analizar las interacciones y los déficits y posibilidades de mejora en la intervención social que se lleva a cabo con las familias de personas con discapacidad intelectual. Desde este análisis podemos comprender la complejidad del itinerario que sigue una persona con discapacidad que entra en conflicto con la ley y cómo por estas razones puede terminar en una situación de reclusión en el sistema penal-penitenciario.

En ambos trabajos se pone de manifiesto la dificultad existente para abordar desde la intervención social los casos que venimos denominando de «largo recorrido y alta complejidad». Tal y como hemos destacado en publicaciones anteriores:

Ante el retroceso de los sistemas de protección se observa que hay personas que, hasta su ingreso en el sistema penitenciario, en su mayoría no habían sido identificadas por esos sistemas, y que, si lo habían hecho, era desde una perspectiva de labeling, es decir, como "casos crónicos» o "casos de largo recorrido", con la consiguiente estigmatización que ello conlleva (Ramos-Feijóo, 2013: 23).

Los resultados presentados ponen de manifiesto la necesidad de un cambio de modelo en la atención a las personas desde los sistemas de protección, un cambio que relacionamos con el Modelo de Atención Integral y Centrado en la Persona, como marco desde el que podemos responder a las necesidades independientemente de las carteras y catálogos de servicios y prestaciones. Coproduciendo con las personas, sus familias y los demás agentes sociales. El Modelo de Atención Integral y Centrado en la Persona parte desde las premisas de la integralidad y la autonomía, desde el marco de la interdependencia y la ética en la intervención social.

Actualmente, Plena Inclusión, entidad decana en la atención a las personas con discapacidad intelectual en España, atiende a 1554 personas que se encuentran dentro de instituciones penitenciarias (según datos de 19 de noviembre de 2019). Este programa se inició tras una visita realizada en 1987, por representantes de la 
entonces FEAPS junto con el secretario del Real Patronato sobre Discapacidad y directivos de ASPRONA (León), que acudieron al Centro Penitenciario Asistencial de León. Allí encontraron una situación de abandono de las personas con discapacidad intelectual que se encontraban en el centro. Tras un largo camino de revisión de las situaciones de cada persona interna y de planificación con las entidades que se implicaron en este tema, se creó un programa de atención especializado que inició su andadura en 1995 y que continúa en la actualidad ${ }^{1}$.

La población con discapacidad intelectual que se encuentra en el ámbito penal-penitenciario se caracteriza por estar constituida por personas en las que, al igual que en el resto de la población penitenciaria, influyen los factores de pobreza en un alto porcentaje, familias con problemas de integración social, situaciones de exclusión y aislamiento social y carencias afectivas. Todas estas circunstancias, unidas a las características propias de las personas con discapacidad intelectual, pueden constituir un ámbito de mayor riesgo para verse inmersas en situaciones de conflicto con la ley (FEAPS, 2006).

Es por ello que se destacarán los factores preventivos que desde la intervención del trabajo social consideramos esenciales para evitar la que puede definirse como situación de máxima exclusión: el ingreso en centros con privación de libertad.

\section{OBJETIVOS}

Como hemos señalado en la introducción, el objetivo de este artículo pretende constituir una línea de reflexión a partir de los resultados de dos tesis que establecen un diálogo sinérgico en torno a la realidad de las personas con discapacidad intelectual y/o trastornos de la salud mental y sus familias en el contexto de situaciones en conflicto con la ley.

Se pretende aportar el análisis de años de investigación en los cuales se han podido ir identificando aquellos factores de la intervención social donde el trabajo social puede aportar su conocimiento y su praxis para la mejora de la calidad de vida de las personas que se encuentran afectas por el régimen penal-penitenciario. Antes aún se pretende realizar un aporte motivador, que pudiera contribuir a promover el debate sobre la necesidad de consolidar políticas integrales y preventivas en la atención a las personas con discapacidad intelectual y sus familias.

A partir de identificar y analizar los procesos de exclusión social que sufren las personas con discapacidad intelectual afectas al medio penal-penitenciario y los posibles itinerarios de integración social de las mismas, se busca conocer las formas de intervención del tercer sector en esta problemática, identificar si los servicios sociales establecen alguna línea de trabajo especial para abordar esta problemática o si se realizan intervenciones preventivas de situaciones de riesgo.

\footnotetext{
${ }^{1}$ https://www.plenainclusion.org/informate/actualidad/noticias/2019/plena-inclusion-atiende-1554-personas-con-discapacidad.
} 
Por otro lado, se ha buscado identificar y analizar el papel del sistema familiar en los procesos de intervención social que se llevan a cabo con las personas con discapacidad intelectual en situación de delito. Describir qué conocen, qué piensan y qué sienten las familias en relación con su participación en los procesos de intervención social relacionados con la persona con discapacidad intelectual y el papel que tienen los sistemas de protección social en la vida de estas personas.

\section{METODOLOGÍA}

En el presente artículo se utilizaron dos estrategias: en primer lugar, se seleccionaron algunos resultados relevantes obtenidos en las dos investigaciones realizadas en los últimos diez ańos por las autoras. En la segunda estrategia, los resultados de estas dos investigaciones se ponen en diálogo con algunos de los principales conceptos teóricos sobre el tema. Partimos de la hipótesis de que la presencia de las personas con discapacidad intelectual y enfermedad mental cuestiona el discurso de la inclusión en materia de discapacidad, dado que cuando convergen en una persona situaciones que complejizan la atención a la discapacidad, los sistemas de protección tienden a aplicar recursos e intervenciones protocolizados que no responden a las necesidades específicas de estos casos. Por último se realizan una serie de reflexiones sobre las situaciones que definimos como de «alta complejidad» en casos de personas con discapacidad intelectual que entran en conflicto con la ley, desde la perspectiva teórica del Modelo de Atención Integral y Centrado en la Persona.

Las investigaciones que se comparan en este artículo responden a una línea de investigación propuesta desde la experiencia y el corpus teórico del trabajo social. El trabajo de campo de ambas investigaciones busca dar respuesta a la formulación de numerosas preguntas de investigación. No obstante, en el marco de este artículo sintetizaremos las mismas para dar prioridad a la descripción y análisis de aquellos resultados que mejor responden a los aspectos claves de la intervención del trabajo social en este contexto.

El enfoque en ambas es esencialmente cualitativo por considerarlo el más indicado en la producción de conocimientos para el trabajo social (Burgos Ortiz, 2011; Cifuentes Gil, 2011), si bien la primera de ellas parte de una triangulación metodológica.

En la primera investigación se destacan las siguientes preguntas:

- ¿A partir de su ingreso en los procesos penales, las personas con discapacidad intelectual encuentran un ámbito de continencia que les ayuda en algunos casos a integrarse socialmente?

- ¿Qué influencia tiene en la construcción de este fenómeno el papel de los agentes sociales como organizaciones de asociaciones de personas con discapacidad, servicios sociales, sistema judicial, fuerzas de seguridad y sistema penitenciario? 
Para dar respuesta a estas preguntas se realizaron 21 entrevistas en profundidad, grupales e individuales, con responsables técnicos y responsables (gerentes) de instituciones penitenciarias, técnicos del programa de intervención en centros penitenciarios de FEAPS (ahora Plena Inclusión), responsables de servicios sociales y sanitarios y usuarios del programa de FEAPS. Las entrevistas fueron transcritas y analizadas desde la construcción de categorías que permitieron la posterior discusión de resultados. Asimismo, se incluyeron los datos estadísticos que permitieron conocer la dimensión de la presencia de personas con discapacidad intelectual en el sistema penitenciario español. Se realizaron también entrevistas de interés para la construcción del marco teórico con equipos del INTRESS (Instituto de Trabajo Social y Servicios Sociales) que se encontraban trabajando en el sistema penitenciario, así como de FEAFES (Confederación de Salud Mental de España), que desarrollan su acción en el campo de la salud mental.

En la segunda investigación, para mostrar algunos resultados, se partió de la pregunta central de investigación:

- ¿Cuál es el papel de la familia de las personas con discapacidad intelectual que han cometido un delito en los procesos de intervención social que se realizan o realizaron con sus hijas e hijos?

Para comprender las respuestas obtenidas a esta pregunta central se indagó, de manera retrospectiva, desde el momento en que la persona con discapacidad intelectual entra en el sistema penal-penitenciario, reconstruyendo los principales acontecimientos de la historia familiar tal y como los percibieron las familias. Para ello se formularon entre otras las siguientes preguntas:

- ¿Qué papel tiene la familia ante el delito cometido por una persona con discapacidad intelectual?

- ¿Cómo perciben las familias que son consideradas sus necesidades y sus potencialidades desde las instituciones y profesionales que intervienen con sus hijos e hijas?

A través de las preguntas de investigación se indaga sobre los aspectos que se ven involucrados para favorecer la participación de las familias en los procesos de intervención social. Entendemos que la participación implica empoderamiento, y para que éste sea real en los procesos de intervención psicosocial, las familias y las personas con discapacidad deben comprender y conocer su propia realidad. La participación intersistémica permite comprender los elementos facilitadores y obstaculizadores en la coproducción de la inclusión social.

Se trabajó con entrevistas en profundidad a través del estudio de 4 casos de familiares directos de personas con discapacidad intelectual que se encontraban cumpliendo medida de seguridad en un hospital psiquiátrico penitenciario. Además de estas entrevistas en profundidad que permitieron la construcción de las historias de vida de cada uno de los casos, se acompañaron en la presentación los genogramas y cronogramas de acontecimientos críticos de cada famila, en los que se identificó 
la presencia de los distintos sistemas de intervención social (McGoldrick y Gerson, 1993). El trabajo se completó con la realización de entrevistas a expertos vinculados a la temática de la discapacidad intelectual y el sistema penal-penitenciario.

Se escoge poner en diálogo los resultados de las investigaciones, siguiendo la idea de los debates del trabajo social en contextos de alta complejidad, planteada por Yañez Pereira (2013: 20) cuando afirma:

En definitiva, nuestros debates se escenifican como una forma de inspiración en la forma de comprender lo social y de comprendernos en ese comprender, logrando generar prácticas, tanto teóricas como empíricas, que cargan de sentido el ser y estar de los y las Trabajadores y Trabajadoras Sociales en la cotidianeidad del mundo de la vida.

\section{PRINCIPALES RESULTADOS PARA LA INTERVENCIÓN DEL TRABAJO SOCIAL}

A continuación se recogen algunos de los resultados que han sido considerados como puntos clave, surgidos tras el trabajo de comparación y análisis de los hallazgos de las investigaciones. Se considera que en ellos confluyen los aspectos que permiten proponer una respuesta a la interpelación al concepto de «inclusión» que nace de la presencia de personas con discapacidad intelectual dentro del sistema penal-penitenciario español.

Se ha procedido a agrupar los resultados seleccionados de ambas investigaciones en categorías, que aportan un análisis para contribuir a desarrollar las posibles políticas preventivas trabajando desde las fortalezas de las personas y sus familias en sinergia con los servicios sociales.

En este sentido, nos reafirmamos en la necesidad de implementar dispositivos de intervención centrados en la persona, partiendo de un modelo de atención integral, que tenga en cuenta toda su realidad, más allá de la exclusiva atención a la discapacidad.

\section{LA CÁRCEL COMO RECURSO SOCIAL}

De la investigación surge la imagen de la institución penitenciaria reconocida como un «recurso social». Asimilamos esta cristalización de la institución penitenciaria como un recurso para personas que presentan una discapacidad intelectual, con el desarrollo de la hipótesis del sociólogo francés Wacquant (2010), que plantea un proceso que se inicia con el Estado de bienestar (wellfare state) para dar paso al workfare (prestaciones a cambio de trabajo) y finalmente a lo que él denomina el Prison fare, que viene a decir que, en cierto modo, para quienes el sistema de protección no tiene recursos adecuados, la respuesta es el sistema penitenciario. Esta idea responde asimismo a fundamentos teóricos aportados por autores como Foucault (1967) y Basaglia (1972), que han precedido a Wacquant en el planteamiento 
de la pobreza como uno de los determinantes en los procesos de exclusión social que culminan con el ingreso de personas vulnerables en la cárcel. Estos determinantes sociales son comprobables en las personas con discapacidad intelectual, a los que se suman otros aspectos, como la falta de habilidades sociales o la baja tolerancia a situaciones de estrés, la carencia de elementos productores de resiliencia en su ámbito familiar, sobre los que también debiera intervenirse y de manera individualizada, para evitar los circuitos de exclusión. Se consolida la evidencia de una necesidad no cubierta por los sistemas de protección social, entendiendo que los servicios sociales generales y especializados no responden a las demandas, por ejemplo, para dar plazas residenciales que eviten el ingreso en prisión o bien para proceder a la excarcelación de las personas con discapacidad intelectual que se encuentran cumpliendo una sentencia. Las razones identificadas son varias; en primer lugar, la carencia de recursos adecuados para personas que no reunirían los requisitos para poder ingresar en los dispositivos de los sistemas de protección. Este argumento es rebatido desde los técnicos implicados en programas de asociaciones del sector que trabajan en cárceles. Se insiste en que no existe una gran diferencia entre estos perfiles, pero lo que sí se identifica es una resistencia motivada por el «estigma de la prisión", que se manifiesta del mismo modo que en la sociedad con quienes no tienen una discapacidad, pero han cumplido una condena penal. En segundo lugar, también se obtiene como reflexión por parte de las administraciones autonómicas la existencia de una falta de flexibilidad a la hora de adaptar los recursos existentes a las necesidades complejas.

A lo largo del proceso vital de la persona con discapacidad se producen diferentes episodios que pueden ir alertando de que entrará en conflicto con la ley. Estas situaciones requieren de una atención precisa. Las intervenciones superficiales, incluso infantilizando a la persona con discapacidad intelectual, no dan respuesta a la necesidad de sistemas de apoyo y devuelven a la familia el problema como la única responsable. Esto recarga la angustia y la tensión en el sistema familiar, que al «no saber» requiere de la "protección» del criterio profesional. Esto nos devuelve a una etapa anterior en la intervención social en el ámbito de la discapacidad, esto es, el modelo médico rehabilitador.

Citamos las reflexiones de Carozza (2014), que refiriéndose a la realidad italiana afirma que éste es uno de los límites atribuibles a los enfoques biomédicos: la inaccesibilidad a apoyos y recursos adecuados perpetúa una aproximación caritativa, que considera a la persona con discapacidad objeto de piedad, dependiente y eternamente niño, instrumento para buenas y virtuosas obras de misericordia (2014: 22) ${ }^{2}$.

Si la familia no recibe una formación y una información adecuada, le es imposible gestionar la situación y ante ello la cárcel se termina constituyendo (cuando se dan situaciones de conflicto con la ley) como el lugar seguro para la persona y para la familia, que siente no poder evitar el riesgo que para sí y para los demás representa su familiar dada la experiencia vivida en el medio abierto.

\footnotetext{
2 Traducción propia.
} 
Dentro de este ciclo, la familia confirma la imagen de la cárcel como recurso social. Si a ello agregamos que la mayoría de los casos de personas con discapacidad intelectual que cumplen penas o medidas de seguridad nunca habían participado en el sector asociativo de la discapacidad, y al llegar al sistema penal-penitenciario entran en contacto con un programa de atención como el que desarrolla Plena Inclusión, donde son atendidos y apoyados desde sus potencialidades, todo confluye en que la cárcel sea interpretada como un recurso terapéutico y social.

Asimismo, es importante recordar que en el informe anual del Defensor del Pueblo presentado en las Cortes en 2019, se destaca como primera conclusión sobre la situación de las personas con discapacidad intelectual en el sistema penal penitenciario:

Hay un gran desconocimiento en la sociedad sobre la existencia y los problemas de las personas con discapacidad intelectual en prisión. Este desconocimiento puede alcanzar, en algunos casos, a jueces, fiscales, abogados o policías, a pesar de los avances que se han producido en sensibilización y formación (Defensor del Pueblo, 2019: 34).

Para luego incluir en sus recomendaciones a la Secretaría de Estado de Servicios Sociales:

Incluir a los presos con discapacidad intelectual en la Agenda Social y, en concreto, en la próxima Estrategia Española y Plan de Acción sobre Discapacidad, como colectivo especialmente vulnerable (Defensor del Pueblo, 2019: 36).

\section{CAPACITACIÓN DE LOS RECURSOS HUMANOS}

En cuanto a la formación de los recursos humanos que atienden a las personas con discapacidad intelectual en los itinerarios previos al ingreso en el sistema penal-penitenciario, se identifican carencias vinculadas a la complejidad de aquellos casos en los que surgen problemas asociados a la discapacidad.

La existencia de patologías duales por consumo de tóxicos, o la presencia de trastorno mental en las personas con discapacidad que puede traducirse en conductas desafiantes, somete a situaciones de gran estrés a los equipos de los sistemas de protección. Esta falta de competencias para poder responder a los casos complejos se agrava por la hiperespecialización de los diferentes sectores que confluyen en la intervención social.

En nuestro análisis consideramos que además se evidencia una tendencia a la fragmentación de la intervención entre los servicios sociales, que atienden los dispositivos para la discapacidad intelectual, y los servicios sanitarios, que se ocupan de los problemas de salud mental. Esta fragmentación pone de manifiesto la falta de coordinación sociosanitaria, que es una de las claves en la atención integral y centrada en la persona.

Todas estas circunstancias aunadas suelen terminar resolviéndose con la expulsión de la persona con discapacidad de los dispositivos en los que participan 
(escuela, asociaciones, centro ocupacional...). Con esta expulsión se inicia un itinerario, a lo largo del cual la familia no va a encontrar apoyos suficientes y adecuados, de modo que estas personas pueden desembocar en la cárcel, convertida en el recurso social del que hablamos en el apartado anterior.

Siguiendo la línea de las rupturas en la comprensión de la problemática de las personas con discapacidad intelectual en conflicto con la ley, se suma el escaso conocimiento de las características de la discapacidad intelectual y de la enfermedad mental que tienen los agentes judiciales y las fuerzas de seguridad. Pese a que en los últimos años desde el movimiento de personas con discapacidad se han hecho numerosos esfuerzos para su sensibilización que se han traducido en cursos, campañas y firma de convenios de colaboración, existen diferentes códigos, lenguajes y tiempos entre la administración de justicia, las fuerzas de seguridad y la intervención social. Éstos requieren de acciones mediadoras en las cuales consideramos que el papel del trabajo social es relevante.

La distinción entre las características de la persona con enfermedad mental y de la persona con discapacidad intelectual se reconoce en el propio Código Penal, englobadas dentro de las llamadas anomalías psíquicas. Así se comprueba en la revisión bibliográfica, en la que se observan las múltiples dificultades que la falta de investigación sobre las relaciones entre enfermedad mental y retraso mental en el entorno español producen a la hora de orientar las intervenciones ${ }^{3}$.

\section{ENFERMEDAD MENTAL Y DISCAPACIDAD INTELECTUAL}

Esta situación da lugar a redefiniciones de la intervención, evidenciadas, entre otras áreas, en el tratamiento penal penitenciario, donde se establecen diferencias parangonables a las que se dan en la intervención de los servicios sociosanitarios, deslindando la realidad de las personas con discapacidad intelectual de la de las personas con enfermedad mental. Hecha esta observación de manera reiterada a lo largo de las investigaciones, así como de los años de trabajo en el tema, se consideró que este factor de «intersección» entre la discapacidad mental y la enfermedad mental podría generar en muchos casos una dificultad a la hora de la intervención y fundamentalmente en el diseño de estrategias que favorezcan los procesos de integración social.

La falta de intervención en los aspectos relativos a la salud mental de las personas con discapacidad intelectual resultan evidentes, y en ella confluyen aspectos técnicos, administrativos e incluso de políticas sociosanitarias que no están adecuadamente definidas.

${ }^{3}$ Se recomienda la visualización del documental $A$ cada lado, realizado por FEAPS y disponible en https://es.video.search.yahoo.com/search/video?fr=mcafee\&p=VImeo+videos+A+cada+La-

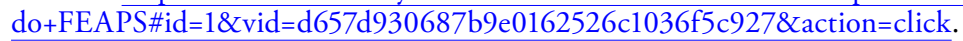


Se hace necesario también insistir en el enfoque de derechos humanos que estas intervenciones deben asumir, toda vez que España ha ratificado la Convención Internacional de los Derechos de las Personas con Discapacidad.

Coincidimos en este apartado en destacar lo planteado con referencia a la ética de los servicios sociales por Begoña Román:

El empoderamiento supone acompańamiento. Este contiene ambas dimensiones de la noción de autonomía, a saber: la referida a la competencia para la toma de decisiones y la relacionada con la funcionalidad en la vida diaria. Las personas han de ser capaces de desarrollar sus capacidades para ser y hacer su propia vida lo más autónoma posible. Ante la vulnerabilidad personal y social, no solo hay que atender la dependencia, también no aumentarla (Román, 2016: 140).

La cita nos conecta con la necesidad de trabajar con las personas acompañando los procesos de autonomía a través del empoderamiento, lo que requiere atender a todas las perspectivas de su realidad, sin fragmentar.

\section{LA FAMILIA Y SUS NECESIDADES DE APOYO}

Se ha puesto de manifiesto la complejidad de los sistemas familiares, a la que se añade la tensión y el estrés por las necesidades y particularidades que puede presentar una persona con discapacidad intelectual.

La historia de cada familia es una secuencia de acontecimientos críticos, éstos requieren de un apoyo que no siempre se encuentra en los sistemas de protección. Se han detectado evidencias de la ausencia de intervenciones profesionales especializadas en el ámbito de la persona con discapacidad intelectual y de sus relaciones con el sistema familiar. En este sentido es importante destacar que no todas las familias que tienen un miembro con discapacidad participan del mundo asociativo, que en nuestra realidad es quien más se especializa en dar apoyo a la discapacidad intelectual.

Entendemos que desde los servicios sociales generales, así como desde los servicios sanitarios de atención primaria, no se llega a trabajar suficientemente en los apoyos que requiere la familia, fundamentalmente cuando las situaciones se complejizan. Asimismo, algunas intervenciones resultan extremadamente puntuales, fragmentadas y protocolarizadas finalizando la relación sin que medie una decisión profesional y participada con la familia. Volvemos a destacar la necesidad de un trabajo fundamentado en la atencion integral y centrada en la persona.

\section{Debilidad de los Sistemas de apoyo para casos complejos}

El sector asociativo de la discapacidad tiene en España un papel de gran relevancia porque ha ido marcando el proceso de cambio desde un modelo rehabilitador a un modelo social donde se da respuesta de una manera más integral a las necesidades de las personas con discapacidad intelectual y a sus familias. En este sentido, 
cabe destacar que en la atención al colectivo en las cárceles, ha sido la coproducción entre el sector público y el tercer sector la que consiguió poner, al menos en parte, dentro de la agenda política la atención a esta problemática.

Sin embargo, la realidad estadística nos devuelve que falta todavía un camino por recorrer, nos referimos al de la prevención de las situaciones de conflicto con la ley. La actividad del tercer sector no constituye en sí misma un «sistema de protección social», sino que contribuye como uno de los actores. En este sentido, entendemos que el sector público debe asumir un papel acorde con su responsabilidad, que cumpla un rol preventivo desde los primeros ańos de vida de las personas, acompańando a las familias, asesorando y a la vez coproduciendo con las asociaciones especializadas. No hemos de olvidar que existen numerosas familias a las cuales no llegan los servicios del mundo asociativo, pero que sí forman parte de la universalidad asignada a los servicios sociosanitarios.

Por parte de los sistemas de protección social, educativo y de salud, no se observa en el estudio de casos realizado una atención centrada en la familia que responda a su necesidad de ser apoyada y asesorada, acompañada y reforzada para hacer frente a los desafíos que le presenta la nueva realidad en un momento dado y que continuará a lo largo de toda la vida.

\section{CONCLUSIÓN A MODO DE PROPUESTA}

El Modelo de Atención Integral y Centrado en la Persona (MAICP) constituye un marco para la intervención social que recoge muchos de los principios del trabajo social. Desde nuestra perspectiva, entendemos que sus postulados aportan un marco desde el que podemos hacer confluir las distintas profesiones involucradas en la intervención social para dar la centralidad y el protagonismo a la persona.

Partimos de la siguiente definición del Modelo de Atención Integral y Centrado en la Persona:

La AICP, fundamentándose y nutriéndose de la evidencia científica, se basa en una serie de principios que parten de la asunción de que todas las personas somos iguales en dignidad y derechos, pero cada una es única (Individualidad); que por muchos apoyos que necesitemos nunca debemos perder el derecho a controlar nuestra propia vida (Autonomía); que debe trabajarse en las intervenciones por minimizar las dificultades de funcionalidad y reducir la dependencia (Independencia); que las personas deben ser tenidas en cuenta en la elaboración de los planes de atención y participar en su comunidad (Participación e Inclusión Social) y que los cuidados han de prestarse de manera coordinada, flexible y sin rupturas (Continuidad), dando prioridad a la permanencia en el domicilio y en la comunidad (Rodríguez et al., 2017: 49).

En la cita confluyen los aspectos que entendemos son esenciales para la intervención social con el colectivo de personas con discapacidad intelectual. Hablamos en primer lugar de individualidad, es decir, que las personas deben ser reconocidas en su contexto familiar, social y comunitario, atendiendo a los apoyos que necesiten para desarrollar sus capacidades; esto nos hace cambiar la mirada en la intervención, 
que suele estar sesgada hacia el déficit, y pasarla a los aspectos positivos con los que se pueda trabajar (Sen, 1989, 1999; Nussbaum, 2012). Pero también nos hace centrar la atención en la persona y no en la cartera de recursos, entendiendo que debemos trabajar desde la innovación para responder a lo que las personas necesitan. La problemática de las personas con discapacidad que entran en conflicto con la ley requiere encontrar un espacio común en que confluyen muchas disciplinas con distintos marcos teóricos, pero que deben poder entenderse.

En este sentido recogemos otra reflexión de Begoña Roman Mestre sobre la transición para la adaptación de los servicios sociales al modelo de derechos promovido por la Convención Internacional sobre los Derechos de las Personas con Discapacidad:

Pero la razonabilidad de la transición es también una cuestión de responsabilidad de los Estados y de cómo dotan a sus servicios sociales. La institucionalización, la vida independiente, las tutelas, no deberían ser términos radicalmente excluyentes: la peculiaridad de las personas, sus distintos grados de diversidad funcional y de contextos, obliga a una cautelosa transición (Román, 2016: 103).

Se destaca así la necesidad de asumir que los cambios son esencialmente procesuales y que requieren de una capacitación de los recursos humanos de los servicios sociales que no se limite a la asimilación de nuevos protocolos, sino a su comprensión para ponerlos al servicio de las personas, es decir, reconfigurar la atención para que su eje sean las personas.

Siguiendo con los principios del MAICP, el desarrollo de la autonomía constituye un factor esencial con el que debemos trabajar en el ámbito de las personas con discapacidad intelectual. Entonces, si hablamos de inclusión, es indudable que debemos acompañarla del desarrollo de la autonomía, lo que implica alejar la idea de sobreprotección para brindar los apoyos acordes con las necesidades que la persona tiene para desarrollar al máximo sus capacidades, acompańando los procesos en los que ha de tomar decisiones.

En el trabajo de campo que acompañó a las investigaciones presentadas, pudo evidenciarse cómo en algunos casos la persona delinquía para ganar el aprecio de un grupo que lo estaba utilizando. En esta anécdota podemos poner de manifiesto la necesidad de fortalecer la autoestima, para evitar ser víctima de la utilización de terceros. Éste es uno de los aspectos que debe ser trabajado y potenciado como elemento preventivo. Es evidente que no existe la posibilidad del «riesgo cero» en la comisión de delitos, pero la prevención debe ser una constante en la intervención social. Coincidimos en afirmar:

Frente a la invulnerabilidad inherente a las filosofías morales modernas, Nussbaum entiende que es la vulnerabilidad humana la que nos lleva a relacionarnos con las demás personas y la compasión es el elemento emocional gracias al cual logramos experimentar y conectar con estas situaciones de infortunio.

Como profesionales del Trabajo Social deberemos entonces propiciar en los ámbitos de trabajo, la creación de espacios de reflexión ética, que por encima de las urgencias cotidianas, nos permitan reflexionar sobre las formas, protocolos y recursos de la 
intervención social. De manera que nuestra práctica y nuestro discurso converjan en la centralidad como sujetos de las personas (Idareta Goldaracena, 2019: 76).

La participación y la inclusión van unidas y son imprescindibles para el desarrollo de las personas. El enfoque del MAICP es de raíz comunitaria, por lo que es necesario poner la responsabilidad de los entornos en la prevención de los delitos y en la auténtica inclusión de las personas con discapacidad intelectual, que, como en todos los colectivos, no constituyen un conglomerado homogéneo, sino que reconocen particularidades.

Cuando se habla de la «inclusión» debe tenerse en cuenta la particularidad que cada persona tiene y que debe atenderse siendo función de los servicios sociales y sanitarios el diseñar e implementar los apoyos contando auténticamente con la participación de las personas, sus familias, el mundo asociativo y la comunidad en general. Partimos de la concepción de que la intervención sigue siempre tres coordenadas (Jaraíz Arroyo, 2012): la intencionalidad, el sustento teórico y los efectos de naturaleza estructural. Así entendida, la intervención del trabajo social en el ámbito de la discapacidad intelectual centra la mirada en la persona como sujeto protagonista de su vida, teniendo en cuenta las diferentes circunstancias que en cada momento según etapas, contextos, subsistemas personales, familiares y entorno comunitario vivirá cada sujeto.

Asumimos que la atención integral y centrada en la persona

... es la que promueve las condiciones necesarias para la consecución de mejoras en todos los ámbitos de la calidad de vida y el bienestar de las personas, partiendo del respeto pleno a su dignidad y derechos, de sus intereses y preferencias y contando con su participación efectiva (Rodríguez y Vilá, 2014: 120).

Desde esta definición consideramos que el trabajo social, como profesión, tiene un papel relevante a desarrollar en la prevención de las situaciones de conflicto con la ley que puedan determinar que una persona con discapacidad intelectual entre en el circuito penal-penitenciario. Esto requiere que la intervención se perfile desde la innovación y el emprendimiento social, desde la coproducción en varios niveles, con las personas y con sus familias, con el tercer sector, con las fuerzas de seguridad y con el sistema judicial, y, por último, con la recuperación de dinámicas de trabajo social comunitario que comprometan a toda la sociedad en la construcción de la inclusión. 


\section{REFERENCIAS BIBLIOGRÁFICAS}

Basaglia, F. (1972). La institución negada. Informe de un Hospital Psiquiátrico. Barcelona: Seix Barral.

Burgos Ortiz, N.M. (2011). Investigación cualitativa. Miradas desde el Trabajo Social. Buenos Aires: Espacio Editorial.

Carozza, P. (2014). Dalla centralità dei Servizi alla centralità della persona. Milano, Italia: Editorial FrancoAngeli.

Cifuentes Gil, R.M. (2011). Diseños de proyectos de investigación cualitativa. Buenos Aires: Noveduc Libros.

Defensor del Pueblo (2019). Las personas con discapacidad intelectual en prisión. Estudio. Separata del volumen II del informe anual 2018, recuperado de https://www.defensordelpueblo.es/ wpcontent/uploads/2019/09/Separata_discapacidad_en_prision.pdf. Última consulta: 01/09/20.

FEAPS (2006). Guía de intervención para personas con discapacidad intelectual, afectas por el régimen penal penitenciario. Madrid: Obra social Caja Madrid, recuperado de http://riberdis.cedd. net/handle/11181/3367. Última consulta: 29/9/20.

Foucault, M. (1967). Vigilar y Castigar. Nacimiento de la prisión. Buenos Aires: Siglo XXI.

Idareta Goldaracena, F. (2019). «Teorías éticas contemporáneas en la Intervención social», en Uriz Peman M.J. (coord.) (2019) La necesaria mirada ética en Trabajo Social. Madrid: Paraninfo Universidad.

Jaraíz Arroyo, G. (2012). Intervencion social, barrio y Servicios Sociales comunitarios. Madrid: FOESSA.

Lorenzo García, J. (2015). El papel de las familias de las personas con discapacidad intelectual en los procesos de intervención social, ante la comisión de un delito. Una mirada desde el Trabajo Social. Tesis doctoral. Universidad de Alicante.

McGoldrick, M. y Gerson, R. (1993). Genogramas en la evaluación familiar. Madrid: Gedisa.

Nussbaum, M.C. (2012). Crear capacidades. Propuestas para el desarrollo humano. Barcelona: Paidós.

Ramos Feijóo, C. (2011). La discapacidad intelectual en el ámbito penal penitenciario. Procesos de exclusión y de integración social. Tesis doctoral. Universidad de Alicante.

Ramos Feijóo, C. (2013). «Las personas con discapacidad intelectual en el sistema penal penitenciario ¿Un fracaso de las políticas de inclusión?», Revista Internacional de Organizaciones n. ${ }^{\circ} 11$, pp. $15-35$.

Rodríguez Rodríguez, P. y Vilá i Mancebo, A. (coords.) (2014). Modelo de Atención Integral y Centrada en la Persona. Teoría y práctica en ámbitos del envejecimiento y la discapacidad. Madrid: Tecnos.

Rodríguez Rodríguez, P. et al. (2017). La atención en domicilios y comunidad a personas con discapacidad y personas mayores. Guia de innovación según el Modelo AICP, recuperado de http:// ibdigital.uib.es/greenstone/collect/portal_social/import/fpilares/fpilares0009.pdf. Última consulta: 01/09/20.

Román Maestre, B. (2016). Ética de los Servicios Sociales. Barcelona: Editorial Herder.

SEN, A. (1989). Sobre ética y economía. Madrid: Alianza. 
Yáñez Pereira, V. (2013). El Trabajo Social en contextos de Alta Complejidad. Reflexiones sobre el Pensum Disciplina. Buenos Aires: Editorial Espacio.

WACQUANT, L. (2010). Castigar a los pobres. El gobierno neoliberal de la inseguridad social. Barcelona: Gedisa. 


\title{
INSERCIÓN LABORAL DEL ALUMNADO CON DISCAPACIDAD EN LA UNIVERSIDAD DE LAS PALMAS DE GRAN CANARIA (ULPGC)
}

\author{
Carmen Delia Díaz Bolaños \\ carmendelia.diaz@ulpgc.es \\ Universidad de Las Palmas de Gran Canaria \\ Celsa Cáceres Rodríguez \\ ccaceres@ull.edu.es \\ Universidad de La Laguna
}

\begin{abstract}
RESUMEN
El empleo es el eje vertebrador del desarrollo pleno en las sociedades actuales. Sin embargo, encontramos que las personas con discapacidad presentan dificultades de acceso al mercado laboral, incluso cuando han culminado con éxito estudios universitarios. Con el propósito de describir y analizar la situación de las personas con discapacidad que han egresado en la ULPGC entre 2000 y 2010, se han revisado las trayectorias laborales de 96 egresados mediante el emparejamiento de los registros de la universidad y los del Observatorio de Empleo de Canarias. Se han utilizado cuatro indicadores: inserción laboral, paro registrado, temporalidad y empleo encajado. Los resultados muestran que una de cada dos personas logra un empleo acorde a su formación al tercer año del egreso, lo que sugiere ciertos efectos positivos de la formación universitaria en la inserción laboral.
\end{abstract}

Palabras clave: discapacidad, universidad, inserción laboral, empleo encajado.

LABOUR INSERTION OF DISABLED STUDENTS AT

THE UNIVERSITY OF LAS PALMAS DE GRAN CANARIA

\begin{abstract}
Nowadays, to have a job is the best way to get a successful personal development. However, we find that people with disabilities have difficulties in accessing the labour market, even when they have successfully completed their university studies. This paper describes and analyzes the situation of people with disabilities who have graduated from the ULPGC between 2000 and 2010. The career trajectories of 96 graduates have been reviewed by matching the records from the ULPGC and those of The Canary Islands Observatory of Employment (OBECAN). Four indicators have been used: job placement, registered unemployment, temporary employment, and occupation. The results show that one in two people achieves a job according to their training in the third year after graduation, which suggests certain positive effects of university studies on job placement.
\end{abstract}

KeYwords: Disability, University, Job placement, Education-Job Match. 


\section{INTRODUCCIÓN}

El colectivo de personas con discapacidad es uno de los grupos que han sufrido una mayor exclusión social a lo largo del tiempo y que, a pesar de los avances en los modelos para explicar la discapacidad y las propuestas para una intervención eficaz, así como la existencia de normativa y recomendaciones internacionales basadas en el respeto de los derechos humanos y el principio de igualdad de oportunidades, sigue encontrándose en situación de desigualdad (Albor, 2019; Díaz-Velázquez, 2011; Huete García, 2013).

Esa discriminación se ha visibilizado en mayor medida en el sistema laboral, puesto que el empleo se configura como un generador de utilidad social y de responsabilidades sobre el que se construye nuestra imagen social y nuestro estatus, se considera la base para la estabilidad personal de todos los individuos; así, el empleo se ha considerado uno de los ejes vertebradores para el desarrollo pleno de las personas con discapacidad en el que se ha basado su inclusión social. De ahí que la falta de empleo se convierta en un factor que agrava la exclusión social, al limitar las oportunidades de la persona para adquirir las cotas de autonomía material y emocional que le permitirían desarrollarse como una persona adulta e independiente.

La Organización Internacional del Trabajo (OIT) entiende por «persona discapacitada toda persona cuyas posibilidades de obtener y conservar un empleo adecuado y de progresar en el mismo queden substancialmente reducidas a causa de una deficiencia de carácter físico o mental debidamente reconocida» (artículo 1.1) (OIT, 1983).

Las personas con discapacidad representan aproximadamente mil millones de personas, un 15\% de la población mundial (OMS, 2020), de las que alrededor del 80 por ciento están en edad de trabajar. Estas, en particular las mujeres con discapacidad, se enfrentan a barreras de distinta naturaleza que dificultan el disfrute en igualdad de oportunidades de un empleo. En comparación con la población sin discapacidad, las personas con discapacidad experimentan mayores tasas de desempleo e inactividad económica y están en mayor riesgo de pobreza y exclusión social (OIT, 2020).

La OIT (2001) destaca que el hecho de presentar una discapacidad tiene implicaciones distintas: mientras para unas personas la influencia en la capacidad para trabajar y participar en la sociedad puede ser prácticamente insignificante, para otras puede tener importantes repercusiones, por lo que se requerirán apoyos considerables, lo que pone en evidencia las múltiples variaciones que pueden darse entre estos extremos.

La inserción laboral de las personas con discapacidad ha estado presente dentro de los marcos de discusión de los diferentes organismos internacionales. En las últimas décadas se han articulado una serie de normativas y políticas sociales tendentes a la integración a través de la igualdad de oportunidades, la participación, la autodeterminación y la dignidad, todo ello auspiciado bajo el paradigma de los derechos humanos (Cabra de Luna, 2004).

A pesar del reconocimiento de los derechos y de las medidas que se han puesto en marcha para favorecer a las personas con discapacidad, siguen teniendo 
poca presencia en los empleos ordinarios, lo que pone de manifiesto que siguen existiendo dificultades para obtener, encontrar y mantener un puesto de trabajo (Pallisera et al., 2003). lo siguiente:

Con relación al empleo, la Organización Internacional del Trabajo plantea

El desarrollo viene con el empleo. Los empleos vinculan a las personas con la sociedad y la economía en las que viven. El acceso a un trabajo seguro, productivo y remunerado de manera justa -asalariado o por cuenta propia- es un factor fundamental para la autoestima de las personas y las familias, que les afirma su sentimiento de pertenencia a una comunidad, y les permite hacer una contribución productiva. El cambio hacia un desarrollo incluyente y sostenible no será posible si se niega a millones de personas la oportunidad de ganarse la vida en condiciones dignas y equitativas (OIT, 2015: 1).

Las personas con discapacidad reivindican el derecho a la participación social en condiciones de igualdad y, entre otros derechos, reclaman la inclusión educativa en todos los niveles de la educación formal y el acceso a empleos acordes a sus capacidades. El afán de la reivindicación de estos derechos tiene como fin último poder desarrollar plenamente su ciudadanía, asumiendo sus propias responsabilidades y contribuyendo activamente en todas las dimensiones de la sociedad en la que están inmersas.

De este marco general se desprende que la formación superior puede ser un medio para facilitar el acceso a mejores empleos; sin embargo, esta realidad ha sido escasamente estudiada. De ahí que nos propongamos estudiar la situación de los egresados con discapacidad de la Universidad de Las Palmas de Gran Canaria (ULPGC), concretamente tratamos de averiguar los efectos que la formación superior ha tenido en las trayectorias laborales de las personas con discapacidad que finalizaron sus estudios entre 2000 y 2010. Para ello, ha sido necesario diseñar una metodología específica que consiste en el emparejamiento de los registros académicos de la ULPGC con los datos disponibles en el Observatorio de Empleo de Canarias, de este modo se puede observar la evolución de los indicadores seleccionados a lo largo del tiempo y determinar la medida en que los empleos corresponden con el nivel de formación logrado.

En los siguientes apartados se presentan los principales antecedentes sobre la situación de las personas con discapacidad en el mercado laboral y en la universidad, así como los estudios previos relacionados con el tema.

\section{EL MERCADO LABORAL Y LAS PERSONAS CON DISCAPACIDAD}

La situación de discriminación y de exclusión en el ámbito laboral sigue siendo una realidad en nuestras sociedades.

Esta discriminación por falta de oportunidades viene dada inicialmente por elementos estructurales como el mercado de trabajo y su configuración, que en las 
últimas décadas se ha polarizado, generando un incremento de la competitividad y la segmentación entre los trabajadores, que tiende a marcar las diferencias entre los candidatos más y menos capacitados. Este último sector se ha incrementado desde mediados de los años ochenta, como lo atestigua el crecimiento combinado del paro. En este contexto hay que situar las elevadas tasas de inactividad, desempleo y paro de larga duración entre las personas con discapacidad, así como su mayor dificultad para acceder al mercado ordinario de trabajo en condiciones de estabilidad y promoción profesional (Colectivo IOÉ, 2003: 171).

Por otro lado, nos encontramos con elementos o características personales que presentan las personas con discapacidad. En general, tienden a pensar que carecen de potencialidades laborales y que, por tanto, han de depender económicamente de las políticas asistenciales, de ahí que el miedo a perder las prestaciones que perciben se convierta en un obstáculo singular para su acceso al empleo (Malo, 2004), a lo que se añade el desconocimiento de las fórmulas de entrada al mercado laboral. A esto se añaden elementos culturales como los estereotipos en relación con las personas con discapacidad, según los cuales los empleadores y la sociedad en general las consideren personas con escasas competencias para el desarrollo de una labor profesional (Malo et al., 2010).

La exclusión y la discriminación por razón de la discapacidad violan diversos derechos humanos universales, en particular el derecho a la igualdad.

La exclusión y la discriminación estructurales por motivo de discapacidad minan la competitividad de nuestros sistemas económicos y la cohesión de nuestros sistemas sociales. La sociedad en su conjunto se ve afectada cuando no se reconoce ni se facilita adecuadamente la expresión del talento y la realización del potencial que atesoran las personas con discapacidad (De Lorenzo, 2003: 78).

En los últimos decenios del siglo xx muchos países del mundo han modificado de forma apreciable sus marcos jurídicos y normativos en torno a la discapacidad, desarrollando políticas dirigidas a promover el derecho al trabajo de este colectivo, garantizando medidas de discriminación positiva, junto con legislaciones antidiscriminatorias o de equidad, tendentes a la inclusión de las personas con discapacidad.

Este es el caso de España, que, desde la creación de los Planes Nacionales de Empleo, los Planes de Acción para las Personas con Discapacidad y los Planes Nacionales para la Inclusión Social, ha centrado sus esfuerzos en la generación y la mejora continua de medidas dirigidas a optimizar la situación laboral de las personas con discapacidad. Sin embargo, a pesar de los cambios que se han producido, la realidad es testaruda y las tasas de actividad y de paro de las personas con discapacidad siguen siendo menores y mayores respectivamente que las de sus pares sin discapacidad.

En España, según los datos del Observatorio sobre Discapacidad y Mercado de Trabajo (ODISMET), en 2018 se contabilizaron 1899800 personas con discapacidad entre los 16 y los 64 años, lo que representa un 6,29\% del conjunto de la población española en edad de trabajar. La tasa de actividad se sitúa en el 34,4 \%, la tasa de empleo tan solo alcanza al $25,8 \%$, situándose la tasa de paro en el $25,2 \%$, de modo que solamente una de cada cuatro personas con discapacidad tiene un 
trabajo remunerado, evidenciándose así la compleja relación entre las personas con discapacidad y el empleo (ODISMET, 2020).

Mientras en la Comunidad Autónoma de Canarias, en 2017, la tasa de actividad de las personas con discapacidad se sitúa en el 30,1\% (43 puntos por debajo de la tasa de actividad de la población canaria sin discapacidad), la tasa de empleo es del 19,5\% (38,2 puntos menos que el conjunto de la población) y la tasa de paro alcanza el 35,2\% (11,8 puntos más que el resto de la población). Cabe añadir que las personas con discapacidad canarias presentan una de las tasas más bajas de participación en el mercado de trabajo y es donde existen mayores dificultades para su acceso al empleo (ODISMET, 2020).

Asimismo, existen evidencias empíricas que muestran que tanto el tipo de discapacidad como de deficiencia, junto con su gravedad, influyen en las probabilidades de ser activos (Cueto, Malo y Rodríguez, 2012; Malo, 2003, 2004). De forma específica, se ha demostrado que, entre todas las discapacidades, las relacionadas con la visión y la audición están asociadas a una mayor probabilidad de trabajar (Cueto, Malo y Rodríguez, 2012; Dávila, 2006; Malo, 2004). En cuanto al sexo, se observa que los hombres con discapacidad tienen más probabilidades de ser activos que las mujeres (Cueto, Malo y Rodríguez, 2012) y que las mujeres con discapacidad suelen tener mayores dificultades en el acceso a un empleo derivadas de la doble discriminación (Dávila, 2006).

En cuanto a la duración de los contratos, una de las consecuencias que ha presentado la crisis económica y el actual marco normativo laboral es el aumento de la temporalidad en el conjunto del mercado de trabajo, que ha crecido desde 2008, realidad y tendencia que también afecta a los contratos realizados por las personas con discapacidad, de forma que, en el 2012, la tasa de temporalidad de los contratos se encontraba en torno al 90\% (SEPE, 2013). Además, cabe señalar que la proporción de contratación indefinida en relación con la temporal es menor entre las personas con discapacidad sensorial y psíquica $(10,8 \%)$ que en el resto de los grupos (11,8\% discapacidad física, $12,3 \%$ sin discapacidad declarada y $13,4 \%$ discapacidad del lenguaje) (SEPE, 2009).

Por su parte, la Fundación ONCE y la Red Mundial de Empresas y Discapacidad de la OIT advierten que el mundo del trabajo se está reconfigurando, ello supone nuevas tendencias y desafíos, relacionados con las tecnologías, las competencias y los cambios cultural, demográfico y climático. Todo esto conlleva modificar la forma de abordaje del empleo de las personas con discapacidad. En ese sentido, se identifican cinco objetivos fundamentales para la inclusión de las personas con discapacidad en el futuro del trabajo:

1. Las nuevas formas de empleo deben incorporar la inclusión de la discapacidad.

2. El desarrollo de competencias y el aprendizaje continuo debe ser inclusivo.

3. Las nuevas infraestructuras, productos y servicios deben seguir los principios de diseño universal (lo cual significa que pueden ser accesibles, comprendidos y utilizados por todos).

4. Las tecnologías de asistencia deben estar disponibles y ser asequibles. 
5. Más medidas para incluir a las personas con discapacidad en las áreas en desarrollo y crecimiento de la economía (Fundación ONCE y ILO Business and Disability Network, 2019: 6).

De lo anterior se puede concluir, que aún queda mucho trabajo por hacer para conseguir que las cotas de participación laboral de las personas con discapacidad sean, al menos, las mismas que para la población sin discapacidad, en tanto que a las dificultades habituales se añadirán las derivadas de los cambios que se están produciendo en el mercado de trabajo.

\section{LA UNIVERSIDAD Y LA INSERCIÓN LABORAL DE LAS PERSONAS CON DISCAPACIDAD}

No cabe duda que el acceso al empleo de las personas con discapacidad va a estar condicionado por la calidad de la formación recibida, por el tiempo de estancia en el sistema educativo, por el entorno social y económico, además de por las circunstancias concretas del mercado laboral en cada momento.

Visto que a mayor nivel de formación alcanzado por las personas con discapacidad mayores probabilidades de acceder a la población activa (Cueto, Malo y Rodríguez, 2012), la necesidad de adaptación de los currículos universitarios a las demandas de la sociedad actual está fundamentada en la búsqueda de una formación universitaria más integral y social, no solo desde el punto de vista de los conocimientos, sino también desde el ámbito personal, humanístico, tecnológico y laboral.

A esto se puede responder dentro del Espacio Europeo de Educación Superior (EEES), que conllevó el diseño de las titulaciones a partir del modelo de competencias que los estudiantes universitarios deben adquirir en su proceso formativo para lograr un título académico. Este modelo educativo provoca que necesariamente se unifiquen los perfiles profesionales de cada titulación conforme a un procedimiento que garantice la transparencia, la homogeneidad y la calidad; ello obliga a las universidades a generar un marco educativo que facilite el aprendizaje a lo largo de toda la vida del alumnado, dotándolo de especialización en función de las demandas sociales, laborales y económicas de cada momento. Asimismo, supone la incorporación de modelos activos de aprendizaje que permitan mantener cierta sincronía entre el mundo universitario y el mundo laboral-profesional.

La incorporación de las universidades españolas al EEES exige desarrollar planes de calidad de sus títulos con el objeto de disponer de datos fiables sobre la adecuación sociolaboral de la formación impartida. En la práctica implica incorporar sistemas de seguimiento para conocer los resultados de la formación, entre otros, los datos de inserción laboral de los graduados y el grado de satisfacción con la formación recibida (ANECA, 2009).

Este nuevo elemento ha producido un cambio en la situación y en los últimos diez años son las universidades las que han ido generando sistemática y periódicamente datos sobre los procesos de inserción laboral, referidos bien al conjunto de las titulaciones de cada universidad o bien a titulaciones específicas. Para ahondar 
en este tema, también se han iniciado estudios sobre egresados y sobre las posibilidades de ajuste entre la oferta de la universidad y las demandas de las empresas; por tanto, se puede hablar de dos líneas de estudios: los que se centran en las necesidades o demandas del mercado de trabajo y los dedicados al análisis del itinerario de transición de la educación universitaria al empleo.

A día de hoy, el sistema universitario español elabora informes anuales sobre todos los aspectos seńalados. Los datos son publicados tanto por las universidades como por la ANECA; además, se difunden a través de encuentros técnicos, publicaciones y congresos. Dicho esto, se asume que el número de estudios es elevado; sin embargo, cabe destacar que en los mismos no se tenga en cuenta, o quizás resulte poco motivador, el análisis de los datos referidos al alumnado con discapacidad que se encuentran en las universidades españolas.

Así, la mayoría de los informes anuales no incluyen apartados específicos destinados al análisis de la situación de las personas con discapacidad, donde se evalúen la formación que se les oferta y los mecanismos de inserción laboral que se facilitan, así como sus resultados, a pesar de que esto debiera ser una prioridad al tratarse de un colectivo con mayores dificultades para la transición al mercado laboral.

\section{ESTUDIOS PREVIOS SOBRE LA SITUACIÓN DE LAS PERSONAS CON DISCAPACIDAD EN LA UNIVERSIDAD Y EN EL MERCADO LABORAL}

En España existen pocos estudios detallados que aporten datos globales sobre los titulados universitarios con discapacidad y su inserción laboral, que además incluyan información específica para las diferentes tipologías de discapacidad, lo que supone un hándicap a la hora de abordar la investigación sobre este tema.

Esta limitación, en parte, queda compensada por los estudios promovidos por algunas entidades relacionadas con la discapacidad y con otros desarrollados en marcos específicos. Se pueden distinguir tres grandes grupos: los promovidos por la Fundación Universia, los realizados desde el Observatorio Estatal de la Discapacidad (OED) y los que se han realizado de manera puntual respondiendo a demandas concretas.

- Estudios realizados por la Fundación Universia, con la colaboración del Comité Español de Representantes de Personas con Discapacidad (CERMI) y otras entidades.

Se trata de una serie de trabajos que analizan la situación de la discapacidad en el sistema universitario español. Se iniciaron en el curso 2011-2012 y se han seguido realizando bianualmente. En estos informes no se trata en profundidad el tema que nos ocupa, pues tan solo se habla de empleo e inserción laboral para el alumnado con discapacidad, cuando se hace referencia a la oferta de los servicios de atención a estudiantes con discapacidad que existen en las universidades participantes en cada uno de ellos. Asimismo, a partir del segundo informe se añade como objetivo analizar 
la evolución de la situación respecto al informe anterior. Se han realizado cuatro informes:

- Estudio sobre el grado de inclusión del sistema universitario español respecto de la realidad de la discapacidad. Universidad y Discapacidad (Fundación Universia y CERMI, 2012), referido a los datos del curso 2011-2012, en el que participaron 48 universidades.

- II Estudio sobre el grado de inclusión del sistema universitario español respecto de la realidad de la discapacidad (Fundación Universia y CERMI, 2014). En esta edición, además de las 59 universidades participaron 426 estudiantes con discapacidad; recoge los datos del curso 2013-2014 y la evolución respecto al anterior.

- III Estudio sobre el grado de inclusión del sistema universitario español respecto de la realidad de la discapacidad (Fundación Universia, 2016). En esta ocasión participaron 55 universidades y 526 estudiantes con discapacidad. Igual que el anterior, analiza la evolución de los indicadores medidos.

- IV Estudio sobre el grado de inclusión del sistema universitario español respecto de la realidad de la discapacidad (Fundación Universia, 2018). En la última edición disponible la participación alcanzó a 72 universidades y 1720 estudiantes con discapacidad.

Del conjunto de estos estudios, tomando los datos que se recogen en el IV Estudio Universidad y Discapacidad (Fundación Universia, 2018), se desprende que el 1,5\% del total de matriculados en las universidades participantes son estudiantes con discapacidad; asimismo, se percibe una variación respecto del primer informe (2012) del 0,4\% mientras la variación respecto del tercer informe (2016) es del -0,2\%. La mayor proporción cursa estudios en las universidades públicas (1,5\% frente a $1,2 \%$ en las privadas) y el $4,1 \%$ opta por la enseñanza no presencial.

En cuanto a las características personales, se puede afirmar que existe equilibrio entre hombres y mujeres ( $51 \%$ y $49 \%$ respectivamente), más de la mitad de las personas tiene una discapacidad física $(55,9 \%)$ y realizan estudios de Ciencias Sociales y Jurídicas (54,5\%), mientras solo 1 de cada 4 personas accedió por el cupo de reserva de plazas para personas con discapacidad que, a su vez, son quienes más adaptaciones curriculares han recibido.

Otro aspecto a destacar es que 6 de cada 10 universidades ofrecen una atención específica y especializada a los universitarios con discapacidad en materia de empleabilidad e inclusión laboral, a través de los servicios de atención a personas con discapacidad (4 de cada 10) o de otros servicios dirigidos al conjunto de estudiantes (2 de cada 10) (Fundación Universia, 2018).

Entre los programas y actuaciones de apoyo a la empleabilidad destacan las de orientación laboral y acompañamiento en la definición de objetivos profesionales; los programas de prácticas en empresas, a través de los que se comunican a los estudiantes las ofertas laborales recibidas, se derivan casos al servicio de empleo de la universidad y se lleva a cabo la coordinación de 
actuaciones. En algún caso, los servicios de atención al alumnado con discapacidad gestionan bolsas de trabajo específicas (Fundación Universia, 2018).

- Estudios realizados por el Observatorio Estatal de la Discapacidad (OED), sobre la situación general de la discapacidad en Espańa, conocidos como Informes Olivenza, coordinados por Agustín Jiménez Lara.

Su objetivo es ofrecer una panorámica general sobre la situación de la población con discapacidad en España a partir del análisis de diversas fuentes secundarias. Contiene una parte dedicada a la inclusión educativa, que recoge algunos datos sobre la población que cursa enseñanzas universitarias, y otro capítulo dedicado al mercado laboral ${ }^{1}$ que ofrece información sobre su vinculación con el empleo y que permite observar algunos de los resultados de los egresados universitarios.

Desde 2010 se publican estudios que proporcionan una actualización exhaustiva de la situación según el conjunto de indicadores seleccionados. En este momento hay siete informes disponibles (Observatorio Estatal de la Discapacidad, 2010; 2014; 2015; 2016; 2017; 2018; 2019)2 .

Tomando como referencia el último informe Olivenza, hay 89400 jóvenes con discapacidad entre los 16 y los 24 años, el 2,2\% sobre el total de jóvenes, de los que solo el 4,8\% han alcanzado estudios superiores, lo que dista de sus homólogos sin discapacidad en 8,3 puntos (13,1\%) (Observatorio Estatal de la Discapacidad, 2019: 436).

Entre las personas con discapacidad ocupadas en 2017, el 29,4\% tiene estudios universitarios (el 58,9\% solo tiene estudios de secundaria) (Observatorio Estatal de la Discapacidad, 2019: 356).

Según este estudio, el perfil de los universitarios con discapacidad son mujeres $(18,3 \%)$ de entre 25 y 44 años $(18,6 \%)$ que viven en áreas densamente pobladas $(20,0 \%)$ con discapacidad visual $(23,4 \%)$ y con un porcentaje de discapacidad legal reconocida entre el $33 \%$ y el $44 \%$ (21,9\%) (Observatorio Estatal de la Discapacidad, 2019: 394).

- El tercer grupo está integrado por estudios independientes que tienen distintos objetivos y metodologías, por lo que seguidamente se resumen.

- Informe sobre el desarrollo profesional de egresados y estudiantes con discapacidad en la Universidad Española a Distancia (UNED) (Rodríguez de Rivera, 2010), realizado en colaboración con la Fundación Mapfre. El propósito de este estudio fue analizar la situación de los

${ }^{1}$ Es una parte del informe que anualmente realiza el Observatorio de Discapacidad y Mercado de Trabajo (ODISMET).

${ }^{2}$ La mayoría se pueden encontrar en la página web del OED: https://www.observatoriodeladiscapacidad.info/category/documentos/observatorio/informe-olivenza-observatorio/. 
titulados y estudiantes con discapacidad en la UNED, de cara a la optimización de la gestión de la bolsa de empleo existente.

Sus resultados indican que más del $80 \%$ de la población de estudiantes y egresados con discapacidad tienen entre 40 y 50 años, predomina la discapacidad física, con un grado de discapacidad entre el 33 y el $45 \%$, aunque existe un tercio de egresados que poseen una discapacidad severa (mayor del 65\%). Los participantes estiman insuficientes los mecanismos de información existentes en la institución para facilitar la adecuada inclusión educativa y laboral. Existe un bajo índice de egresados buscando empleo, la mayoría se encontraban trabajando en la Administración pública. Respecto al ajuste del puesto de trabajo con la titulación cursada, algo más del $30 \%$ considera que es adecuado, mientras que más del $40 \%$ habla de un claro desajuste.

- Integración laboral de los universitarios españoles con discapacidad. Detección de las fortalezas y debilidades en el momento del acceso al mercado laboral español. Percepción de los universitarios y percepción de las empresas (Dalmau-Montalá et al., 2010), financiado por la Fundación Universia y elaborado desde la Universitat Ramón Llull. El objetivo de este estudio fue explorar los puntos fuertes y los puntos débiles detectados por los titulados universitarios españoles con discapacidad en su proceso de inserción en el mercado laboral ordinario, así como la experiencia y la opinión de las empresas sobre este tema. Una síntesis de este trabajo fue publicada con el título Formación universitaria e inserción laboral. Titulados españoles con discapacidad y competencias profesionalizadoras (Dalmau-Montalá et al., 2013). Se trata de un estudio de ámbito nacional en el que participaron 687 titulados universitarios con discapacidad y 77 estudiantes con discapacidad, 19 servicios de apoyo y 16 empresas. Sus resultados apuntan que los titulados universitarios con discapacidad, generalmente, no reciben en la universidad los apoyos adecuados para poder desarrollar, suficientemente, las competencias profesionales; las prácticas profesionalizadoras son una oportunidad para la inserción laboral de los titulados con discapacidad; la discapacidad prevalece por encima de la calidad del curriculum vitae en el momento del acceso al mercado laboral ordinario (Dalmau-Montalá et al., 2013).

- Estudio sectorial por comunidades autónomas de la accesibilidad del entorno universitario y su percepción (Guasch, 2010). Es un trabajo muy extenso cuyo objetivo principal es valorar la accesibilidad, en sentido amplio, de las universidades españolas. Incluye un capítulo sobre la percepción de los universitarios con discapacidad, y, entre otras muchas cuestiones, se les pregunta por la inserción laboral. Entre sus resultados cabe destacar que el $75 \%$ de las universidades participantes ofrecen servicios de inserción laboral específicos (Guasch, 2010: 131), pero solo el 7,5\% de los entrevistados han hecho uso de los servicios de apoyo a la inserción laboral que ofre- 
cen los servicios de apoyo a la discapacidad de las universidades (Guasch, 2010: 129), ya que, en general, el alumnado con discapacidad piensa que su integración laboral será más o menos normal (Guasch, 2010: 145).

- La integración laboral de universitarios con discapacidad (Fundación Adecco, Fundación Bancaja y Universitat de València, 2012). Se trata de un diagnóstico sobre la inserción laboral y la situación en la que se encontraban los universitarios con discapacidad titulados entre 2007 y 2011 en la Universidad de Valencia. Su objetivo fue el análisis y conocimiento de las herramientas, recursos y dificultades que encuentra este grupo de estudiantes en su inserción laboral. Los resultados principales indican que el perfil general se corresponde con un hombre de entre 22 y 36 años, con discapacidad física, que estudia una carrera de Ciencias Sociales (Magisterio [13\%], Psicología [10,6\%], Filología [8,4\%], Enfermería [6,5\%] y Derecho $[6,5 \%])$. En cuanto a la inserción laboral, un $62 \%$ de los titulados con discapacidad se encontraba trabajando (en 2012) y un $14,7 \%$ no había tenido nunca empleo. De los que lograron un empleo lo hicieron en educación y formación $(26,1 \%)$ y en sanidad y salud (20,7\%); así, si se tiene en cuenta que las dos carreras más estudiadas son Magisterio y Psicología, se podría concluir que la mayoría trabaja en un empleo relacionado con lo que ha estudiado.

- Discapacidad, Estudios Superiores y Mercado de trabajo. Barreras de acceso y repercusión en la inserción laboral (Red2Red Consultores, 2013)3. El objetivo de este estudio fue realizar un diagnóstico de la participación y acceso de las personas con discapacidad al sistema de enseñanzas superiores de régimen general (incluye la formación profesional de segundo ciclo), de los factores que generan desigualdad y discriminación en el acceso y continuidad en la realización de estos estudios y de las posibilidades de su posterior inclusión en el mercado laboral.

En términos generales, sus resultados apuntan una evolución positiva en el acceso a los estudios superiores por parte de las personas con discapacidad, si bien todavía persisten barreras y dificultades que estas tienen que superar tanto para acceder como para culminar estos estudios. Asimismo, se pone de manifiesto que las personas con discapacidad con estudios superiores aún siguen sin acceder en igualdad de condiciones, con el conjunto de la población activa, al mercado laboral, aunque sus posibilidades de inserción son mayores

\footnotetext{
3 Elaborado en el marco del Programa Operativo de Lucha contra la Discriminación 20072013 y cofinanciado por el Fondo Social Europeo.
} 
que las de aquellas que no tienen estudios superiores (Red2Red Consultores, 2013: 103-105).

Todos los trabajos comentados han facilitado información sobre la realidad de la discapacidad en las universidades que han permitido ir desarrollando acciones que promuevan la mejora de los niveles de inserción laboral del alumnado universitario con discapacidad en nuestro país. Para ello se han articulado medidas y servicios de orientación y apoyo a la inserción laboral, como la creación de bases de datos o de bolsas de empleo específicas, donde los empresarios tengan fácil acceso a los titulados universitarios. A estos se añaden las acciones de sensibilización social que allanan el terreno para derribar estereotipos que dificultan la inserción laboral.

Actualmente, la universidad, a pesar de los avatares en los que se ha visto inmersa, sigue siendo una institución con un claro papel social para contribuir a mejorar la calidad de vida de las personas con discapacidad a través de su inclusión en la formación superior. Los resultados que muestran los estudios revisados apuntan la necesidad de seguir trabajando desde las universidades para mejorar el acceso a los estudios superiores de las personas con discapacidad, fortalecer los servicios de apoyo durante los mismos y seguir perfeccionando los programas de apoyo a la transición universidad-empleo (ordinario y adecuado al nivel de estudios logrado) de quienes egresan y tienen una discapacidad.

Tal y como se avanzó al inicio, teniendo en cuenta que la formación universitaria puede contribuir a mejorar la posición de las personas con discapacidad en el mercado de trabajo y que los estudios detallados sobre la transición al empleo de personas universitarias con discapacidad son muy escasos, se estima pertinente realizar este estudio, que tiene como objetivo describir y analizar la situación en el mercado de trabajo de las personas con discapacidad que han egresado en la ULPGC entre 2000 y 2010, observando en primer lugar la situación laboral y en segundo lugar la calidad del empleo logrado.

\section{METODOLOGÍA}

Para describir la situación laboral de los egresados universitarios con discapacidad, se toman como referencia los indicadores habituales: empleo y paro registrado. Para estimar la calidad del empleo, se ha optado por la combinación de dos factores: la estabilidad en el empleo tomando como indicador de referencia la duración del contrato suscrito (Malo y Muñoz-Bullón, 2006) y el ajuste entre los estudios realizados y el puesto de trabajo ocupado o «empleo encajado", que se puede asimilar con el «emparejamiento ocupacional» (occupational matching) (Blázquez y Herrarte, 2011), si bien en este enfoque se toma como referencia la ocupación que figura en la demanda de empleo de cada persona. Ambas dimensiones se han analizado mediante la observación de las trayectorias laborales de los egresados con un seguimiento a largo plazo (tres, cinco o diez años desde el inicio de la búsqueda de empleo) (Aguilar, 2005), para lo que ha sido necesario llevar a cabo análisis indi- 
viduales que permitan el emparejamiento entre las características personales y la situación laboral a lo largo del tiempo.

Cabe añadir que entre los antecedentes disponibles no se han encontrado estudios que se basen en el análisis de las trayectorias laborales individuales y utilicen el empleo encajado como forma de estimación de la calidad del empleo logrado por los egresados universitarios con discapacidad.

Para el desarrollo de esta investigación se han utilizado dos fuentes de información primarias: la base de datos de registros académicos de la ULPGC ${ }^{4}$ y la base de datos Observatorio Canario del Empleo y la Formación Profesional (OBECAN) del Gobierno de Canarias ${ }^{5}$, accesibles al amparo del Protocolo de Intercambio de Datos Administrativos suscrito entre ambas instituciones.

Por consiguiente, para lograr el objetivo propuesto, se construyeron las trayectorias laborales emparejando los registros individuales de ambas bases de datos. Esto permite observar la adaptación al mercado laboral del alumnado de la ULPGC con algún tipo de discapacidad mediante el análisis de la situación laboral y de la calidad del empleo obtenido.

El análisis de la situación laboral se estima mediante la inserción laboral y la situación de desempleo. La primera se entiende que se ha producido cuando, dentro de un periodo determinado, el/la egresado/a ha obtenido un empleo por cuenta ajena y la segunda se observa a partir del paro registrado, entendido como el número de egresados que se encuentran registrados como demandantes de empleo en un momento dado.

La calidad del empleo busca conocer el ajuste entre las condiciones laborales reales y la formación universitaria recibida. Para ello se analiza el tipo de contrato según su duración (tiempo indefinido o duración determinada) y la ocupación reseñada en el mismo. Específicamente se trata de observar si el empleo logrado se puede considerar «empleo encajado», que se produce si la ocupación registrada en el contrato está dentro de las tres primeras categorías de la Clasificación Nacional de Ocupaciones (CNO).

En cuanto a la información sobre los estudios realizados, se ha seguido la clasificación utilizada por el observatorio de empleo de la ULPGC, que utiliza seis Grupos de Estudio: Enseñanzas Técnicas; Humanidades; Ciencias de la Salud; Empresariales, Económicas y Turismo; Ciencias Jurídicas; y, Educación y Deportes.

${ }^{4}$ Base de datos de registros académicos. Es la principal fuente de información, ya que ha permitido identificar al alumnado del curso académico 2010/11 que tenían algún tipo de discapacidad. Las principales variables utilizadas de este fichero son DNI, nacionalidad, tipo de discapacidad, año académico de matrícula, año académico de salida, código de estudio, tipo de ingreso a la universidad, municipio de procedencia, estudios de los padres, ocupación de los padres, grado de discapacidad reconocida.

5 Base de datos del Observatorio Canario del Empleo y la Formación Profesional (OBECAN), del Gobierno de Canarias. A través de esta base de datos se analiza y ofrece información sobre la evolución de las profesiones y del mercado de trabajo en la Comunidad Autónoma de Canarias. Para ello, toma los datos estadísticos elaborados por el Instituto Canario de Estadística y el Servicio Canario de Empleo. 


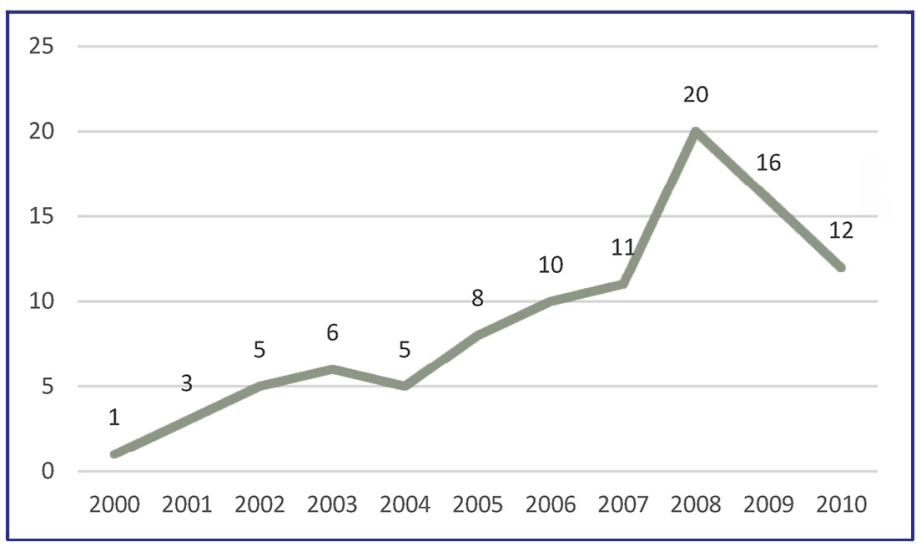

Fuente: elaboración propia a partir de los registros de la ULPGC.

Gráfico 1. Evolución del número de egresados con discapacidad por año.

Por tanto, las variables utilizadas han sido inserción laboral, paro registrado, tipo de contrato (duración) y ocupación (empleo encajado). Los datos de cada una de ellas se han agrupado por sexo, tipo de discapacidad y grupo de estudio.

Una vez seleccionados los datos ${ }^{6}$ correspondientes a las variables descritas, mediante el campo documento nacional de identidad (DNI) se procedió a emparejar los registros de ambas bases de datos (registros académicos y OBECAN). Esta combinación permite obtener las trayectorias laborales por cuenta ajena de los egresados de la ULPGC desde la finalización de sus estudios. Así, se puede conocer la evolución temporal (6 meses, 1, 2, 3 y 5 años desde el egreso) de la inserción laboral (empleo y paro registrado) y la calidad del empleo (tipo de contrato y ocupación-empleo encajado).

La muestra del estudio la componen las trayectorias laborales de 96 personas con discapacidad matriculadas en la ULPGC, cuyo egreso tuvo lugar entre el 2000 y el 2010, que suponen el 30,5\% del total de personas que aportaron el certificado de discapacidad en el momento de formalizar su ingreso en la universidad ${ }^{7}$.

Del total 49 eran mujeres $(50,3 \%)$ y 47 hombres $(49,7 \%)$; 9 con discapacidad auditiva $(9,2 \%), 68$ con discapacidad física $(71,4 \%), 3$ con discapacidad psíquica o intelectual $(3,1 \%)$ y 13 con discapacidad visual $(14,3 \%)$.

${ }^{6}$ Las bases de datos se trataron de acuerdo al compromiso de confidencialidad suscrito y las referencias a información personal fueron debidamente anonimizadas.

7 El total de personas con discapacidad matriculadas en la ULPGC, hasta el curso 20092010, que aportaron certificado de discapacidad fue de 314. En relación con el número medio de matriculados de la ULPCG para un curso académico, en torno a 20000 , esta población supone una proporción muy pequeña $(0,16 \%)$. 


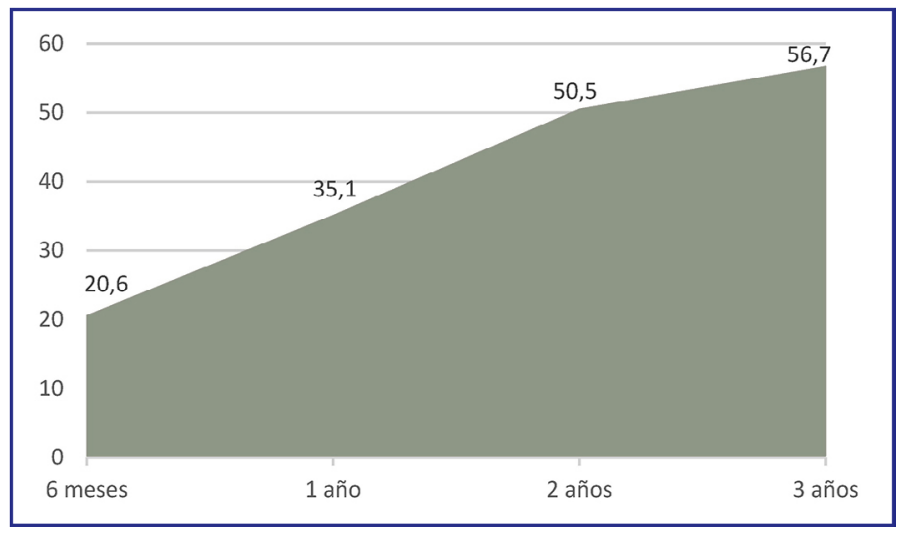

Fuente: elaboración propia.

Gráfico 2. Distribución temporal de la inserción laboral del alumnado con discapacidad egresado.

En cuanto a la distribución por grupos de estudio, 8 cursaron Humanidades (8,2\%), 56 Ciencias Sociales y Jurídicas (58,2\%), 15 Enseñanzas Técnicas (15,3\%) y 17 Ciencias de Salud (18,4\%). La media de permanencia en la universidad fue de 6,3 años (mujeres 5,7 y hombres 6,9). El 80\% egresaron a partir del 2005 (gráfico 1).

\section{RESULTADOS}

A continuación, se presentan los resultados para inserción laboral, paro registrado, tipo de contrato (duración) y empleo encajado (correspondencia entre ocupación del contrato y estudios finalizados). Primero se encuentran los datos globales y luego desagregados por discapacidad, sexo y grupo de estudio.

\section{INSERCIÓN LABORAL DE LOS EGRESADOS CON DISCAPACIDAD DE LA ULPGC}

El 20,5\% de los 96 egresados con discapacidad han obtenido un empleo a los seis meses, dentro de este grupo un $66,7 \%$ corresponde a las personas que tienen discapacidad psíquica o intelectual, seguido del $35,7 \%$ para el grupo con discapacidad visual, mientras que quienes presentan discapacidad auditiva apenas alcanzan el $11,1 \%$. De ahí que la diferencia entre el colectivo con mayor inserción y menor inserción sea de 55,5 puntos porcentuales (gráficos 2 y 3).

Según se puede observar en el gráfico 2 , el porcentaje de alumnos egresados con discapacidad que logran un empleo aumenta hasta el $56,7 \%$ a los tres años de haber egresado, si bien en ese momento el grupo con menor cota de contratación laboral corresponde a la discapacidad física, con un 50,7\%.

Por tanto, podemos decir que el nivel de inserción laboral global de este colectivo evoluciona positivamente a lo largo de los ańos, pues se pasa del 20,5\% 


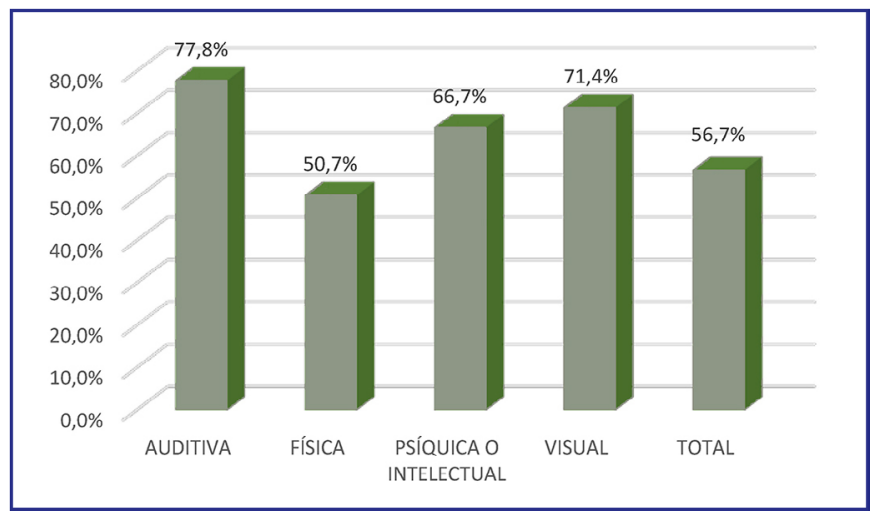

Fuente: elaboración propia.

Gráfico 3. Distribución de la inserción laboral según tipo de discapacidad a los 3 años.

a los seis meses hasta llegar al 56,7\% a los tres años, observándose un incremento significativo (15 puntos porcentuales) entre los dos primeros periodos.

Por tipos de discapacidad, se observa que el mayor índice de inserción $(77,8 \%)$ corresponde a las personas con discapacidad auditiva, seguidas de quienes tienen discapacidad visual $(71,4 \%)$. Mientras el grupo con menor cota de contratación es el grupo con discapacidad física (50,7\%) (gráfico 3).

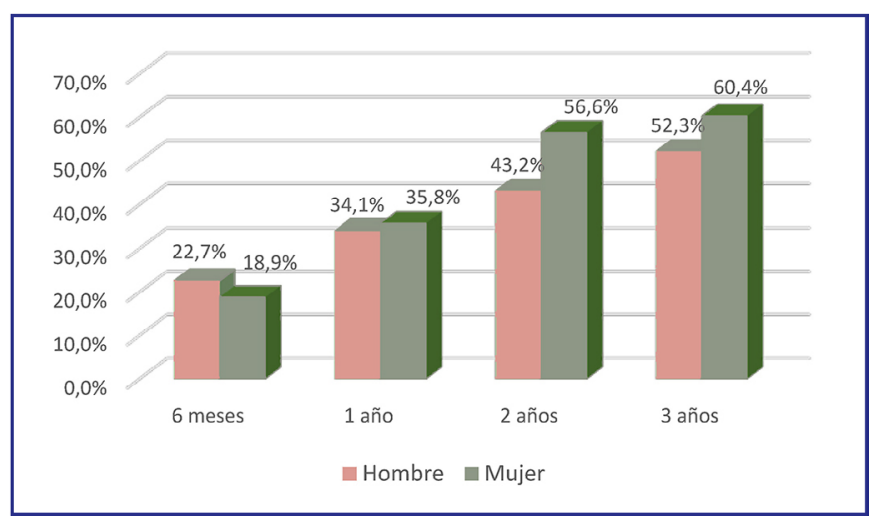

Fuente: elaboración propia.

Gráfico 4. Distribución de la inserción laboral del alumnado con discapacidad egresado según sexo.

En general, las mujeres presentan porcentajes de empleo sutilmente mayores que los de los hombres (gráfico 4), excepto en los empleos logrados en los primeros seis meses, donde se observa una diferencia de 3,8 puntos a favor de los hombres. 


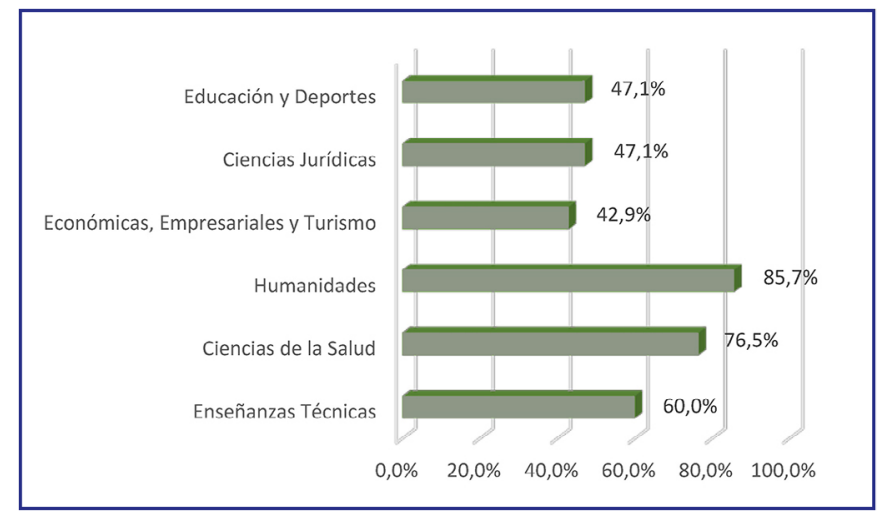

Fuente: elaboración propia.

Gráfico 5. Distribución de la inserción laboral del alumnado con discapacidad egresado según grupo de estudios a los 3 años.

Asimismo, cabe destacar que la mayor diferencia entre sexos se da en el segundo año, en el que las mujeres superan a los hombres en 13,4 puntos porcentuales.

En cuanto a los empleos logrados por grupos de estudios al tercer año de haber finalizado la formación universitaria, encontramos que la práctica totalidad $(85,7 \%)$ corresponde con quienes han cursado Humanidades, seguido por la formación en Ciencias de la Salud (76,5\%) y en Enseñanzas Técnicas (60\%). Mientras el alumnado con estudios de Económicas es el que presenta un menor nivel de inserción laboral (42,9\%) (gráfico 5).

En cuanto a la evolución temporal registrada por grupos de estudio, se observa un estancamiento del alumnado con estudios de Económicas y en Ciencias de la Salud, que presentan el mismo nivel en el segundo y el tercer año $(42,9 \%$ y $76,5 \%$ respectivamente). Por el contrario, el mayor incremento de incorporación al mercado laboral, entre el segundo y el tercer ańo, corresponde al grupo de Humanidades, cuya variación es de 14,3 puntos porcentuales.

Si se observa la evolución desde los seis meses a los tres ańos, los egresados que han cursado Enseñanzas Técnicas son el grupo con una mayor progresión en la inserción laboral, pues hay una diferencia de 46,7 puntos porcentuales entre ambos periodos.

\section{Paro Registrado de los egresados Con discapacidad de la ULPGC}

Como se indicó antes, como parte del análisis de la situación laboral se observa el paro registrado, que coincide con las personas que están inscritas como demandantes de empleo en el Servicio Canario de Empleo en los momentos observados durante el periodo de referencia.

Como se puede observar en el gráfico 6, el paro registrado en el alumnado con discapacidad egresado oscila entre el $22,3 \%$ a los seis meses y el $15,6 \%$ 


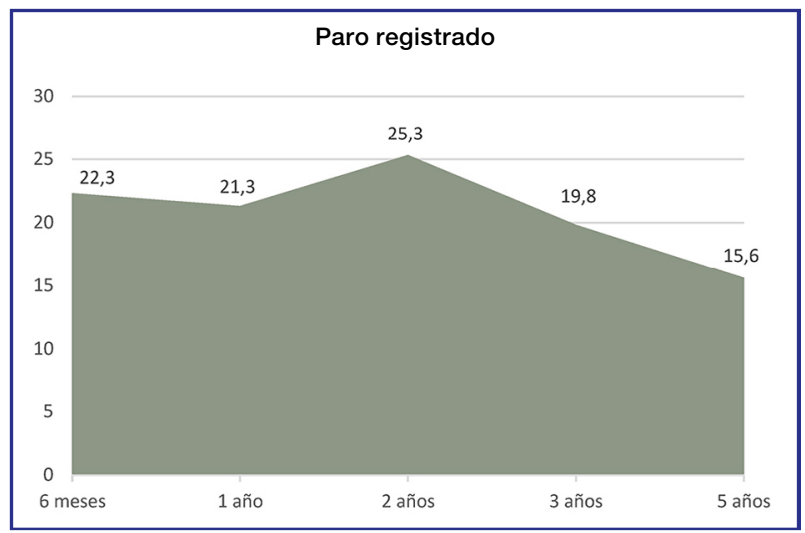

Fuente: elaboración propia.

Gráfico 6. Evolución temporal del paro registrado del alumnado con discapacidad egresado.

a los 5 años. Cabe señalar que es al segundo año del egreso cuando se registra el valor máximo $(25,3 \%)$, mientras al quinto ańo este se ha reducido en diez puntos porcentuales.

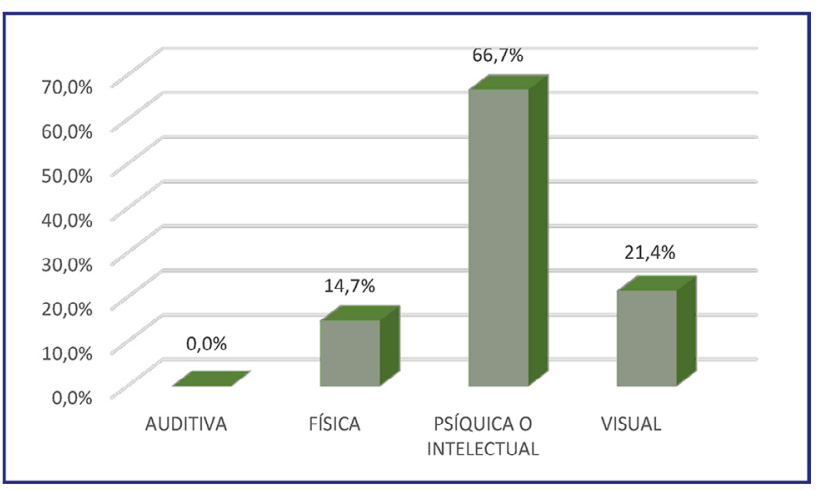

Fuente: elaboración propia.

Gráfico 7. Distribución del paro registrado del alumnado egresado según tipo de discapacidad a los 5 ańos.

Por tipo de discapacidad, encontramos que las personas con discapacidad auditiva pasan del 33,3\% de paro registrado a los seis meses al 37,5\% en el primer año para desaparecer al quinto año de haber terminado sus estudios. En el extremo opuesto se encuentran las personas con discapacidad intelectual, cuyo paro registrado al quinto ańo alcanza el $66,7 \%$, aunque a los seis meses no había ninguna persona registrada como demandante de empleo con este tipo de discapacidad (gráfico 7). 
Por tanto, entre las personas con discapacidad intelectual o psíquica es donde se observa el mayor incremento de paro registrado entre los seis meses y el año, que se incrementa en 50 puntos porcentuales, mientras para la visual aumenta 10 puntos y para la auditiva tan solo sube 4 puntos. Cabe añadir que el grupo personas con discapacidad física es el único que presenta un retroceso en el porcentaje de paro registrado, que se reduce en 5 puntos en ese periodo.

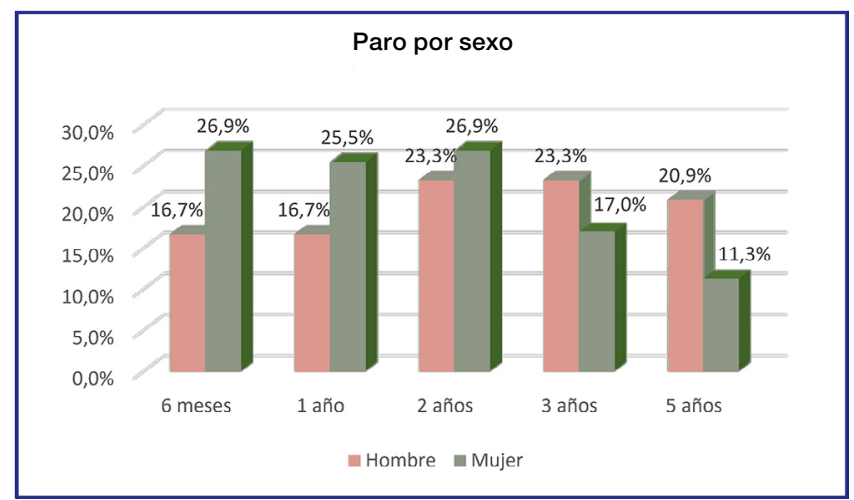

Fuente: elaboración propia.

Gráfico 8. Evolución temporal del paro registrado del alumnado egresado según sexo.

En el gráfico 8, se observa que el paro registrado entre las mujeres es mayor que entre los hombres hasta el segundo año, invirtiéndose a partir del tercer año, donde los hombres tienen porcentajes mayores de paro. Cabe destacar que mientras el paro femenino se reduce en torno a 15 puntos porcentuales al quinto ańo, el masculino aumenta solo 4 puntos.

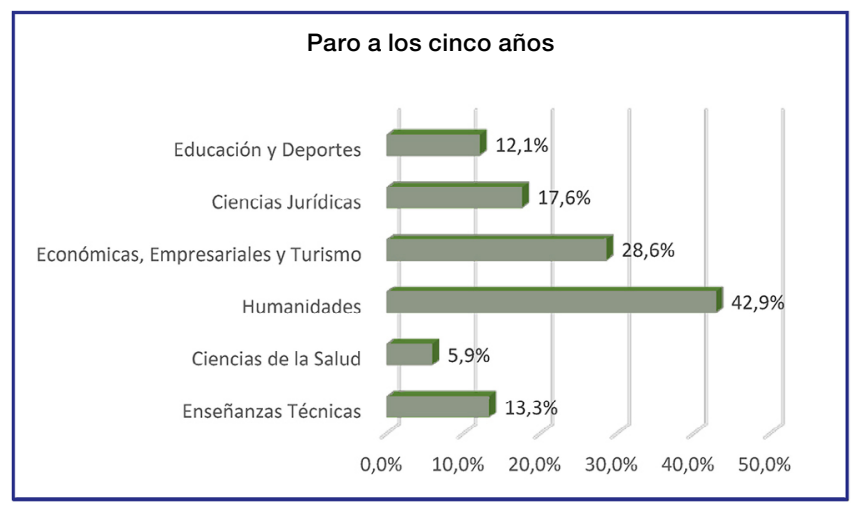

Fuente: elaboración propia.

Gráfico 9. Evolución del paro registrado del alumnado egresado según grupo de estudios a los 5 años. 
Como se puede observar en el gráfico 9, el mayor porcentaje de paro registrado al quinto año de haber finalizado los estudios corresponde a los estudios de Humanidades (40\%), seguido de los estudios de Económicas y Empresariales (28\%). Mientras el menor índice de paro corresponde al grupo de Ciencias de la Salud (7\%).

Respecto a la evolución en el tiempo, es igualmente en los estudios de Humanidades en los que se observa un mayor incremento del paro, 14 puntos en relación con los periodos anteriores; le sigue el grupo de Económicas y Empresariales, que duplica su tasa de paro. El resto de los grupos desarrollan una tendencia a la baja, mientras el de Ciencias Jurídicas permanece estable en todo el periodo.

\section{Tipo DE CONTRATO DE LOS EGRESADOS CON DISCAPACIDAD DE LA ULPGC}

El tipo de contrato que prevalece durante todo el periodo analizado es el de duración determinada, que se encuentra por encima del 75,5\% de los casos, frente al contrato indefinido, que se encuentra por debajo del $20 \%$.

En el gráfico 10 se puede observar que mientras los contratos temporales se reducen 15 puntos porcentuales entre su máximo nivel a los seis meses $(95,0 \%)$ y el más bajo en el segundo año $(75,5 \%)$, los contratos indefinidos se incrementan en la misma medida (pasan del 5\% a 24,5\%). Al tercer ańo del egreso sigue siendo mucho mayor la proporción de contratos temporales (80\%) que la de indefinidos (20\%), lo que parece reflejar la alta temporalidad del mercado de trabajo español.

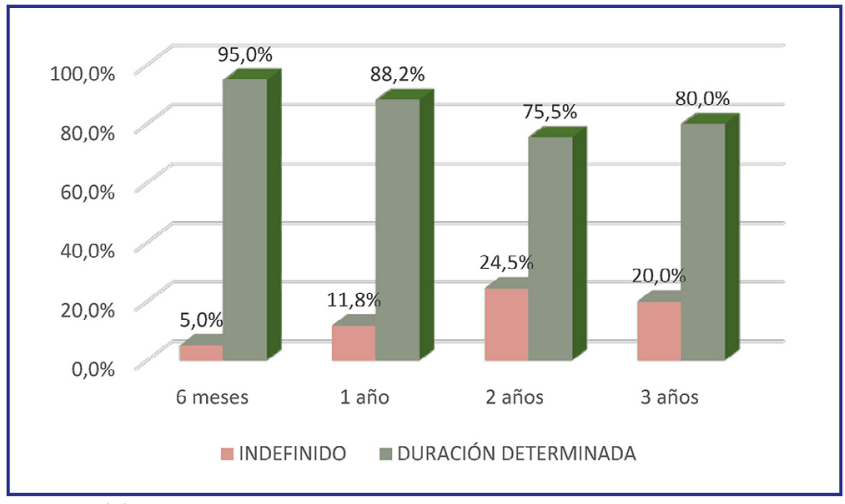

Fuente: elaboración propia.

Gráfico 10. Evolución por duración del contrato suscrito por los egresados con discapacidad.

Respecto al tipo de discapacidad, en el caso de la psíquica o intelectual la contratación temporal alcanza el 100\% de los casos y se mantiene constante durante todo el periodo analizado, siendo este grupo el que presenta el mayor nivel de temporalidad en el empleo y, por lo tanto, la mayor inestabilidad laboral, en comparación 


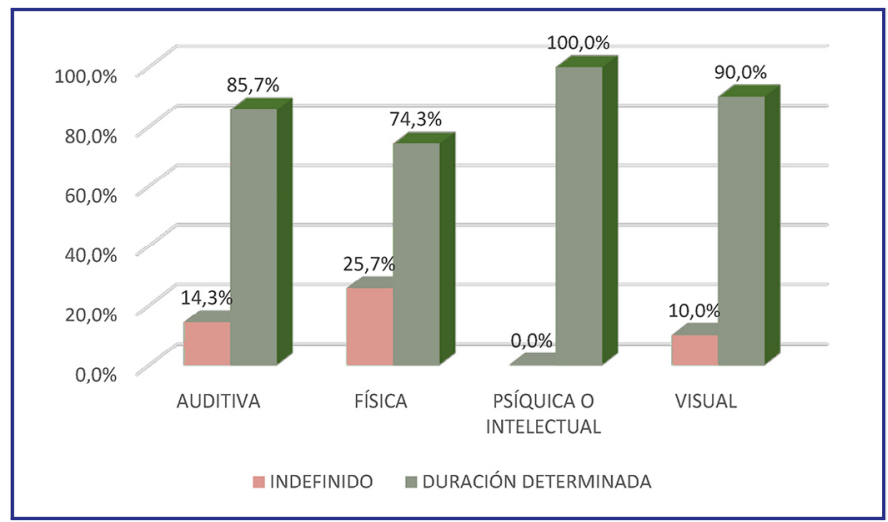

Fuente: elaboración propia.

Gráfico 11. Distribución de la duración del contrato suscrito según tipo de discapacidad al tercer año.

con el resto de tipos de discapacidad (gráfico 11). Cabe mencionar que, en el caso de las personas con discapacidad física, al menos 1 de cada 4 contratos es indefinido.

En relación con la contratación por sexos, los contratos temporales son mayores entre las mujeres, mientras que la contratación indefinida es mayor en los hombres, en todos los momentos del análisis (gráfico 12).

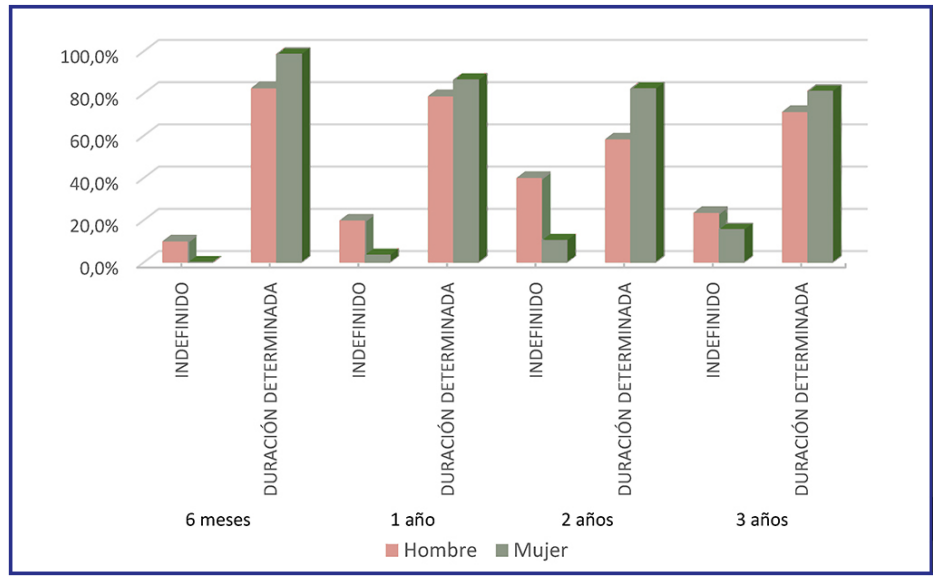

Fuente: elaboración propia.

Gráfico 12. Evolución temporal de la duración del contrato según sexo de los egresados con discapacidad.

El análisis por grupos de estudios igualmente refleja la temporalidad del mercado de trabajo español. En este caso, los contratos indefinidos presentan la 


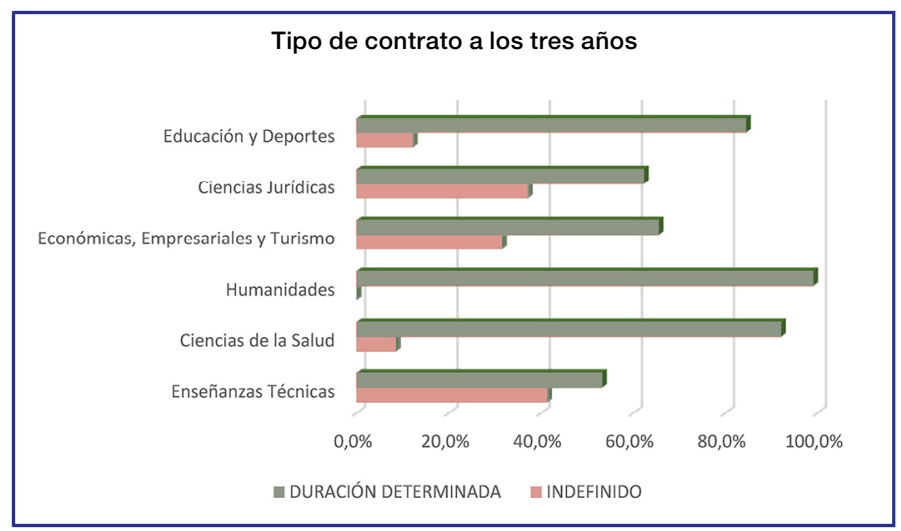

Fuente: elaboración propia.

Gráfico 13. Distribución de la duración del contrato suscrito según grupo de estudios a los 3 años.

mayor proporción entre los egresados de las Enseñanzas Técnicas, al contrario que en Humanidades, donde no existe ninguna contratación indefinida (gráfico 13).

EMPleo enCAJAdo de los Egresados CON DisCAPACIDAD dE LA ULPGC

Como se puede observar en el gráfico 14, el empleo encajado se mantiene estable durante prácticamente todo el tiempo analizado. Alcanza su mayor cota $(55,9 \%)$ el primer año y la menor al tercer año $(50,9 \%)$.

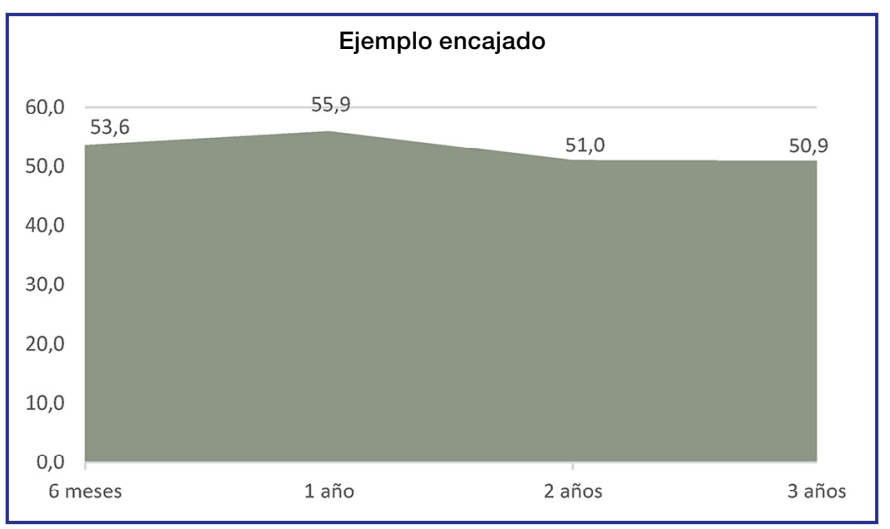

Fuente: elaboración propia.

Gráfico 14. Distribución temporal del empleo encajado del alumnado con discapacidad egresado. 
En conjunto el mayor porcentaje de empleo encajado al tercer año lo registra el grupo de personas con discapacidad visual $(70 \%)$ y el menor se observa en el de discapacidad física (45,7\%) (gráfico 15).

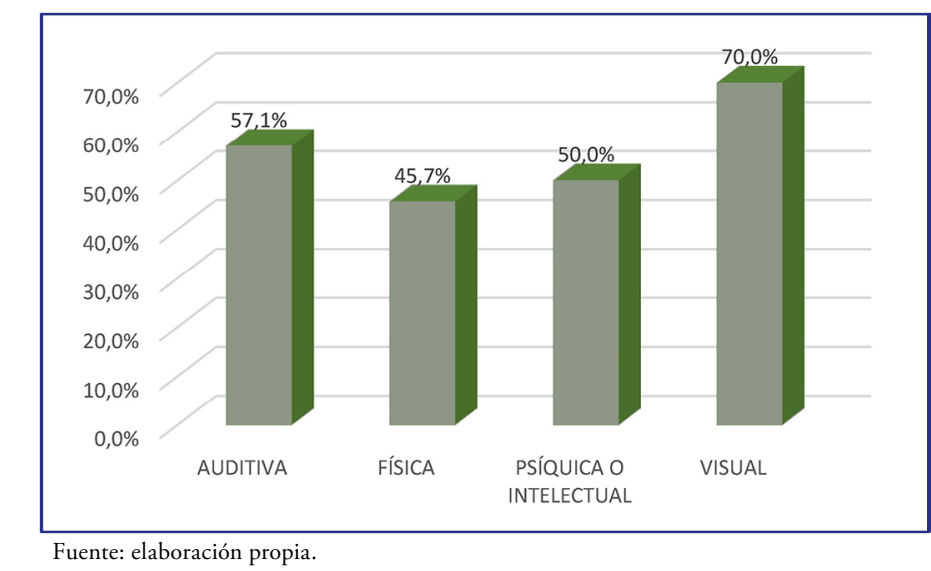

Gráfico 15. Distribución del empleo encajado del alumnado con discapacidad egresado según el tipo de discapacidad a los 3 años.

El análisis de la evolución temporal del empleo encajado por tipos de discapacidad muestra que a los seis meses es la discapacidad visual la que presenta el mayor porcentaje, un $80,0 \%$, mientras que el resto de las discapacidades se sitúan en torno al 50,0\%. Al cabo de un ańo, se produce un crecimiento principalmente entre las personas con discapacidad visual, situándose en el 85,7\%, seguidas de la discapacidad auditiva, cuyo empleo encajado alcanza el 66,7\%.

$\mathrm{Al}$ segundo año de inserción laboral se produce un estancamiento de la discapacidad intelectual en el 50\% y una caída generalizada del empleo encajado en todos los tipos de discapacidad. En el tercer año, nos encontramos con que la discapacidad intelectual y la auditiva sigue en los mismos parámetros del 50\% y el 57,1\% de empleo encajado, mientras que, en la discapacidad visual se observa una caída de 5 puntos. Por su parte, la discapacidad física es la única que experimenta un ligero aumento, 0,5 puntos, con respecto al ańo anterior.

Por sexos, se observan porcentajes mayores de empleo encajado entre los hombres, si bien esta proporción desciende en 23 puntos porcentuales a lo largo del tiempo. Por el contrario, entre las mujeres se observa la tendencia contraria, pues aumenta en 13 puntos el empleo encajado entre los seis primeros meses y el tercer año (gráfico 16). En conjunto, se observa que las diferencias por sexos en el empleo encajado tienden a desaparecer a lo largo del tiempo.

Para terminar, se muestran los resultados de empleo encajado por grupos de estudio, que, según se puede observar en el gráfico 17, a los tres años de la contra- 


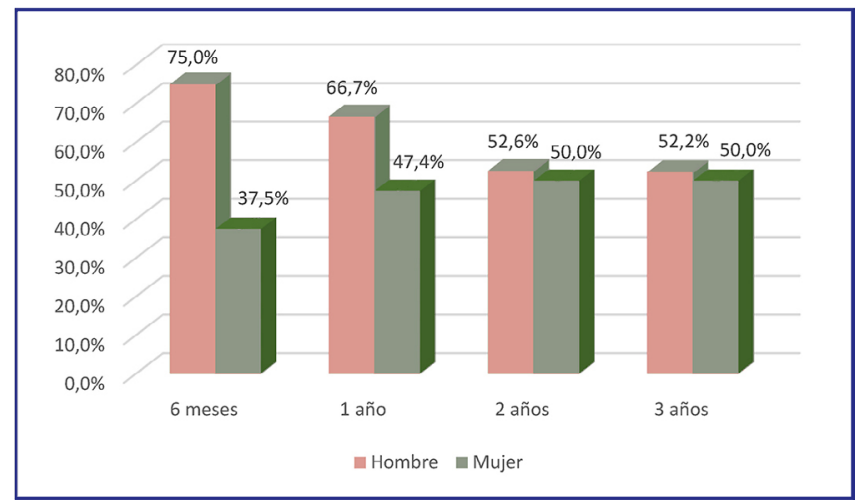

Fuente: elaboración propia.

Gráfico 16. Distribución temporal del empleo encajado del alumnado con discapacidad egresado según sexo.

tación, es el grupo de estudios de Ciencias de la Salud el que muestra el mayor porcentaje $(76,9 \%)$, mientras las Enseñanzas Técnicas apenas alcanzan una cuarta parte de los egresados $(22,2 \%)$.

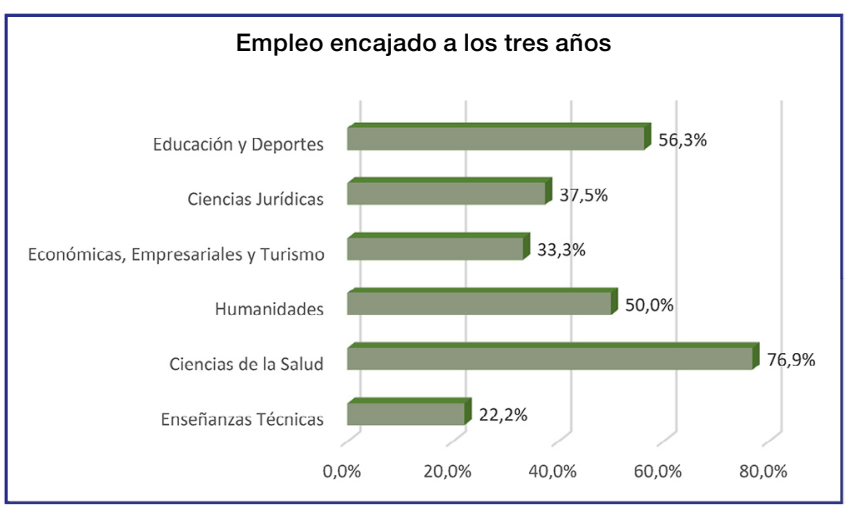

Fuente: elaboración propia.

Gráfico 17. Distribución de empleo encajado del alumnado con discapacidad egresado según grupo de estudios a los 3 años.

\section{DISCUSIÓN Y CONCLUSIONES}

Con este estudio nos propusimos describir y analizar la situación de las personas con discapacidad que han egresado en la ULPGC entre 2000 y 2010. Para analizar la evolución de la situación laboral de los participantes y la calidad del empleo logrado, fue necesario construir una base de datos específica con las trayec- 
torias laborales individuales, lo que fue posible mediante el emparejamiento de los registros académicos de la ULPGC y los datos laborales del OBECAN.

En cuanto a la situación laboral de los egresados, queremos resaltar que la inserción laboral lograda por los egresados de la ULPGC se sitúa en niveles superiores al $20 \%$ a los 6 meses y al $57 \%$ al cabo de tres años, cifra cercana al $62 \%$ de empleados señalado en el estudio de los egresados de la Universidad de Valencia (Fundación Adecco, Fundación Bancaja y Universitat de València, 2012), siendo la discapacidad intelectual la que presenta mayores niveles de colocación a los seis meses y la auditiva a los tres años, lo que coincide con lo apuntado por Cueto, Malo y Rodríguez (2012), Dávila (2006) y Malo (2004).

Respecto al sexo, la inserción femenina es sutilmente mayor que la masculina en todo el periodo, mostrando una diferencia de más de 13 puntos en el segundo ańo, lo que sugiere que la doble discriminación señalada por Dávila (2006) puede no estar afectando a este grupo. En lo relativo al logro de un empleo según los grupos de estudios, los egresados en Humanidades son los que muestran mayores cotas de empleo al tercer año.

En contrapartida se observa que el paro registrado decrece con el tiempo (del $22,3 \%$ al 15,6\%). Las personas con discapacidad auditiva son el grupo con menor paro registrado al quinto año, mientras las mujeres superan a los hombres, lo que coincide con las probabilidades apuntadas por Cueto, Malo y Rodríguez (2012), y quienes cursaron estudios de humanidades suponen el mayor porcentaje de desempleo al quinto ańo desde el egreso de la universidad.

En relación con la calidad del empleo logrado, observando la duración de los contratos, prevalecen los temporales sobre los indefinidos durante todo el periodo analizado, si bien la proporción es algo menor de la que existía en años anteriores en el conjunto del mercado de trabajo español (SEPE, 2013), lo que puede ser un indicador de la relativa mejoría del empleo que se ha producido al finalizar la última crisis económica. Por tipo de discapacidad, la psíquica o intelectual es la que presenta una tasa mayor de temporalidad, tal y como se ha venido observando históricamente (SEPE, 2009); igualmente, la temporalidad afecta más a las mujeres que a los hombres, lo que de algún modo reproduce las condiciones generales del mercado de trabajo y podría estar reflejando cierta forma de discriminación (Dávila, 2006).

En el segundo indicador analizado para valorar la calidad del empleo, el empleo encajado, nuestros resultados muestran niveles en torno al $50 \%$ superior al 30\% de la UNED (Rodríguez de Rivera, 2010) y al 46\% de la Universidad de Valencia (Fundación Adecco, Fundación Bancaja y Universitat de València, 2012); es logrado mayoritariamente por las personas con discapacidad visual, algo mayor entre los hombres y se concentra en el grupo de estudios de Ciencias de la Salud. En conjunto, parece que el logro de un empleo encajado refleja ciertas tendencias generales del mercado de trabajo, particularmente la que apunta a la masculinización de las ocupaciones de mayor nivel en el sector de la salud, y quizás también indique la mayor intensidad de los apoyos que por parte de la ONCE reciben las personas con discapacidad visual.

Estos resultados vienen a ratificar que los egresados con discapacidad de la ULPGC se encuentran dentro de los parámetros recogidos en los informes sobre 
actividad laboral realizados en las últimas décadas. Por tanto, se podría afirmar que los esfuerzos realizados por la ULPGC, en los últimos 15 años, para aplicar las recomendaciones realizadas por los organismos internacionales y nacionales en materia de discapacidad y educación, especialmente el contenido de la legislación española vigente, han contribuido al éxito observado en las trayectorias laborales de los egresados analizadas en este estudio.

Asimismo, cabe destacar que el empleo encajado alcance al 50\% de la población, en tanto que sugiere que la formación universitaria puede contribuir a mejorar la calidad del empleo logrado por las personas con discapacidad. Esto podría estar indicando que la prevalencia de la discapacidad sobre la educación en el momento de acceder a un empleo (Dalmau-Montalé et al., 2013) se podría estar revirtiendo, pues la credencial que supone el título universitario parece que está siendo bien valorada por las empresas que las contratan.

Como se expuso antes, los estudios previos sobre la inserción laboral de personas con discapacidad universitarias son escasos, los disponibles abordan cuestiones generales de la situación de la discapacidad en la universidad, aspectos concretos de la transición al empleo, centrados más en los perfiles de los empleadores y en el tipo de empleo al que se accede; mientras otros analizan algunos aspectos específicos de la inserción laboral del alumnado con discapacidad o la situación general de la población con discapacidad en el mercado de trabajo.

Como consecuencia de ello, surge la necesidad de profundizar en los análisis sobre las trayectorias laborales del alumnado con discapacidad que finaliza con éxito los estudios superiores. En ese sentido, creemos que el presente trabajo aporta una visión novedosa, tanto porque supone uno de los pocos estudios específicos que se han hecho en las universidades españolas como por la metodología usada, ya que no se han encontrado estudios concretos que utilicen el emparejamiento individual como procedimiento de análisis de las trayectorias laborales de las personas con discapacidad universitarias.

En cualquier caso, creemos que este estudio exploratorio aporta una visión general de la situación laboral de las personas con discapacidad tituladas en la ULPGC, que puede tomarse como punto de referencia para realizar comparaciones con los datos que puedan proporcionar otras universidades en el Espacio Europeo de Educación Superior.

Mirando al futuro, por una parte, creemos que otras universidades podrían emular el protocolo de intercambio de datos administrativos que suscribió la ULPGC con el OBECAN, lo que permitiría la construcción de trayectorias laborales individuales y por consiguiente hacer seguimiento de la inserción laboral a medio plazo, para lo que podría ser útil replicar la metodología usada en este trabajo. Por otra parte, consideramos que sería muy interesante realizar estudios en los que participaran diferentes universidades, tanto públicas como privadas, que ofrecieran una visión global de la transición al empleo de los egresados con discapacidad al mismo tiempo que permitirían comparar los niveles de eficiencia y eficacia de las acciones y los servicios de apoyo a la inserción laboral del alumnado con discapacidad. 


\section{REFERENCIAS BIBLIOGRÁFICAS}

Aguilar, M.I. (2005). La inserción laboral de los Jóvenes en España. Un enfoque econométrico. Navarra: Aranzadi Thomson-Civitas.

Albor, J. (2019). Discapacidad: la exclusión social no es solo cosa de pobres. Documento de Trabajo n. ${ }^{\circ} 3.11$. Madrid: Fundación FOESSA, Cáritas Española Editores, recuperado de https://biblioteca. fundaciononce.es/publicacion/descarga/nojs/1497b30b31ee70a673b7d6e296728867. Última consulta: 07/09/20.

ANECA (2009). Los procesos de inserción laboral de los titulados universitarios en España. Factores de facilitación y de obstaculización, recuperado de http://www.aneca.es/Documentos-y-publicaciones/Estudios-de-interes-para-el-ambito-universitario/Los-procesos-de-insercion-laboral-de-los-titulados-universitarios-en-Espana. Última consulta: 10/02/15.

Blázquez, M. y Herrarte, A. (2011). «Cualificación, emparejamiento ocupacional y versatilidad profesional». Economistas, 126: 225-232.

Cabra de Luna, M. (2004). «Discapacidad y aspectos sociales la igualdad de oportunidades, la no discriminación y la accesibilidad universal como ejes de una nueva política a favor de las personas con discapacidad y sus familias. Algunas consideraciones en materia de protección social». Revista del Ministerio de Trabajo y Asuntos Sociales, 50: 21-46.

Colectivo IOÉ (2003). «La inserción laboral de las personas con discapacidades». Barcelona: Fundación La Caixa, recuperado de https://www.colectivoioe.org/index.php/publicaciones_libros/ show/id/46. Última consulta: 20/04/20.

Cueto, B., Malo, M.A. y Rodríguez, V. (2012). «La brecha de la participación laboral de las personas con discapacidad en España. Un análisis con la EDAD-2008». Cuadernos del Mercado de Trabajo, 8: 26-33.

Dalmau-Montalá, M. et al., (2010). Integración laboral de los universitarios españoles con discapacidad. Detección de las fortalezas y debilidades en el momento del acceso al mercado laboral español. Percepción de los universitarios y percepción de las empresas. Fundación Universia y Universidad Ramon Llull, recuperado de https://www.fundacionuniversia.net/wp-content/ uploads/2016/04/Integracion_Laboral_Universitarios_Discapacidad_RamonLlull.pdf. Última consulta: 17/08/2020.

Dalmau-Montalá, M. et al. (2013). "Formación universitaria e inserción laboral. Titulados espańoles con discapacidad y competencias profesionalizadoras». Revista Española de Discapacidad, I (2): 95-118. http://dx.doi.org/10.5569/2340-5104.01.02.06.

DÁvila, C.D. (2006). «Discapacidad y género: Un estudio de participación en el mercado de trabajo español». Moneda y Crédito, 223, 127-158.

De Lorenzo, R. (2003). El futuro de las personas con discapacidad en el mundo. Desarrollo humano y Discapacidad. Madrid: Fundación ONCE y Ediciones del Umbral.

Díaz-Velázquez, E. (2011). «Estratificación y Desigualdad por motivo de Discapacidad». Intersticios: Revista Sociológica de Pensamiento Crítico, 5(1): 157-170.

Fundación Adecco, Fundación Bancaja y Universitat de Valencia (2012). «La integración laboral de universitarios con discapacidad. Informe de investigación 2012", recuperado de http//www.fundacionbancaja.es/archivos/publicaciones/informe_integracion_discapacidad.pdf. Última consulta: 10/03/16. 
Fundación ONCE y ILO Business and Disability Network (2019). Making the future of work inclusive of people with disabilities, recuperado de https://biblioteca.fundaciononce.es/publicaciones/colecciones-propias/programa-operativo/making-future-work-inclusive-people. Última consulta: 16/08/2020.

Fundación Universia (2016). «Universidad y discapacidad. III Estudio sobre el grado de inclusión del sistema universitario español respecto de la realidad de la discapacidad», recuperado de: http://riberdis.cedd.net. Última consulta: 10/03/17.

Fundación Universia (2017). «Universidad y discapacidad. III Estudio sobre el grado de inclusión del sistema universitario español respecto de la realidad de la discapacidad", recuperado de http:// riberdis.cedd.net. Última consulta: 10/03/17.

Fundación Universia (2018). «Universidad y discapacidad. IV Estudio sobre el grado de inclusión del sistema universitario español respecto de la realidad de la discapacidad», recuperado de http:// riberdis.cedd.net. Última consulta: 10/03/17.

FUNDACIÓN UNIVERSIA y CERMI (2012). «Estudio sobre el grado de inclusión del sistema universitario español respecto de la realidad de la discapacidad», recuperado de https://sid.usal.es/idocs/F8/ FDO26384/inclusion_universidad.pdf. Última consulta: 18/08/2020.

Fundación Universia y CERMI (2014). «Universidad y Discapacidad. II Estudio sobre el grado de inclusión del sistema universitario español respecto de la realidad de la discapacidad», recuperado de http://riberdis.cedd.net. Última consulta: 10/03/17.

Guasch, D. (dir.) (2010). Estudio sectorial por comunidades autónomas de la accesibilidad del entorno universitario y su percepción. Barcelona: Observatorio Universidad y Discapacidad (entidad formada por Fundación ONCE y la Universidad Politécnica de Cataluña-Barcelona Tech), recuperado de https://www.uva.es/export/sites/uva/6.vidauniversitaria/6.11.accesibilidadarquitectonica/_documentos/Observatorio-Universidad-y-Discapacidad-09.pdf. Última consulta:16/08/20.

Huete García, A. (2013). «La exclusión de la población con discapacidad en España. Estudio específico a partir de la Encuesta Social Europea». Revista Española de Discapacidad, I (2): 7-24. http://dx.doi.org/10.5569/2340-5104.01.02.01.

Malo, M.A. (2003). «Las personas con discapacidad en el mercado de trabajo español». Revista del Ministerio de Trabajo e Inmigración, (46): 99-126.

Malo, M.A. (2004). «¿Cómo afectan las discapacidades a la probabilidad de ser activo en Espańa?». Cuadernos de Economía, 27(74): 75-108.

Malo, M.A. (dir.), Cueto, B., Dávila, C.D., Pagán, R. y Rodríguez, V. (2010). Evaluación de la politica de bonificaciones y reducciones de cuotas de la Seguridad Social destinada a Personas con Discapacidad. Madrid: Ministerio de la Presidencia. Agencia Estatal de Evaluación de las Políticas Públicas y la calidad de servicios, recuperado de http://www.aeval.es/es/ difusion_y_comunicacion/publicaciones/Informes/Informes_de_Evaluacion/Evaluaciones_2009/E19.html. Última consulta: 26/08/2020.

Malo, M.A. y Muñoz-Bullón, F. (2006). «Employment promotion measures and the quality of the job for persons with disabilities». Hacienda Pública Española/Revista de Economía Pública, 179(4): 79-111.

Observatorio estatal de la Discapacidad (2010). "Las personas con discapacidad en España. Informe Olivenza 2010", recuperado de http://riberdis.cedd.net. Última consulta: 26/01/15. 
Observatorio estatal de la Discapacidad (2014). "Las personas con discapacidad en España. Informe Olivenza 2014", recuperado de http://riberdis.cedd.net. Última consulta: 26/01/15.

Observatorio estatal de la Discapacidad (2015). «Las personas con discapacidad en España. Informe Olivenza 2016», recuperado de http://riberdis.cedd.net. Última consulta: $13 / 01 / 2016$.

Observatorio estatal de la Discapacidad (2016). "Las personas con discapacidad en España. Informe Olivenza 2016", recuperado de http://riberdis.cedd.net. Última consulta:13/03/2017.

Observatorio estatal de la Discapacidad (2017). «Las personas con discapacidad en España. Informe Olivenza 2018", recuperado de http://riberdis.cedd.net. Última consulta:13/05/2018.

Observatorio estatal de la Discapacidad (2018). «Las personas con discapacidad en España. Informe Olivenza 2018», recuperado de https://www.observatoriodeladiscapacidad.info/ category/documentos/observatorio/informe-olivenza-observatorio. Última consulta: 26/08/20.

Observatorio estatal de la Discapacidad (2019). «Las personas con discapacidad en España. Informe Olivenza 2018», recuperado de https://www.observatoriodeladiscapacidad.info/ category/documentos/observatorio/informe-olivenza-observatorio. Ultima consulta: 26/08/20.

ODISMET (2020). Integración Laboral y Mercado de Trabajo. Datos 2018, recuperado de https:// www.odismet.es/banco-de-datos/1integracion-laboral-y-tendencias-del-mercado-de-trabajo. Última consulta: 26/08/20.

OIT (1983). Convenio 159 (OIT), de 22 de junio de 1983, sobre la readaptación profesional y el empleo de personas inválidas, recuperado de https://www.ilo.org/dyn/normlex/es/f?p=NORMLEXPUB:12100:0::NO::P12100_ILO_CODE:C159. Última consulta: 26/08/20.

OIT (2001). Repertorio de recomendaciones prácticas sobre la gestión de discapacidades en el lugar de trabajo, recuperado de https://www.ilo.org/public/spanish/standards/relm/gb/docs/ gb282/pdf/tmemdw-2.pdf. Última consulta: 16/08/20.

OIT (2015). La importancia del empleo y los medios de vida en la agenda para el desarrollo con posterioridad a 2015. Nota conceptual de la OIT sobre la agenda de desarrollo post 2015, recuperado de https://www.ilo.org/wcmsp5/groups/public/---dgreports/---dcomm/documents/statement/wcms_206443.pdf. Última consulta: 16/08/2020.

OIT (2020). Discapacidad y Trabajo, recuperado de https://www.ilo.org/global/topics/disability-and-work/WCMS_475652/lang--es/index.htm. Última consulta: 26/08/20.

OMS (2020). 10 Datos sobre la Discapacidad, recuperado de https://www.who.int/features/factfiles/ disability/es/. Última consulta: 26/08/20.

Pallisera, M. et al. (2003). "La integración laboral de personas con discapacidad en la empresa ordinaria en España aproximación a través de una investigación». Siglo Cero, 34(208): 5-18.

Red2Red Consultores (2013). Discapacidad, estudios superiores y mercado de trabajo. Barreras de acceso y repercusión en la inserción laboral. Madrid: Fundación ONCE y Fondo Social Europeo, recuperado de https://www.fundaciononce.es/sites/default/files/Discapacidad_estudios_superiores.pdf. Última consulta: 26/08/20.

Rodríguez de Rivera, I. (2010). «Informe sobre el desarrollo profesional de egresados y estudiantes con discapacidad en la UNED». Centro de atención a universitarios con discapacidad (UNIDIS). Madrid: UNED-Fundación Mapfre.

SEPE (2009). Informe del Mercado de Trabajo de las PCD Estatal. Datos 2008. Madrid: Servicio Público de Empleo Estatal. Observatorio de Ocupaciones, recuperado de https://www. 
sepe.es/HomeSepe/que-es-el-sepe/observatorio/informes-mercado-trabajo/informes-anuales-mercado-trabajo-estatal/ver-resultados.html?documentType=informes\&tipo=1\&periodo=anual\&ambito=Nacional. Última consulta: 26/08/20.

SEPE (2013). Informe del Mercado de Trabajo de las PCD Estatal. Datos 2012. Madrid: Servicio Público de Empleo Estatal. Observatorio de Ocupaciones, recuperado de https://www. sepe.es/HomeSepe/que-es-el-sepe/observatorio/informes-mercado-trabajo/informes-anuales-mercado-trabajo-estatal/ver-resultados.html?documentType=informes\&tipo=1\&periodo=anual\&ambito=Nacional. Última consulta: 26/08/20. 


\section{INVESTIGACIÓN NOVEL /}

NOVEL INVESTIGATION 



\title{
LA ALTERACIÓN DE LA SALUD DEL TRABAJADOR COMO FACTOR DE DISCRIMINACIÓN EN LAS RELACIONES LABORALES: DISCAPACIDAD Y ENFERMEDAD
}

\author{
Patricia Orlanda Rodríguez Padrón \\ $\frac{\text { alu0100889864@ull.edu.es }}{\text { Universidad de La Laguna }}$
}

\section{RESUMEN}

El concepto de discapacidad, no unitario en nuestro ordenamiento jurídico, se encuentra en constante evolución, y prueba de ello es la reciente jurisprudencia del TJUE, que en el ámbito de la ocupación y el empleo ha supuesto la configuración de un concepto flexible de discapacidad, que permite extender la protección jurídica de la Directiva 2000/78/CE del Consejo, de 27 de noviembre de 2000, relativa al establecimiento de un marco general para la igualdad de trato en el empleo y la ocupación, a aquellos trabajadores/as que padezcan dolencias que, pese a no ser calificadas administrativamente como discapacidad, sean acreedoras de esta especial tutela. Esta doctrina supone una novedad, ya que, aun circunscrita a las relaciones laborales, se abandona la concepción tradicional de la discapacidad como situación permanente e irreversible.

Palabras clave: discapacidad, enfermedad, discriminación, ajustes razonables.

\section{ALTERING WORKERS' HEALTH AS A FACTOR OF DISCRIMINATION IN EMPLOYMENT RELATIONSHIPS: DISABILITY AND ILLNESS}

\section{Abstract}

The concept of disability, which is not unitary in our legal system, is in constant evolution, and proof of this is the recent jurisprudence of the TJUE, which in the field of occupation and employment, has meant the configuration of a flexible concept of disability, which allows for the extension of the legal protection of Council Directive 2000/78/EC, of 27 November 2000, relating to the establishment of a general framework for equal treatment in employment and occupation, to those workers who suffer from ailments which, despite not being administratively classified as a disability, are worthy of this special protection. This doctrine is a novelty since, even though it is limited to labour relations, it abandons the traditional conception of disability as a permanent and irreversible situation.

KeYwords: Disability, Ilness, Discrimination, Reasonable Adjustments. 


\section{INTRODUCCIÓN}

Las personas con discapacidad constituyen un colectivo que ha sido históricamente discriminado y excluido, especialmente en lo que se refiere a su incorporación y permanencia en el mercado de trabajo, en el cual siempre se han desenvuelto con especiales dificultades. Consciente de ello, la Directiva 2000/78/CE, de 27 de noviembre de 2000 , relativa al establecimiento de un marco general para la igualdad de trato en el empleo y la ocupación (DOUE-L-2000-82357, de 2 de diciembre de 2000), ha centrado parte de sus esfuerzos en la lucha contra la discriminación por razón de discapacidad en las relaciones laborales. Y ello, por considerar que «el empleo y la ocupación son elementos esenciales para garantizar la igualdad de oportunidades para todos y contribuyen decisivamente a la participación plena de los ciudadanos en la vida económica, cultural y social, así como a su desarrollo personal» (cfr. su considerando octavo). A tal fin, la referida norma articula un sistema que, además de proteger a los trabajadores/as frente a tratamientos discriminatorios, les brinda la oportunidad de que se implanten todas aquellas medidas de adaptación del puesto de trabajo que resulten más adecuadas.

En los últimos años, por parte tanto de la doctrina científica como de la propia jurisprudencia laboral, se ha valorado la posibilidad de que la enfermedad, como situación fronteriza con la discapacidad, sea merecedora de la especial tutela antidiscriminatoria con que cuenta el trabajador con discapacidad. Precisamente a raíz de los recentísimos pronunciamientos del Tribunal de Justicia de la Unión Europea, en adelante TJUE, se ha constatado la necesidad de construir un nuevo concepto de discapacidad, que -sentado sobre las bases del modelo social- permita la inclusión de aquellas enfermedades que, aun no respondiendo a la concepción tradicional de la discapacidad, supongan una limitación para el adecuado desarrollo de su puesto de trabajo.

Las personas con discapacidad gozan de un sólido marco jurídico protector, tanto a nivel europeo como nacional. Un recorrido por la normativa existente a lo largo de la historia refleja la evolución que ha tenido lugar en cuanto a la forma de concebir el fenómeno de la discapacidad, de modo que, aunque inicialmente se ponía el foco de atención en la superación de la dolencia, actualmente se centran gran parte de los esfuerzos en la adopción de toda clase de medidas que posibiliten la integración social de las personas con discapacidad. De este modo, se observa que las primeras normas reguladoras de la materia responden al denominado modelo médico rehabilitador, para el que -configurando la discapacidad desde una perspectiva individualista- la solución pasaba por el tratamiento médico enfocado en la disminución o eliminación de la discapacidad, sin que se haga alusión a ningún instrumento dirigido a posibilitar la plena inserción en la sociedad ni a la responsabilidad del Estado en la consecución de dicha labor. De igual modo, la construcción del concepto de discapacidad ha sido fruto de una larga evolución empleándose diversos términos para hacer referencia a la misma, entre la contundencia descriptiva y el eufemismo (Pérez, 2015: 91).

Una de las primeras normas dictadas en la materia es la Orden de 7 de noviembre de 1968, por la que se conceden ayudas a centros de empleo protegido 
para trabajadores minusválidos ( $B O E$ núm. 288, de 30 de noviembre), que, como ejemplo paradigmático de la plasmación del modelo médico, no articula ningún mecanismo de inclusión ni medidas de adaptación por parte de las empresas. De este modo, la norma se limita a constatar la imposibilidad de incorporación al mercado laboral en el régimen ordinario, quedando limitada la prestación de trabajo al ámbito de los centros de empleo protegido. En el artículo primero del citado cuerpo legal se acuña el hoy ya abandonado concepto de "minusválido», en el que se incluye «todo trabajador en edad laboral, considerándose como tal la comprendida entre los dieciocho y los sesenta y cinco años que, encontrándose en situación de desempleo, se vea además afectado por una disminución de su capacidad física superior a un 30 por 100 que le impida el acceso a puestos de trabajo en Empresas de régimen de trabajo normal precisamente a causa de tal merma de capacidad». El campo protector de la norma se circunscribe, por tanto, a las personas que acrediten un grado superior de discapacidad. Dos años más tarde, por obra del Decreto 2531/1970, de 22 de agosto, sobre empleo de trabajadores minusválidos (BOE núm. 221, de 15 de septiembre), comienza tímidamente la transición hacia el denominado modelo social que, orientado desde una perspectiva colectiva, se centra en la adopción de medidas de integración de las personas con discapacidad, proponiendo que sea la sociedad la que deba brindarles todos los instrumentos necesarios a fin de facilitar la inserción social. De nuevo, esta norma condiciona la adquisición del estatus de persona con discapacidad a la constatación del grado que reglamentariamente se determine, sin que en ningún caso pueda ser inferior al 33 por 100.

A partir de la aprobación de la Constitución española de 1978, en adelante $\mathrm{CE}$, se consolida el modelo social de protección de las personas con discapacidad, incluyéndose en su articulado una mención expresa al referido colectivo junto con un claro mandato a los poderes públicos. Se trata del artículo 49 de la CE, el cual dispone que «los poderes públicos realizarán una política de previsión, tratamiento, rehabilitación e integración de los disminuidos físicos, sensoriales y psíquicos a los que prestarán la atención especializada que requieran y los ampararán especialmente para el disfrute de los derechos que este Título otorga a todos los ciudadanos». Dicho mandato constitucional debe ser puesto en relación con el artículo 9.2 de la propia $\mathrm{CE}$, en virtud del cual «corresponde a los poderes públicos promover las condiciones para que la libertad y la igualdad del individuo y de los grupos en que se integra sean reales y efectivas; remover los obstáculos que impidan o dificulten su plenitud y facilitar la participación de todos los ciudadanos en la vida política, económica, cultural y social». En definitiva, deben promoverse las condiciones necesarias para garantizar la igualdad de las personas con discapacidad, consideradas individualmente. Como puede observarse, el lenguaje empleado por el legislador -a mi juicio, poco afortunado- supone un cierto anacronismo respecto a la normativa precedente, toda vez que continúa utilizando el término «disminuido».

La aprobación de la Ley 13/1982, de 7 de abril, de Integración Social de los Minusválidos ( $B O E$ núm. 103, de 30 de abril), en adelante LISMI, supone un verdadero punto de inflexión, visto que constituye la primera norma que contiene una regulación integral en materia de inserción de las personas con discapacidad en los distintos ámbitos de la sociedad. No obstante, no se elabora un concepto de dis- 
capacidad genérico que integre todo el sistema jurídico, limitándose su alcance al estricto ámbito de la ley. De este modo, el artículo 7 de la referida norma dispone lo siguiente: «A los efectos de la presente Ley se entenderá por minusválidos toda persona cuyas posibilidades de integración educativa, laboral o social se hallen disminuidos como consecuencia de una deficiencia, previsiblemente permanente, de carácter congénito o no, en sus capacidades físicas, psíquicas o sensoriales». En su momento, esta definición dio lugar a serias dudas interpretativas, en tanto no se precisaba en ella qué grado de discapacidad hacía a una persona acreedora de la protección otorgada por la ley; cosa, por cierto, que sí se había hecho en normas anteriores, pudiendo entenderse que encuentran encaje en la norma aquellas personas cuya disminución de las posibilidades de integración resulte significativa, de modo que evidencien un desajuste merecedor de corrección (Pérez, 2015: 154). Si bien la LISMI aún se encontraba incardinada dentro del modelo médico, orientado a la superación de las deficiencias, se entendía que la inclusión social que se desarrolla por la educación y el trabajo debía ser un proceso integral, flexible y dinámico (García, 2019: 4), de ahí que se estableciese la obligación de los empresarios de «adoptar las medidas adecuadas para la adaptación del puesto de trabajo y la accesibilidad de la empresa, en función de las necesidades de cada situación concreta, con el fin de permitir a las personas con discapacidad acceder al empleo, desempeñar su trabajo, progresar profesionalmente y acceder a la formación, salvo que esas medidas supongan una carga excesiva para el empresario" (artículo 37 bis LISMI).

Más adelante, la Ley 51/2003, de 2 de diciembre, de Igualdad de oportunidades, no discriminación y accesibilidad universal de las personas con discapacidad (BOE núm. 289, de 3 de diciembre), en adelante LIONDAU, supone el regreso al criterio cuantitativo, supliendo el vacío conceptual que supuso la LISMI en cuanto a la determinación del grado de discapacidad exigible. En su artículo 1.2, se contiene una definición indirecta de discapacidad (Pérez, 2015: 162) al disponer que tienen tal carácter aquellas personas «que presenten deficiencias físicas, mentales, intelectuales o sensoriales a largo plazo que, al interactuar con diversas barreras, puedan impedir su participación plena y efectiva en la sociedad, en igualdad de condiciones con los demás». Continúa diciendo el mismo artículo 1.2 que, a los efectos de esta Ley, «tendrán la consideración de personas con discapacidad aquellas a quienes se les haya reconocido un grado de discapacidad igual o superior al 33 por ciento». De la propia configuración del citado precepto se desprende que se trata de una conceptualización limitada al estricto ámbito de aplicación de esta ley, desaprovechándose de nuevo la oportunidad de crear un concepto de discapacidad que integre todo el sistema. 


\section{MARCO JURÍDICO DE PROTECCIÓN FRENTE A LA DISCRIMINACIÓN POR RAZÓN DISCAPACIDAD EN EL ÁMBITO DE LAS RELACIONES LABORALES}

En el plano europeo, el artículo 10 del Tratado de Funcionamiento de la Unión Europea proclama que «la Unión tratará de luchar contra toda discriminación por razón de sexo, raza u origen étnico, religión o convicciones, discapacidad, edad u orientación sexual» (DOUE-Z-2010-70002, de 30 de marzo). A partir de la década de los noventa del siglo pasado, se comienza a demandar por parte de algunos sectores una ampliación de los supuestos amparados por la normativa sobre prohibición de discriminación; y entre ellos, la discapacidad. En el año 2000, como respuesta a la referida demanda, se aprueba la Directiva 2000/78/CE del Consejo, de 27 de noviembre, relativa al establecimiento de un marco general para la igualdad de trato en el empleo y la ocupación, cuyo considerando decimoprimero reconoce que «la discriminación por motivos de religión o convicciones, discapacidad, edad u orientación sexual puede poner en peligro la consecución de los objetivos del Tratado CE, en particular el logro de un alto nivel de empleo y de protección social, la elevación del nivel y de la calidad de vida, la cohesión económica y social, la solidaridad y la libre circulación de personas».

En particular, el artículo 3 de la Directiva citada concreta que sus disposiciones serán de aplicación -entre otras materias- a las condiciones de acceso al empleo, a la actividad por cuenta propia y al ejercicio profesional, al acceso a la formación profesional, a las condiciones de empleo y trabajo y a la afiliación y participación en una organización de trabajadores/as o de empresarios/as. Conviene advertir que la Directiva no desarrolla un concepto de discapacidad; como tampoco existe una remisión al derecho interno de los Estados miembros a fin de definir dicho concepto. Precisamente por ello, ha sido el TJUE -como en tantas otras ocasiones- el que ha asumido la labor de delimitar el contenido y alcance del concepto de discapacidad, debiendo los estados miembros aplicarlo de forma homogénea. En este sentido, la jurisprudencia europea, tal y como se analizará con mayor profundidad más adelante, ha asumido el concepto elaborado por la Convención sobre los Derechos de las Personas con Discapacidad, hecha en Nueva York el 13 de diciembre de 2006 (BOE núm. 96, de 21 de abril de 2008), que define la discapacidad como una situación que «resulta de la interacción entre las personas con deficiencias y las barreras debidas a la actitud y al entorno que evitan su participación plena y efectiva en la sociedad, en igualdad de condiciones con las demás» (preámbulo de la citada Convención, letra e).

La Directiva 2000/78/CE se traspuso a nuestro ordenamiento jurídico a través de la Ley 62/2003, de 30 de diciembre, de medidas fiscales, administrativas y del orden social ( $B O E$ núm. 313, de 31 de diciembre). Esto se tradujo, fundamentalmente, en la modificación del Estatuto de los Trabajadores/as, en adelante ET; y más en concreto, de su artículo 4.2.c), donde se reconoce como derecho básico de los trabajadores/as el de «no ser discriminados directa o indirectamente para el empleo, o una vez empleados, por razones de sexo, estado civil, edad dentro de los límites marcados por esta ley, origen racial o étnico, condición social, reli- 
gión o convicciones, ideas políticas, orientación sexual, afiliación o no a un sindicato, así como por razón de lengua, dentro del Estado español». Añade el precepto que «tampoco podrán ser discriminados por razón de discapacidad, siempre que se hallasen en condiciones de aptitud para desempeñar el trabajo o empleo de que se trate ${ }^{1}$. El art. 4.2.c) del ET debe ponerse en relación con el artículo 17 del mismo cuerpo legal, donde se consagra la nulidad de los pactos o cláusulas que den lugar a situaciones discriminatorias por razón de discapacidad en el ámbito del empleo.

Sin perjuicio de todo cuanto acaba de exponerse, hoy por hoy, el marco normativo principal en relación con los derechos de las personas con discapacidad viene integrado fundamentalmente por el Real Decreto Legislativo 1/2013, de 29 de noviembre, por el que se aprueba el Texto Refundido de la Ley General de Derechos de las Personas con Discapacidad y de su inclusión social (BOE núm. 289, de 3 de diciembre), en adelante LGPD, cuyo artículo 2.a), siguiendo las directrices de la Convención de la Organización de Naciones Unidas, en adelante ONU, define la discapacidad como «una situación que resulta de la interacción entre las personas con deficiencias previsiblemente permanentes y cualquier tipo de barreras que limiten o impidan su participación plena y efectiva en la sociedad, en igualdad de condiciones con las demás». Por su parte, el artículo 4.1 de la LGPD afirma que «son personas con discapacidad aquellas que presentan deficiencias físicas, mentales, intelectuales o sensoriales, previsiblemente permanentes que, al interactuar con diversas barreras, puedan impedir su participación plena y efectiva en la sociedad, en igualdad de condiciones con los demás». Añade, además, en su apartado segundo que «a todos los efectos, tendrán la consideración de personas con discapacidad aquellas a quienes se les haya reconocido un grado de discapacidad igual o superior al 33 por ciento". La discapacidad se configura, por tanto, como un concepto jurídico que pivota sobre tres elementos fundamentales: la concurrencia de cualquier tipo de deficiencia, la existencia de barreras en la sociedad y la interacción de las deficiencias con dichas barreras. De modo que provocan discriminación por razón de discapacidad "tanto la existencia de barreras sociales como la inexistencia de medidas de apoyo de todo tipo que permitan sortear dichos obstáculos hasta que éstos se pueden eliminar» (De Fuentes, 2016: 85).

${ }^{1}$ Respecto a esta cuestión resulta conveniente destacar la STSJ de Asturias de 12 diciembre de 2008 (rec. 1431/2008), en la que se declara no apto a un trabajador para un puesto como minero, por padecer asma bronquial. De modo que la enfermedad padecida por el trabajador es incompatible con el trabajo en el interior de las minas, no siendo admisible que el empresario asuma la excesiva carga que implica el alto riesgo para la salud del trabajador. Sobre esta misma cuestión, véase la STSJ de Andalucía (Granada) de 24 junio de 2003 (rec. 294/2003). 


\section{MECANISMOS DE PROTECCIÓN EN FAVOR DE LAS PERSONAS CON DISCAPACIDAD FRENTE A LAS SITUACIONES DE DISCRIMINACIÓN EN LAS RELACIONES LABORALES}

\subsection{LA PROHIBICIÓN DE DISCRIMINACIÓN POR RAZÓN DE DISCAPACIDAD}

El principal mecanismo de protección con el que cuentan las personas con discapacidad es la prohibición de discriminación en las relaciones laborales, de modo que se les garantice el acceso y la conservación del empleo en igualdad de condiciones que el resto de trabajadores/as. Por ello, las próximas líneas tienen por misión analizar a -a través de la casuística jurisprudencial- los motivos más frecuentemente esgrimidos por la empresa, ya sea para limitar el acceso al empleo, ya sea para dar por extinguida la relación laboral. El tratamiento desfavorable puede revestir múltiples formas y, si bien gran parte de la problemática gira en torno a las limitaciones para acceder a un puesto de trabajo ${ }^{2}$, no conviene olvidar que no siempre la situación discriminatoria consiste en una conducta concreta del empresario/a que atente contra el derecho a la igualdad del individuo. En efecto, nuestra jurisprudencia ha admitido la existencia asimismo de discriminación cuando el empresario/a no da cumplimiento a aquellas medidas de acción positiva establecidas en la legislación aplicable. En este sentido, la sentencia del Tribunal Superior de Justicia, en adelante TSJ, de Canarias (Las Palmas) de 23 de noviembre de 2018 (rec. 1024/2018) ha considerado que el hecho de incumplir la legislación de reserva de puestos de trabajo para discapacitados del $2 \%$ de la plantilla no implica exclusivamente la infracción de lo dispuesto en la LGPD (artículo 42), sino que constituye una auténtica discriminación en el acceso al empleo prohibida por los artículos 4.2.c) y 17.1 del ET. A mayor abundamiento, entiende la Sala canaria que, aunque no existan trabajadores/as con el perfil requerido por la empresa, ello no le exime del cumplimiento de las medidas excepcionales alternativas.

Sin embargo, particular atención merece la casuística jurisprudencial relativa a la extinción de la relación laboral por causa de la situación de discapacidad del trabajador/a. En este sentido resulta ineludible profundizar en la problemática que se suscitó en torno a la aplicación del artículo 52.d) del ET, donde se regula el despido objetivo por faltas de asistencia al trabajo justificadas, conforme al cual el contrato podrá extinguirse "por faltas de asistencia al trabajo, aun justificadas pero intermitentes, que alcancen el veinte por ciento de las jornadas hábiles en dos meses

2 En este sentido cabe citar la SJS de Murcia de 7 de mayo de 2018 (rec. 13/2018), en la que se limita la contratación de un trabajador con discapacidad bajo el pretexto de no haber informado acerca de su condición. El juez concluyó que no era necesario acreditar tal extremo, por lo que, con arreglo al principio de inversión del onus probandi, consideró el juzgador que existe una discriminación en el acceso al empleo. Por su parte, la SJS n. 3 de Gijón de 18 de abril de 2018 (rec. 697/2017) constata la existencia de discriminación en la resolución del contrato durante el periodo de prueba, y ello dado que la trabajadora ha aportado indicios suficientes que hacen desplazar la carga de la prueba al empresario; concretamente, que la trabajadora solicitó determinadas mejoras en el puesto de trabajo. 
consecutivos siempre que el total de faltas de asistencia en los doce meses anteriores alcance el cinco por ciento de las jornadas hábiles, o el veinticinco por ciento en cuatro meses discontinuos dentro de un periodo de doce meses». En particular, merece un especial análisis la sentencia del TJUE de 18 de enero de 2018, asunto Ruiz Conejero (C-270/16). El juzgador español fundamenta la cuestión prejudicial en la existencia de una aparente contradicción entre el citado precepto y la Directiva 2000/78/CE; y ello con base en que la normativa podría estar encubriendo un supuesto de discriminación indirecta, ya que, si bien a priori se trataba de una disposición neutra que se aplicaba por igual a todos los trabajadores/as, sin ningún tipo de distinción, se derivaba sin embargo una desventaja particular para el colectivo de personas con discapacidad. A tal efecto, entiende el TJUE que el riesgo de aplicación de este artículo es mayor en los trabajadores/as con discapacidad, al ser más propensos a acumular días de baja por las enfermedades derivadas de tal situación; no obstante, para poder concluir que nos encontramos ante un supuesto de discriminación indirecta conviene dilucidar si dicho tratamiento desfavorable se encuentra amparado por una finalidad legítima; y siempre y cuando los medios aplicados para su consecución sean adecuados, y no vayan más allá de lo necesario para alcanzar la finalidad prevista. En efecto, para el TJUE dicho precepto cuenta con la finalidad legítima de combatir el absentismo laboral, si bien será el juzgador nacional el encargado de verificar la adecuación de los medios empleados para su consecución, debiendo tener en cuenta para ello una serie de factores; entre ellos, si los umbrales numéricos establecidos en el artículo 52.d) del ET se han calculado efectivamente para paliar el absentismo, así como los costes directos e indirectos que han de soportar las empresas como consecuencia de las faltas de asistencia. Del mismo modo se debe valorar si el legislador, al configurar dicho precepto, ha omitido datos relevantes respecto al colectivo de trabajadores/as con discapacidad.

El juzgado de lo social, en adelante JS, de Cuenca concluye que hubo una clara omisión por parte del legislador, ya que en la relación de faltas de asistencia excluidas del cómputo - las bajas médicas de duración superior a 20 días, o las derivadas de tratamiento médico por enfermedad grave o cáncer, entre otras- no existe una mención expresa a las faltas de asistencia derivadas de la discapacidad del trabajador/a, y es por ello por lo que considera que dicha medida excede de lo necesario para alcanzar la finalidad de combatir el absentismo, y que los medios no son idóneos, adecuados y necesarios. La sentencia del TSJ de Castilla-La Mancha, de 10 de abril de 2019 (rec. 664/2018), ratifica este pronunciamiento y ańade que «la justificación de política social y empleo de dicho precepto no puede excluir los efectos de la discriminación indirecta por causa de su discapacidad provocados por su aplicación, pues los medios para la consecución de dicha finalidad no son los adecuados al no tomar en consideración la desventaja que su aplicación produce en las personas con discapacidad, factor de discriminación prohibido».

No está de más advertir, pese a que gran parte de la doctrina y la jurisprudencia venía poniendo de manifiesto la necesidad de abordar una reforma del art. 52.d) del ET (Rojo, 2019; De Heredia, 2019), de modo que se incluyeran las faltas de asistencia al trabajo derivadas de la situación de discapacidad, lo cierto es que también se demandaba por parte de algunos sectores la íntegra derogación del mismo. 
Como resultado de estas reivindicaciones, y especialmente tras el enorme impacto social ocasionado por la controvertida sentencia del Tribunal Constitucional, en adelante TC, 118/2019, de 16 de octubre (rec. 2960/2019), que concluía que el despido del trabajador por faltas de asistencia justificadas no vulneraba el derecho a la salud ni el derecho a la integridad física -haciendo primar el derecho a la libertad de empresa sobre los mismos ${ }^{3}$-, se produjo la derogación del precepto a través del Real Decreto Ley 4/2020, de 18 de febrero (BOE núm. 43, de 19 de febrero). La fundamentación del recién citado Real Decreto Ley pivota sobre dos ejes fundamentales. Por una parte, la adecuación de la legislación española a la jurisprudencia del TJUE, en aras de evitar que el trabajador/a se vea abocado a «una situación de gran vulnerabilidad profesional, personal y social»; y por otro, «la necesidad imperativa de evitar que se produzcan más resoluciones judiciales a nivel interno que resulten contradictorias entre sí» (Disp. 3.a del RD Ley 4/2020). En este sentido, la norma se hace eco de la más reciente jurisprudencia europea, en particular en lo que se refiere a la extensión de la tutela antidiscriminatoria a los supuestos de enfermedad, donde existe una clara divergencia de criterios, tal y como se expondrá más adelante. Es importante reseñar que se considera que el precepto no se ajusta a la doctrina europea en tanto que el artículo 52.d) del ET se aplica de forma automática - una vez que se alcancen los umbrales establecidos-, de modo que impide al juzgador llevar a cabo el juicio de adecuación de los medios y proporcionalidad de conformidad con la doctrina europea. En definitiva, la norma se dicta "para erradicar la situación susceptible de generar discriminaciones, inseguridad jurídica e incumplimiento de las obligaciones derivadas de nuestra pertenencia a la Unión Europea» (Disp. 7.a del RD Ley 4/2020).

\subsection{LA PROTECCIÓN DE LA DISCAPACIDAD A TRAVÉS DE LAS MEDIDAS DE ACCIÓN POSITIVA: LOS AJUSTES RAZONABLES}

Uno de los aspectos que, de acuerdo con la Directiva 2000/78, se tienen en consideración a fin de excluir el carácter discriminatorio de un tratamiento desfavorable es la realización de ajustes razonables por parte de la empresa. Su artículo 5 impone al empleador/a la obligación de realizar ajustes razonables, como se aprecia cuando dispone lo siguiente: «Los empresarios tomarán las medidas adecuadas, en función de las necesidades de cada situación concreta, para permitir a las personas con discapacidades acceder al empleo, tomar parte en el mismo o progresar profesionalmente, o para que se les ofrezca formación, salvo que esas medidas supongan una carga excesiva para el empresario. La carga no se considerará excesiva cuando

3 En relación con esta cuestión véase el voto particular formulado por la magistrada doña María Luisa Balaguer Callejón, en el cual defiende que la libertad de empresa o la defensa de la productividad no pueden ser antepuestas al derecho a la integridad física y moral de los trabajadores/as «ni a un valor tan esencial como es la protección de la salud humana». 
sea paliada en grado suficiente mediante medidas existentes en la política del Estado miembro sobre discapacidades». En la legislación española, el artículo 2.m) de la LGPD define los ajustes razonables como «las modificaciones y adaptaciones necesarias y adecuadas del ambiente físico, social y actitudinal a las necesidades específicas de las personas con discapacidad que no impongan una carga desproporcionada o indebida, cuando se requieran en un caso particular de manera eficaz y práctica, para facilitar la accesibilidad y la participación y para garantizar a las personas con discapacidad el goce o ejercicio, en igualdad de condiciones con las demás, de todos los derechos».

A diferencia de la normativa europea -que circunscribe la adopción de ajustes razonables al ámbito estrictamente laboral-, en la española se ha optado por un concepto más amplio que abarca todas las esferas de la vida personal. No obstante, el artículo 40.2 de la LGPD concreta la exigibilidad de esta obligación en el ámbito laboral, al disponer que «los empresarios están obligados a adoptar las medidas adecuadas para la adaptación del puesto de trabajo y la accesibilidad de la empresa, en función de las necesidades de cada situación concreta, con el fin de permitir a las personas con discapacidad acceder al empleo, desempeñar su trabajo, progresar profesionalmente y acceder a la formación, salvo que esas medidas supongan una carga excesiva para el empresario». Como puede observarse, tanto a nivel europeo como nacional, se configura un concepto genérico de ajustes razonables, sin que se precisen las concretas medidas que cabe adoptar. «La falta de determinación de las medidas de ajuste y su tipología dificulta sustancialmente la detección de los ajustes a realizar y su tipología, generándose -en abstracto- infinitas opciones de ajuste» (Gutiérrez, 2015: 21).

Para determinar cuándo las empresas están sujetas a la obligación de realizar ajustes debemos determinar primero cuándo son razonables. Respecto a este concreto extremo, la Directiva 2000/78 no proporciona ningún parámetro que permita precisar el término «razonable». Ausencia de detalle, como se ha puesto de manifiesto, que «se deba tal vez a que se trata de una Directiva, disposición comunitaria sobre un determinado aspecto que ha de ser incorporada a su Derecho por los Estados de la UE, que ha de ser respetada como nivel de exigencia mínima, pero que los países miembros, en el proceso de transposición, pueden elevar y ampliar» (Pérez, 2012: 9). La concreción de la razonabilidad del ajuste dependerá, por tanto, del desarrollo legislativo de cada ordenamiento interno. En este sentido, desde un punto de vista comparado, cabe distinguir tres tipos de planteamientos: estados que condicionan la razonabilidad de la medida al coste económico, los que la condicionan a la eficacia de la medida y los que tienen en cuenta tanto el coste económico como la eficacia (Carrasquero, 2018: 43).

En España, el artículo 66.2 de la LGPD es el que arroja un poco de luz sobre esta cuestión y nos concreta los aspectos que tenemos que considerar a fin de determinar si un ajuste es o no razonable. Se trata, fundamentalmente, del coste de la medida, del efecto discriminatorio que supone para el individuo la no adopción del ajuste, así como de la posibilidad de acceder a sistemas públicos de ayuda para sufragar los costes derivados de la adaptación. El carácter excesivo de la medida se encuentra estrechamente vinculado al concepto de ajuste razonable, en tanto en 
cuanto el hecho de que la carga resulte excesiva determinará que el ajuste pierda la consideración de razonable, configurándose, por tanto, como un límite para su adopción (Fernández, 2017: 20). La LGPD concreta cuáles son los aspectos que debemos considerar para determinar si una carga es o no excesiva para la empresa; en particular, «si es paliada en grado suficiente mediante las medidas, ayudas o subvenciones públicas para personas con discapacidad, así como los costes financieros y de otro tipo que las medidas impliquen y el tamaño y el volumen de negocios total de la organización o empresa» (artículo 40 párr. 2. ${ }^{\circ}$ LGPD). Todos estos criterios -de marcada naturaleza económica- evidencian que no estamos ante "un concepto estático ni uniforme para todo tipo de empresa» (Rodríguez Sanz, 2014: 85 y ss.), toda vez que una misma medida puede resultar excesiva para una empresa y razonable para otra, atendiendo a las circunstancias concurrentes en cada caso.

A mi juicio, el incumplimiento del deber de realizar ajustes razonables se puede considerar como una forma de discriminación autónoma, ya que, llevando a cabo una interpretación teleológica de la norma, podemos concluir que vincular la obligatoriedad de realizar el ajuste a la previa constatación de una situación discriminatoria supone atentar contra el fin fundamental perseguido por la Directiva de garantizar el acceso al empleo de las personas con discapacidad. Así pues, la negativa del empresario a realizar un determinado ajuste constituiría en sí misma una discriminación. En este sentido, conviene citar la sentencia del TSJ del País Vasco de 9 de julio de 2019 (rec. 1167/2019), en la que se declara la nulidad del despido de un trabajador/a con discapacidad que solicitó determinadas adaptaciones en su puesto de trabajo, y ello porque «el actor tenía derecho a que su situación, su estado físico, fuera tratado de forma individualizada con las necesarias adaptaciones».

Por lo que respecta a las concretas medidas de ajuste que cabe adoptar, si bien es cierto que con carácter general no se enumeran, el considerando 20 de la Directiva 2000/78 -a modo ilustrativo- dispone que entre las medidas a adoptar se encuentran las dirigidas a "acondicionar el lugar de trabajo en función de la discapacidad, por ejemplo, adaptando las instalaciones, equipamientos, pautas de trabajo, asignación de funciones o provisión de medios de formación o encuadre». Además, y como posible contenido de la medida, cabe destacar la recolocación en un puesto de trabajo adaptado a la discapacidad del trabajador/a, así como la reducción de la jornada de trabajo (sentencia del TSJ Cataluña de 9 de diciembre de 2014, rec. 6157/2014).

\subsection{La extensión de la tutela de la Directiva europea 2000/78/CE a los SUPUESTOS DE ENFERMEDAD: LA CASUÍSTICA JURISPRUDENCIAL}

La posibilidad de que un trabajador/a enfermo/a goce del mismo nivel de protección que otro con discapacidad, especialmente en materia de despido, con las consecuencias que se derivan de la declaración de nulidad, ha sido objeto de un profundo debate, tanto por parte de la doctrina como de la jurisprudencia. La interpretación del TJUE se ha ido flexibilizando a lo largo de los años, de modo que -aunque inicialmente mantenía una postura rígida y nada proclive a la equipara- 
ción entre enfermedad y discapacidad- ha tenido lugar una progresiva ampliación del concepto de discapacidad, y con ello la extensión de la tutela antidiscriminatoria a muchos trabajadores/as que con anterioridad se encontraban desamparados. Debemos considerar, como punto de partida, la sentencia del TJUE de 11 de julio de 2006, asunto Chacón Navas (C-13/05), que, respondiendo a las cuestiones prejudiciales planteadas por el JS n. ${ }^{\circ} 33$ de Madrid, valora la posibilidad de incluir en el campo de aplicación de la Directiva europea a los trabajadores/as enfermos/as. Aclara el tribunal que la enfermedad no se incluye dentro del catálogo de causas de discriminación prohibidas por la norma ni cuenta tampoco con un reconocimiento autónomo en la normativa internacional, no siendo posible la equiparación pura y simple de ambos conceptos.

Más adelante, la sentencia del TJUE de 11 de abril de 2013, asunto Ring (acumulados C-335/11 y C-337/11), dictada a propósito del despido de dos trabajadoras danesas por faltas de asistencia al trabajo derivadas de las dolencias que padecían, supone la flexibilización de esta postura, admitiéndose por vez primera la posibilidad de asimilar los conceptos de enfermedad y de discapacidad. El TJUE, asumiendo por completo el concepto de discapacidad configurado en la Convención de la ONU -la cual fue ratificada por la UE mediante decisión de 26 de noviembre de 2009 (DOUE L 23/35)-, la define como «una limitación, derivada en particular de dolencias físicas, mentales o psíquicas que, al interactuar con diversas barreras, puede impedir la participación plena y efectiva de la persona de que se trate en la vida profesional en igualdad de condiciones con los demás trabajadores», de modo que contarían con amparo legal aquellas enfermedades o dolencias que supongan tal limitación, siempre y cuando se trate de dolencias de carácter duradero. No proporcionaba, sin embargo, ningún criterio o parámetro que permitiese verificar el carácter duradero, de modo que es el juzgador interno el que debía asumir la ardua tarea de constatar si el trabajador padece o no una limitación de carácter prolongado o indefinido en el tiempo.

La sentencia del TJUE de 1 de diciembre de 2016, asunto Daouidi (C-395/15), articula una serie de indicios que orientan al juzgador a fin de valorar si una determinada dolencia tiene carácter duradero, a efectos de incluirse en el concepto de discapacidad europeo, entre ellos que «en la fecha del hecho presuntamente discriminatorio, la incapacidad del interesado no presente una perspectiva bien delimitada en cuanto a su finalización a corto plazo» o bien que «dicha incapacidad pueda prolongarse significativamente antes del restablecimiento de dicha persona». De igual modo, el juez debe servirse de todos los datos objetivos de los que disponga, y en particular de los documentos y certificados que reflejen el estado de salud del individuo.

A la luz de la jurisprudencia referenciada se constata cómo ha tenido lugar una progresiva flexibilización del concepto de discapacidad. A mi juicio, y atendiendo a la definición funcional y social de la discapacidad, se trata de una ampliación conceptual que deja atrás la configuración clásica de la discapacidad, como limitación permanente e irreversible, tradicionalmente condicionada a la acreditación de un concreto grado por parte de la Administración, desdibujando la tradicional línea divisoria entre enfermedad y discapacidad. En efecto, ahora se extiende 
a aquellas enfermedades que, sin perjuicio de su carácter temporal y curable, tienen una proyección a largo plazo que repercute negativamente en el desarrollo personal del trabajador/a. En definitiva, con carácter general el enorme salto cualitativo que ha dado la jurisprudencia europea merece una valoración positiva, si bien no conviene olvidar que los criterios facilitados por el TJUE son genéricos y se alude a múltiples conceptos jurídicos indeterminados, por lo que «la disparidad de criterios puede llegar a ser notable, lo que, podría dificultar una unificación de doctrina $y$, en definitiva, redundar negativamente en la seguridad jurídica» (De Heredia, 2016). En definitiva, es el juzgador nacional el que debe valorar en cada caso si la situación del individuo puede ser calificada como discapacidad, por lo que se hace patente su marcado carácter casuístico.

La necesidad de un concepto flexible de discapacidad, que permita extender el marco protector frente al despido a los trabajadores/as enfermos/as, surge a raíz de la reforma operada por la Ley 11/1994, de 19 de mayo, por la que se modifican determinados artículos del Estatuto de los Trabajadores, y del texto articulado de la Ley de Procedimiento Laboral y de la Ley sobre Infracciones y Sanciones en el Orden Social (BOE núm. 122, de 23 de mayo). Esta modificación legislativa supuso la desaparición del antiguo artículo 55.6 del ET, en el cual rezaba que «el despido de un trabajador que tenga suspendido un contrato de trabajo se considerará nulo si la jurisdicción competente no apreciase su procedencia», de modo que desaparecía una vía de tutela específica para aquellas personas que padecen enfermedades no reconocidas formalmente como discapacidad.

De este modo, la postura pacífica que tradicionalmente venía manteniéndose por los tribunales españoles -consolidada por nuestro Tribunal Supremo, en adelante TS - era la de considerar que el despido de un trabajador/a enfermo/a merece la calificación jurídica de improcedente, y no nulo. Y ello, con base en la productividad de la empresa, toda vez que la enfermedad es una situación «que hace que el mantenimiento del contrato de trabajo del actor no se considere rentable por la empresa» (sentencia del TS, de 23 de mayo de 2005, rec. 2639/2004). De hecho, en un principio, ajeno al concepto social de discapacidad, la Sala de lo Social del TS dicta varios pronunciamientos condicionando la existencia de una situación de discapacidad al reconocimiento formal, mediante «la declaración de minusválido» (sentencias del TS de 29 de enero de 2001, rec. 1566/2000, y de 22 de noviembre de 2007, rec. 3907/2006). La enfermedad no constituye, con carácter general, una causa de discriminación prohibida, en virtud del artículo 14 de la CE -salvo que exista un elemento de segregación ${ }^{4}-$, ni en particular en el ámbito laboral, de conformidad con el artículo 4.2 c) del ET; de ahí la necesidad de configurar un nuevo concepto de discapacidad, que permita dar respuesta a aquellas personas que padez-

${ }^{4}$ La sentencia del TC 62/2008, de 26 de mayo, aclara que existe tal elemento de segregación cuando la decisión se basa en «la mera existencia de la enfermedad en sí misma considerada o en la estigmatización como persona enferma de quien la padece». 
can una enfermedad, la cual, al interactuar con las diversas barreras existentes en la sociedad, dé lugar a una discapacidad.

Tras la interpretación efectuada por el TJUE en el asunto Chacón Navas, el JS n. 33 de Madrid (sentencia de 16 de octubre de 2006, rec. 641/2004) resuelve declarando la improcedencia del despido. El juzgado madrileño -partiendo de la necesaria distinción entre enfermedad y discapacidad-considera que si bien la actora demostró el padecimiento de una dolencia física, no consiguió acreditar «la probabilidad cierta de que sus limitaciones se iban a prolongar en el tiempo» y, por tanto, no se desplazó a la empresa la carga de probar la razonabilidad de su actuación. Existe, en definitiva, una continuidad de la línea jurisprudencial marcada por el TS. No obstante, es cierto que a raíz de los últimos pronunciamientos del TJUE, especialmente tras el asunto Daoudidi, ha tenido lugar una cierta flexibilización de esta postura, abriéndose la puerta a la posibilidad de considerar la nulidad del despido de un trabajador/a enfermo/a, por considerarse la existencia de una situación de discapacidad. Sin embargo, los tribunales españoles no han asumido la doctrina del TJUE de forma unívoca, lo que ha derivado en pronunciamientos judiciales dispares en cuanto a la calificación judicial del despido.

Por otro lado, se presentan especiales dificultades para la determinación del carácter duradero de la dolencia, ya que debido a la amplitud de los criterios sentados por el TJUE, es el juzgador nacional el que debe valorar este extremo caso por caso. Sin embargo, sí que se han ido consolidando una serie de parámetros en nuestra jurisprudencia laboral; entre ellos, la duración de la baja laboral por incapacidad temporal (IT), si bien no existe consenso respecto al concreto lapso temporal que cabe considerar como prolongado. En este sentido, para el TS y gran parte de la jurisprudencia menor, la existencia de una situación de IT de pocos días de duración no es acreedora de la condición de discapacidad, de modo que se ha tomado como referencia el agotamiento del plazo máximo de duración de la IT de 365 días (sentencias del TS de 3 de mayo de 2016, rec. 3348/2014, y del TSJ de Castilla y León, de 30 de noviembre de 2017, rec. 1828/2017). No obstante, no se trata de una postura pacífica en nuestros tribunales, existiendo pronunciamientos judiciales en los que se declara la nulidad del despido con base en una situación de enfermedad de corta duración.

A modo de ejemplo, cabe citar la sentencia del JS de Barcelona de 23 de diciembre de 2016 (rec. 1219/2014), en la que el juzgador considera que la patología padecida por el trabajador podía ser catalogada como de larga duración. Y ello, por entender que del resultado de la primera resonancia realizada se desprende que las lesiones del actor "hacían impensable una reincorporación a corto plazo, en especial la rotura del ligamento" (FD 38. ${ }^{\circ}$ ), lo que unido a la duración de la IT, que se prolongó hasta casi 10 meses, supone, a juicio del juez de instancia, que la limitación no "presentaba una perspectiva bien delimitada en cuanto a su finalización a corto plazo». Es importante destacar que esta sentencia fue revocada a su vez por la sentencia del TSJ de Cataluña de 12 de junio de 2017 (rec. 2310/2017), al entender que resta relevancia a la duración total de la IT, visto que, cuando tiene lugar el despido, solamente ha transcurrido un mes y medio desde el accidente, y tal y como había sentado el TJUE debe tenerse en cuenta el estado de incapacidad del 
interesado en la fecha en la que se adopta contra él el acto presuntamente discriminatorio 5 . La sentencia del JS de Cuenca de 29 de mayo de 2018 choca frontalmente con esta idea, en la medida en la que se califica como nulo el despido de una trabajadora atendiendo al riesgo de recaer en el cáncer de mama que había padecido en el pasado. La importancia de esta resolución radica en que, a diferencia de las anteriores resoluciones, para determinar si la actora ostenta o no la condición de discapacitada no se tiene tanto en cuenta su estado de salud actual, sino la probabilidad de que sufra en el futuro nuevos procesos de IT atendiendo a su historial médico. En esta misma línea, la sentencia del TSJ de Cantabria de 18 de enero de 2019 (rec. 833/2018) declara la nulidad del despido disciplinario de una trabajadora mientras se encuentra en situación de IT por padecer cáncer de útero. La Sala cántabra argumenta que, dado el impacto negativo que normalmente tiene el cáncer en la vida del individuo (sobre todo su tratamiento, que habitualmente conlleva cirugía, radiación o quimioterapia), se puede concluir que la dolencia de la trabajadora es de carácter duradero y que impedirá su participación plena y efectiva en la actividad profesional. En definitiva, existe una divergencia entre los criterios interpretativos que parecían estar sentados por nuestros tribunales, de modo que la duración de la IT no siempre resulta determinante a fin de calificar una dolencia como discapacidad.

Por otra parte, la sentencia del TS de 15 de marzo proporciona un nuevo criterio, cual es la existencia de resolución relativa a la duración en el futuro de la dolen$\mathrm{cia}^{6}$. En particular, argumenta aquí la Sala que «la situación de incapacidad temporal en la que se hallaba la trabajadora al ser despedida, fecha en la que ni siquiera había agotado el periodo máximo y mucho menos existía resolución alguna acerca de una situación duradera de futuro no permite identificarla con la noción de discapacidad distinta de "la enfermedad en cuanto tal"». Sin embargo, de nuevo, en la sentencia del JS de Mataró, de 20 de noviembre de 2017 (rec. 367/2017), se declara nulo el despido disciplinario de un trabajador que ha sufrido diversas crisis epilépticas, que han derivado en varios procesos de IT de corta y media duración. Si bien los procesos de IT sí tienen una duración bien delimitada (16 y 38 días), el hecho de que el empresario fuera conocedor de la enfermedad del actor, y que hubiese padecido 4 crisis en los últimos meses, precisando incluso de tratamiento médico, son indicios suficientes que permiten considerar que se trata de una dolencia de naturaleza duradera. No está de más señalar la existencia de cierta doctrina crítica con este fallo (De Heredia, 2017), por considerar que el último periodo de baja del trabajador (38 días) sí que está bien delimitado en el tiempo y por tanto no cabría encuadrar la situación del trabajador en el concepto de discapacidad. Claro que este argumento también podría oponerse, con arreglo a la propia jurisprudencia del TJUE

5 En sentido contrario, la sentencia del TSJ de País Vasco de 26 de septiembre de 2017 (rec. 1734/2017) toma en consideración la ampliación de la duración de la IT inicial acaecida con posterioridad al despido.

${ }^{6}$ En este mismo sentido, véase también la STSJ Cataluña, de 14 de enero de 2019 (rec. $5527 / 2018)$ 
(asunto Daoudidi), que, dentro del sistema de indicios que configura, no solo contempla el criterio que atiende a la falta de delimitación a corto plazo de la duración de la dolencia, sino que alternativamente también considera si dicha incapacidad puede prolongarse significativamente antes del restablecimiento de dicha persona. Por eso mismo, y atendiendo a la propia naturaleza de la enfermedad padecida por el trabajador, una epilepsia en tratamiento que ha derivado en cuatro crisis en un corto periodo de tiempo, permitiría aventurar la posibilidad de que la enfermedad se mantenga durante un largo periodo de tiempo.

La adopción por la empresa de ajustes razonables se configura también como uno de los aspectos esenciales que debe valorar el juzgador a fin de determinar si la decisión del empleador/a puede ser calificada o no como discriminatoria, por razón de la discapacidad de la persona trabajadora. En este sentido, resulta ineludible la cita de la sentencia del TS de 22 de febrero de 2016 (rec. 160/2016.), donde se niega la concurrencia de discriminación por razón de discapacidad cuando la empresa ha llevado a cabo diversas medidas de adaptación del trabajo a la enfermedad. Esta sentencia trae causa de la demanda interpuesta por una trabajadora a la que -tras sufrir un atraco con arma de fuego- se le diagnostica estrés postraumático, por lo cual sufre diversos procesos de IT, hasta que finalmente es despedida por ineptitud sobrevenida. El TS considera que la situación de la trabajadora puede ser calificada como de discapacidad y, por lo tanto, le son de aplicación todas las garantías que la Directiva prevé; entre ellas, la adopción de ajustes razonables. Ahora bien, dado que "por parte de la empresa, se llevaron a cabo distintas y sucesivas medidas todas ellas tendentes a la readaptación de la concreta situación de la actora a otros puestos de trabajo que pudieran minimizar las consecuencias de la afectación», la decisión empresarial no se considera aquí discriminatoria. Esta postura supone la completa asunción de la jurisprudencia europea, que concibe las medidas de ajuste como la consecuencia de la discapacidad, y no el elemento constitutivo, de modo que aquellas «son aplicables sólo a condición de que exista una discapacidad» (apdo. 46 de la sentencia del TJUE de 11 de abril de 2013). No obstante, algún autor mantiene lo contrario, sobre la base de que la adopción de medidas de ajuste o apoyo es el elemento constitutivo de la discapacidad, de modo que cabría extender el marco protector a los trabajadores/as enfermos/as que, aun no encajando en el concepto de discapacidad europeo, requieran unas concretas medidas de adaptación del puesto de trabajo, a fin de evitar que la interacción con las barreras existentes dé lugar a una situación de discapacidad (De Fuentes, 2016: 88, 89 y 90).

De la jurisprudencia analizada, se desprende que la duración de la IT es el factor principal a fin de calificar como discapacidad la situación del trabajador/a. Ahora bien, aunque es cierto que puede configurarse como un importante indicio de la durabilidad de la enfermedad, no conviene, a mi juicio, considerar este criterio en exclusiva, sino que debe ser integrado o complementado por otros. En efecto, no conviene olvidar su marcado carácter subjetivo, quedando condicionado a la valoración personal de cada juzgador. Además, la existencia de una resolución sobre la duración de la enfermedad en el futuro se erige como el otro pilar fundamental que debe ser valorado por el juzgador. Debido a la inconcreción del término «resolución", algún autor ha planteado si con dicho término se hace referencia a la existen- 
cia de una resolución administrativa de incapacidad, con el consecuente abandono del concepto funcional de discapacidad, retornándose a los orígenes del modelo médico (Olmos, 2019: 7). De las citadas resoluciones parece deducirse que en el término «resolución» cabe incluir la documentación médica de cualquier tipo que permita presumir que el trabajador no se recuperará a corto plazo.

A la luz de cuanto acaba de exponerse, podemos afirmar que los tribunales españoles parecen haberse decantado por una interpretación restrictiva de las bases sentadas por la jurisprudencia del TJUE. De ahí la conveniencia de la valoración de otros aspectos más allá de la mera extensión temporal, tales como los antecedentes médicos del individuo, la existencia con anterioridad de bajas por IT causadas por la misma enfermedad, así como el carácter crónico de la enfermedad, en la medida en la que los síntomas suelen repetirse de forma cíclica dando lugar a periodos de baja intermitentes. En este sentido, resulta irrelevante el hecho de que el trabajador/a se encuentre en situación de alta médica cuando es despedido. La jurisprudencia del TJUE ha supuesto el nacimiento de un nuevo concepto de discapacidad, dejando atrás aquella concepción en virtud de la cual el individuo debía padecer una limitación de carácter permanente e irreversible, inevitablemente ligada a la resolución administrativa que la reconociera como tal. Ahora, tal y como ha ido perfilando dicho tribunal, nos encontramos ante un concepto de discapacidad flexible (García, 2018: 87-88), el cual ha permitido dar amparo a aquellos/as trabajadores/as que -aun no teniendo un grado de discapacidad reconocido formalmente- presentan determinadas dolencias que, atendiendo a sus especiales características o duración, son merecedoras de la tutela antidiscriminatoria reforzada por razón de discapacidad.

\section{VALORACIÓN FINAL}

El marco jurídico vigente de protección de las personas con discapacidad deja patente la completa asunción en nuestro ordenamiento jurídico del modelo social, el cual pone su foco de atención en la existencia de barreras en la sociedad que impiden la participación plena y efectiva del individuo, en igualdad de condiciones que el resto de la ciudadanía. Pese a que debemos partir de la necesaria distinción entre enfermedad y discapacidad - por tratarse de fenómenos completamente distintos-, la reciente jurisprudencia de la Unión Europea se ha hecho eco de la necesidad de configurar un nuevo concepto de discapacidad que dé respuesta a los trabajadores/as que, aun no considerándose integrados en el colectivo de personas con discapacidad, con el correspondiente reconocimiento formal, sean acreedores de esta tutela jurídica reforzada en el ámbito laboral, y ello a fin de evitar que determinadas barreras sociales los coloquen en una situación de desventaja particular. En definitiva, ha cambiado el modo tradicional de entender el fenómeno de la discapacidad, y en consonancia con ello deben centrarse los esfuerzos en la adopción de medidas de adaptación del puesto de trabajo, incluso con carácter previo a la aparición de la situación de discapacidad. 


\section{BIBLIOGRAFÍA}

Carrasquero, M. (2018). «Los ajustes razonables para personas con discapacidad en la Unión Europea». Revista de Estudios Europeos, 71: 38-47.

De Fuentes García, C. (2016). «Sobre el concepto jurídico de persona con discapacidad y la noción de apoyos necesarios». Revista Española de Discapacidad, 4(2): 81-99.

De Heredia, I. (2016). Caso Daouidi (TJUE): incapacidad temporal, despido y discriminación (en línea), recuperado de https://ignasibeltran.com/2016/12/02/caso-daouidi-tjue-incapacidad-temporal-despido-y-discriminacion/. Último acceso 25 de marzo de 2020.

De Heredia, I. (2017). Extinción injustificada durante incapacidad temporal: 3 nuevos casos de nulidad ('ex' Daouidi) y 4 de improcedencia (en línea), recuperado de https://ignasibeltran. com/2017/12/27/extincion-injustificada-durante-incapacidad-temporal-3-nuevos-casos-de-nulidad-ex-daouidi-y-4-de-improcedencia/. Último acceso 4 de abril de 2020.

De Heredia, I. (2019). Despido objetivo por faltas de asistencias y el caso Ruiz Conejero: el TSJ de CLM ratifica la existencia de discriminación indirecta (en línea), recuperado de https:// ignasibeltran.com/2019/04/26/despido-objetivo-por-faltas-de-asistencias-y-el-caso-ruiz-conejero-el-tsj-de-clm-ratifica-la-existencia-de-discriminacion-indirecta/. Último acceso 10 de abril de 2020.

García, A. (2018). Necesidades especiales de apoyo laboral en colectivos con discapacidad. En particular el empleo protegido. Pamplona: Aranzadi.

García, A. (2019). «El Tribunal Supremo vuelve a establecer la necesaria distinción entre discapacidad e incapacidad permanente laboral». Revista Española de Derecho del Trabajo, 221: 171-188.

Gutiérrez, D. (2015). «La obligación de realizar ajustes razonables del puesto de trabajo a personas con discapacidad en EE. UU. y España: una visión comparada». Revista Internacional y Comparada de Relaciones Laborales y Derecho del Empleo, 3: 32-63.

Olmos, I. (2019). «El despido en situación de incapacidad temporal, la enfermedad y la discapacidad». Nueva revista Española de Derecho del Trabajo, 217: 75-98.

Pérez, J. (2015). Contratación laboral de personas con discapacidad. Incentivos y Cuotas de reserva, Pamplona: Thomson Reuters.

Pérez, L. (2012). La Configuración jurídica de los ajustes razonables (en línea), recuperado de https://www.cermi.es/sites/default/files/docs/novedades/LA_CONFIGURACI_N_JUR_ DICA_DE_LOS_AJUSTES_RAZONABLES.pdf. Último acceso 18 de marzo de 2020.

Rodríguez SANZ, B. (2014). «La obligación de realizar ajustes razonables del puesto de trabajo a las personas con discapacidad». Revista Temas Laborales, 127: 85-120.

Rojo, E. (2019). El TSJ de Castilla-La Mancha confirma que existe discriminación cuando se procede al despido de un trabajador por bajas en el trabajo que derivan de su estado de discapacidad. Notas a la sentencia de 10 de abril de 2019, y recordatorio de las sentencias del TJUE y del JS (en línea), recuperado de http://www.eduardorojotorrecilla.es/2019/04/el-tsj-de-castillala-mancha-confirma.html. Último acceso 6 de abril de 2020. 
MISCELÁNEA / MISCELLANY 



\title{
DINÁMICA Y CAUTIVA: LA CULTURA MATERIAL DE LA CASA. UNA MIRADA ETNOGRÁFICA SOBRE EL HABITAR EN HAEDO, PROVINCIA DE BUENOS AIRES
}

\author{
María Florencia Blanco Esmoris* \\ flor.blancoesmoris@gmail.com \\ Centro de Investigaciones Sociales (CIS)-Instituto de Desarrollo Económico y Social (IDES) / \\ Consejo Nacional de Investigaciones Científicas y Técnicas (CONICET)-Buenos Aires, Argentina
}

\section{RESUMEN}

Este artículo busca problematizar, por un lado, la relación que establecen las personas con sus casas en la dinámica cotidiana. Esto es, cómo ocupan, decoran, usan y organizan los ambientes de la vivienda. Por otro lado, el objetivo es conocer cómo ese habitar se produce con relación a la localidad en donde viven: Haedo. Se apela a la cultura material en dos sentidos: de la vivienda y de los objetos que componen el habitar. Los datos surgen a partir de la etnografía que realicé entre 2015 y 2019 con la familia de Gloria, residente de Haedo. PAlabras Clave: etnografía, casa, cultura material, Haedo.

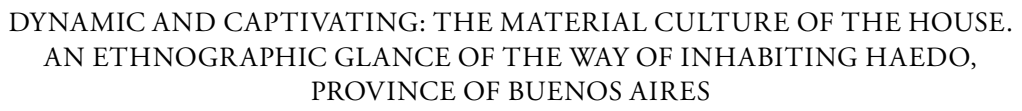

\section{Abstract}

This article aims to problematize, on the one hand, the relationship that people establishes with their homes in the daily dynamics. That is, how they occupy, decorate, use and organize the environments of the house. On the other hand, the objective is to know how this living is produced in relation to the locality where they live: Haedo. The material culture is appealed to in two senses: of the house and of the objects that compose the inhabitant. The data comes from the ethnography I made between 2015 and 2019 with the family of Gloria, a resident of Haedo.

KEYwORDs: ethnography, house, material culture, Haedo. 


\section{INTRODUCCIÓN}

La casa es a la vez lugar de salida y de llegada.

Pero ante todo es un lugar de distancia.

Incluso estando fuera de ella, cuando pensamos en la casa,

nos pensamos en ella (Ambriz Aguilar, 2009)

La casa atraviesa nuestras vidas. Con distintos matices y de forma variada, recorremos sus espacios, la apropiamos, la significamos, trazamos historias y memorias que quedan marcadas en sus paredes y su estructura; incluso tenemos lidias con ella. La exhibimos y, también, invitamos a otros a que la transiten. Trazamos continuidades y discontinuidades con sus espacios y los objetos que allí disponen. En materialidades más frágiles y fragmentadas, en algunas más robustas y transitables, nos aprehende y la aprehendemos. En suma, la habitamos.

A menudo damos por sentado no sólo la existencia de una casa -en la que vivimos-, sino que también homologamos nuestro vínculo con ella al que tienen otras personas, y no nos detenemos a interrogar las experiencias que surgen de/en ella. El interrogante respecto a la materialidad de la vivienda y en la vivienda excede el campo disciplinar de la antropología, tornándose de importancia para las ciencias sociales, humanidades, el urbanismo y la arquitectura. Por eso, propongo distintos lentes que, a lo largo del escrito, me permitirán ir haciendo zoom sobre el objeto de estudio: las características de la vivienda de Gloria y su habitar en Haedo (Provincia de Buenos Aires, Argentina).

Desde comienzos de siglo xx en Argentina, la vivienda moderna en sectores medios $^{1}$ era vinculada con la especificidad funcional de sus ambientes y con ciertas disposiciones de acuerdo con los cuartos, es decir, con la predefinición y segmentación de cada espacio - marcada por una fuerte normatividad-conforme al ideal de la familia nuclear mayormente difundido. Sin embargo, esto no resultaba una práctica usual en una sociedad cuya vida doméstica seguía organizada con base en una familia de tipo extendida (Aboy, 2008). Para mediados de siglo, un progresivo «achicamiento familiar» va a ser una planificación de largo plazo que incluirá diversos arreglos intrafamiliares tanto para acceder a la vivienda como para modificarla y mantenerla.

En este artículo, presento la familia de Gloria: una familia nuclear con una vivienda -como veremos- de extensiones amplias y que, de acuerdo con los materiales y el diseño arquitectónico, permite pensar otro abanico de experiencias y

* Esta investigación fue financiada por CONICET.

${ }^{1}$ En este artículo utilizaré el concepto de sectores medios ya que numerosos investigadores han dado cuenta de que la categoría problemáticamente ha sido empleada como objetiva y universal y que, al clasificar, ha tendido a homogeneizar las características de acuerdo con los criterios del investigador y experto (Visacovsky, 2008). Sin embargo, ocasionalmente la alusión explícita o implícita a la idea de clase media se escurre en los discursos y prácticas de las personas con las que realizo trabajo de campo. 
morfologías del habitar de quienes en la actualidad se reconocen dentro de los sectores medios. Asimismo, para reflexionar respecto a la elección de la vivienda resultan significativas las formas singulares y "globales» de ocupación, singularización y habitabilidad del espacio (Ballent y Liernur, 2014; Arizaga, 2017). Advierto entonces que en un escenario global y regional en donde los procesos identitarios parecieran concebirse como fluidos o sin apego (Castells, 2001) la vida continúa desarrollándose en "términos estrictamente locales» (Mc Dowell, 2000: 13), en este caso, entre la ciudad y la casa. En consecuencia, abordar el habitar me permite un acercamiento al mundo material y simbólico de ese homo quotidianus (Martínez, 2014: 6) de manera situada, abonando así a lo que Tim Ingold denominó la «perspectiva del habitar» (dwelling perspective) (Ingold, 1995). En esta línea, en Argentina existen antecedentes contemporáneos sobre la vivienda y su relación con el barrio (cerrado o abierto) en donde se encuentra, muchos de los cuales hacen foco en la Ciudad Autónoma de Buenos Aires (CABA)² (Arizaga, 2000; Wortman, 2001; Cosacov, 2017).

Cecilia Arizaga (2005), a partir de analizar los discursos publicitarios que exponen y circulan representaciones respecto del espacio doméstico, señala los nuevos agentes que se incorporan al mercado de la vivienda estableciendo las condiciones (objetos y usos) que marcan el «buen vivir» de las llamadas para comienzos de siglo xxi: las «nuevas clases medias». Arizaga destaca que dicho mercado se organiza alrededor de construcciones simbólicas que se imprimen tanto en las ciudades como en las casas. Algunas características que destaca la autora me interesa analizarlas por afuera del espacio geográfico de CABA, más específicamente en Haedo, localizado en el Gran Buenos Aires, área comúnmente denominada conurbano bonaerense ${ }^{3}$. Es en esta área de vacancia donde ubico mi trabajo. Me moviliza conocer aquellos condicionantes y posibilidades, objetivos y subjetivos, que atraviesan las experiencias y narrativas en la vida cotidiana de quienes residen en una vivienda, así como sus decisiones respecto a cómo se ha de habitar (Miller, 2001).

Este artículo es un desprendimiento de interrogantes más amplios que, en el marco de mi tesis doctoral, se interesan por los sentidos, usos y apropiaciones sobre y en la casa. Para este fin recupero notas de campo de mi investigación etnográfica de Gloria y su familia, quienes residen en la localidad de Haedo. Como presento a continuación, esta familia prescribe su habitar de acuerdo con su casa, su localidad y sus expectativas para vivir «bien». Me pregunto entonces ¿̨de qué manera, en la casa, las personas delimitan y negocian espacios y relaciones respecto a cómo se ha de habitar?

2 También denominada Capital Federal.

3 Existe una amplia literatura respecto a la definición del conurbano, cuyos límites de acuerdo con el criterio utilizado pueden variar considerablemente. Inicialmente, en el Censo de 1947, comenzó a utilizarse el término Gran Buenos Aires para referir a una unidad censal conformada tanto por la Ciudad Autónoma de Buenos Aires como por los municipios del Gran Buenos Aires que la rodean, en ese entonces 17, hoy 24 (Segura, 2015), también denominada Área Metropolitana de Buenos Aires (AMBA). En este trabajo, continuando con cierta tradición en la literatura académica consultada, hablamos de conurbano delimitado por los 24 municipios-partidos. 


\section{METODOLOGÍA}

Entre 2015 y 2019 realicé un trabajo de campo etnográfico en casas de familias, el cual privilegió la observación participante y la entrevista no directiva (Guber, 2001) como técnicas de generación de conocimiento. Este fue efectuado en diversas casas de familias que se autoperciben y autoadscriben como parte de los sectores medios - a menudo aludiendo a la noción de "clases medias»- residentes en Haedo y sus inmediaciones (Municipio de Morón, Gran Buenos Aires, Argentina). Mi ingreso a cada casa fue mediado por las mujeres. Como mencioné anteriormente, para este artículo, presento a Gloria y su familia ${ }^{4}$.

Incorporarme a la vida cotidiana y al espacio íntimo supuso identificar aquellos canales de confianza que podían auspiciar de llave para el acceso etnográfico en las casas. Por lo que mi estrategia metodológica se centró en activar mis círculos de afinidad. En particular, vinculados a mi escolarización en un colegio considerado, con razón a su antigüedad, "tradicional» en la zona y de orientación religiosa católica y de gestión privada (localizado en El Palomar) $)^{5}$. Esta estrategia me permitió armarme de una red de contactos para comenzar el trabajo de campo. De esta manera, el colegio se convirtió en "portero" para acceder a estas familias. Con relación a Gloria, como exalumnas, participamos desde el año 2009 del mismo espacio de entrenamiento de hockey sobre césped.

La delimitación de esta familia surge a partir de ciertos observables que me permitieron establecer una aproximación heurística a los sectores medios en la zona trabajada. Estos observables (extensión y estética de la casa, la zona en la que se sitúa, la escolaridad de sus hijos y su tipo de gestión, el acceso a servicios de salud, entre otros) se complementaron con algunas dimensiones como ocupación e ingreso ${ }^{6}$. Mis entradas al campo fueron, en algunos casos, semanales -incluso alcanzando una frecuencia de tres veces por semana- $y$, en otros, quincenales o mensuales de acuerdo con el momento del año. Esta temporalidad se vio signada por eventos cotidianos, imponderables y otras circunstancias de la organización familiar. Con el correr de los meses y los años fui formando parte de variadas situaciones y eventos (como el día de la madre, cumpleaños, entre otros) que me permitieron asir lo relacional en lo material. En ese sentido, notando cómo los límites se tornaban móviles y dinámicos, anclados no sólo en los objetos, sino en las prácticas que los (re)actualizaban

${ }^{4}$ Cabe señalar que esta familia puede incorporarse a los sectores medios de acuerdo con diversos criterios socioeconómicos (como los de ingresos, su nivel educativo, sus accesos a servicios de salud de gestión privada, características de la vivienda, aprovisionamiento, entre otras características).

5 Este colegio cuenta con nivel maternal y jardín, primario, secundario y escuela técnica. Se ubica en la localidad de El Palomar, lindante con la localidad de Haedo. Se fundó en 1954 por un padre alemán y hoy en día su matrícula asciende a los/las 2500 estudiantes.

${ }^{6}$ El nivel de ingreso mensual de este hogar supera hasta más de tres veces el ingreso promedio relevado para aglomerados urbanos (Bonfiglio et al., 2008). Para el momento en que se realizó el trabajo de campo, según este informe, el nivel de ingreso total familiar para el estrato socioeconómico medio alto era de \$36347 para diciembre de 2016 . 


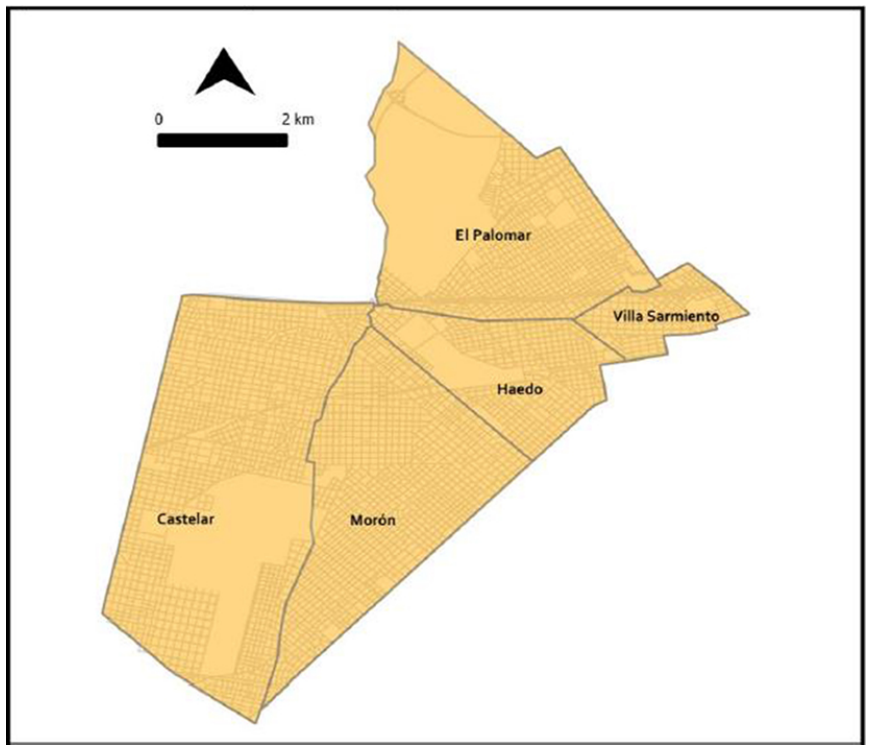

Fuente: Acumar. Límites municipales: Av. Presidente Perón, Colihue, Cańada de Juan Ruiz, Rawson, Pueyrredón, Don Bosco, Fray Cayetano Rodríguez, Av. Rivadavia, Güemes.

y los significaban. La cotidianidad puede parecer que no encierra artilugio alguno; sin embargo, se presenta como un «escenario en donde se multiplican los efectos» (Balandier, 1994) y las formas de habitar la casa a través de la objetos, bienes y artefactos entendidos en tanto cultura material ${ }^{7}$ y sus articulaciones con la localidad.

\section{HABITAR HAEDO, VALORAR SUS RITMOS ${ }^{8}$}

Haedo no es un pueblo. Es una ciudad. No tiene subtes, no tiene cadenas de gimnasios y en la actualidad no tiene boliches. Está localizada dentro del Municipio de Morón (mapa I) y lindante con los municipios de La Matanza, Ituzaingó,

7 Sobre la cultura material cabe decir que, si bien inicialmente dentro de la antropología estuvo fuertemente articulada con la práctica arqueológica e incluso en los primeros pasos de la antropología moderna al método evolucionista -que clasificaba las culturas a partir de sus «vestigios»-, en las últimas décadas renovadas relecturas y novedosos aportes han dado cuenta de la importancia de retomar tal agenda que había quedado relegada desde las primeras décadas del siglo xx. En particular puede consultarse Miller $(2001 ; 2005 ; 2008)$, quien arrimó trabajos empíricos en torno a la vida cotidiana y a las casas en diversas ciudades de Londres.

${ }^{8}$ Algunas descripciones que se expresan en este apartado fueron presentadas en otro artículo de mi autoría, Blanco Esmoris (2019). 
Merlo, Hurlingham y Tres de Febrero. Dentro del Municipio de Morón encontramos las localidades de Morón, Villa Sarmiento, Castelar, Haedo y El Palomar.

El nombre de esta localidad es en conmemoración a Mariano José Haedo, presidente de la Comisión Directiva del Ferrocarril del Oeste, que decide crear una estación empalme en esa tierra por $1887^{\circ}$. La piedra fundamental que le dio inicio se colocó en 1889. Para ese entonces, Haedo era un pueblo de veraneo de las familias de Buenos Aires, con grandes casas quintas. A principios de siglo, junto con Ramos Mejía, eran los lugares de descanso y retiro de la ciudad. Y, al mismo tiempo, como lo señalaba una edición del periódico La Tribuna en agosto, 1967, Haedo a principios de siglo se consolidaba como un punto neurálgico de las comunicaciones ${ }^{10}$. Tras el golpe militar de 1930 Haedo se vio -paradójicamente- «revitalizada» por el gobernador Manuel Fresco ${ }^{11}$, quien va a elegir una antigua casona ubicada en esta localidad para residir ${ }^{12}$.

Con el correr de las décadas, Haedo fue incorporando a su trama urbana casas y locales comerciales. Para fines de los sesenta se emplaza la Universidad Tecnológica Nacional (UTN), cercana al Parque Industrial «La Cantábrica», y a mediados de los setenta nace la Biblioteca Pública de Haedo tras una iniciativa de una asociación civil vecinal. En Haedo se encuentran las estaciones del tren General Roca y la línea General Sarmiento, un centro comercial -centrado en la avenida Rivadavia y que continúa en sus inmediaciones-, algunos colegios, un shopping-Al Oeste- y al menos una decena de líneas de colectivos la atraviesan. El Club Sportivo Haedo (CASH) y el Club Haedo Juniors, junto con la Sociedad de Fomento Haedo Sur, llevan en su nombre la localidad. Si bien la proliferación de casas y cierto «boom inmobiliario" puede ser anticipado desde la década del ochenta, en los últimos 20 años se percibe una intensa actividad inmobiliaria (Clarín, 26-07-2005) ${ }^{13}$. Con más de 35000 habitantes, según el último censo, efectuado en 2010 ${ }^{14}$, en Haedo también encontramos una delegación municipal, la Unidad de Gestión Comunitaria (UGC 2), que en los discursos y las prácticas de las personas pasa desapercibida.

En Haedo, algunas casas -las más antiguas- se caracterizan por ser de dos plantas, tener jardines delanteros y ladrillos a la vista. Otras construcciones, posteriores y más pequeñas, se destacan por sus tejados a dos aguas, sus paredes de cemento alisado y sus puertas de madera maciza. Aunque en menor cantidad, también hay

9 Municipio de Morón, información respecto a la localidad de Haedo, disponible en http:// www.moron.gob.ar/municipio/localidades/haedo/.

${ }^{10}$ En La Tribuna, agosto 1967, especial por Norberto P. Devoto «Haedo, 1902».

11 En el marco del golpe de Estado de 1930 y bajo un proyecto presentado por el senador Dr. Obregón, el gobierno provincial aprobó el cambio de nombre a "Seis de Setiembre» en honor al día en que el golpe militar derrocó al presidente Hipólito Yrigoyen; el nombre Morón será restituido a la localidad en 1946 bajo la intendencia de César Albistur Villegas.

12 Hoy cedida a un centro cultural autogestivo denominado «El Transformador».

13 L. Ceriotto, «El boom inmobiliario llega al interior», Diario Clarín, 26 de julio de 2005, sección Noticias.

${ }_{14}$ Municipio de Morón, disponible en http://www.moron.gob.ar/municipio/localidades/ haedo/. 
edificios, ubicados en el centro comercial, mayoritariamente frente a la estación. Por otra parte, las unidades constructivas más recientes se caracterizan por tener paredes de hormigón alisado pintadas con colores pasteles, techos de chapa galvanizada color negro y -a diferencia de los chalets más antiguos- sin tejas, y entradas a la calle caracterizadas por sus portones metálicos en color gris topo. En la actualidad, Haedo es una de las tres localidades del conurbano oeste que, junto con Ramos Mejía y Castelar, en las últimas décadas han devenido en "altamente valoradas» (Kamitz, 2015) por la industria inmobiliaria y el mercado del suelo, alcanzando valores por metro cuadrado similares a los de las localidades del Corredor Norte de la Provincia de Buenos Aires ${ }^{15}$. Este reciente "boom inmobiliario» ${ }^{16}$ ha hecho de esta localidad un atractivo para situarse fuera de la ciudad - pero un acceso a la misma garantizado- y con un estilo de vida "más saludable» (Kamitz, 2015). Esta localidad se exhibe como un "polo residencial» emergente para los sectores medios (Kamitz, 2015: 12), ya manifiesto y explícito desde el 2001. El ritmo de esta localidad se desacelera cuando cae la noche, momento en el que un par de restaurantes, un bar, la estación de servicios y una casa de comidas rápidas mantienen vida. En mi investigación, noté que la vinculación de la localidad con el municipio presentaba matices y formas variadas en donde lo geográfico y lo moral parecían asirse. Esto es, que las fronteras morales también eran ancladas geográficamente. Algunas delimitaciones al interior de la localidad identificadas por mis interlocutores son Haedo Sur, Haedo Chico/Residencial y Haedo Norte ${ }^{17}$ (véase mapa II). En particular, como veremos, para Gloria «Haedo Chico» configura su medio, que le da «seguridad».

Como en otras localidades, en esta también los agentes comerciales y las personas precisan distinciones conforme tanto a la infraestructura material de la ciudad como a lugares que son significativos en sus circulaciones cotidianas; para Gloria, esto involucra límites precisos como el túnel, la barrera, la avenida, "Gaona", la autopista, El Colegio, entre otros. En mi trabajo de campo, estos límites, poco a poco, comenzaban a marcar una serie de territorios morales, sentidos y valoraciones asociadas a esos puntos geográficos. En algunos casos, a partir de binomios: frente a un Haedo «bien y seguro» contraponían la localidad de Morón -localidad cabecera del municipio (ver mapas I y II)- como un espacio «inseguro y peligroso». Ahí noté que la misma ciudad presentaba fragmentaciones, al menos, para algunas personas y sus usos. De esto se desprendía una forma de habitar el espacio urbano donde la localidad tenía su correlato en las casas y sus narrativas. Mientras para

15 En este caso, Haedo y Ramos Mejía, con un precio por $\mathrm{m}^{2}$ del terreno entre los U\$S 550 y U\$S 760, similar a aquellos valores de los terrenos en localidades del Corredor Norte, tales como Martínez (U\$S 692,0) o Acassuso (U\$S 616,0), ambas en el Partido de San Isidro (Informe de Distribución Territorial del Precio de Oferta, 2014: 17 y ss.).

16 Diario Clarín 2005. «El boom inmobiliario llega al interior: en el sur y oeste del GBA también aumentaron los precios de departamentos», noticias, 26 de julio.

17 Los límites de zonas de acuerdo con el municipio pueden consultarse en Límite municipal: Honorable Consejo Deliberante, disponible en http://www.hcdmoron.gov.ar/cou/codigo/limiteszonas.html. 


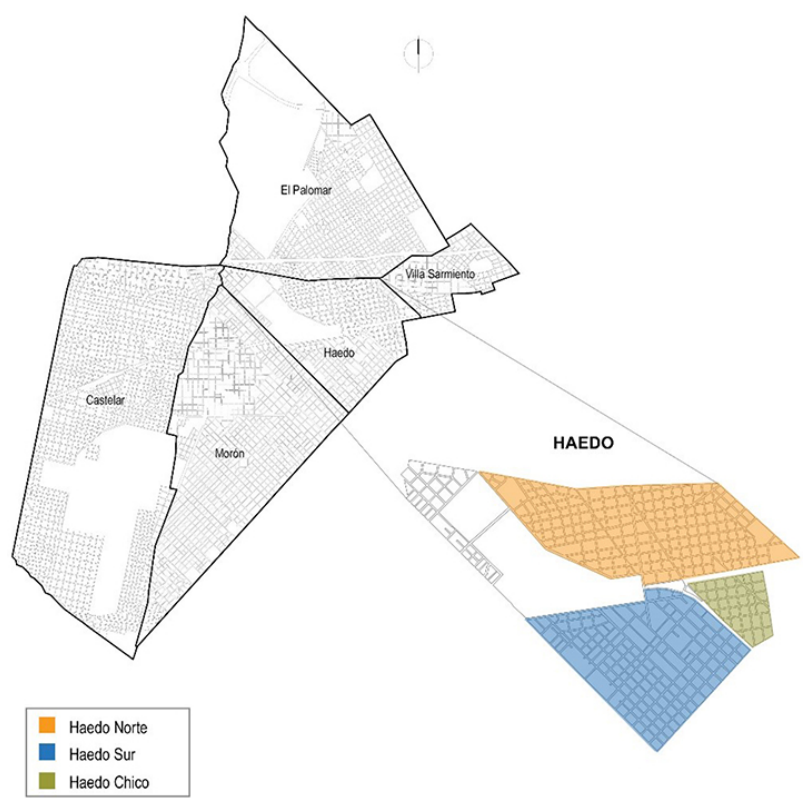

Fuente: elaboración propia con la información provista desde el Municipio de Morón y precisiones de mis interlocutores.

algunos Haedo es una transición para ir a otros puntos del conurbano bonaerense o para ir a CABA, para otros, el lugar donde viven. Gloria ${ }^{18}$ pertenece al segundo grupo. Ella y su familia viven a unas 12 cuadras de la estación de Haedo, a 6/7 de avenida Rivadavia, en la zona denominada como Haedo Chico. Justamente, para Gloria, Haedo es parte de su «ser en el mundo».

Gloria vive en Haedo «desde siempre». Nació el 26 de enero de 1976, tiene una hermana -que vive con su familia en Ciudad Autónoma de Buenos Aires (CABA) - y un hermano -vive en Italia- y fue a un colegio católico de gestión privada ubicado en la localidad de El Palomar. De joven jugó al hockey en el colegio y en el Club San Martín. Estudió en un terciario la tecnicatura en Estudios ambientales, pero hoy en día se dedica «a la casa y a los chicos». Recientemente inició junto con una amiga un emprendimiento de venta de ropa deportiva. Está casada con Ariel, oriundo de Haedo, quien durante el secundario fue al mismo colegio que Gloria. También nacido en el 76, vivió a tres cuadras de la clase de Gloria, además de compartir un grupo católico denominado Partida. Ariel trabaja en la industria del

18 Todos los nombres son ficticios a fin de preservar la identidad de los actores. A Gloria la conozco desde el año 2009, en que se comienza a armar un grupo de hockey de madres y exalumnas. 
hormigón, es independiente y tiene una fábrica en zona norte. Aunque Ariel no es ni arquitecto ni ingeniero, siempre le apasionó lo artesanal; como me dijo Gloria, «aprendió de mirar a su papá arreglar la casa». Su experiencia religiosa en el grupo Partida -donde conoció a su marido-, ser parte de una sociabilidad tradicional en Haedo, transitar por espacios con «valores»-como el colegio al que acudió- expresan en ella y en su familia vínculos estrechos en la significación de lo local y de su casa.

Camino a su casa, paso por una verdulería, un supermercado chino, una clínica privada, una casa de pastas y un almacén. El barrio está en silencio, algunas personas están en la vereda, barriendo o cruzando con bolsas cargadas de mercadería. «No podría vivir en otro lugar», me había dicho Gloria hace algunas semanas. Resulta que, para ella, así como para algunos miembros de su familia, su entorno y vida social están allí, a lo sumo en localidades aledañas como Ramos Mejía-Palomar (donde ella, Ariel y hoy día sus hijos van al colegio) -Morón-. Gloria y su familia van -casi- exclusivamente al centro -Capital Federal- para ver a su hermana, que vive en el barrio de Palermo. Para ella el centro es caótico, «un bardo», esto no es nada nuevo. Creo que cualquiera que va $-y$ no necesariamente vive- al centro, más específicamente el micro, seguramente haya pensado lo mismo que Gloria. Para ella Haedo implica cierta tranquilidad que no se logra en la gran ciudad. Para ella el centro es todo uno, no hay gradientes, así como tampoco categorías intermedias, Gloria va delineando un conjunto de oposiciones homólogas: Centro-caótico/ Haedo-tranquilo. Para Gloria en Haedo la gente es «más amigable» y corre con la ventaja de que "se conocen todos»; por momentos me da la sensación de que para Gloria hay cierta contigüidad entre Haedo y su casa. En este escenario viven Gloria (41) y Ariel (41), con sus tres hijos: Nicanor (14), Lola (11) y Santiago (7) [registro de campo, noviembre 2015].

\section{MORAR EN HAEDO: LA CASA DE GLORIA}

Del latín morari, morar remite a permanecer y residir, pero también al obrar con lentitud. Si desde mediados de siglo xx en Argentina la vivienda moderna en sectores medios era vinculada a la especificidad funcional de sus ambientes, una normatividad del espacio y una llamada de atención sobre su transgresión (Pérez, 2012), hoy en día, en las diversas casas en las que me encuentro haciendo trabajo de campo, observo formas singulares y "globales» de la apropiación, ocupación y habitabilidad del espacio. De forma práctica emergieron algunos interrogantes que me permitieron organizar este apartado: ¿qué formas de diseño arquitectónico se presentan?, ¿cómo se organizan el tiempo y el espacio en el hogar?, ¿¿de qué manera nuevos objetos irrumpen la escena cotidiana?

Según la Real Academia Española (RAE), la primera definición de casa es «edificio para habitar»" . A su vez, la misma entidad prescribe inicialmente hogar

${ }_{19}$ Real Academia Española (RAE), disponible en http://dle.rae.es/?id=7lsKMtR. 
como «sitio donde se hace lumbre en las cocinas, chimeneas, hornos de fundición, etc. $\nu^{20}$. Mientras la primera supone prescribir la estructura edilicia, la segunda remite a una congregación alrededor del fuego. Aun cuando para arquitectos, urbanistas, agentes inmobiliarios y el mismo municipio casa parece limitarse a la designación de la RAE, los usuarios utilizan la misma palabra para designar múltiples cosas que exceden su materialidad. Hogar no es ni una categoría nativa ni una forma efectiva de referir a sus casas.

Hace más de seis años que Gloria y Ariel compraron un amplio terreno a tan sólo unas cuadras de una propiedad horizontal $(\mathrm{PH})^{21}$ de la familia de Ariel en donde vivieron mientras criaban a sus primeros dos hijos. Tras la compra, edificaron una casa y se mudaron. Recuerdo que llamó mi atención apenas la visité, pues su geometría y su escala cromática sólo iban del blanco al gris. La casa es de grandes extensiones y ambientes amplios. Es lo que podría denominar «minimalista», tiene colores monocromáticos y texturas simples. En arquitectura, el minimalismo se vincula al concepto iniciado por el arquitecto y diseñador industrial Ludwig Mies van der Rohe (1886-1969) de "menos es más», fundamentalmente difundido a finales de la década del sesenta y caracterizado por materiales como el cemento, la piedra, el acero, el vidrio y la madera. Justamente, la idea es evitar el «exceso» en la construcción.

Al frente, hay una puerta para el acceso de personas y otra para el ingreso de autos, en el estacionamiento entran dos autos (en ese momento sólo estaba la camioneta familiar Suran de Volkswagen, que es la que utiliza ella). Se ingresa a través de una pesada puerta de madera de casi 3 metros de alto y 2 de ancho. Es un rectángulo que, si bien en términos analíticos podría dividir en dos partes arriba/ abajo-adentro/afuera, parecen fundirse - dado su estilo arquitectónico-. La primera de ellas es el ambiente cerrado - «la casa» propiamente dicha- (plano I), si algo la caracteriza es la falta de paredes, todo está a la vista y los lugares pueden ser circulados por cualquier persona. La otra parte es el afuera: el deck, el patio, la pileta y el quincho. Todo el perímetro de la casa está monitoreado por cámaras de seguridad que se pueden monitorear desde la cocina.

¿Qué cosas de esa casa habían llamado mi atención? Llamó mi atención la falta de divisiones/fragmentaciones edilicias -que en mí ya eran naturales- bajo las cuales había transitado mi propia experiencia biográfica. Automáticamente, pensé en mi casa, ubicada a unas 20/25 cuadras de lo de Gloria, en el partido de La Matanza, en donde los espacios de la casa no sólo eran más reducidos, sino que las paredes delimitaban dicha funcionalidad, así como a las personas. La normatividad y la restricción a las distintas habitaciones eran parte del cotidiano. En mi casa predominan las divisiones y materiales como la madera. Sus colores oscuros la

${ }^{20}$ Real Academia Española (RAE), disponible en http://dle.rae.es/?id=KYIGBW2.

${ }^{21}$ En Argentina, las propiedades horizontales, mayormente sintetizadas con la sigla $\mathrm{PH}$, constan de un inmueble en planta baja con un pasillo común que comunica las viviendas. En términos legales implica la situación dominal compartida con condóminos (dueños/as). 


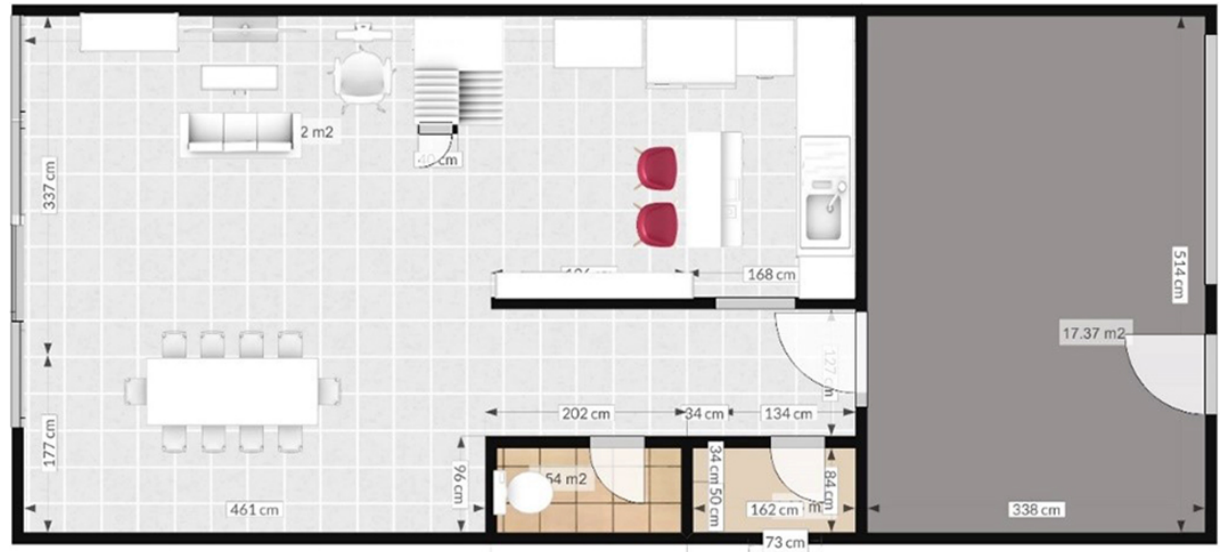

Fuente: elaboración propia en base a observación. Programa Homebyme.

hacen más lúgubre. De ladrillos a la vista, mis padres la habían construido durante la primera mitad de la década del noventa. La casa de Gloria, edificada a fines de la primera década del 2000, parecía tener otras reglas y funcionalidades, así como tonalidades. Una casa que deja la compartimentación y se torna un único espacio. Allí donde suponía «muros» había ambigüedad, equívocos y porosidad. La producción del espacio y su delimitación parecían balancearse de acuerdo con el lugar, el asunto, los actores, así como el sentido otorgado.

Entonces, a mi entender, en la casa de Gloria no había «medias tintas»: no había cortinas -que tapen parcialmente-, no había paredes -en la planta baja-, todo estaba a la vista y, en este caso, no eran los ladrillos sino los juguetes, el material de trabajo, la comida, los útiles, la tecnología y lo artesanal; todo era parte de uno. Entonces, ¿cómo comprender una espacialidad que a priori presentaba más continuidades que discontinuidades edilicias?

Poco a poco fui incorporándome a la materialidad de la casa. La planta baja, abierta y transitada, es de recepción y permanencia. Encarna un espacio privado pero permitido. Sus muebles son nuevos, de colores claros. Al entrar de mano izquierda hay un pequeño cuartito en donde dejan abrigos, camperas, palos de hockey, zapatillas. El cuarto que le sigue es un baño. Contiguo a este, hay un amplio ambiente, algunos le dirían la living-comedor, en donde hay una robusta y maciza mesa de madera con sillas para 10-12 personas que marca un espacio formal para las comidas. Allí, Gloria y su familia comparten las comidas diarias (más frecuentemente cenas), así como los eventos familiares y extrafamiliares. En invierno las cenas se hacen allí, mientras que en verano es reemplazada por la mesa ratona del deck en el exterior de su casa con vista a la pileta. Del lado izquierdo, al costado de la mesa, hay un cuadro - cedido por su hermana- de fondo blanco y con "personitas» dibujadas en los colores rojo y negro. Gloria me contó que se lo había regalado su hermana y que ella justo tenía ahí el cable del aire y le servía para tapar todo eso 
(el cuadro tiene un fondo blanco y personas de distintos tamaños están haciendo diferentes cosas, están pintadas de color negro y por momentos hay trazos en color rojo). El uso del cuadro para Gloria no remitía tanto a patrones estéticos, sino a una forma práctica de resolver, ocultar aquel cable del aire acondicionado. Al derecho de la gran mesa, un futón, la mesa ratona, la tele frente al futón, la computadora en un extremo demarcan -de forma más o menos estricta- lo que sería el living. Hay dos consolas de videojuegos (PlayStation y una Wii), equipo de sonido que acompañan la televisión de pantalla plana-de más de 50 pulgadas-, un objeto de disputa entre los hijos de Gloria y Ariel. Tienen televisión por cable y Netflix. Ariel suele mirar tutoriales por internet, para bajarse unos programas, habla con Nicanor sobre fútbol -miran a River Plate- y/o se dedica a arreglar o a hacer algo para la casa. En el living, muchas veces se sientan los invitados; es un lugar distendido, el orden no es la regla, sí en cambio la comodidad y la disponibilidad de todo, no sólo para los chicos, sino para quien lo necesite. Gloria te indica dónde está cada cosa, te describe el espacio y el objeto, y te da su aval para que vayas a buscarla. Cada invitado es un poco anfitrión, la idea es que esté todo dispuesto y disponible. En el living, se encuentran lo cercano y lo nuevo, sea un invitado a la casa como una compra en materia de tecnología; la disposición y adquisición de bienes es variable. El uso del living se vincula de manera casi exclusiva al sillón, la mesa ratona, la tv, los videojuegos y la computadora a un costado. Este espacio suele ocuparse por Ariel, Nicanor, Lola, Santiago y Ariel más que nada luego del mediodía, horario en que los hijos de Gloria y Ariel regresan de su escolaridad, y en las tardes-noches cuando regresa Ariel del trabajo.

Al subir las escaleras está la planta alta de la casa. Allí hay dispuestos dos baños, tres cuartos habitables (uno para Ariel y Gloria, otro para los hijos varones y uno para Lola) y uno de servicio -en donde está el lavadero-. Hay una claraboya desde la cual se puede ver el cielo. El diseño se continúa en concordancia con la planta baja en cuanto a colores (blancos y grises -en los espacios de transición-) y terminaciones. El cuarto de Ariel y Gloria tiene muebles de madera, cama tipo sommier, posee un baño en suite y predominan los colores claros en las paredes, que hacen contraste con la cama.

\section{CONTINUAR LA ESPACIALIDAD, SEGMENTAR SUS USOS}

En la parte baja, en la cocina, predominan los tonos grises, el negro, blanco y el rojo. Hay en medio una «isla» con las hornallas y un desayunador integrado. Es uno de los lugares privilegiados de Gloria, donde pasa tanto la mañana, la tarde y la noche.

Recuerdo la primera vez que ingresé a su cocina, parecía de revista, Gloria me dijo que era de Johnson. Yo no entendía mucho de cocinas. Busqué un poco y leí que Johnson se dedicaba a la fabricación de cocinas industriales y se las vendían a espacios con una producción intensiva y de grandes volúmenes y que posteriormente comenzaron a trasladarse al ámbito doméstico y, por tanto, cotidiano. Según la 
web institucional ${ }^{22}$, es una empresa dedicada específicamente al acero y luego se expandió al amueblamiento con "soluciones para mejorar el confort y la calidad del hábitat». Para Gloria, esa marca sintetizaba muchas cosas, entre ellas el «buen cocinar» [registro de campo, agosto 2015].

La cocina es un espacio que no sólo alberga momentos de alimentación, sino que también propicia un lugar de charla, tarea, juego y variadas cosas. La cocina, para Gloria y Ariel, se vuelve sinónimo de práctica, más aún su mesada-desayunador. La cocina se encuentra equipada con una cuantiosa e interesante cantidad de artefactos. Cuenta con una heladera de puerta doble con una mesada de mármol, lavavajilla, horno, microondas, la máquina de café expreso -Nespresso- con algunas capsulas exhibidas al costado sobre una mesada (frente a la isla) en donde está la bacha, también hay una pecera con una tortuga («Tortu»), un monitor por el que regula las cámaras de la casa, y el teléfono inalámbrico. La relación entre tecnología, alimentación y aprovisionamiento es intensa y continua. En el quincho, poseen un freezer donde conservan alimentos y bebidas, así como otras cosas de la casa. Cuando hay algún acontecimiento, previsto o imprevisto, el quincho es garante del aprovisionamiento. En sus compras mensuales destinan tiempo, presupuesto y espacio para sus adquisiciones. La improvisación no parece ser la regla.

Dentro de este espacio, la máquina de Nespresso (que combina una marca Nescafé y un tipo de café Expresso) llamó mi atención, menos por su exclusividad ${ }^{23}$ y más por la regularidad con la que la veía en distintas casas de amigos/as por esa localidad. Respecto al café en general y al boom de la máquina de expreso, encontraba que este tipo de comercialización -en monodosis y con distintos sabores- remitía no sólo a una forma de "empujar al consumo", sino de llamar la atención respecto a una "sofisticación» del gusto ${ }^{24}$. En este sentido, el hogar comenzaba a presentarse como una suerte de escenario en donde se dan a conocer objetos y adquisiciones (Miller, 2001: 2008), que permiten clasificar(se) en un mundo social deseado sobre el que empiezan a tener injerencia otros.

Gloria divide el tiempo ordinario en «con los chicos y sin los chicos». En el momento en que no están los chicos, es tiempo de limpieza, de quehaceres del hogar -ya que la persona que se encarga de la limpieza renunción ${ }^{25}$, sale a comprar lo que hace falta (normalmente a los almacenes del centro de Haedo) y, ahora, dedica parte de su tiempo a un emprendimiento. Después de buscar los chicos al colegio, prepara el almuerzo, habla con ellos, organiza los turnos con los médicos, lava, entre

${ }^{22}$ Cocinas y revestimientos Johnson. Puede consultarse mayor información en su sitio de comercialización: http://www.johnsonacero.com/.

${ }^{23}$ Aunque sus valores iniciales superan los $\$ 2000$ por artefacto, para el tipo de cambio oficial al 31 de agosto de 2015, en Argentina serían USD 215.

${ }^{24}$ Apellido de café, entrevista a Martín Cabrales -tercera generación de la empresa líder del rubro- en Infonegocios, 3 de junio 2013.

${ }_{25}$ Gloria me contó que la causa de su renuncia fue porque tenía que quedarse ayudando a su hermana embarazada. 
muchas otras cosas. Gloria divide el tiempo que comparte con Ariel como «en zona norte [en su trabajo] y acá [en su casa]». Así, el espacio se vincula con Gloria en una triple función: esposa, madre y emprendedora.

Si la barra-desayunador- parece un accesorio, esto no es así en la práctica. En el tiempo ordinario (lunes a viernes al mediodía, algunas noches), la barra de la cocina es la mesa principal, es decir, que hay un uso normalizado. En el tiempo extraordinario (cumpleaños, día de la madre/padre, celebraciones) la barra se utiliza para los preparativos, y la robusta mesa del comedor, para disponer todos los comestibles y bebibles para disfrutar del encuentro. La parte baja de la casa es un espacioso y luminoso único ambiente que se conecta con la cocina, como un continuum. En la parte baja de la casa, transita la familia, los amigos e invitados, es un espacio de recepción, circulación y permanencia. Los amplios ambientes facilitan eso. No hay divisiones claras impresas en la arquitectura, más bien esas divisiones se apoyan en los objetos allí posicionados: mesa, futón, dispositivos de entretenimiento. No hay división entre un living y un comedor, así como no la hay entre luz y oscuridad.

En la parte alta, hay divisiones, paredes y puertas. El tránsito es menor, no suben los invitados, sólo algunos amigos de la familia y familiares lo hacen. Es el lugar de la intimidad y del descanso. Casi no hay aparatos tecnológicos: sólo una tele -y los celulares- en el cuarto de Ariel y Gloria. En el cuarto de Lola predomina el color lila, en el de los chicos el azul y verde. En ambos cuartos encuentro una numerosa cantidad de juguetes y de osos. En el de servicio, Gloria se encarga de lavar la ropa, a veces le pide ayuda a Lola. La parte alta tiene dos momentos de activación en el día: las mañanas y las noches. Es la parte del descanso y del trabajo, al menos del de Gloria. Con el transcurrir del día, va siendo mayor el tiempo en esta planta. En la tarde-noche, Gloria y Ariel les dicen a los más grandes, Nicanor y Lola, que tienen que bañarse, mientras Santiago es acompañado por alguno de los dos. El espacio está determinado estructuralmente y las puertas abren y cierran momentos, conversaciones y relatos. La escalera es la intermediaria de estos dos cosmos de arriba y abajo.

Para Gloria, su casa y las cosas que están allí remiten a modo de ser y estar en el mundo estrechamente orientado a su posición social. La valoración de lo que tiene y cómo mantenerlo se organiza más con relación a una lógica funcional y menos a una lógica de tipo estética. Un ejemplo de ello fue la forma de "resolver» la salida del cable del aire acondicionado y el agujero que estaba allí con el cuadro que le regaló su hermana. Es importante destacar esto porque en su casa los objetos pueden adoptar significaciones ambiguas y sus funciones son dinámicas de acuerdo con esa "casa practicada». De igual manera, lo que Gloria considera valioso en la casa se vincula con la concepción de Haedo «tranquilo, sociable», en donde la limpieza y la tradición emergen como formas del «bienestar material» (material wealth) ${ }^{26}$ (Miodownik, 2013). Es decir, el conjunto de bienes que conforman la cultura

${ }^{26}$ Una traducción posible de este término puede ser «riqueza material», pero considero que la noción de bienestar provee de mayor elasticidad a este término, más si tenemos en cuenta los pro- 
material de su casa, en parte, garantizan ese «vivir bien» y, para Gloria, «segura» en esta localidad. Este bienestar, de manera más integral, se ve acompañado por artefactos y decisiones arquitectónicas que median tales experiencias y sensaciones: sea por la cámara que controla el acceso a su casa, el paredón de concreto que pone el límite entre el adentro y el afuera con la localidad o la enorme puerta de madera maciza que termina por establecer una distancia con el espacio público; como un modo específico de experimentar lo propio «sin riesgos». En este orden de cosas es que identifico cierta contigüidad entre lo deseable para su localidad y lo proyectado para su casa. Dicha continuidad se encuentra garantizada por el lugar que ha elegido para vivir $\mathrm{y}$, del mismo modo, de acuerdo con los vínculos sociales que establece la familia producto de la sociabilidad local, complementariamente articulada por la elección educativa para sus hijos e hija. Las biografías de Gloria y Ariel están estrictamente relacionadas con su profesión y educación de la religión católica y los valores morales, con una retroalimentación dinámica en relación con la morfología urbana encapsulada de Haedo. Con esto refiero a los lazos que pueden establecerse entre la participación de la familia en variadas dinámicas de sociabilidad en Haedo -y en Palomar-que contribuyen al establecimiento de cierto orden moral diferencial (Duarte y Gomes, 2008) en diálogo con un tipo de experiencia que modula ciudadvivienda y prescribe sus elecciones. Siguiendo este horizonte, la previsión del tiempo, su organización, las pautas de aprovisionamiento y la planificación forman parte de sus vidas y de su cotidiano.

Gloria y Ariel prefiguran un futuro para la familia. Las decisiones diarias, la rutina, la economía de la casa, la gestión de la cocina y los bienes y su propio negocio toman parte de esta figura del futuro. Su casa no es un espacio más, sino el espacio en donde se condensa una temporalidad más amplia -el futuro- y formas de gestión de la cotidianeidad que hacen raíz en la figura de Gloria: principal garante y cuidadora del habitar de esta familia. Es en esa organización de la institución familia donde Gloria provee de formas prácticas de gestionar y performar el futuro de cada uno de sus miembros gestionando su propia subjetividad. En este punto, siguiendo el trabajo de Han (2011) considero fértil poder pensar en la fenomenología de la espera ("phenomenology of the waiting») como un lugar de producción de sentidos y de exposición de los usos. Es decir, la configuración familiar en la casa implica el cumplimiento de diversos tipos de roles sociales. Gloria, como muchas mujeres, es central en este proceso de asegurar un tipo de reproducción familiar y de valores conforme a lo propio, pero también a lo apropiado. Su gestión doméstica resulta significativa a los fines de producir un horizonte de lo deseable y de lo posible. Cierto es que, como vimos a lo largo del artículo, la casa es una actividad de tiempo completo.

cesos contemporáneos de adquisición y apropiación material que se despliegan como parte de una narrativa global más fluida sobre la adaptabilidad, la flexibilidad y el cuidado del $y o$. 
Comencé este artículo con una cita de Ambriz Aguilar (2009), quien loa el carácter material y simbólico de la casa, ponderando esa casa practicada. El título de este trabajo alude a dos características que sobrevuelan este análisis. Cautiva insinúa que la casa aún constituye un terreno de interrogantes e incertidumbres poco aprehensibles en ciertas investigaciones si no se tiene en cuenta su carácter vivo y practicado. Dinámica, por su carácter variable, que de acuerdo con el emplazamiento de la casa toma formas específicas.

A partir de Gloria y su familia en Haedo, vimos cómo la elección del habitar se ve sugestionado por experiencias previas conforme a la sociabilidad y a la localidad en un lugar determinado. En ese proyecto de largo plazo, la casa se torna una materialidad vital que posibilita la organización del bienestar. Este bienestar se traduce en diversas elecciones materiales que buscan asegurar la vida "puertas adentro». Aun la diversidad de experiencias, en el caso de esta familia las redes familiares y de sociabilidad resultan significativas para vertebrar este habitar. En este artículo, me interesaba presentar el modo en que un habitar contemporáneo se articula con decisiones que hacen a la vida cotidiana de las personas y aquello que es o no deseable. En este escenario, la figura de Gloria es vital para asegurar un conjunto de prerrogativas. Con relación a esto último, esbocé cómo la espera se transforma en un estado activo de habitar y producir sentidos respecto de la vida propia y la de terceros/as.

Como vimos, las formas de habitar los espacios y significarlos se ven atravesadas por las biografías y geografías de sus habitantes, en donde la experiencia de la familia de Gloria no es la excepción. Este escrito no hace más que deslizar interrogantes respecto a la cultura material, pero también respecto a procesos de significación más amplios donde ella entiende sus decisiones. Cierto es que «no nos encontramos frente a términos estables, sino a conceptos y prácticas en constante mutación, cuyas nuevas expresiones es necesario registrar y conocer» (Ballent y Liernur, 2014: 23). En parte, la pregunta por las formas de vida, la experiencia social y la relación con la naturaleza son motores del devenir disciplinar en humanidades y ciencias sociales. Como formas de espacializar las relaciones sociales que responden tanto a elecciones personales como a tramas familiares que se articulan con la zona en la que se vive tanto como en lo que se proyecta para sí y para otros. Como vimos, la vivienda y su cultura material aún edifica gran parte de la cotidianidad de las personas tanto como sus vínculos sociales. 


\section{REFERENCIAS BIBLIOGRÁFICAS}

Авоу, R. (2008.) «Arquitecturas de la vida doméstica. Familia y vivienda en Buenos Aires, 19141960». Anuario IEHS (23): 355-384.

ACUMAR (2014). «Observatorio Unidad Sanitaria Ambiental de Morón». Informe sociodemográfico $y$ de salud del Partido de Morón. Noviembre.

Ambriz Aguilar, C.E. (2009). «Texto tomado. Análisis narratológico de 'Casa tomada' de Julio Cortázar». Espéculo, Revista de Estudios literarios. Universidad Complutense de Madrid (42).

Arizaga, M.C. (2000). «Murallas y barrios cerrados. La morfología espacial del ajuste en Buenos Aires». Nueva Sociedad, (166): 22-32.

Arizaga, M.C. (2005). «La construcción del gusto legítimo en el mercado de la casa». Bifurcaciones, (5), s/n.

Arizaga, M.C. (2017). Sociología de la Felicidad: autenticidad, bienestar y management del yo. Buenos Aires: Biblos.

Balandier, G. (1994). El poder en escenas. De la representación del poder al poder de la representación. Buenos Aires: Paidós.

Ballent, A. y Liernur, J.F. (2014). La casa y la multitud: vivienda, politica y cultura en la Argentina moderna. Buenos Aires: Fondo de Cultura Económica.

Blanco Esmoris, M.F. (2019). «¿La indeterminación del orden binario? Notas descriptivas para pensar La casa o el mundo dado vuelta de Pierre Bourdieu en una etnografía contemporánea». Cuadernos del Centro de Estudios en Diseño y Comunicación, (88): 111-127. Capital Federal: Cuadernos del Centro de Estudios en Diseño y Comunicación-Universidad de Palermo.

Bonfiglio, J.I., Vera, J. y Salvia, A. (coord.) (2008). Condiciones materiales de vida. Hábitat, pobreza y desigualdad en los hogares urbanos de la Argentina (2010-2017). Ciudad Autónoma de Buenos Aires: Educa.

Castells, M. (2001). La Era de la Información: Economía, Sociedad y Cultura. Madrid: Alianza Editorial.

Cosacov, N. (2017). «El papel de la familia en la inscripción territorial. Exploraciones a partir de un estudio de hogares de clase media en el barrio de Caballito, Buenos Aires». Población \& Sociedad, vol. 24 (1): 35-65.

Devoto, N.P. (1967). «Haedo, 1902». La Tribuna, especial agosto.

Duarte, L. y Gomes, E. (2008). Três Famílias. Identidades e Trajetórias Transgeracionais nas Classes Populares. Rio de Janeiro: Editora FGV.

Guber, R. (2001). La etnografía, método, campo y reflexividad. Bogotá: Grupo Editorial Norma.

HAN, C. (2011). «Symptoms of another life: time, possibility and domestic relations in Chile's credit Economy». Cultural Anthropology (26) 1.

Infonegocios (2013). «Apellido de café», entrevista a Martín Cabrales -tercera generación de la empresa líder del rubro-, 3 de junio, recuperado de https://infonegocios.info/in-semanal/ apellido-de-cafe. Última consulta: 29/04/2020.

INGOLD, T. (1995). «Building, dwelling, living: How animals and people make themselves at home in the world», en M. Strathern (ed.), Shifting Contexts. London: Routledge. 
Kamitz, R. (2015). Condominios Urbanos. Análisis sobre el polo residencial de Ramos Mejía, Haedo y Villa Sarmiento. Alternativa para la revalorización de enclaves urbanos en áreas potenciales para el desarrollo inmobiliario (tesis de maestría). Belgrano: Universidad de Belgrano.

Martínez, E. (2014). «Configuración urbana, habitar y apropiación del espacio». XIII Coloquio Internacional de Geocritica. Barcelona: Universidad de Barcelona.

McDowell, L. (2000). Género, identidad y lugar. Madrid: Eds. Cátedra.

Miller, D. (ed.) (2001). Home possesions: material culture behind close doors. UK: Bloomsbury Academic.

Miller, D. (2005) Materiality. Duke: Duke University Press.

Miller, D. (2008) The comfort of things. Cambridge: Polity Press.

Miodownik, M. (2013). Stuff Matters, The Strange Stories of the Marvellous Materials That Shape Our Man-Made World. Londres: Penguin.

Pérez, I. (2012). El hogar tecnificado. Familias, género y vida cotidiana 1940-1970. Buenos Aires: Biblos.

Segura, R. (2015). «La imaginación geográfica sobre el conurbano. Prensa, imágenes y territorio», en G. Kessler (dir.), Historia de la provincia de Buenos Aires: El Gran Buenos Aires. Ciudad Autónoma de Buenos Aires: Edhasa, Gonnet, UNIPE, Editorial Universitaria.

VISAcovsky, S. (2008). «Estudios sobre 'clase media' en la antropología social: una agenda para la Argentina». Avá Revista de Antropología, (13): 9-37.

Wortman, A. (2001). «Globalización cultural, consumos y exclusión social». Nueva Sociedad (175): 134-142. 


\title{
CAMBIOS EN LA POBLACIÓN DE LOS MUNICIPIOS \\ DE HASTA 5000 HABITANTES DE ESPAÑA (2000-2019): \\ UNA APROXIMACIÓN A LA CRISIS DEMOGRÁFICA \\ EN EL TERRITORIO RURAL
}

\author{
Xosé Elías Trabada Crende \\ xetc@emic-etic.eu \\ Universidad de Vigo y Consultora Emic-Etic
}

\section{RESUMEN}

El territorio rural español del interior peninsular se encuentra inmerso en una grave crisis demográfica que amenaza la supervivencia de una parte relevante de sus municipios. Durante las casi dos décadas transcurridas del siglo xxi no se han corregido las tendencias de despoblación y abandono, de envejecimiento y masculinización de la población rural, sino que se han cronificado para derivar en un intenso proceso de desertización demográfica del hábitat rural segregado de las redes y actividades de la globalización capitalista. Urge un cambio copernicano en las políticas de ordenación y planificación del territorio, mediante el cual se ha de promover una reforma de la Administración local hacia la constitución federal de comarcas y un ecodesarrollo endógeno e integral que, básicamente, rejuvenezca la población rural gracias a la inmigración.

Palabras clave: municipios rurales, despoblación, sobreenvejecimiento, masculinización, desertización demográfica.

CHANGES IN THE POPULATION OF THE MUNICIPALITIES

WITH LESS THAN 5000 INHABITANTS IN SPAIN (2000-2019):

AN APPROACH TO THE DEMOGRAPHIC CRISIS IN THE RURAL TERRITORY

\section{Abstract}

The Spanish rural territory of the peninsular interior is immersed in a serious demographic crisis that threatens the survival of a relevant part of its municipalities. During the almost two decades of the 21st century, the trends of depopulation and abandonment, of aging and masculinization of the rural population have not been corrected, but have been chronified to lead to an intense process of demographic desertification of the rural habitat segregated from networks and activities of capitalist globalization. A Copernican change in territorial planning and planning policies is urgently needed, promoting a reform of the Local Administration towards the federal constitution of Comarcas and an endogenous and integral ecodevelopment that basically rejuvenates the rural population thanks to the immigration.

KEYWORDs: rural municipalities, depopulation, over-aging, masculinization, demographic desertification. 


\section{PRESENTACIÓN}

La mayoría de nuestros municipios rurales de la España peninsular han continuado sufriendo un proceso de despoblación y abandono durante las dos décadas transcurridas del siglo xxi, que es estructural y parece irreversible, el cual ha alcanzado en muchos de ellos un grado de gravedad propio de un 'desierto demográfico', que debilita y amenaza la supervivencia misma de las comunidades locales más afectadas. Con este artículo, pretendemos dar a conocer la magnitud cuantitativa del proceso demográfico que desertiza el territorio rural del Estado español, centrando nuestra mirada de sociología de la población en el intervalo temporal de 2000 a 2019 y en los municipios españoles de hasta 5000 habitantes, pero con un enfoque comparativo con los municipios que superan dicho umbral de poblamiento. Además de la despoblación, nos interesamos por los fenómenos demográficos del envejecimiento, la masculinización y la inmigración extranjera, así como de la densidad de población en el territorio, con el propósito de conocer su evolución y dimensión cuantitativa entre los municipios de hasta 5000 habitantes y, a su vez, indagamos en qué rasgos de esos fenómenos se diferencian con respecto a los municipios de más de 5000 habitantes.

Sin embargo, el objetivo de nuestro artículo no se limita a conocer la dimensión cuantitativa de la crisis demográfica que debilita y amenaza la supervivencia de una parte relevante de los municipios rurales del interior peninsular, sino que también queremos reflexionar sobre su dimensión cualitativa en un sentido propositivo. Parafraseando la famosa tesis undécima de Marx sobre Feuerbach, apreciamos que las y los sociólogos explicamos la realidad rural de diferentes maneras, pero también debemos esforzarnos por contribuir a cambiarla. Por consiguiente, hemos elaborado este artículo con la finalidad estratégica de 'conocer para actuar', ya que pensamos que la sociología no solo ha de ser una disciplina científica con carácter semántico, sino también pragmático: su interés respecto del objeto de estudio tiene que abarcar las vertientes del 'decir' y del 'hacer', aunando las perspectivas distributiva y estructural con el enfoque dialéctico (Ibáñez, 1991). De ahí que finalicemos este artículo con un apartado dedicado a recomendar varias propuestas dirigidas a actuar contra la crisis demográfica que sufre el mundo rural.

En cuanto a la metodología empleada, realizamos un análisis secundario demográfico de los datos cuantitativos generados por dos fuentes secundarias: la Estadística del Padrón Continuo, con referencia temporal a 1 de enero de 2000 y 2019, y los Censos de Población y Viviendas, principalmente los comprendidos de 1981 a 2011, ambas fuentes del Instituto Nacional de Estadística (INE). En líneas generales, efectuamos un análisis secundario de carácter demográfico de varios indicadores con relación a la cantidad y evolución de la población total, la estructura por edad (edades medias, porcentajes de menores de 15 años y de mayores de 64 años, índices de envejecimiento), la estructura por sexo (evolución y ratios de masculinidad), la población total según su nacionalidad (porcentajes de población extranjera), además de analizar la densidad de habitantes por $\mathrm{km}^{2}$. Indicadores cuantitativos que se refieren a los municipios españoles distribuidos en estratos según su tamaño 
poblacional, un tipo de clasificación que utiliza el INE en la explotación estadística de los Censos de Población y del Padrón Continuo.

El tamaño demográfico de los municipios se aprecia en sociología y geografía como uno de los criterios principales para caracterizar los territorios rural y urbano, estableciéndose generalmente un umbral o límite concreto para adscribir a un municipio en uno u otro tipo de hábitat. De la clasificación estadística que realiza el INE con los municipios españoles según su tamaño demográfico, hemos optado por hasta 5000 habitantes como el umbral por debajo del cual es bastante probable que nos encontremos ante municipios rurales, pues desde 5001 a 10000 habitantes pensamos que aumenta la posibilidad de que se trate de 'municipios híbridos o mixtos', donde se combinan atributos rurales y urbanos (los espacios rururbano y periurbano). Somos conscientes de que la variable del tamaño demográfico, siendo pertinente y adecuada, sin embargo es insuficiente para definir un municipio como rural o urbano, ya que debería complementarse con otras variables, como el grado de urbanización y de densidad demográfica y la estructura económica. En todo caso, pensamos que entre los municipios españoles de hasta 5000 habitantes se encuentran la gran mayoría de los que realmente son rurales ${ }^{1}$, incluyendo los que son cabeceras de una comarca rural, los cuales no debemos excluirlos del medio rural por el simple hecho de desempeñar ese rol de centralidad en el territorio, lo que de manera mecánica se suele identificar como un atributo exclusivo del hábitat urbano.

Finalicemos la presentación del artículo mencionando que se desagrega en ocho apartados: despoblación y abandono, el sobreenvejecimiento de la estructura por edad, la masculinización de la estructura por sexo, la inmigración extranjera, las pirámides de población, un desierto demográfico, conclusiones y algunas recomendaciones.

\section{DESPOBLACIÓN Y ABANDONO}

Comencemos por los datos estadísticos del Padrón Continuo de 1 de enero de 2019 (datos definitivos), donde observamos que el conjunto de los municipios de hasta 5000 habitantes sufrió un ligero decremento de $-0,2 \%$ con respecto a la población total empadronada en el año anterior: en términos absolutos, sus residentes menguaron en 11058 efectivos. A diferencia del conjunto de los municipios de más de 5000 habitantes, cuya población empadronada aumentó en 314286 individuos, significando un incremento del $0,8 \%$, que es responsable del crecimiento interanual experimentado por la totalidad de la población de España $(0,6 \%)$.

${ }^{1}$ En el artículo 3 de la Ley 45/2007 de 13 de diciembre, para el Desarrollo Sostenible del Medio Rural (LDSMR), se define el 'medio rural' como el espacio geográfico formado por la agregación de municipios o entidades locales menores definido por las administraciones competentes que posean una población inferior a 30000 habitantes y una densidad inferior a los 100 habitantes por $\mathrm{km}^{2}$. Además, define el «municipio rural de pequeño tamaño» como el que posea una población residente inferior a los 5000 habitantes y esté integrado en el medio rural. 


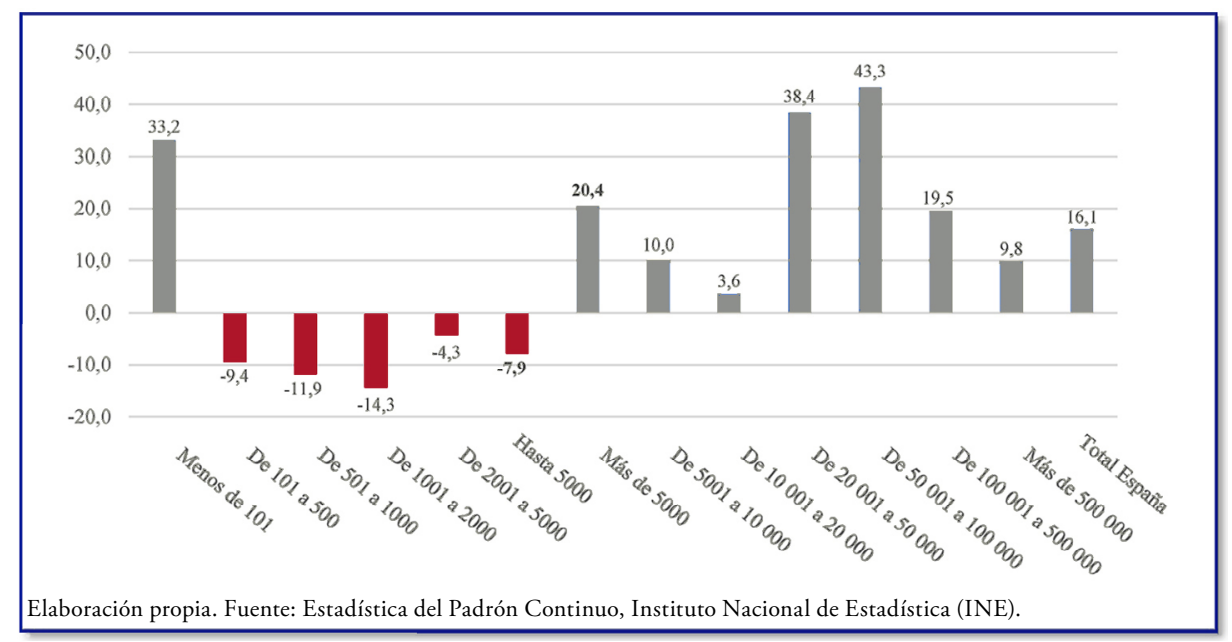

Gráfico 1. Evolución de la población, ambos sexos, entre el 1 de enero de 2000 y 2019 en el Padrón Continuo (datos definitivos) de los municipios españoles clasificados por tamańo demográfico: incrementos (\%) o decrementos (-\%).

Al contemplar la evolución entre el 1 de enero de 2000 y 2019, se observa con mayor nitidez la desigual dinámica demográfica que ha actuado en los dos conjuntos municipales: la población empadronada en los de hasta 5000 habitantes decreció en $-7,9 \%$, mientras en los municipios que superaron ese umbral creció en $20,4 \%$. Entre los términos municipales que suponemos rurales ( $\leq 5000$ residentes) se manifiesta una única excepción a la corriente dominante de declive demográfico: la población sí aumentó entre los de menos de 101 habitantes $(+33,2 \%)$, aunque más bien se debe a que creció el número de municipios que se precipitaron a este pequeño tamaño, motivado por el intenso proceso de despoblación y abandono que sufre el medio rural con una demografía inferior y más debilitada. Por el contrario, la población empadronada sí creció en cada uno de los seis tramos en los que el INE clasifica los términos municipales que superan los 5000 habitantes, como podemos observar en el gráfico 1 .

En un escenario estatal de crecimiento demográfico (16,1\%) entre el 1 de enero de 2000 y 2019, el declive de residentes en los municipios de hasta 5000 habitantes ha implicado que estos perdiesen representación en el total de la población española. Así, su significación menguó en casi tres puntos porcentuales: del 15,3\% en 2000 al 12,1\% en 2019. De hecho, sobre el total estatal, entre el 1 de enero de 2000 y 2019 creció la representación relativa de los tramos municipales de 20001 a 50000 (de 13,9\% a 16,5\%), de 50001 a 100000 (de 10,5\% a 12,9\%) y, ligeramente, de 100001 a 500000 habitantes (de 23,1\% a 23,8\%). Por consiguiente, se acrecentó la relevancia poblacional de los municipios propiamente urbanos (ver tabla I), en general de las ciudades pequeńas y medianas, pero no así de las grandes 
urbes y metrópolis que superan los 500000 habitantes. En suma, durante el tiempo transcurrido del siglo XXI, ha proseguido la concentración de la población en el territorio urbano $^{2}$, donde se centralizan las actividades económicas, los empleos y servicios, tanto privados como públicos, de la formación social española.

Ahora bien, ¿̇cuántos municipios tienen menos de 5001 habitantes? Al comenzar el año 2019, de los 8131 municipios españoles existentes, 6829 no superaron ese umbral de poblamiento; en términos porcentuales, representan el $84 \%$ del total. Además, casi dos tercios de los municipios espańoles - concretamente 5000, que simbolizan el 61,5\% del total- no lograron superar los 1000 habitantes. Asimismo, prácticamente la mitad de nuestro universo municipal -precisamente 3997 municipios, que significan el 49,2\% del total- no consiguieron rebasar los 500 residentes. Y nada menos que 1352 términos municipales no superaron el nivel más bajo de poblamiento, esto es, hasta 100 habitantes, los cuales representan el 16,6\% del total municipal.

\begin{tabular}{|c|c|c|c|c|c|c|}
\hline $\begin{array}{r}\text { TABLA I. DISTRII } \\
\text { Y DE } 2019 \text { EN } \\
\text { DEMOG }\end{array}$ & $\begin{array}{l}\text { EA PADRÓN } \\
\text { RÁFICO DI }\end{array}$ & $\begin{array}{l}\text { ONTINU } \\
\text { MUNICI }\end{array}$ & $\begin{array}{l}\text { (DATOS I } \\
\text { O: \% RESI }\end{array}$ & $\begin{array}{l}\text { FINITIVO } \\
\text { CTO TOTA }\end{array}$ & EGÚN TA & $\begin{array}{l}\text { DE } 2000 \\
\text { AÑO }\end{array}$ \\
\hline Tramos municipales & $\begin{array}{c}\text { N. }{ }^{\circ} \\
\text { Municipios } \\
01 / 01 / 2000\end{array}$ & $\begin{array}{l}\text { POBLACIÓN } \\
01 / 01 / 2000\end{array}$ & $\begin{array}{c}\% \\
\text { Pob. EsPAÑa } \\
01 / 01 / 2000\end{array}$ & $\begin{array}{c}\text { N. }{ }^{\circ} \\
\text { Municipios } \\
01 / 01 / 2019\end{array}$ & $\begin{array}{l}\text { PoBLACIÓN } \\
01 / 01 / 2019\end{array}$ & $\begin{array}{c}\% \\
\text { Poв. EsPAÑA } \\
01 / 01 / 2019\end{array}$ \\
\hline Menos de 101 habitantes & 928 & 57677 & 0,14 & 1352 & 76828 & 0,16 \\
\hline De 101 a 500 & 2879 & 726261 & 1,79 & 2645 & 658384 & 1,40 \\
\hline De 501 a 1000 & 1148 & 818273 & 2,02 & 1003 & 721203 & 1,53 \\
\hline De 1001 a 2000 & 1005 & 1450856 & 3,58 & 877 & 1242862 & 2,64 \\
\hline De 2001 a 5000 & 996 & 3134288 & 7,74 & 952 & 3000351 & 6,38 \\
\hline Hasta 5000 hab. & 6956 & 6187355 & 15,28 & 6829 & 5699628 & 12,12 \\
\hline Más de 5000 hab. & 1148 & 34312436 & 84,72 & 1302 & 41326580 & 87,88 \\
\hline De 5001 a 10000 & 511 & 3515907 & 8,68 & 549 & 3865826 & 8,22 \\
\hline De 10001 a 20000 & 329 & 4622754 & 11,41 & 340 & 4787781 & 10,18 \\
\hline De 20001 a 50000 & 190 & 5609225 & 13,85 & 265 & 7765329 & 16,51 \\
\hline De 500001 a 100000 & 63 & 4241165 & 10,47 & 85 & 6075765 & 12,92 \\
\hline De 100001 a 500000 & 49 & 9368333 & 23,13 & 57 & 11196460 & 23,81 \\
\hline Más de 500000 & 6 & 6955052 & 17,17 & 6 & 7635419 & 16,24 \\
\hline Total España & 8104 & 40499791 & 100,00 & 8131 & 47026208 & 100,00 \\
\hline
\end{tabular}

Elaboración propia. Fuente: Estadística del Padrón Continuo, Instituto Nacional de Estadística (INE).

${ }^{2}$ Los 118 municipios que, a 1 de enero de 2000, superaron los 50000 habitantes sumaron 20564550 personas empadronadas ( $50,8 \%$ de la población total), aumentando a 148 municipios los que consiguieron superar dicho umbral demográfico en el Padrón Continuo de 1 enero de 2019 (datos definitivos, INE), los cuales acogieron 24907644 personas empadronadas (53\% de la población total). 


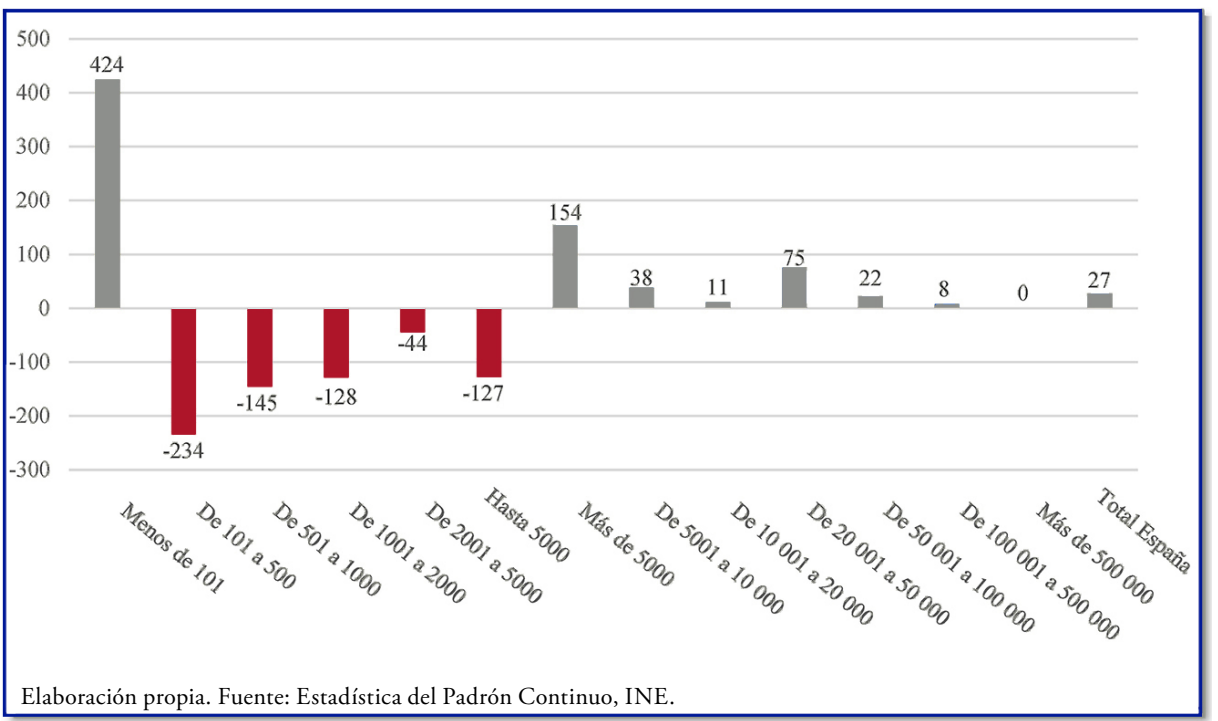

Gráfico 2. Diferencia en el número de municipios españoles clasificados según tamaño demográfico entre el 1 de enero de 2000 y 2019 en el Padrón Continuo (datos definitivos).

Aparte de eso, entre 2000 y 2019 se produjo un notorio desplazamiento de municipios hacia el tramo con menor poblamiento (ver gráfico 2 ): el número de términos municipales con menos de 101 habitantes aumentó en 387 unidades (de 928 a 1352), un incremento del $45,7 \%$ durante el tiempo que transcurrió del siglo XXI, en el que solamente se crearon 27 nuevos municipios en el Estado español (+0,3\%). Al mismo tiempo, disminuyó el número de municipios comprendidos en los cuatro tramos de 101 a 5000 habitantes, con un retroceso global de 551 términos, los cuales simbolizan un decremento de $-9,8 \%$. En resumen, estos datos nos advierten del imparable avance del proceso de despoblación y abandono entre los municipios rurales que, a su vez, está exacerbando el problema de la atomización municipal española.

\section{EL SOBREENVEJECIMIENTO DE LA ESTRUCTURA POR EDAD}

El proceso continuado y selectivo de despoblación (sobre todo, de jóvenes y adultos) ha generado una estructura de edad envejecida en el territorio rural que no es rururbano o periurbano, alejado de las urbes y segregado de las redes económicas de la globalización capitalista. En un contexto demográfico general de avance 


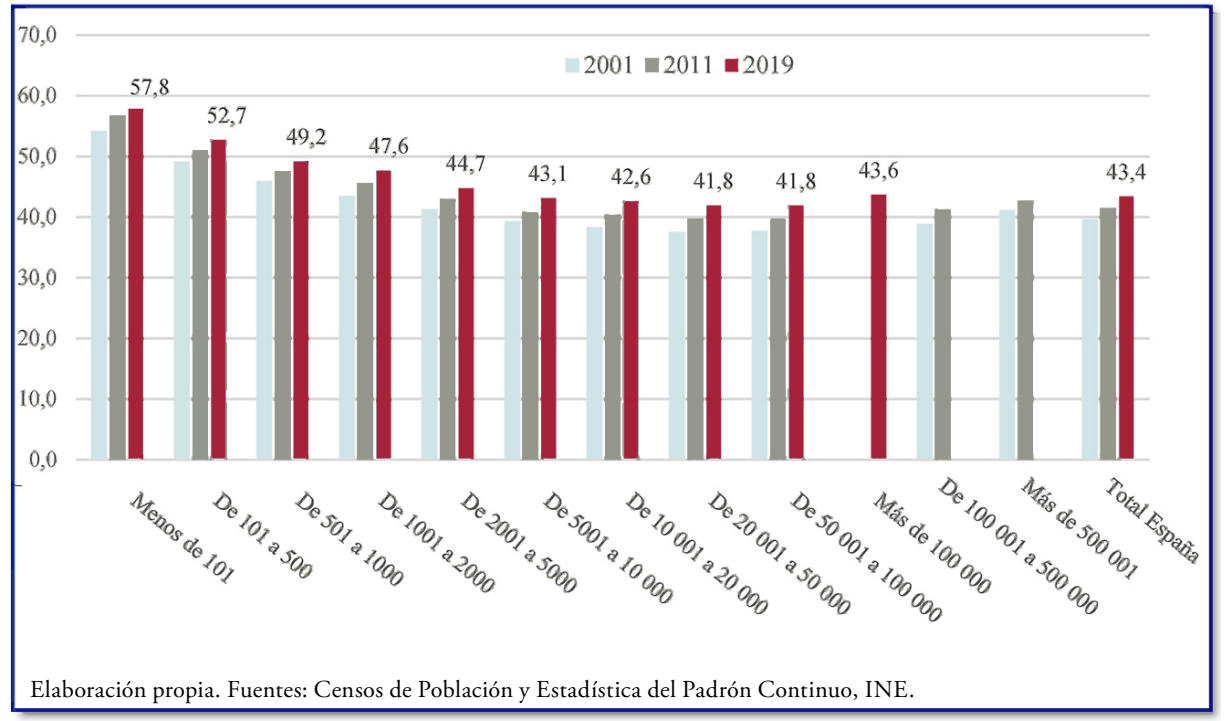

Gráfico 3. Edades medias de la población, ambos sexos, en los Censos de Población de 2001 y 2011 y en el Padrón Continuo de 2019 (datos provisionales) en los municipios españoles según tamaño demográfico.

del proceso de envejecimiento ${ }^{3}$, los municipios de hasta 5000 habitantes son los más afectados: de hecho, se manifiesta una clara relación inversa entre el tamaño demográfico de los municipios y la edad media de la población (EMP). Esto es, cuanto menor es el tamaño, mayor resulta la EMP de ambos sexos. En la Estadística del Padrón Continuo de 1 de enero 2019 (datos provisionales ${ }^{4}$ ), se percibe con claridad dicha asociación inversa (ver gráfico 3): en los municipios de menos de 101 habitantes, la EMP para ambos sexos es de 57,8 ańos, mientras entre los municipios que superaron los 100000 habitantes su valor se reduce a 43,6 años; nada menos que 14,2 años de diferencia en la EMP entre los dos polos del tamaño municipal.

En cuanto a la variable sexo, en el Padrón Continuo de 1 de enero de 2019 (datos provisionales), las edades medias de las mujeres superaron las respectivas de

3 Como expresa la demógrafa Inmaculada Santos: «Así, entiendo por envejecimiento demográfico la modificación progresiva de la estructura por edad de la población, que se traduce en un aumento de la proporción de los grupos de edad avanzada, frente a una disminución pareja de los grupos de edad más joven, o, lo que es igual, la proporción creciente del grupo de edad 65 ańos y más respecto del total de la población» (Santos, 1996: 178).

${ }^{4}$ El INE publica el cruce de la edad media de la población según el tamaño del municipio y el sexo en los datos provisionales de la Estadística del Padrón Continuo, pero no para sus datos definitivos. 


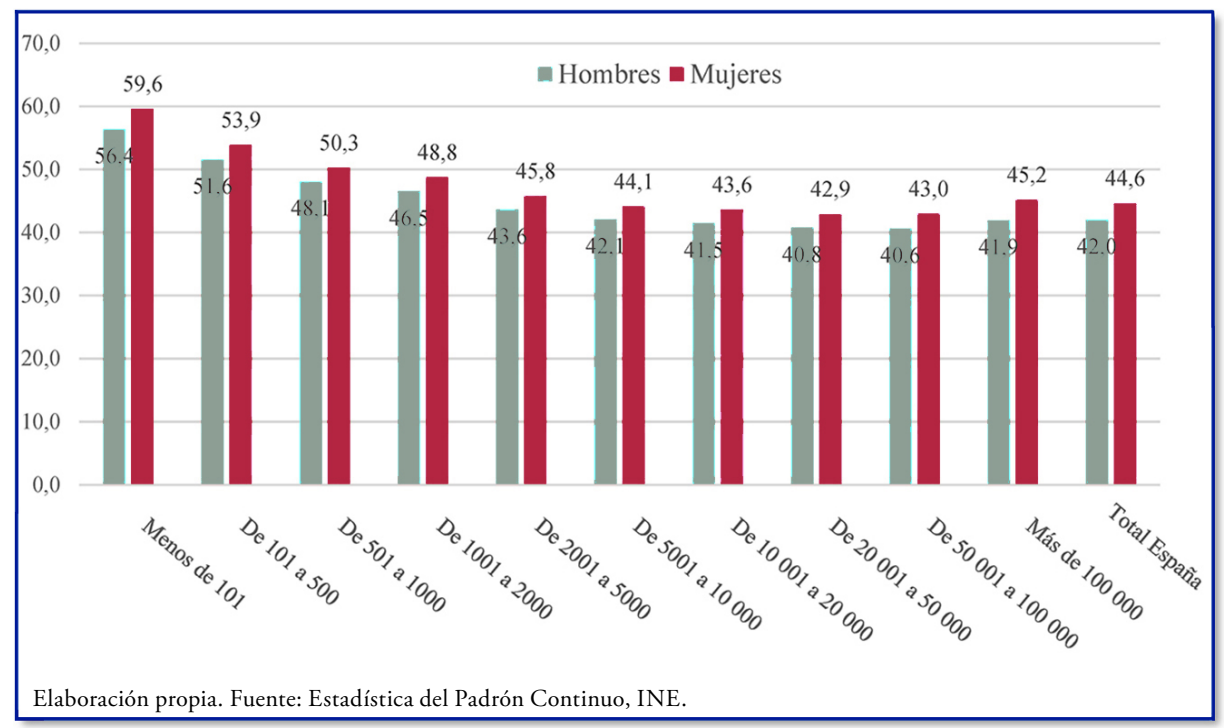

Gráfico 4. Edades medias de la población según sexo en el Padrón Continuo de 2019 (datos provisionales) en los municipios españoles por tamaño demográfico.

los hombres en cada uno de los tramos municipales, unas diferencias favorables para las mujeres que abarcan entre 2 años (de 5001 a 10000 ) y 3,3 años (más de 100000 habitantes), como consecuencia de la mayor longevidad femenina o, desde la vertiente del otro género, por la sobremortalidad masculina. Además, en el gráfico 4, de nuevo observamos que el envejecimiento es un fenómeno demográfico que afecta en mayor medida a los municipios rurales, ya que las edades medias de hombres y mujeres en los cinco tramos de menos de 5001 habitantes son notoriamente más altas con relación a las edades medias por sexo correspondientes a los cinco tramos municipales de más de 5000 habitantes.

En general, la estructura por edad de los municipios de menos de 5001 habitantes se manifiesta visiblemente más envejecida debido a la persistente y selectiva corriente emigratoria que ha despoblado la mayoría de los municipios rurales, fundamentalmente desde la segunda mitad del siglo xx. La emigración masiva de efectivos de las cohortes de la juventud y adultez durante el éxodo rural del segundo franquismo, no solamente despojó a los municipios rurales afectados de la capacidad socioeconómica de las y los emigrantes, sino también de la de renovar y aumentar su demografía, que derivó a continuación en una estructura por edades que se envejeció con precocidad.

Resaltar que el movimiento emigratorio desde los municipios rurales ha continuado durante el actual régimen democrático de monarquía parlamentaria, aunque en cantidades menores, debido al importante despoblamiento y debilitamiento de su capacidad de renovación demográfica que provocó el éxodo rural franquista (ver gráfico 5). En este sentido, de 1981 a 2019 (datos definitivos del Padrón Con- 


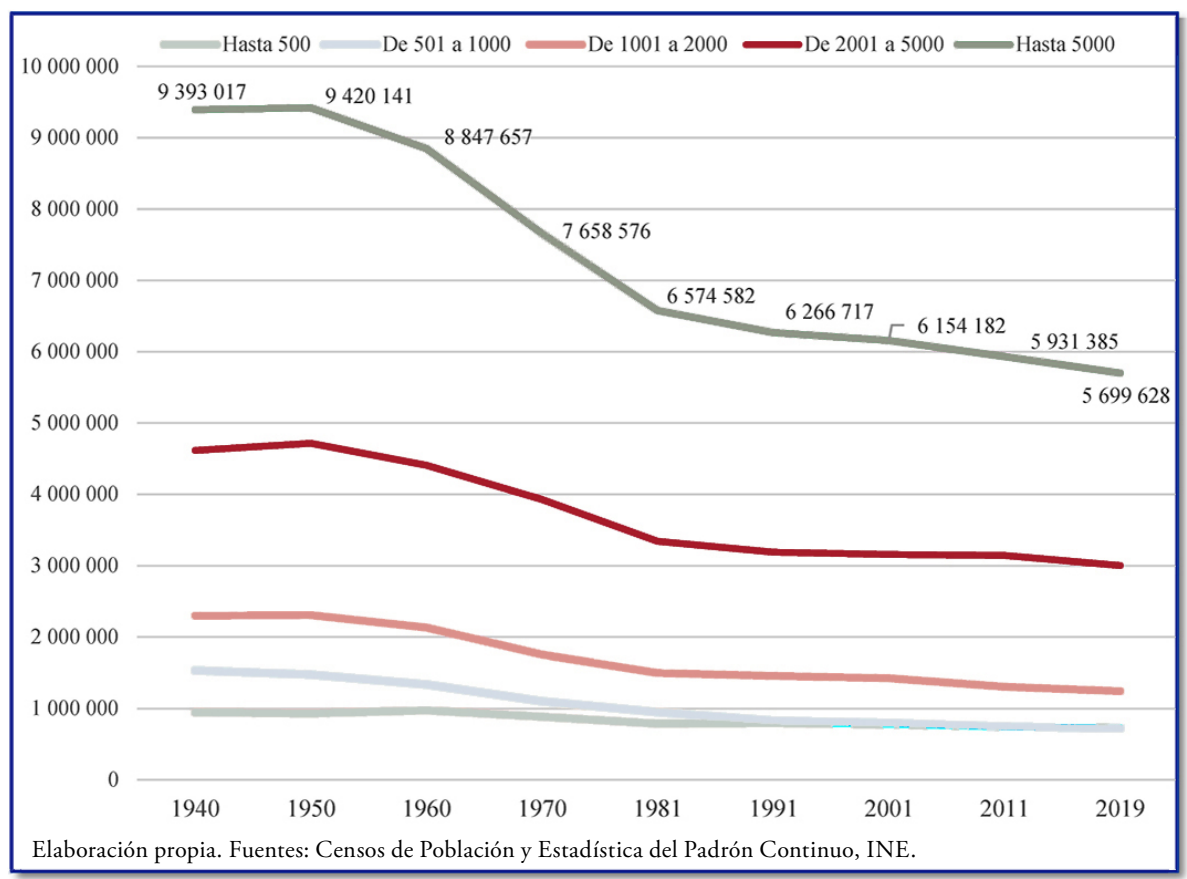

Gráfico 5. Evolución de la población, ambos sexos, entre 1940 y 2019

(datos definitivos) según tramos municipales por tamaño hasta 5000 habitantes.

tinuo), los municipios de hasta 5000 habitantes decrecieron demográficamente un $-13,3 \%$ y, en términos absolutos, en 874954 residentes, mientras entre 1950 y 1981 disminuyeron sus pobladores en 2845559 personas, que representan en términos porcentuales un declive demográfico del $-30,2 \%$ de sus residentes de partida. Si en el segundo período temporal distinguimos entre los subperíodos de 1981-2001 y 2001-2019, conocemos que durante el primero la población de los municipios de hasta 5000 habitantes decreció un $-6,4 \%$ y durante el segundo un $-7,4 \%$, unos decrementos que significan en números absolutos 420400 y 454554 habitantes, respectivamente. Por tanto, el problema demográfico en los municipios rurales se ha cronificado y agravado durante las dos décadas transcurridas del siglo Xx.

En líneas generales, la emigración rural durante las últimas décadas ha sido más limitada y selectiva, nutriéndose en mayor medida de personas jóvenes y adultas con estudios posobligatorios y superiores (FP de grado superior y titulaciones universitarias). Sin embargo, su impacto cualitativo ha sido bastante negativo para el mundo rural, pues le ha despojado de buena parte de los sujetos sociodemográficos, a priori, más capacitados para idear, organizar y dirigir un cambio sociocultural y económico que revalorice el espacio rural y promueva un discurso crítico y una política alternativa para el reequilibrio de las relaciones entre el campo y la ciudad, actualmente dominadas por la segregación, la discriminación y la desigualdad 
estructural, en las que el territorio rural se ve sometido al urbano, especialmente al metropolitano, sujeto a una especie de neocolonialismo 5 .

Reflexionemos un momento en la emigración de las y los jóvenes, los cuales suelen adquirir una educación y formación superior a la de sus padres y madres, y con frecuencia tienden a emigrar debido a que las oportunidades de empleo existentes en el mercado de trabajo comarcal están bastante limitadas a oficios y ocupaciones de menor cualificación. La escasa transformación e industrialización agroalimentaria en muchas comarcas rurales ha impedido el crecimiento de ocupaciones técnicas, de gestión-dirección o de servicios a las empresas en las que se hubiesen insertado laboralmente parte de las y los jóvenes rurales con titulaciones superiores que se han visto obligados a emigrar por escasear los puestos de trabajo de nivel medio y superior adecuados a sus perfiles educativos-formativos.

En el ambiente rural de las explotaciones familiares, mediatizado por valores patriarcales y androcéntricos, con frecuencia se espera que sea un hijo varón el que continúe con la actividad económica, pero un cúmulo de condicionantes negativos ha provocado un bloqueo y crisis en el relevo generacional (Trabada et al., 2007; Trabada, 2019). Por otro lado, ciertos valores y actitudes de padres y madres fomentan el fenómeno de la emigración juvenil: desean para sus hijos e hijas una formación educativa y una trayectoria profesional de cuello blanco, de grado medio o superior. Infravaloran los oficios agropecuarios, ya que los perciben como carentes de estatus y prestigio social. Generalmente, están influenciados por un proceso de aculturación que les genera desafección por sus oficios y formas de vida rurales $\mathrm{y}$ atracción por las urbanas.

En cuanto a las mujeres jóvenes, también emigran a las urbes para buscar un escenario social más propicio para la satisfacción de sus deseos y aspiraciones de desarrollo personal, mediante unas relaciones menos condicionadas por la desigualdad entre géneros ${ }^{6}$. Parece que el poder de los viejos valores y prácticas patriarcales y androcéntricas se resiste en el espacio rural con mayor firmeza al poder emergente de los nuevos valores y prácticas igualitarias entre géneros, en cierta medida

${ }^{5}$ En el período actual neofordista o posfordista del desarrollo capitalista, la desigualdad campo-ciudad está basada en el control y explotación indirecta que ejercen las grandes agroindustrias y empresas de distribución-comercialización de productos alimentarios, generalmente con su sede social y mayoría de accionistas en áreas urbanas-metropolitanas, sobre las explotaciones agropecuarias familiares a través de los mercados de insumos (fertilizantes, agroquímicos, semillas, maquinaria y equipos técnicos) y los mercados de productos agrarios en origen y de consumo final. Este dominio indirecto que ejercen las grandes agroindustrias y empresas de distribución-comercialización sobre el territorio rural, en el que el sector agrícola aún es relevante, no es muy diferente del que ejercen los países capitalistas más desarrollados a través de sus empresas multinacionales sobre los países de la semiperiferia y la periferia del capitalismo globalizado. A diferencia de las relaciones colonialistas, donde el control y la explotación son directos, en las relaciones neocoloniales tienden a ser indirectos, generalmente a través del mecanismo de precios de los mercados y los intercambios comerciales desiguales.

${ }^{6}$ Esta emigración de las jóvenes rurales nos recuerda el antiguo aforismo medieval de origen germánico «el aire de la ciudad te hace libre». 
una consecuencia de la estructura por edad más envejecida (el efecto generación). Por ejemplo, en la titularidad de las explotaciones agrarias familiares, el 67,6\% de las personas titulares son hombres por el 32,4\% de mujeres, según la Encuesta sobre la estructura de las explotaciones agricolas de 2016 (INE). Unos datos que reflejan la problemática de la desigualdad de género y la invisibilidad del trabajo femenino en el sector agrario, donde parte de las mujeres, que son trabajadoras agrícolas y cónyuges de varones que desempeñan el rol de titulares jefes de explotaciones familiares agrarias, son relegadas a la situación de 'ayuda familiar' en vez de apreciarse como cotitulares jefas de la explotación?

Regresemos al análisis demográfico de los resultados de los Censos de Población y del Padrón Continuo (datos definitivos): en el Censo de 1981, el primero realizado durante el actual régimen de monarquía parlamentaria, ya se percibía con claridad que la estructura por edades de la población de los municipios de menos de 5001 habitantes mostraba un grado de envejecimiento mayor con relación a la población que residía en los municipios que superaban ese tamaño demográfico. En concreto, las y los mayores de 64 años significaron el 16,3\% de la población total censada en el primer conglomerado municipal, mientras el porcentaje de envejecimiento se redujo al 10,2\% entre la población censada en los municipios de más de 5000 residentes. Este mayor grado de envejecimiento de la población en los municipios de menos de 5001 habitantes se intensificó en los siguientes Censos de Población (ver gráfico 6): 19,9\% sobre 12,7\% en 1991 y $24 \%$ sobre $15,5 \%$ en 2001 , mientras en el último Censo de 2011 el porcentaje de envejecimiento fue de 23,3\% en los municipios de menos de 5000 residentes sobre 16,1\% en los de más de 5000 . Pero al inicio de 2019 se observa que el porcentaje de envejecimiento vuelve a crecer en los municipios de menos de 5000 habitantes, manteniéndose casi estable en los de más de 5000: 24,8\% sobre 16,3\%.

En resumen, aunque las poblaciones de los dos conjuntos municipales comparten el progreso del fenómeno del envejecimiento, sin embargo, ha avanzado con bastante más ímpetu entre los municipios de menos de 5001 habitantes. En concreto, a 1 de enero de 2019, las y los mayores de 64 años duplicaron a las y los menores de 15 años empadronados en los municipios de menos de 5000 habitantes (203 por cada 100), mientras entre los municipios que superaron ese umbral de poblamiento, el índice de envejecimiento solo se mostró moderadamente favorable para las personas de 65 y más años (123 por cada 100). En síntesis, la estructura de edad de la población rural, más que envejecida, está sobreenvejecida.

Por lo demás, la desaceleración del proceso de envejecimiento entre los Censos de Población de 2001 y 2011 seguramente estuvo motivada por los flujos de la inmigración extranjera, cuya estructura por edades se distingue por ser más joven

7 En el Registro de Titularidad Compartida de Explotaciones Agrarias (RETICOM), a 31 de diciembre de 2019, solamente se contabilizaron un total acumulado de 631 explotaciones con titularidad compartida. La Ley 35/2011, de 4 de octubre, sobre titularidad compartida de las explotaciones agrarias entró en vigor el 5 de enero de 2012 y el Registro RETICOM se regula por la Orden AAA/1408/2012 de 26 de junio (fuente: Titularidad compartida en las explotaciones agrarias, MAPA). 


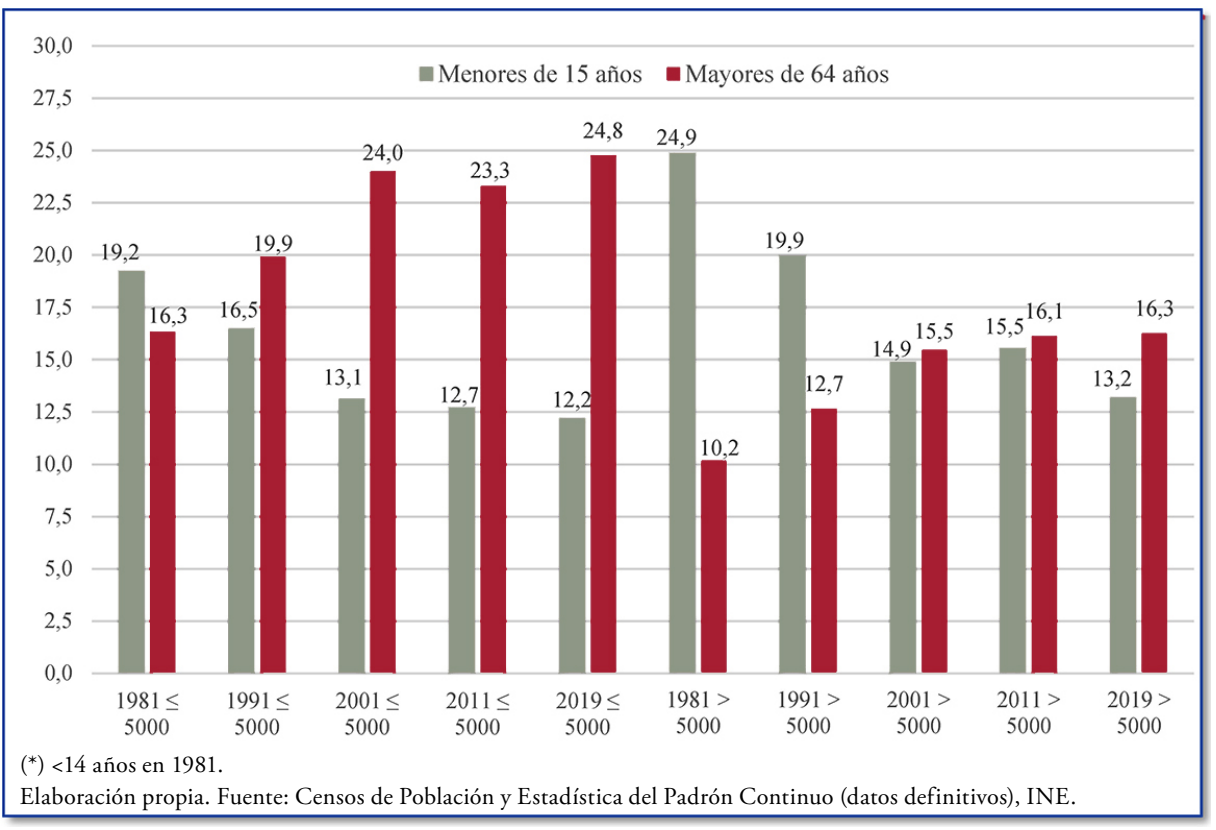

Gráfico 6. Porcentajes que representan las cohortes de $<15$ años y de $>$ de 64 años, ambos sexos, sobre total de la población en los municipios de hasta 5000 y de más de 5000 habitantes en los Censos de $1981\left(^{*}\right), 1991,2001$ y 2011 y Padrón Continuo 2019.

que la respectiva de la población de nacionalidad española. Efectivamente, según el Censo de 2011 y para ambos sexos, la edad media de la población extranjera era de 34,1 años frente a 42,2 años en la española. Asimismo, en todos los estratos municipales definidos por su tamaño demográfico, la EMP extranjera fue visiblemente inferior con respecto a la EMP española, si bien las diferencias más elevadas se expresaron en los estratos municipales de menor tamaño poblacional, normalmente correspondientes al medio rural, como se observa en el gráfico 7. En suma, las y los nuevos vecinos de nacionalidad extranjera han contribuido, sin lugar a duda, a frenar o mitigar el proceso de sobreenvejecimiento que sufre la población rural.

\section{LA MASCULINIZACIÓN DE LA ESTRUCTURA POR SEXO}

Normalmente, una población con una estructura por edad afectada por el proceso de envejecimiento suele tener una distribución entre sexos escorada hacia las mujeres, debido a su mayor longevidad o por la sobremortalidad masculina. No obstante, el movimiento migratorio puede modificar la distribución hacia uno u otro sexo. Calculemos la ratio de masculinidad (RM) referida a los Censos de Población 


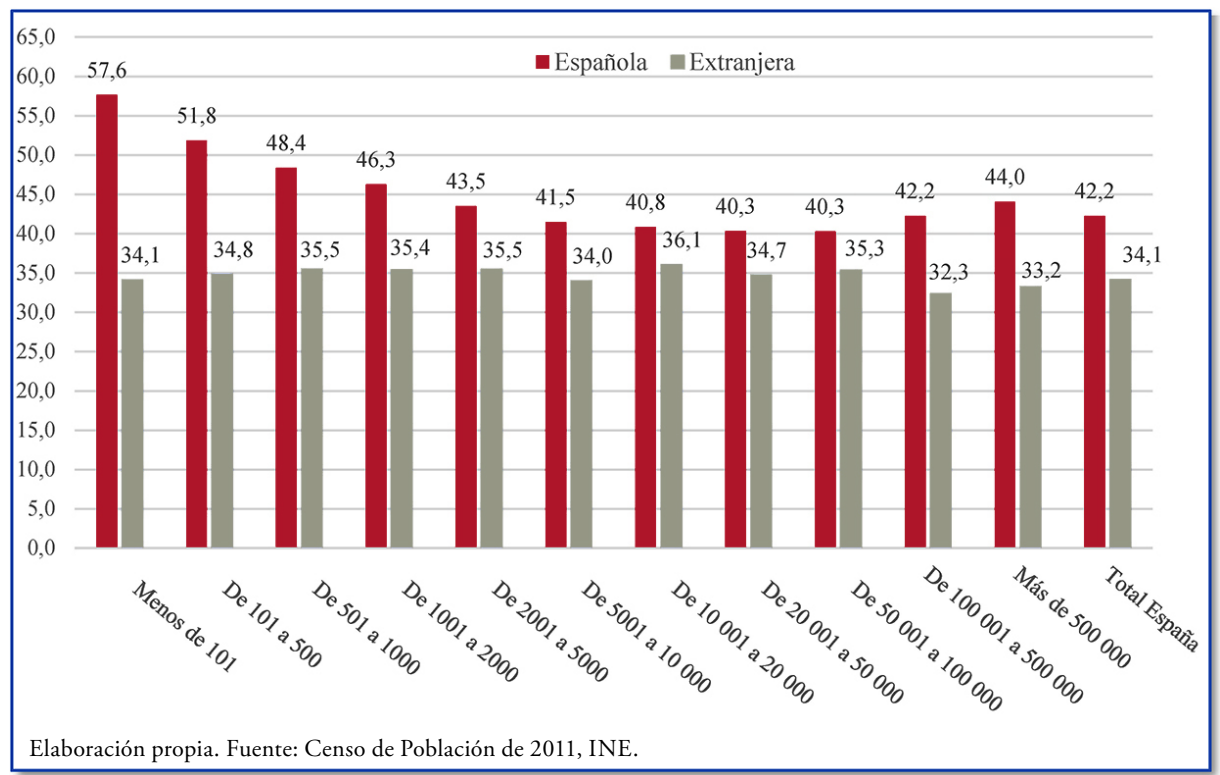

Gráfico 7. Edades medias de la población, ambos sexos, según nacionalidad en los municipios espańoles clasificados por tamaño demográfico en el Censo de Población de 2011.

de 1981 a 2011 y también al Padrón Continuo de 1 de enero de 2019 (datos definitivos) para los dos conjuntos municipales delimitados por el umbral de 5000 habitantes (ver gráfico 8). En 1981, la población de los municipios de hasta 5000 residentes concretizó un valor de 101,1 varones por cada 100 mujeres, mientras entre los municipios de más de 5000 habitantes fue de 95,4 por 100. En los siguientes Censos se manifestó repetidamente esa diferencia, pero con tendencia a crecer en los municipios de menos de 5001 residentes, definiendo en el último Censo de 2011 unas RM de 106 sobre 96,5 varones por 100 mujeres, respectivamente. En cuanto a la información estadística más actual, el Padrón Continuo de 1 de enero de 2019 nos informa que las RM concretizaron 105 hombres por cada 100 mujeres en los municipios de hasta 5000 residentes, reduciéndose a 95 varones por cada 100 mujeres en los que superaron ese tamaño. En resumen, el conjunto de los municipios de menos de 5001 habitantes muestra una clara masculinización de su población, un rasgo que se ha acentuado desde 1981.

En los municipios donde crece la ratio de masculinidad, generalmente se debe a un movimiento migratorio diferenciado por sexo: emigran más mujeres que hombres y/o inmigran más varones que mujeres. Las ocupaciones que dominan o escasean en los mercados locales y comarcales de trabajo determinan el sentido y género de los flujos migratorios en la población activa. En este sentido, si en el mercado de trabajo de los municipios y comarcas rurales faltan ocupaciones del sector 


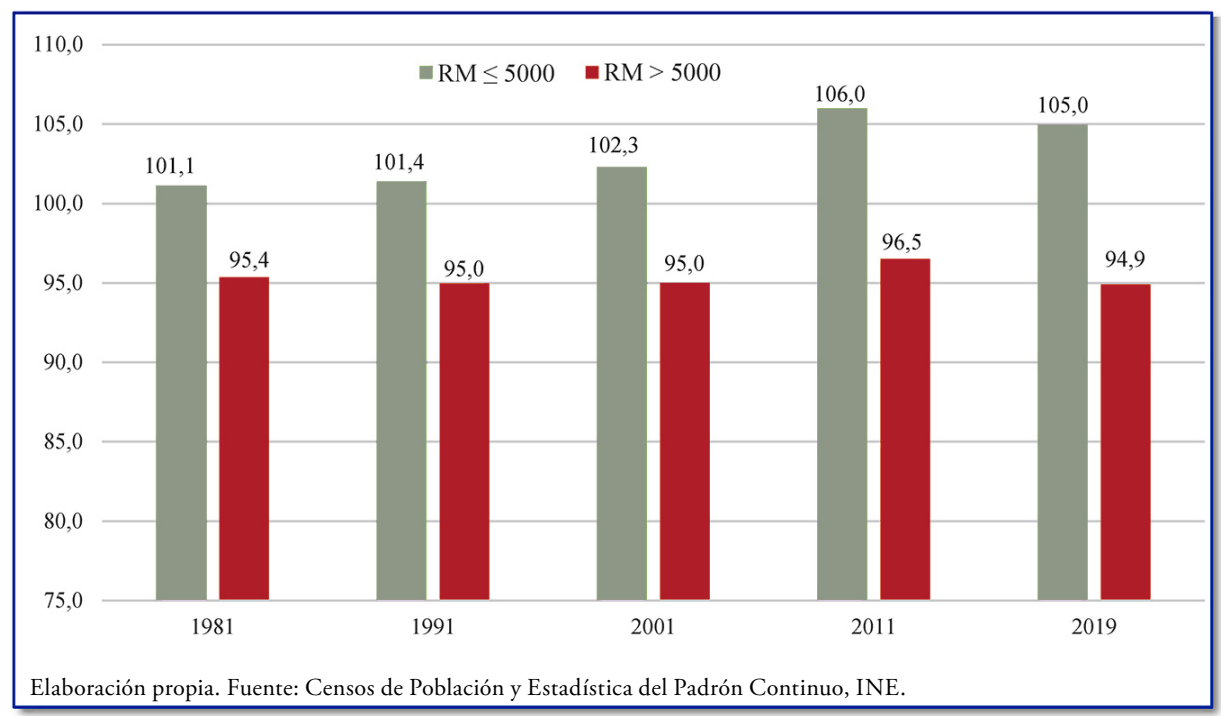

Gráfico 8. Ratios de masculinidad (hombres por cada 100 mujeres) en los municipios españoles de hasta 5000 y de más de 5000 habitantes en los Censos de Población de 1981, 1991, 2001 y 2011 y el Padrón Continuo de 2019 (datos definitivos).

terciario ${ }^{8}$, lo más probable será una corriente emigratoria de mujeres jóvenes y adultas activas hacia las urbes en busca de un empleo. Asimismo, si faltan ocupaciones de cualificación medio-alta en el mercado de trabajo local-comarcal, seguramente tendrá lugar una mayor emigración femenina, dado que su nivel de estudios suele ser más elevado con relación a los varones, una sobrecualificación femenina que sobre todo se manifiesta entre las jóvenes (Camarero y Sampedro, 2008).

Por lo general, la emigración femenina ha superado en cantidad a la masculina, implicando la masculinización de la estructura por sexo de la población en bastantes municipios rurales, contrarrestando la propensión a la feminización que suele derivar del proceso de envejecimiento en una población, motivada por la mayor longevidad de las mujeres. Al mismo tiempo, la inmigración extranjera ha contribuido a reforzar la masculinización de la población en el territorio rural, tal

${ }^{8}$ En el Censo de Población de 2011, el 58,4\% de la población ocupada de 16 y más años que residía en los municipios de hasta 5000 habitantes trabajaba en actividades del sector servicios, elevándose esta categoría al 76,2\% entre las y los ocupados de 16 y más años censados en los municipios que superaron los 5000 residentes. Entre las mujeres ocupadas de 16 y más años, el sector terciario significó el 77,3\% del total en los municipios de hasta 5000 habitantes, mientras este indicador se elevó al $87,5 \%$ entre las mujeres ocupadas de 16 y más años censadas en los municipios de más de 5000 residentes (fuente: Censo de Población de 2011, INE). 


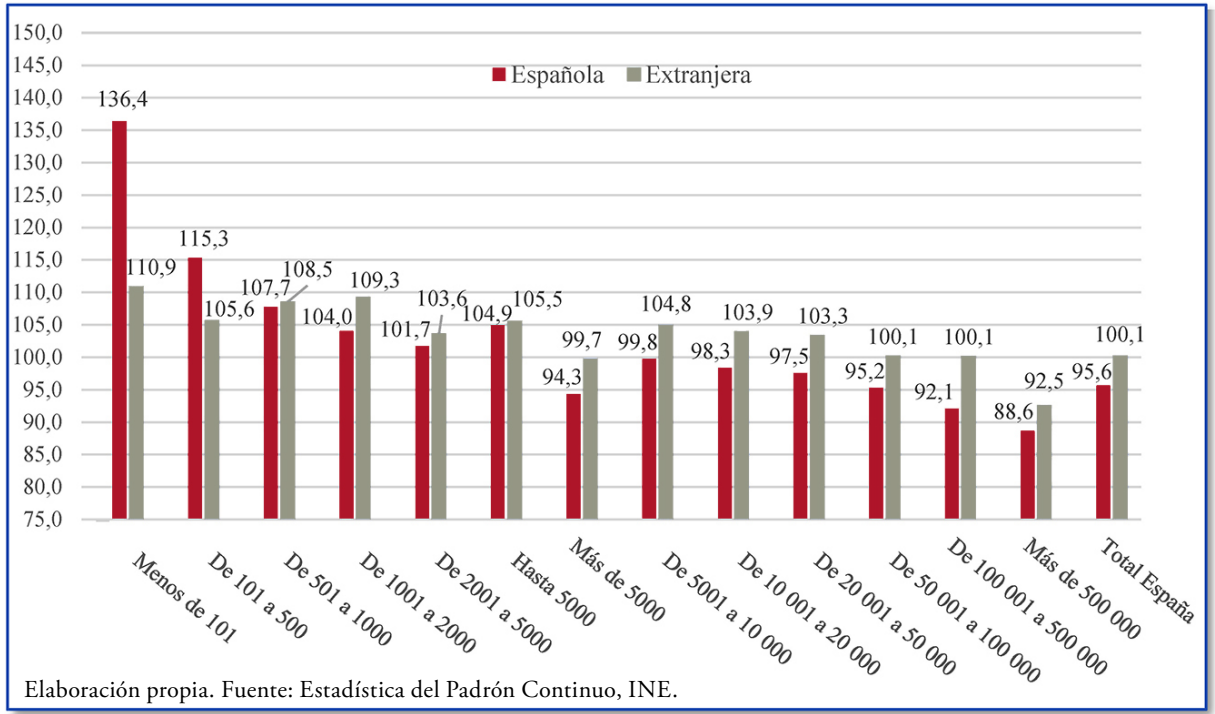

Gráfico 9. Ratios de masculinidad (hombres por cada 100 mujeres) según nacionalidad en los municipios españoles clasificados por tamaño demográfico en el Padrón Continuo de 1 de enero de 2019 (datos definitivos).

como se observa en el gráfico 9: según el Padrón Continuo de 1 de enero de 2019 (datos definitivos), la ratio de masculinidad entre las y los extranjeros empadronados en los municipios de hasta 5000 habitantes fue de 105,5 varones por cada 100 mujeres, cuando entre el colectivo de extranjeros empadronados en los municipios de más de 5000 vecinos la RM se redujo a 99,7 por 100. Más en concreto, en cada uno de los cinco estratos municipales con menos de 5001 habitantes, las RM de la población extranjera sobrepasaron el umbral de 100 (más varones que mujeres), y en los tres estratos de 501 hasta 5000 habitantes su valor se situó por encima de la RM de la población española.

\section{LA INMIGRACIÓN EXTRANJERA}

En general, los movimientos migratorios internacionales adquieren una gran importancia en el contexto de la Segunda Transición Demográfica, un marco conceptual propuesto por Ron Lesthaeghe y Dick van de Kaa (1987) para explicar los cambios sociodemográficos que observaron en las sociedades capitalistas posindustriales. Grosso modo, debido a la caída de la fecundidad y la natalidad, la población tiende a la estabilidad cuantitativa e incluso a decrecer (repunte de la mortalidad por el proceso de envejecimiento) en los países de capitalismo posindustrial, salvo que pasen a ser territorios receptores de los flujos migratorios internacionales. A partir 


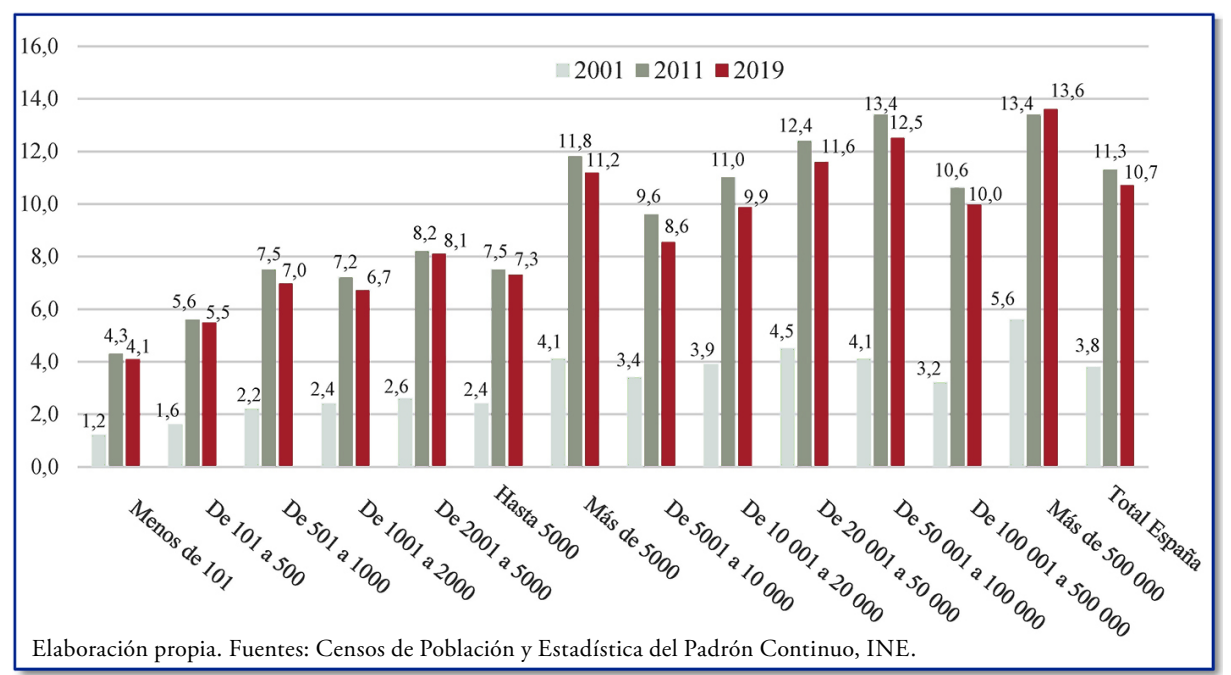

Gráfico 10. Porcentajes de población de nacionalidad extranjera, ambos sexos, en los Censos de Población de 2001 y 2011 y el Padrón Continuo de 2019 (datos definitivos) en los municipios espańoles clasificados por tamaño demográfico.

del último lustro del siglo xx, diversas áreas geográficas del Estado español comenzaron a recibir importantes flujos de inmigrantes extranjeros en busca de empleo y mejora de sus condiciones de vida, los cuales provocaron un cambio copernicano en los municipios donde se asentaron con cierta relevancia cuantitativa: la renovación y el rejuvenecimiento de la cohorte de personas activas y, en general, de la estructura por edad de la población, el aumento de la fecundidad y la natalidad, de la población infantil a escolarizar, etc. En este sentido, el declive demográfico de los municipios españoles de menos de 5001 habitantes hubiese sido aún mayor sin el aporte efectuado por la inmigración extranjera.

En el Censo de Población de 2001, las y los extranjeros censados en los municipios con hasta 5000 habitantes sumaron 147176 personas, que representaron el $2,4 \%$ de la población total residente en ese conjunto municipal. A 1 de enero de 2019 (datos definitivos), se contabilizó una cantidad de 416430 personas de nacionalidad extranjera, que significaron el 7,3\% de la población total empadronada en los municipios de hasta 5000 habitantes (ver gráfico 10). En general, entre noviembre de 2001 y enero de 2019, en los municipios de ese tamaño se manifestó una evolución muy positiva, pues el colectivo de residentes de nacionalidad extranjera creció nada menos que un $182,9 \%$, si bien con un incremento inferior con respecto al experimentado por los municipios que superaron los 5000 habitantes (224,3\%).

Por otro lado, la presencia relativa de la población extranjera en los municipios de hasta 5000 habitantes es inferior con respecto a la que alcanza entre los municipios que superan dicho tamaño: al iniciarse 2019, el 7,3\% frente al 11,2\% de 
la población empadronada en los municipios de más de 5000 habitantes. La asociación positiva entre el porcentaje de población extranjera y el tamaño del municipio se constata claramente, expresándose el mayor porcentaje de residentes extranjeros entre la población empadronada en los municipios de más de 500000 habitantes: $13,6 \%$ del total.

Generalmente, la integración social de los inmigrantes extranjeros en los municipios rurales ha sido un proceso complejo, salpicado de diversas barreras y dificultades, ante la preeminencia de valores y actitudes conservadoras entre la población rural, con una estructura por edad más envejecida. También hay que resaltar que no se ha producido una conflictividad generalizada, sino más bien bastante localizada en enclaves rurales especializados en la agricultura intensiva, condicionados por una importante concentración de trabajadores inmigrantes que laboran y sobreviven en condiciones de elevada explotación y precariedad, así como por una fuerte movilidad espacial (temporeros/as).

Por lo demás, el desempleo, la inestabilidad laboral, la pobreza más o menos severa, las dificultades materiales por las que ha pasado la formación social española debido a la última crisis capitalista de 2008 a 2013 han incidido negativamente en la permanencia de las personas y familias extranjeras en los municipios rurales. En este sentido, la denominada Gran Recesión disminuyó el colectivo de residentes extranjeros, cuya cantidad no se ha recuperado con suficiencia durante la nueva etapa de crecimiento económico: en el conjunto de los municipios de hasta 5000 habitantes se registró un decremento de -6,8\% entre el Censo de Población de noviembre de 2011 y el Padrón Continuo de enero de 2019 (datos definitivos). En todo caso, buena parte de las y los inmigrantes extranjeros han optado por permanecer en los municipios rurales, lo que revaloriza su potencialidad para contribuir al rejuvenecimiento de la población activa y sostenibilidad demográfica de los municipios rurales, parte de los cuales, sin su beneficiosa aportación, estarían abocados irremediablemente al abandono. No obstante, las oportunidades de empleo a las que pueden acceder, con frecuencia sujetas a la precariedad y explotación laboral, y las dificultades/facilidades para crear y desarrollar sus proyectos familiares, incluyendo la accesibilidad a una vivienda asequible y habitable, condicionarán su arraigo y permanencia o movilidad espacial (Camarero y Sampedro, 2016).

\section{LAS PIRÁMIDES DE POBLACIÓN}

A continuación, vamos a representar gráficamente la estructura por sexo y edad de la población del conjunto de municipios de hasta 5000 habitantes mediante la figura de una pirámide, que trazaremos para los datos del Censo de Población de 1991 y del Padrón Continuo de 1 de enero de 2019 (datos definitivos). En el gráfico 11, al comparar la pirámide de población de 2019 con la respectiva de 1991, observamos con claridad en los dos sexos una significativa contracción en los histogramas correspondientes a las cohortes de la infancia ( 0 a 14 años) y la juventud (15 a 34 años), así como una dilatación bastante pronunciada en los histogramas de las cohortes de la adultez (35 a 49 años) y madurez (50 a 59 años). Con relación al 


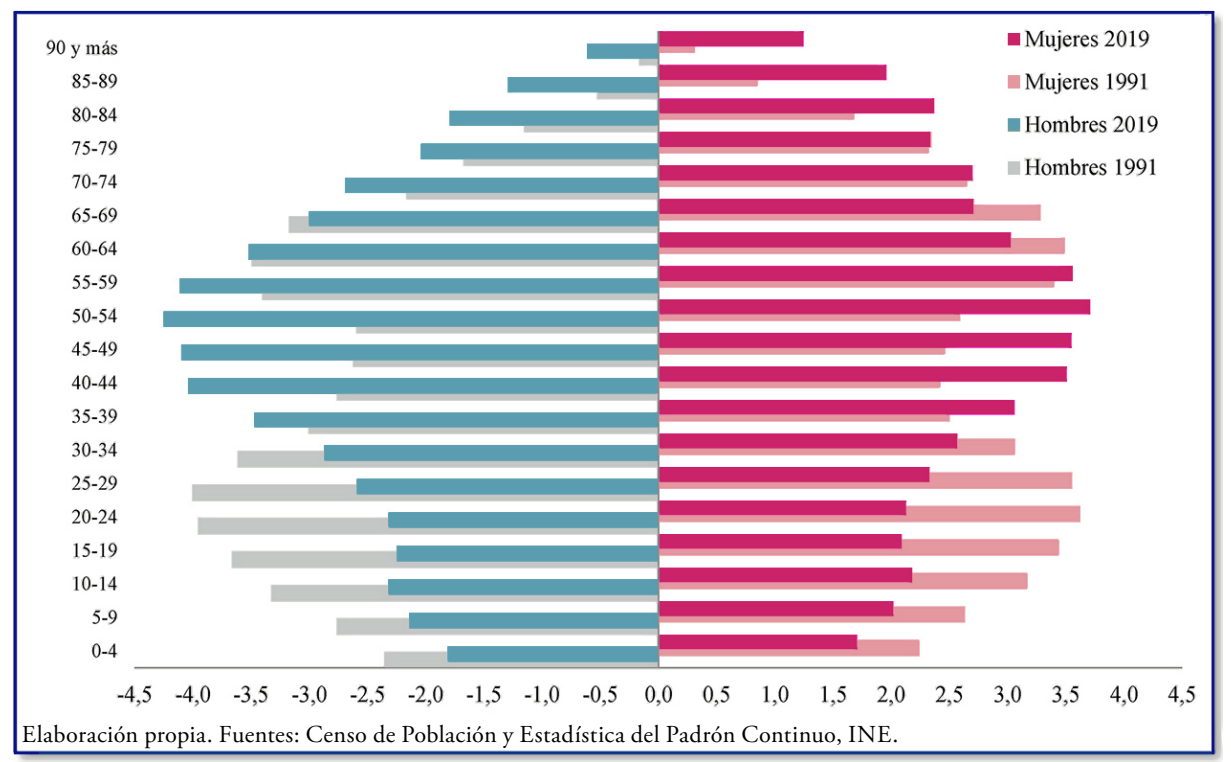

Gráfico 11. Pirámides de población de los municipios de hasta 5000 habitantes en el Censo de Población de 1991 y el Padrón Continuo de 2019 (datos definitivos).

área de la cúspide de la pirámide se advierte que en los varones (izquierda) los histogramas se expanden a partir de 70-74 años, mientras entre las mujeres la dilatación es algo más tardía, a partir de 80-84 años.

Si en el Censo de Población de 1991, la estructura por sexo y edad de la población de los municipios de hasta 5000 habitantes ya se mostraba envejecida (19,2\% de efectivos de 65 y más años) y moderadamente masculinizada (101,4 varones por cada 100 mujeres), en el Padrón Continuo de 1 de enero de 2019 ambos rasgos demográficos se han acrecentado (24,8\% y 104,9, respectivamente). Más en concreto, la pirámide de población de los municipios de hasta 5000 habitantes en 2019 refleja una estructura por edad con preeminencia de las cohortes de la madurez $(22,2 \%)$ y vejez $(24,8 \%)$, con una presencia relevante de la 'cuarta edad' (9,3\% de personas de 80 y más años). La masculinización de la estructura por sexo comienza a manifestarse con claridad en la cohorte de la juventud (109,9 varones por cada 100 mujeres), acentuándose a continuación en las cohortes de la adultez $(114,6)$ y madurez $(115,3)$, mientras en la vejez la mayor longevidad femenina determina una mayoría de mujeres (85,8 hombres por cada 100 mujeres).

Por otro lado, en el gráfico 12 recogemos las pirámides de población para los conjuntos municipales de hasta 5000 y de más de 5000 habitantes según el Padrón Continuo de 1 de enero de 2019 (datos definitivos). A derecha (mujeres) e izquierda (hombres) de la pirámide para los municipios de menos de 5001 residentes se observa una mayor concavidad en los histogramas de la infancia (0 a 14 


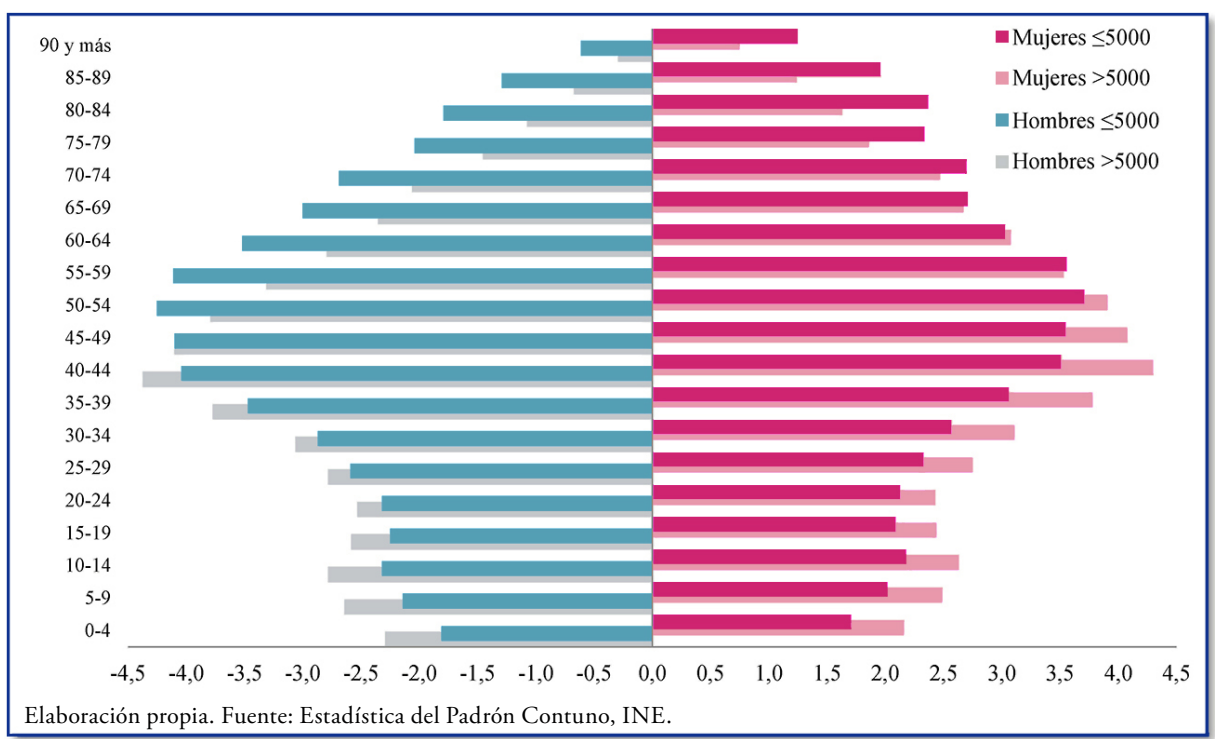

Gráfico 12. Pirámides de población de los municipios de hasta 5000 y de más 5000 habitantes en el Padrón Continuo de 2019 (datos definitivos).

años), juventud (15 a 34 ańos) y adultez (35 a 44 años). Por el contrario, a partir del grupo de 50-54 años en los varones y de 60-64 años en las mujeres se percibe una mayor longitud en los histogramas de la pirámide de población de los municipios de hasta 5000 habitantes. Ambos rasgos -contracción en los histogramas de la base y dilatación en los de la cúspide piramidal- son característicos de una población más afectada por el proceso de envejecimiento. Por último, queremos señalar que en la cohorte de 35 a 64 años, en la que se concentra la población activa, se observa una amplitud mayor de los histogramas de los varones que de las mujeres entre la población del conjunto de los municipios de hasta 5000 habitantes, seguramente por la mayor emigración femenina.

\section{UN DESIERTO DEMOGRÁFICO}

Aparte del sobreenvejecimiento y la masculinización de la población, la consecuencia más grave del proceso persistente de despoblación y abandono que sufre el medio rural consiste en la 'desertización humana' del territorio. Si indagamos sobre el grado de despoblación y abandono mediante el indicador de la densidad municipal de población (ver tabla II), conocemos que los municipios de hasta 100 habitantes solamente tienen una densidad media de 2,3 habitantes por $\mathrm{km}^{2}$ y los de 101 a 500 habitantes de 6 residentes por $\mathrm{km}^{2}$ con referencia temporal al Padrón Con- 
tinuo de 1 de enero de 2019 (datos definitivos). Observamos que ambos estratos municipales tienen densidades medias inferiores a 10 habitantes por $\mathrm{km}^{2}$, el nivel de poblamiento de un territorio que en sociología de la población y rural consideramos propio de un 'desierto demográfico'. Además, el siguiente estrato municipal de 501 a 1000 habitantes define una densidad media de 11,6 residentes por $\mathrm{km}^{2}$, muy cercana a esa frontera que da paso al desierto demográfico, donde seguramente se situará este estrato municipal en una próxima revisión anual del Padrón Continuo.

\begin{tabular}{|c|c|c|c|c|}
\hline \multicolumn{5}{|c|}{$\begin{array}{c}\text { TABLA II. DENSIDAD DE POBLACIÓN PARA LOS ESTRATOS MUNICIPALES SEGÚN } \\
\text { TAMAÑO DEMOGRÁFICO A } 1 \text { DE ENERO DE } 2019 \text { (DATOS DEFINITIVOS): } \\
\text { NÚMERO DE HABITANTES POR KM }{ }^{2}\end{array}$} \\
\hline ESTRATOS MUNICIPALES & $\begin{array}{c}\text { N.o } \\
\text { Municipios }\end{array}$ & Población & $\begin{array}{c}\text { Superficie } \\
\mathrm{KM}^{2}\end{array}$ & $\begin{array}{l}\text { DENSIDAD DE } \\
\text { POBLACIÓN: } \\
\text { HABS. POR KM }\end{array}$ \\
\hline Menos de 101 habitantes & 1352 & 76828 & 33728,94 & 2,28 \\
\hline De 101 a 500 habitantes & 2645 & 658384 & 110383,04 & 5,96 \\
\hline De 501 a 1000 habitantes & 1003 & 721203 & 62096,79 & 11,61 \\
\hline De 1001 a 2000 habitantes & 877 & 1242862 & 70055,91 & 17,74 \\
\hline De 2001 a 5000 habitantes & 952 & 300351 & 80448,79 & 37,30 \\
\hline Hasta 5000 habitantes & 6829 & 5699628 & 356713 & 15,98 \\
\hline Más de 5000 habitantes & 1302 & 41326580 & 148031 & 279,17 \\
\hline De 5001 a 10000 habitantes & 549 & 3865826 & 51625,70 & 74,88 \\
\hline De 10001 a 20000 habitantes & 340 & 4787781 & 32363,61 & 147,94 \\
\hline De 20001 a 50000 habitantes & 265 & 7765329 & 35875,27 & 216,45 \\
\hline De 50001 a 100000 habitantes & 85 & 6075765 & 14223,65 & 427,16 \\
\hline De 100001 a 500000 habitantes & 57 & 11196460 & 11587,92 & 966,22 \\
\hline Más de 500000 habitantes & 6 & 7635419 & 2355,19 & 3241,96 \\
\hline ESPAÑA & 8131 & 47026208 & 504744,80 & 93,17 \\
\hline
\end{tabular}

Elaboración propia. Fuentes: Estadística del Padrón Continuo de 01/01/2019 (datos definitivos) del Instituto Nacional de Estadística (INE) y Nomenclátor Geográfico de Municipios y Entidades de Población del Instituto Geográfico Nacional (IGN).

Resaltar que, a 1 de enero de 2019, en 3530 municipios el valor de este indicador no logró superar los 10 habitantes por $\mathrm{km}^{2}$. Con respecto al total de municipios españoles (8131), representan nada menos que el $43,4 \%$ de todos ellos y, en cuanto a la superficie de España, abarcan el 43,2\% del territorio estatal, sumando una población de 997359 habitantes, que tan solo significa el 2,1\% del total espańol, con una densidad promedio para este conjunto municipal de 4,6 residentes por $\mathrm{km}^{2}$. Dentro de esta categoría de municipios donde los seres humanos escasean, 2153 términos (26,5\% de todos los municipios españoles) destacan por acoger menos de 5 habitantes por $\mathrm{km}^{2}$, los cuales albergan en conjunto una población de 366717 personas ( $0,8 \%$ del total español), que se dispersan por un cuarto $(25,9 \%)$ del territorio estatal y representan una densidad media de 2,8 habitantes por $\mathrm{km}^{2}$. 
A continuación, atendamos a la distribución de los municipios con menos de 10 habitantes por $\mathrm{km}^{2}$ entre las 17 comunidades autónomas (ver tabla III): al iniciarse 2019, se observa que casi la mitad se concentran en Castilla y León (1582 términos que significan el 44,8\% del total estatal), despuntando en segundo lugar, pero a cierta distancia, Castilla-La Mancha (582 que representan el 16,5\%) y Aragón (522 que simbolizan el 14,8\%). Las tres comunidades autónomas suman el 76,1\% del total de municipios españoles con menos de 10 habitantes por $\mathrm{km}^{2}$, los cuales representan un nivel de poblamiento propio de un desierto demográfico.

\begin{tabular}{|c|c|c|c|c|c|c|}
\hline \multicolumn{7}{|c|}{$\begin{array}{l}\text { TABLA III. DISTRIBUCIÓN POR COMUNIDADES AUTÓNOMAS DE LOS MUNICIPIOS } \\
\text { CON UNA DENSIDAD DE POBLACIÓN INFERIOR A } 10 \text { HABITANTES POR KM² } \\
\text { A } 1 \text { DE ENERO DE } 2019 \text { (DATOS DEFINITIVOS) }\end{array}$} \\
\hline $\begin{array}{l}\text { COMUNIDADES } \\
\text { AUTÓNOMAS }\end{array}$ & $\begin{array}{c}\text { (A) N. }{ }^{\circ} \\
\text { MUNICIPIOS }\end{array}$ & $\begin{array}{l}\% \text { (A) SOBRE TOTAL } \\
\text { MUNICIPIOS DE } \\
\text { C. AUTÓNOMA }\end{array}$ & $\begin{array}{c}\% \text { (A) SOBRE TOTAL } \\
\text { MUNICIPIOS } \\
<10 \text { HAB. POR KM }{ }^{2}\end{array}$ & Población & $\begin{array}{l}\text { SUPERfiCIE } \\
\mathrm{KM}^{2}\end{array}$ & $\begin{array}{l}\text { DENSIDAD } \\
\text { MEDIA DE } \\
\text { POBLACIÓN: } \\
\text { HABS. POR KM }{ }^{2}\end{array}$ \\
\hline Andalucía & 117 & 14,90 & 3,31 & 120885 & 19091,32 & 6,33 \\
\hline Aragón & 522 & 71,41 & 14,79 & 120422 & 32490,05 & 3,71 \\
\hline Asturias & 22 & 28,21 & 0,62 & 19394 & 3354,88 & 5,78 \\
\hline Balears (Illes) & 1 & 1,49 & 0,03 & 212 & 139,39 & 1,52 \\
\hline Canarias & 1 & 1,14 & 0,03 & 758 & 103,71 & 7,31 \\
\hline Cantabria & 26 & 25,49 & 0,74 & 14061 & 2389,34 & 5,88 \\
\hline Castilla y León & 1582 & 70,37 & 44,82 & 283636 & 65754,98 & 4,31 \\
\hline Castilla-La Mancha & 582 & 63,33 & 16,49 & 186524 & 46453,22 & 4,02 \\
\hline Cataluña/Catalunya & 205 & 21,65 & 5,81 & 55405 & 11940,53 & 4,64 \\
\hline C. Valenciana & 93 & 17,16 & 2,63 & 31746 & 6120,47 & 5,19 \\
\hline Extremadura & 142 & 36,60 & 4,02 & 93570 & 16958,53 & 5,52 \\
\hline Galicia/Galiza & 27 & 8,63 & 0,76 & 27760 & 4363,55 & 6,36 \\
\hline Madrid & 19 & 10,61 & 0,54 & 3236 & 541,10 & 5,98 \\
\hline Murcia & 1 & 2,22 & 0,03 & 7839 & 952,61 & 8,23 \\
\hline Navarra/Nafarroa & 90 & 33,09 & 2,55 & 16641 & 3779,27 & 4,40 \\
\hline País Vasco/Euskadi & 13 & 5,18 & 0,37 & 6163 & 1088,93 & 5,66 \\
\hline La Rioja & 87 & 50,00 & 2,46 & 9107 & 2678,51 & 3,40 \\
\hline ESPAÑA & 3530 & 43,41 & 100,00 & 997359 & 218200,39 & 4,57 \\
\hline
\end{tabular}

Elaboración propia. Fuentes: Estadística del Padrón Continuo de 01/01/2019 (datos definitivos), Instituto Nacional de Estadística (INE) y Nomenclátor Geográfico de Municipios y Entidades de Población del Instituto Geográfico Nacional (IGN).

En el mapa 1, recogemos las comunidades autónomas según el porcentaje de municipios con menos de 10 habitantes por $\mathrm{km}^{2}$ a 1 de enero de 2019 y observamos que, en cuatro autonomías, este tipo de municipios representan por lo menos la mitad de sus términos municipales: La Rioja (50,0\%), Castilla-La Mancha (63,3\%), Castilla y León $(70,4 \%)$ y Aragón $(71,4 \%)$. Además, con alrededor de un tercio de 


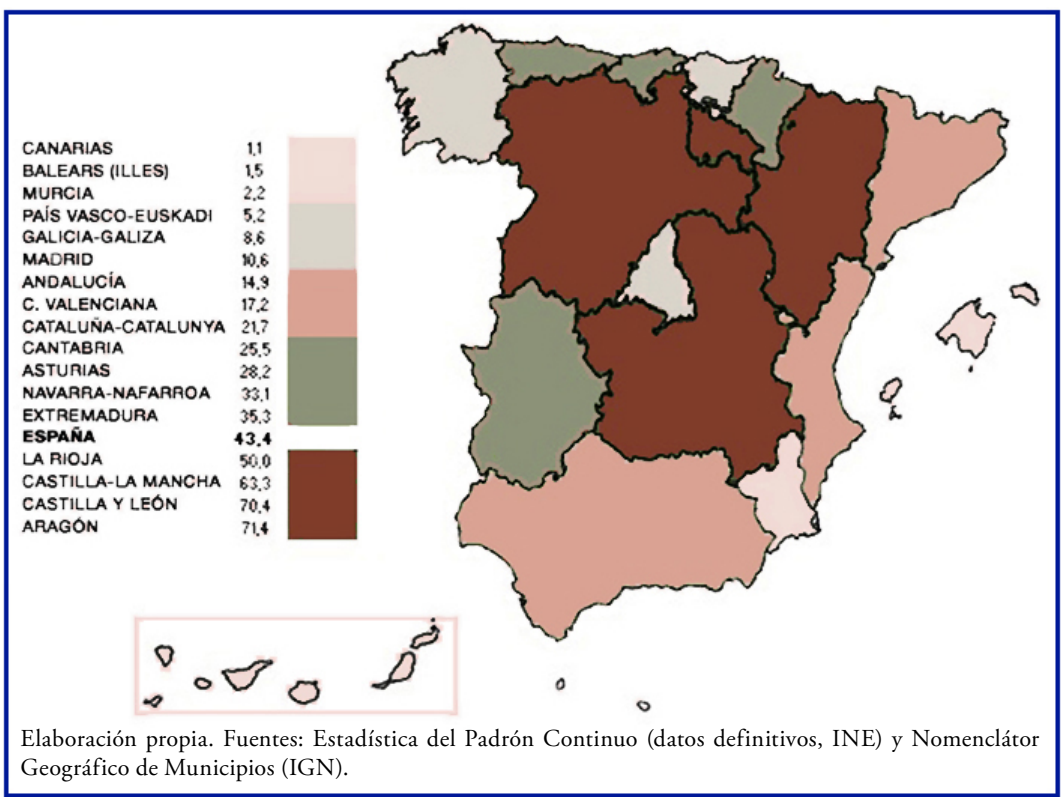

Mapa 1. Comunidades autónomas según el porcentaje de municipios con menos de 10 habitantes por $\mathrm{km}^{2}$ sobre total de municipios de la C.A. en el Padrón Continuo de 01/01/2019.

sus municipios con esa baja densidad demográfica, propia de un 'desierto humano', aparecen otras dos comunidades: Navarra $(33,1 \%)$ y Extremadura (36,6\%). En resumen, la problemática de la desertización demográfica del territorio rural afecta principalmente a las comunidades autónomas del interior peninsular, en las cuales se concentra la 'España vacía' (Del Molino, 2016), que nosotros preferimos denominar 'vaciada', en la medida en que las políticas y actuaciones públicas y privadas han promovido, directa o indirectamente, su despoblación y abandono.

\section{CONCLUSIONES}

La mayoría del territorio rural del interior peninsular está atrapado en un proceso de despoblación y abandono, con consecuencias de sobreenvejecimiento y creciente masculinización de su estructura por edad y sexo, como ejemplifican los indicadores demográficos que hemos analizado para los cinco estratos en los que el INE clasifica estadísticamente los municipios de hasta 5000 habitantes. Así, entre 2000 y 2019 , este conjunto de municipios perdió el $8 \%$ de sus residentes y su índice de envejecimiento aumentó desde 184,3 hasta 203,3 mayores de 64 años por cada cien menores de 15 años, lo que nos permite afirmar que la estructura por edad de los municipios de hasta 5000 habitantes, más que envejecida, está sobreenvejecida, pues uno de cada cuatro habitantes tiene más de 64 años. 
En cuanto a la estructura por sexo, la ratio de masculinidad nos manifiesta que durante las dos primeras décadas del siglo Xxi ha proseguido afianzándose el fenómeno demográfico de la masculinización de la población residente, ya que su valor aumentó desde 102,3 hasta 105 varones por cada cien mujeres en los municipios de hasta 5000 habitantes. La masculinización de la población rural nos advierte de una emigración más numerosa entre las mujeres activas, en su mayoría de la cohorte con potencialidad reproductiva ( 15 a 49 años), constituyendo uno de los principales talones de Aquiles, si no es el fundamental, para la renovación y la misma supervivencia del poblamiento rural que está alejado de las ciudades y no ha conseguido insertarse en las redes económicas de la globalización capitalista (Trabada et al., 2007; Trabada, 2019).

En este escenario rural de demografía regresiva, a contracorriente destaca el aumento de la población de nacionalidad extranjera: si en el Censo de Población de 2001 solo significaron el 2,4\% de la población total de los municipios de hasta 5000 habitantes, en la revisión del Padrón Continuo de 2019 su importancia se elevó al 7,3\%. Por consiguiente, resalta como el colectivo demográfico que ha moderado las pautas de despoblación y sobreenvejecimiento que dominan en la mayoría de los municipios rurales, aunque con respecto a la masculinización de la población rural ha contribuido a potenciarla (105,5 varones por cada 100 mujeres de nacionalidad extranjera).

Con relación a la desertización humana del territorio, al comenzar el año 2019 se contabilizan 3530 municipios cuya densidad de población no consiguió superar el umbral de los 10 habitantes por $\mathrm{km}^{2}$, los cuales significan el $43,4 \%$ del total de municipios españoles y, por término medio, tienen una densidad de 4,6 residentes por $\mathrm{km}^{2}$. Este grupo de municipios escasamente poblados se concentran en las comunidades autónomas del interior peninsular, resaltando Castilla-La Mancha (63,3\%), Castilla y León $(70,4 \%)$ y Aragón $(71,4 \%)$, ya que más de la mitad de sus términos municipales tienen menos de 10 habitantes por $\mathrm{km}^{2}$.

En resumidas cuentas, el declive de población, el sobreenvejecimiento de la estructura por edad, la masculinización de la estructura por sexo y la desertización demográfica del territorio conforman un escenario de profunda crisis demográfica y, dada la estrecha relación que se establece entre población, economía, sociedad y Administración local en el medio rural, seguramente implicará que proseguirá agravándose en los municipios rurales segregados, cuando no excluidos, de las redes y actividades económicas del capitalismo globalizado, tal como ha sucedido durante el tiempo transcurrido del siglo XXI.

La crisis demográfica contribuye a la crisis de la economía local, y el entrelazamiento de ambas promueve la crisis institucional y social en el territorio rural. Las relaciones negativas de retroalimentación o feed-back (causa $\leftrightarrows$ efecto) entre estas crisis conforman una crisis estructural de 'círculo vicioso' (ver cuadro 1) que impulsa la creciente desinversión y posterior cierre de explotaciones agrarias, de empresas y negocios por falta de 'masa crítica' (relevo generacional, mano de obra, consumidores), así como la pérdida del capital invertido y el abandono de instalaciones y medios de producción, como ya sucede en los municipios de la 'España vaciada'. 


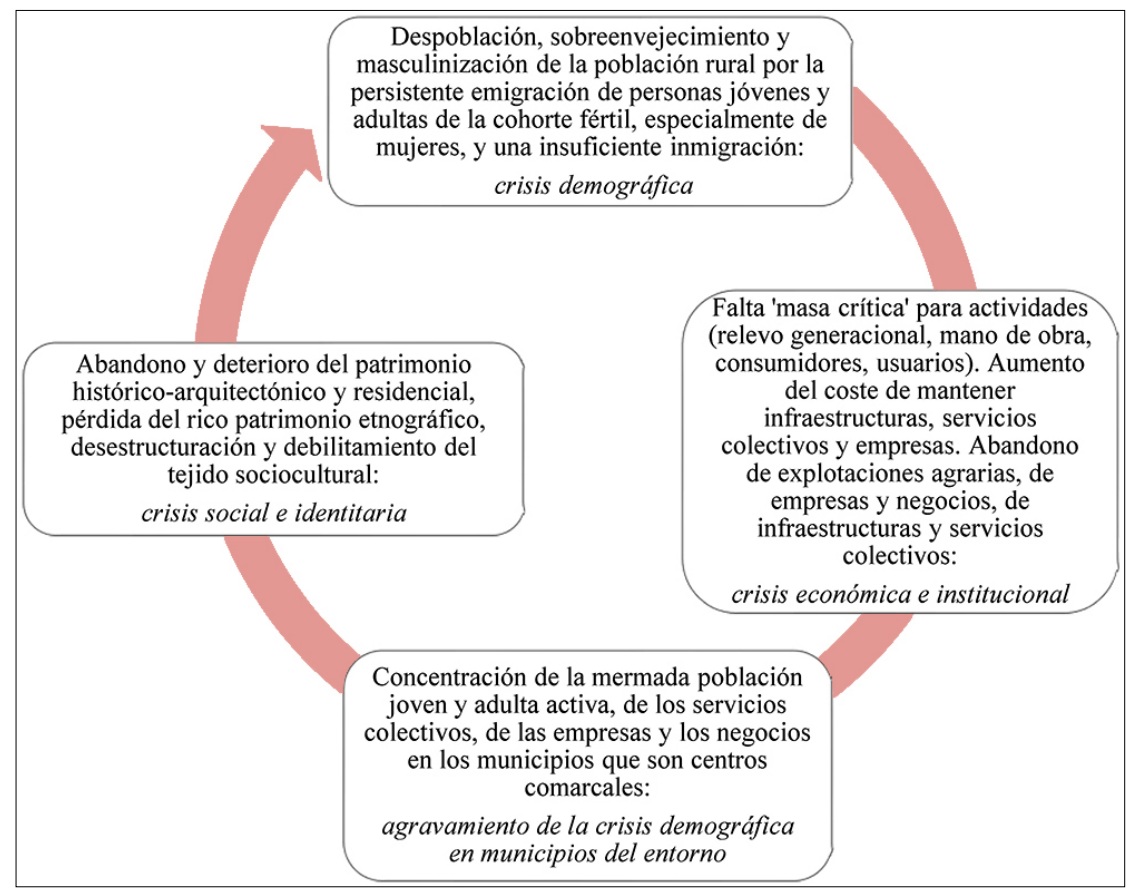

Elaboración propia. Fuente: Trabada, E. (2019).

A la par, se produce una concentración de la mermada población activa joven y adulta con hijos en los municipios rurales que son centros comarcales, en los cuales se centralizan los servicios colectivos básicos (centro de salud de especialidades y urgencias, farmacias, centros de educación obligatoria, oficinas agrarias autonómicas, oficinas bancarias, gestorías, comercios, talleres de reparación, restauración y ocio, etc.), exacerbando la crisis demográfica en los municipios de su área de influencia. Por lo demás, la mayoría del personal técnico y cualificado ocupado en los servicios colectivos públicos y privados no suelen residir en los municipios rurales en los que trabajan diariamente, pues prefieren alojarse con sus familias en la capital provincial o, si está muy distante, en el municipio que actúa como cabecera comarcal en su zona de trabajo.

El encadenamiento de las crisis demográfica y económica siembra una crisis institucional que se manifiesta en el abandono y deterioro de infraestructuras públicas y el cierre de equipamientos colectivos, tanto públicos como privados, necesarios para la vida cotidiana de las y los ruralitas. Otro tanto sucede con el patrimonio residencial e histórico-arquitectónico, con la pérdida del rico y heterogéneo patrimonio etnográfico del mundo rural, junto con la creciente desestructuración y debilitamiento de su tejido sociocultural (redes y grupos animadores 
de la vida local), derivando en una crisis social e identitaria profunda, que genera anomia y desarraigo intenso entre las y los ruralitas. En resumen, vuelta de tuerca tras vuelta de tuerca, la concatenación y retroalimentación de las crisis demográfica, económica, institucional y social se va imponiendo como un escenario de crisis estructural irreversible, que conlleva necesariamente la desertización humana del territorio rural afectado.

\section{ALGUNAS RECOMENDACIONES}

El territorio rural que se distingue por la escasez de seres humanos nos remite a una realidad local muy condicionada por carencias y desatenciones absolutas, en cuanto a las necesidades y demandas básicas de la población rural, así como por sobrecostes e ineficacias crecientes en la gobernanza municipal, las cuales determinan un modelo atomizado y minifundista de Administración local, que gestiona como puede y cuando puede un extenso y abandonado medio rural, una situación frecuente en el interior peninsular. Urge, pues, una reforma política de la Administración local, pero en la que domine una lógica democrática ascendente (de abajo hacia arriba) en vez de despótica descendente (de arriba hacia abajo) respecto de la gobernanza, ordenación y planificación del territorio que necesita la sociedad rural que ya es un desierto demográfico o parece destinada irreversiblemente a serlo. En este sentido, la reforma político-administrativa que apuntamos debería centrarse en la construcción democrática de instituciones intermunicipales (mancomunidades o comarcas), que surjan de la asociación federativa de municipios -en vez de crearse por imposición legal-, las cuales deberán disponer de suficiente presupuesto y capacidad técnico-burocrática, además del apoyo de la Administración autonómica, para dar los servicios necesarios a las y los ruralitas en su ámbito territorial.

En esta reforma político-administrativa tan necesaria para el presente y el futuro de nuestro territorio rural, se debería debatir y consensuar entre los actores sociales, económicos y políticos - con principal protagonismo de los rurales-sobre qué hacer con las treinta y ocho diputaciones provinciales existentes ${ }^{9}$. En principio, hay dos opciones a considerar: o se mantienen, pero reformándolas en profundidad, o se suprimen y sustituyen por instituciones de ámbito comarcal. Pensamos que es necesaria la existencia de una organización pública supramunicipal entre las administraciones municipales y autonómicas, especialmente en las comunidades pluriprovinciales. Tras un proceso constituyente comarcal, basado en municipios veci-

9 No nos referimos a las tres diputaciones forales de la C.A. de Euskadi, los siete cabildos insulares de la C.A. de Canarias y los cuatro consells isulars de la C.A. Illes Balears, unas instituciones de la Administración local del Estado español cuyos miembros son elegidos por sufragio directo y que disfrutan de una especial protección jurídica, cuya supresión implicaría una reforma de la Constitución española de 1978. A diferencia de las 38 diputaciones provinciales de régimen común, cuya supresión no exigiría una reforma constitucional. 
nos que se federan en $\operatorname{comarcas}^{10}$, estas instituciones podrían cumplir con eficacia y eficiencia con ese rol de gobierno y Administración intermedia, pero, a su vez, la Administración autonómica deberá asumir infraestructuras provinciales, como el mantenimiento de la red viaria, y apoyar económica y técnicamente a las comarcas en aquellos servicios colectivos que requieran de su colaboración o impliquen a dos o más comarcas vecinas. En este nuevo escenario, las diputaciones provinciales serían reemplazadas gradualmente por las comarcas y una parte de su burocracia pasará a formar parte de las nuevas administraciones comarcales y el resto se integraría en las delegaciones autonómicas provinciales.

Somos conscientes de que no hay soluciones que, a modo de panaceas, puedan modificar sustancialmente el escenario rural de crisis demográfica y estructural que hemos descripto anteriormente. Pero tampoco nuestros pueblos y municipios rurales han de ser abocados y abandonados, como si fuese su destino inexorable, a la despoblación continuada y al vaciamiento total, como si todos ellos tuviesen que repetir maquinalmente la historia de Ainielle, la localidad oscense deshabitada recreada por Julio Llamazares en su novela La lluvia amarilla (1988).

Apreciamos que es urgente un 'cambio copernicano' en las políticas de ordenación y planificación territorial, diseñando e implementando democráticamente unas políticas alternativas que -promovidas desde abajo hacia arriba por la sociedad rural, mediante el empoderamiento de las y los ruralitas y sus asociaciones- posibiliten una reordenación y requilibrio entre los territorios rural y urbano en el Estado español. Unas políticas alternativas que pretendan superar el modelo neocolonialista que domina actualmente en las relaciones entre el campo y la ciudad, que tanto perjudican al primer tipo de hábitat. Que frente al productivismo, la hipercompetitividad, hiperespecialización e hiperflexibilidad que imponen los actores capitalistas dominantes en los mercados nacionales y mundiales, se prime la calidad y la sostenibilidad ambiental, la convivencialidad ${ }^{11}$, la economía social y el buen vivir de los pobladores humanos y el bienestar de los otros animales, así como la biodiversidad en el ecosistema rural.

Existen alternativas posibles que sí pueden desencadenar cambios socioeconómicos positivos de cierta magnitud, mediante las cuales se implementen nuevas tendencias y procesos de renovación, recualificación, reequilibrio y cohesión socioterritorial, que posibiliten la supervivencia de una parte relevante de los municipios rurales actualmente inmersos en una grave crisis demográfica que amenaza su exis-

${ }^{10}$ Una mancomunidad creada para mejorar el abastecimiento de agua o la recogida y tratamiento de residuos entre varios municipios puede ser una excelente base institucional desde la que promover la constitución democrática y federal de una comarca entre esos y otros municipios vecinos.

11 Para Iván Illich: «Una sociedad convivencial es la que ofrece al hombre la posibilidad de ejercer la acción más autónoma y más creativa, con ayuda de las herramientas menos controlables por los otros. La productividad se conjuga en términos de tener, la convivencialidad en términos de ser. En tanto que el incremento de la instrumentación, pasados los umbrales críticos, produce siempre más uniformación reglamentada, mayor dependencia, explotación e impotencia, el respeto a los límites garantizará un libre florecimiento de la autonomía y de la creatividad humanas» (Illich, 1985: 20). 
tencia. Pensamos que las políticas alternativas pasan, necesariamente, por promover un ecodesarrollo endógeno e integral que supere los artificiales divorcios y contradicciones entre ecología, economía y sociedad (Naredo, 2006). Así, en cada una de las comarcas rurales que surjan de la federación de municipios vecinos se debería diseñar y planificar un plan comarcal de ecodesarrollo endógeno e integral (Vázquez, 2007), basándose en una metodología integrada e intersectorial, participativa y bidireccional (ascendente $\leftrightarrows$ descendente), que promueva 'conjuntos de acción' comarcales (Rodríguez-Villasante, 2009), con la suficiente transversalidad, cooperación y coordinación entre los diferentes actores, instituciones y sectores implicados (Izquierdo, 2002).

A través de los planes comarcales se debería poner en marcha un proceso de transición ecológica mediante la progresiva desintensificación de las explotaciones agrarias, que incluya el fomento de la agroecología (Sevilla, 2006), pero también de formas híbridas o mixtas como la ganadería y agricultura familiar semiintensiva o semiextensiva con una doble finalidad: a) potenciar la sostenibilidad ambiental y la circularidad de la economía agraria comarcal, y b) frenar la despoblación generada por el proceso de concentración-intensificación de las actividades agropecuarias en explotaciones de mayor tamaño, capital y tecnificación, las cuales emplean menos fuerza de trabajo y alimentan el declive demográfico (Trabada, 2019). Asimismo, hay que promover la transformación y comercialización directa de los productos agroecológicos y de calidad diferenciada a través de microempresas de la misma comarca, dando prioridad a la economía social para superar la tragedia de los comunes $^{12}$, lo que contribuirá a fijar mujeres de la cohorte fértil, personas jóvenes y adultas con estudios superiores, renovando la sobreenvejecida y declinante población activa (Trabada, 2020).

Por otro lado, la crisis sociosanitaria provocada por el covid-19 y las medidas de confinamiento y restricción de la movilidad de la población aprobadas por los gobiernos estatal y autonómicos han generado una oportunidad factible para el

12 Con la tragedia de los comunes, no solo nos referimos al dilema que surge en el aprovechamiento de los recursos y bienes comunes entre la lógica del interés individual que pretende maximizar el beneficio particular y la lógica del interés colectivo que pretende, mediante la coerción-regulación, un aprovechamiento sostenible de esos mismos recursos y bienes más allá del corto plazo, como teorizó el biólogo y demógrafo Garret Hardin (2005). También queremos aludir al dilema socioeconómico que se plantea en las explotaciones familiares respecto de competir o cooperar entre ellas para mejorar su estrategia de sobrevivencia, eficacia y calidad de vida. En la regulación neoliberal y la PAC se prioriza la competitividad, productividad, eficiencia y rentabilidad de las explotaciones familiares, una lógica económica que ha conducido a la competencia entre las explotaciones familiares y al cierre y abandono de las que han sido incapaces de continuar en esa loca carrera capitalista, lo que ha supuesto el despoblamiento y la crisis demográfica de bastantes municipios rurales, cuyos hogares vivían de las actividades agropecuarias. En este sentido, si queremos priorizar la fijación y renovación de población en el territorio rural debemos cambiar con urgencia el modelo de agricultura y ganadería hacia una lógica económica en la que predomine la cooperación entre las explotaciones familiares, así como la sostenibilidad ambiental de sus recursos, la calidad en sus producciones y la comercialización a través de sus asociaciones. 


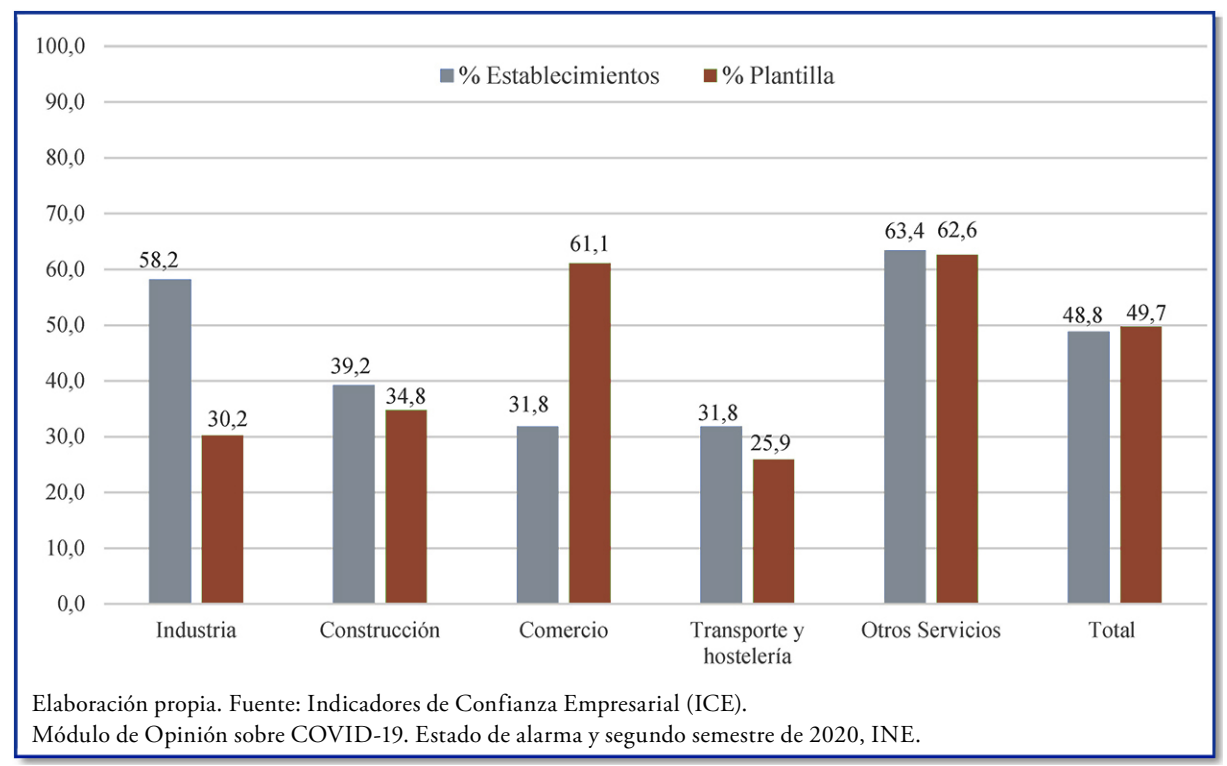

Gráfico 13. Porcentajes de establecimientos y de plantilla que han utilizado el teletrabajo durante el estado de alarma en España según sectores de actividad durante el segundo semestre de 2020.

maltrecho y olvidado territorio rural que sufre la crisis demográfica, que se debería aprovechar. Según los resultados de la encuesta de Indicadores de Confianza Empresarial del INE referida al segundo semestre de 2020 (ver gráfico 13), casi la mitad de los establecimientos en España $(48,8 \%)$ han utilizado el teletrabajo durante el estado de alarma, afectando a la mitad de la plantilla (49,7\%), lo que supone un importante crecimiento en el uso del teletrabajo con respecto al momento anterior al estado de alarma (14,8\% de establecimientos y 32,1\% de las plantillas). Además, casi la tercera parte de los establecimientos (32,2\%) que optaron por el teletrabajo durante el estado de alarma declara que lo mantendrá en el futuro (al menos durante los seis meses próximos).

Los representantes de las administraciones públicas, del empresariado y de las organizaciones sindicales deberían consensuar, dentro del marco legal y fiscal que regule e incentive el teletrabajo, un objetivo y línea estratégica de actuación que desarrolle su potencialidad para contribuir al repoblamiento y rejuvenecimiento de los municipios rurales. En este sentido, es necesario desarrollar un plan de inversiones públicas que garanticen un acceso de calidad a internet de los municipios y comarcas rurales que actualmente disponen de una mala e insuficiente conectividad digital, para que puedan acoger el teletrabajo que se deslocalice desde el medio urbano hacia el rural. Por consiguiente, es fundamental reducir la brecha digital que segrega y margina al territorio rural. 
Paralelamente, la deslocalización del teletrabajo urbano en cantidades significativas hacia municipios rurales tendría consecuencias beneficiosas en las ciudades y áreas metropolitanas, ya que ayudaría a descongestionarlas de residentes, actividades y del tráfico motorizado, reduciendo la contaminación ambiental y el calentamiento del clima local que sufren. Asimismo, la emigración de urbanitas al medio rural ayudaría a moderar los precios de la vivienda, de las oficinas y de los locales comerciales en las urbes, además de desahogar de usuarios a los servicios colectivos y el espacio público, contribuyendo a que fuesen un entorno más habitable y saludable.

En definitiva, necesitamos unas políticas alternativas que apoyen realmente el retorno de las y los emigrantes y, a su vez, la inmigración de 'neorrurales' de las cohortes económicamente activas, tanto nacionales como extranjeros. Esto es, de urbanitas que sufren un malestar psicosocial por verse obligados a mal vivir en unas urbes artificiosas y contaminantes, donde la precariedad, la segregación y la deshumanización proliferan. Para los cuales, el teletrabajo bien podría ser la forma laboral para liberarse y comenzar el buen vivir en el territorio rural. Un movimiento neorrural (Trabada y Rodríguez, 1991) que podrá focalizar sus deseos y necesidades personales y grupales, buscar y construir en el territorio rural, con mayor libertad e igualdad, unos estilos de vida más satisfactorios, saludables, convivenciales y sostenibles, a la vez que realizará importantes aportaciones demográficas, económicas y socioculturales a un mundo rural que quiere y lucha por sobrevivir.

Recibido: 23 de julio de 2020; ACEptado: 27 de octubre de 2020 


\section{REFERENCIAS BIBLIOGRÁFICAS}

Camarero, L. y Sampedro, R. (2016). «Inmigrantes, estrategias familiares y arraigo: las lecciones de la crisis en las áreas rurales». Migraciones. Publicación del Instituto Universitario de Estudios sobre Migraciones, 40: 3-31, recuperado de https://revistas.comillas.edu/index.php/ revistamigraciones/article/view/7561. Última consulta: 20/07/2020.

Camarero, L. y Sampedro, R. (2008). «¿Por qué se van las mujeres? El continuum de movilidad como hipótesis explicativa de la masculinización rural». Revista Española de Investigaciones Sociológicas (Reis), 124: 73-105, recuperado de http://www.reis.cis.es/REIS/PDF/ REIS_124_031222873178255.pdf. Última consulta: 20/07/2020.

Del Molino, S. (2016). La España vacía. Viaje por un pais que nunca fue. Madrid: Turner.

Hardin, G. (2005). «La tragedia de los comunes». Polis Revista Latinoamericana, 10: 1-14, recuperado de http://journals.openedition.org/polis/7603. Última consulta: 20/07/2020.

IвÁñez, J. (1991). El regreso del sujeto. La investigación social de segundo orden. Santiago de Chile: Editorial Amerinda.

Illich, I. (1985). La convivencialidad. México: Joaquín Mortiz/Planeta, recuperado de http://ivanillich.org.mx/convivencial.pdf. Última consulta: 20/07/2020.

INE (2020). Indicador de Confianza Empresarial (ICE). Módulo de Opinión sobre el Impacto de la Covid-19. Estado de alarma y segundo semestre de 2020. Nota de prensa 10/07/2020, recuperado de https://www.ine.es/daco/daco42/ice/ice_mod_covid_0320.pdf. Última consulta: 20/07/2020.

IzQuierdo, J. (2002). Manual para Agentes de Desarrollo Rural: Ideas y propuestas para moverse entre la conservación del patrimonio y el Desarrollo Local. Madrid: Ediciones Mundi-Prensa.

Llamazares, J. (1988). La lluvia amarilla. Barcelona: Seix Barral.

Naredo, J. (2006). Raíces económicas del deterioro ecológico y social. Más allá de los dogmas. Madrid: Siglo XXI de España Editores, SA.

Rodríguez-Villasante, T. (2009). "Conjuntos de acción y participación rural». Documentación Social, 155: 41-56.

Santos, I. (1996). «Envejecimiento demográfico: diferencias por género». Revista Española de Investigaciones Sociológicas (Reis), 73: 177-190, recuperado de http://www.reis.cis.es/REIS/PDF/ REIS_073_11.pdf. Última consulta: 20/07/2020.

Sevilla, E. (2006). De la Sociología Rural a la Agroecología. Barcelona: Icaria.

TRABADA, E. (2020). Encuesta a residentes de 16 y más años en pueblos o municipios rurales e Informe de la población y la economía de seis zonas o comarcas de actuación de COCEDER. Consultora Emic-Etic. Valladolid: Confederación de Centros de Desarrollo Rural (COCEDER).

Trabada, E. (2019). Estudo sociolóxico sobre a crise demográfica na Pastoriza: Análise e estratexia de desenvolvemento local. Consultora Emic-Etic. A Pastoriza (Lugo): Alcaldía.

Trabada, E. (dir.) y Renes, V. (coord.) et al. (2007). Estudo sociolóxico sobre o territorio rural de Galicia. Consultora Emic-Etic. Santiago de Compostela: Fundación FOESSA, Cáritas de Galicia e Obra Social da Fundación CaixaGalicia.

Trabada, E. y Rodríguez, B. (1991). «De la ciudad al campo: el fenómeno social neorruralista en España». Política y Sociedad, 9: 73-86, recuperado de https://dialnet.unirioja.es/ejemplar/93149. Última consulta: 20/07/2020.

Van de KaA, DJ. (1987). «Europe’s Second Demographic Transition». Population Bulletin, 42(1): 1-59.

VÁzQuez, Antonio (2007). «Desarrollo endógeno. Teorías y políticas de desarrollo territorial». Investigaciones Regionales $=$ Journal of Regional Research, 11: 183-210, recuperado de https:// dialnet.unirioja.es/ejemplar/179583. Última consulta: 20/07/2020. 


\title{
MULTIPARTIDISMO PARLAMENTARIO Y PLURIPARTIDISMO GUBERNAMENTAL. VICISITUDES DEL SISTEMA DE PARTIDOS DEL ESTADO ESPAÑOL (2015-2020)*
}

\author{
Roberto Rodríguez Guerra \\ rrguerra@ull.edu.es \\ Universidad de La Laguna
}

\section{RESUMEN}

Este trabajo aborda los importantes cambios que ha experimentado el sistema de partidos del Estado español desde las elecciones generales de 2015 hasta las de noviembre de 2019 y el presente. Analiza así su tránsito desde el pluripartidismo limitado al multipartidismo y, al tiempo que seńala sus más relevantes cambios, argumenta la posibilidad de caracterizarlo como un sistema de multipartidismo parlamentario y pluripartidismo gubernamental.

Palabras clave: sistema de partidos, multipartidismo, pluripartidismo, elecciones, España.

\author{
PARLIAMENTARY MULTIPARTIDISM \\ AND GOVERNMENTAL PLURIPARTIDISM. \\ VICISSITUDES OF THE PARTY SYSTEM \\ OF THE SPANISH STATE (2015-2020)
}

\section{Abstract}

This paper addresses the important changes that the party system of the Spanish State has undergone from the general elections of 2015 to those of November 2019 and the present. Thus, it analyzes its transition from limited pluripartidism to multipartidism and, while pointing out its most relevant changes, argues the possibility of characterizing it as a system of parliamentary multipartidism and governmental pluripartidism.

KEYwORDS: party system, multipartidism, pluripartidism, elections, Spain. 


\section{INTRODUCCIÓN}

Desde las elecciones generales de 1977 hasta los momentos previos a las generales de 2015 el sistema de partidos del Estado español había sido tipificado como un sistema de «bipartidismo imperfecto» (García Cotarelo y Bobillo, 1991: 18 y ss.; Sánchez Medero y Sánchez Medero, 2015: 125 y ss.) o como «sistema de partido predominante» (Martínez Sospedra, 1992). Pero acaso con mayor acierto admitía, aunque con algunos matices, su caracterización como "pluralismo limitado y no excesivamente polarizado» (Ramírez, 1991: 100). Sin embargo, como decíamos en un trabajo anterior sobre las vicisitudes del sistema de partidos del Estado español durante este periodo ${ }^{1}$, esta misma caracterización debería reconocer igualmente la constante presencia en tal sistema de dos grandes partidos que habían estado constantemente enfrentados entre sí, se habían disputado la hegemonía político-institucional y, de hecho, casi que se habían alternado en el Gobierno. Es precisamente por esto último por lo que afirmaba en dicho trabajo que una tipificación más precisa del sistema de partidos del Estado español durante el citado periodo debería formularse en términos de un sistema de pluripartidismo parlamentario de bipolaridad moderada y de bipartidismo gubernamental ${ }^{2}$. En cualquier caso, de todos es sabido que esa situación cambia drásticamente a partir de los resultados de las elecciones generales de 2015, aunque de hecho tal cambio podría retrotraerse incluso a las elecciones europeas de 2014. Es entonces cuando es ya evidente el declive de los dos grandes partidos tradicionales (Partido Popular y Partido Socialista Obrero Español, en adelante PP y PSOE), el fin de un sistema de partidos relativamente consolidado y

* Este trabajo ha sido realizado en el marco del Grupo de Investigación «Repensar la filosofía» (RPF) de la Universidad de La Laguna.

${ }_{1}$ Cf. al respecto Rodríguez Guerra (2020), donde, además de establecer algunas precisiones conceptuales que facilitan la comprensión de aquel y de este trabajo, tuve ocasión de ocuparme de estas caracterizaciones, así como de la dinámica y evolución del sistema de partidos del Estado español desde las generales de 1977 hasta las de 2011. Una opinión similar, al menos hasta las elecciones de 1982, en Gunther y otros (1986: 437 y ss.).

2 A tal caracterización subyace una suerte de personal síntesis entre la clasificación de M. Duverger (1951: 234 y ss.), que distingue entre sistemas de partido único, bipartidistas y multipartidistas (aunque dentro de este último tipo diferencia entre tripartidistas, cuatripartidistas y polipartidistas), y la clasificación de G. Sartori (1989: 160), quien a su vez diferencia entre sistemas de partido único, de partido hegemónico, de partido predominante, bipartidistas, de pluralismo limitado, de pluralismo extremo y de atomización. Así mismo, a los efectos que aquí nos interesa, usaremos las nociones de bipartidismo, pluripartidismo o multipartidismo "parlamentario" para referirnos a aquellas situaciones en las que el sistema de partidos se caracteriza por la presencia parlamentaria de dos partidos (bipartidismo parlamentario), de tres a seis partidos (pluripartidismo parlamentario) o de siete o más partidos (multipartidismo parlamentario). Una caracterización similar, aunque con algunos matices diferenciales, en José Vilas Nogueira (2003: 278 y ss.). Por último y en un sentido equivalente, usaremos las nociones de bipartidismo, pluripartidismo o multipartidismo "gubernamental» para referirnos a aquellos casos en que, durante un largo periodo y en varias legislaturas, los partidos que efectivamente "cuentan» (Sartori) a la hora de formar Gobierno han sido dos (bipartidismo gubernamental), tres/seis (pluripartidismo gubernamental) o siete o más (multipartidismo gubernamental). 
estable y, finalmente, el tránsito hacia un nuevo ciclo político-electoral generado por fuertes alteraciones electorales y significativos cambios en el mismo sistema de partidos. Es de este tránsito y de estos cambios de lo que se ocupará el presente trabajo, que trata de demostrar la hipótesis de que -desde ese momento (elecciones generales de 2015) hasta el presente- el sistema de partidos del Estado español puede ser caracterizado como un sistema de multipartidismo parlamentario y pluripartidismo gubernamental. En él, tras esbozar de modo general el cambio del panorama electoral y partidista acaecido entre las generales de 2015 y las de 2019, nos adentramos con cierto detalle en distintos y concretos fenómenos ocurridos a lo largo de este mismo periodo con el fin de ir dando cuenta de la dinámica de competencia partidista y de los cambios en el sistema de partidos. De este modo, nos acercamos, en primer lugar, al multipartidismo, el Gobierno en minoría y la situación de inestabilidad político-institucional resultante de las generales de 2015 y 2016; en segundo lugar, a las posibilidades e infructuosos intentos de superar el bipartidismo gubernamental tras la generales de 2015; en tercer lugar, al nuevo "empate minoritario» y la presentación de una moción de censura tras las generales de junio de 2016; en cuarto lugar, al fin de la denominada "excepción española» y la emergencia de los «cordones sanitarios» tras las generales de abril de 2019; en quinto lugar, a la continuidad del multipartidismo parlamentario y la emergencia del pluripartidismo gubernamental tras las generales de noviembre de 2019. Por último, el trabajo terminará con algunas conclusiones generales sobre los avatares del sistema de partidos y su situación actual.

\section{MULTIPARTIDISMO, POLARIZACIÓN Y BLOQUEO GUBERNAMENTAL: DE LAS ELECCIONES GENERALES DE 2015 A LAS DE NOVIEMBRE DE 2019}

Las elecciones generales de diciembre de 2015, así como - debido a su repetición, por primera vez en la reciente historia de la democracia en el Estado español, a causa de la imposibilidad de formar gobierno- las generales de junio de 2016, generaron un cambio sin precedentes y situaron a la democracia representativa española ante un nuevo ciclo político-electoral marcado por un sistema de partidos nítidamente multipartidista y polarizado, así como por gobiernos en minoría y una situación posterior de bloqueo gubernamental. Por otra parte, las elecciones generales anticipadas de abril de 2019 no hicieron más que acentuar estos rasgos, mientras las generales de noviembre de 2019 condujeron -pese a los pronósticos iniciales-a la formación de un Gobierno de coalición entre el PSOE y Unidos Podemos (UP) con el apoyo externo de otras fuerzas políticas. A lo largo de los siguientes apartados iremos desglosando diversos aspectos y acontecimientos ocurridos durante este periodo. No obstante, quizá sea necesario comenzar este acercamiento general al convulso periodo que comentamos indicando que las causas últimas de los importantes cambios en el sistema de partidos del Estado espańol durante el periodo analizado acaso residan, fundamentalmente, en la crisis económica de 2008 y las políticas austericidas (con sus durísimos efectos sociales y económicos sobre la mayoría 
social) aplicadas por entonces, así como en la persistencia de la corrupción política sistémica (que afectó inicial y severamente al PSOE, pero que luego se centró en el $\mathrm{PP})$, y, por supuesto, en el conflicto catalán con sus muy diversas y complejas derivaciones. Pero junto a estos hechos y circunstancias ha de señalarse que el sistema se vio igualmente afectado por lo que podríamos considerar «el fin de la pospolítica» (Mouffe, 2007: 54 y ss.) o el auge de una fuerte polarización ideopolítica. En cualquier caso, la emergencia del $15 \mathrm{M}$ y la revitalización de una multiplicidad de mareas ciudadanas, movimientos sociales (feminismo, sanidad, pensionistas...) y redes de ciudadanía crítica dieron pie a un primer y potente ciclo de protestas que se atrevió a poner en cuestión tanto el «consenso en el centro» (Ramírez, 1991: 105; Rodríguez Guerra, 2020) sobre el que hasta entonces basculaba el sistema de partidos del Estado español como buena parte de los dogmas e instituciones del sistema económico y del sistema representativo del mismo. Es más, junto a estos y otros fenómenos sociopolíticos que mostraron la indignación ciudadana con el pluripartidismo limitado de bipartidismo gubernamental ${ }^{3}$ hasta entonces reinante, cabe destacar igualmente -a partir de las generales de abril 2019- el «fin de la excepción española» (Encarnación, 2017; González-Enríquez, 2017) a través de la irrupción de Vox con 24 escańos y la emergencia -en este caso a raíz de los resultados de las generales de noviembre de 2019- de un nuevo partido estatal a causa de la incorporación de Más País, si bien con una débil presencia de tres escaños. De este modo, el corto periodo de cuatro años que va desde diciembre de 2015 hasta noviembre de 2019 constituye un nuevo y conflictivo ciclo político-electoral marcado, de una parte, por el paso de cuatro a seis partidos de ámbito estatal con diferentes posibilidades de formar Gobierno y, de otra, por la persistencia (y hasta el incremento) de las fuerzas nacionalistas/regionalistas. Volveremos más adelante sobre la aparición de estas otras fuerzas políticas. Por el momento conviene detenernos en las generales de 2015, cuyos datos más significativos acaso fuesen la crisis de los dos grandes partidos y la irrupción de los partidos popularmente llamados «del cambio» (Podemos y las confluencias) o "del recambio» (Ciudadanos), que aspiraban -cada uno su modo- a consolidar una nueva forma de hacer política, la nueva política, y a sustituir o cuando menos debilitar seriamente a los partidos de la vieja política.

3 Tal y como ya se ha señalado en la anterior nota a pie de página, aquí usamos el término «bipartidismo gubernamental» para referirnos a una situación en la que, durante un largo periodo temporal y en varias legislaturas, los partidos que efectivamente han formado Gobierno han sido dos. En relación con el caso español alude al concreto hecho de que, entre 1977 y 2011, solo dos partidos (UCD y PSOE primero y posteriormente PSOE y PP) accedieron al Gobierno y en la práctica -salvo el largo ciclo socialista (Ramírez, 1991: 11 y ss.) que se inicia en 1982 y termina en 1996casi se alternaron en el mismo. 


\section{MULTIPARTIDISMO Y GOBIERNO EN MINORÍA: LAS GENERALES DE 2015 Y 2016}

Las elecciones generales de diciembre de 2015 supusieron el inicio de un nuevo ciclo político-electoral. De hecho, generaron un cambio sin precedentes y con profundas implicaciones en el sistema de partidos del Estado español, cambio que -como ya hemos señalado-supondría su tránsito hacia un sistema abiertamente multipartidista y polarizado. No obstante, antes de adentrarnos en el mismo, quisiera referirme a otro aspecto relativamente novedoso de este proceso electoral: el retorno de las coaliciones electorales.

Probablemente a causa de la debilidad y segmentación de los partidos políticos tras el fin de la dictadura y los inicios de la transición a la democracia en el Estado español, la fórmula de las coaliciones electorales había tenido cierto éxito en elecciones generales de 1977 y 1979. Así, en estas últimas obtuvieron representación en el Congreso seis coaliciones (Unión de Centro Democrático, Coalición Democrática, Herri Batasuna, Unión Nacional, Euskadiko Ezquerra y Unión del Pueblo Canario) y una federación de partidos (Convergència i Unió). Pero en las generales de 1982 su número desciende significativamente, quizá debido a tendencias centrípetas, al reforzamiento de los dos grandes partidos (PSOE y PP), a la consolidación de otras fuerzas políticas (PCE/IU, Partido Nacionalista Vasco, CiU) o, en fin, a la disolución o reconstrucción de otras (Unión de Centro Democrático/Centro Democrático y Social). De hecho, son dos o, a lo sumo, tres las coaliciones o federaciones de partidos que desde entonces concurren a las elecciones.

Sin embargo, en las generales de 2015 nos encontramos nuevamente con siete coaliciones electorales. Entre ellas destacan tanto aquellas en las que está presente Podemos como fuerza estatal (En Comú Podem, En Marea, Compromís-Podemos) como las conformadas por diversas fuerzas nacionalistas (Democràcia $\mathrm{e}$ Llibertat, Euskal Herria Bildu, Esquerra Republicana de Catalunya-Catalunya Sí, Coalición Canaria-Partido Nacionalista Canario). No es fácil aventurar explicaciones generales para tal proceso, pero la emergencia de nuevas coaliciones electorales acaso tenga mucho que ver, por un lado y en el caso de las fuerzas progresistas de ámbito estatal (fundamentalmente las coaliciones en las que está presente Podemos $y$, en menor medida, Izquierda Unida), con la intención de dar respuesta a las nuevas demandas de la sociedad civil (15M, Mareas...), de ofrecer plataformas políticas capaces de recoger esta nueva sensibilidad y protesta social y, al mismo tiempo, al intento de combinar en diversas circunscripciones electorales el eje izquierda/derecha con el estatalista/nacionalista para salir a ganar y maximizar las posibilidades de éxito electoral y de cambio político; y, por otro y en el caso de las fuerzas nacionalistas, con la pretensión -en especial en Cataluña y en el País Vasco- de sumar fuerzas entre opciones afines -tanto en la derecha como en la izquierda- que competían por un mismo espacio electoral y, al tiempo, con la decisión de sumar abriéndose a esas mismas demandas de cambio en sus respectivos espacios electorales. De cualquier modo, lo que nos interesa destacar aquí es que, por su apoyo electoral, por el número de escaños que obtiene, por su carácter de fuerzas políticas significativas o, finalmente, por sus posibilidades de incidir sobre la formación de gobierno, esas 
coaliciones alteran el sistema de partidos del Estado español configurándolo como un sistema de multipartidismo parlamentario mucho más complejo que el previamente existente entre 1977 y 2015.

No obstante, el cambio más relevante de los resultados de las elecciones generales de diciembre de 2015 vino dado por dos fenómenos de suma importancia: el fuerte descenso electoral de las fuerzas del bipartidismo gubernamental (PSOE y PP) y la irrupción de dos nuevas fuerzas políticas de ámbito estatal (Podemos/UP y Ciudadanos). El descenso de los dos grandes partidos y, cuando menos, el fin del -así llamado- «bipartidismo imperfecto» ${ }^{4}$ (que no del bipartidismo gubernamental) quedó abiertamente reflejado tanto en los resultados de las generales de 2015 como en los derivados de las generales de 2016.

Así, por parte del Partido Popular cabe señalar que mientras en las generales de 2011 había obtenido mayoría absoluta y 186 escaños, en las generales de 2015 pierde nada menos que 63 escaños y se queda con tan solo 123, si bien aún mantiene la mayoría simple del Congreso. Así mismo, en la repetición de las generales en junio de 2016, el PP experimenta una ligera subida de 14 escańos y alcanza los 137, pero se queda de nuevo muy lejos de la mayoría absoluta, aunque manteniendo la mayoría simple.

Por su parte, la trayectoria del PSOE es aún más compleja. Sumido en una clara desorientación ideológica y en una profunda crisis interna (Rodríguez Guerra, 2018), ya en las elecciones de 2011 había perdido la friolera de 59 escaños descendiendo hasta los 110. Pero en las generales de 2015 experimenta un nuevo descenso, perdiendo otros 20 escaños y quedándose con tan solo 90 . Así mismo, en las generales de junio de 2016 vuelve a experimentar otro retroceso electoral de cinco escaños y retrocede hasta los 85 , esto es, obteniendo los peores resultados de su historia reciente, si bien aún sigue siendo la segunda fuerza política.

Si tomamos ahora como punto de referencia los resultados obtenidos por los dos grandes partidos en las generales de 2011, nos encontramos con que los descensos electorales del PSOE y el PP en las generales de 2015 se traducen en la pérdida de 122 escaños (63 del PP y 59 del PSOE) y de 113 escaños en las generales de 2016 (49 del PP y 64 del PSOE). De hecho, también cabe señalar que -como venía siendo habitual en los diferentes procesos electorales- mientras en 2011 los dos grandes partidos (PP y PSOE) habían obtenido cerca del $80 \%$ de los escańos y del $70 \%$ de los votos, en las generales de diciembre de 2015 tan solo obtienen en torno al $60 \%$ de los escaños y el $50 \%$ de los votos.

Resulta obvio por tanto no solo que en ambas convocatorias electorales ocurrió un importante cambio de preferencias ideopolíticas entre el electorado (fuerte movilidad electoral en favor de Podemos/UP y de Ciudadanos) y se inició una nueva y más agria fase de la contienda político-partidista. También es evidente que el espacio político y electoral abierto por las nuevas fuerzas políticas fue en verdad

\footnotetext{
4 Para una reflexión crítica sobre el uso de la noción de «bipartidismo imperfecto» $c f$. Rodríguez Guerra (2020: 16 y ss.)
} 
muy amplio y que el grado de fragmentación y polarización del sistema se amplió considerablemente. Así, en el caso de Podemos, si bien se alejaba de aquel «asalto a los cielos» (Rivero, 2014) que se había propuesto en su primer Congreso, celebrado en diciembre de 2014 y conocido como Vistalegre I, sus resultados en las elecciones generales de 2015 se traducen en la obtención de 42 escaños y conformando -a través de los escaños los obtenidos por las confluencias/coaliciones En Comú Podem (12), Podemos-Compromís (9) y Podemos-En Marea-Anova-EU (6)- un importante grupo parlamentario de 69 escaños, o de 71 si a ellos sumamos los dos obtenidos por IU. Así mismo, en las generales de 2016 obtiene idénticos resultados (71), si bien en este caso ya bajo la coalición electoral Unidos Podemos conformada entre Podemos-IU-Equo y otras formaciones políticas.

Por su parte, en el caso de Ciudadanos hay que señalar que en las generales de 2015 obtiene una más que significativa presencia electoral y parlamentaria. Tanto es así que obtiene casi el $14 \%$ de los votos y 40 escaños. No obstante, en las de 2016 desciende 8 escaños, reduciéndose su presencia al 13\% de los votos y 32 escaños.

Por lo demás, las fuerzas nacionalistas/regionalistas pierden posiciones respecto de las generales de 2011, pues, mientras en estas habían obtenido un total de 36 escaños (CiU 16, Amaiur 7, PNV 5, ERC 3, Bloque Nacionalista Galego 2, Coalición Canaria-Nueva Canarias 2, Geroa Bai 1), en las generales de 2015 pierden 13 escaños y se quedan con un total de 23 (ERC 9, Democràcia i Llibertat 6, PNV 6, Cambio-Aldaketa 1 y CC-PNC 1). Podría decirse así que las nuevas fuerzas políticas no solo presionan y compiten con los dos partidos tradicionales (PSOE y PP), sino también con las de ámbito no estatal. No obstante, estas mismas fuerzas políticas, si bien con algunos cambios, inician un proceso de recuperación de su espacio político y mejoran en dos escaños en las generales de 2016 (ERC-CatSi 9, PDCat 8, PNV 5, EH-Bildu 2 y CC-PNC, 1).

Por último, además de lo ya mencionado, las generales de 2015 y 2016 supusieron otros cambios significativos respecto a las de 2011. En las de 2015 no solo desaparece Unión Progreso y Democracia (que en 2011 había obtenido cinco escaños), sino que $\mathrm{CiU}$-inmersa en una fuerte crisis interna- se presenta a través de la coalición DiL y, aun así, pierde 8 de los 16 escaños que tenía en 2011. A su vez, ERC, que en 2011 había obtenido 3 escańos, incrementa significativamente su presencia parlamentaria y obtiene 9 escańos, resultado que repite en las generales de 2016. Finalmente, cabe reseñar que en las generales de 2015 el BNG pierde los 2 escaños que había ganado en 2011.

De todos estos resultados, que acontecen en un contexto de fuerte competitividad y polarización políticas que llega a expresarse, bien a través de la descalificación y hasta el cuestionamiento de la legitimidad del adversario, o bien por medio de una fuerte movilidad electoral, pueden destacarse cuando menos cuatro conclusiones generales: a) las fuerzas del bipartidismo (PP y PSOE) han experimentado un fuerte descenso, siendo la crisis del PSOE bastante más acusada que la del PP; b) las fuerzas emergentes (Podemos/UP/Confluencias y Ciudadanos) experimentan una rápida aparición sumando aproximadamente nada menos que 120 escaños, si bien ninguna de ellas logra el famoso sorpasso o triunfo sobre sus respectivos adver- 
$\operatorname{sarios}^{5}$; c) la existencia de cuatro fuerzas políticas estatales que obtienen un importante respaldo electoral que les otorga presencia en casi todas las circunscripciones electorales y comunidades autónomas del Estado y, por tanto, que configuran una novedosa competencia tanto entre la izquierda y la derecha como, sobre todo, en y dentro de cada uno de esos espacios, esto es: si en el espacio de la derecha la competencia gira ahora entre el PP y Ciudadanos, en el espacio de la izquierda dicha competencia se produce entre PSOE y Podemos/UP; y d) el importante peso político de las fuerzas estrictamente nacionalistas (ERC, DiL/PDCat, PNV...), que, debido a la fuerte polarización política entre la derecha y la izquierda y al hecho de que en ninguno de estos dos espacios ideopolíticos sus fuerzas suman para formar Gobierno, ahora pueden «contar» (Sartori, 1989: 155 y ss.) de forma decisiva a la hora de formar Gobierno. En suma, las elecciones generales de diciembre de 2015 nos colocan ante un sistema de multipartidismo parlamentario caracterizado por la presencia tanto de cuatro grandes partidos estatales que cuentan a la hora de formar Gobierno (PSOE, PP, Podemos/UP y Ciudadanos) cuanto por la de otras fuerzas nacionalistas/regionalistas que también son necesarias para la misma tarea (ERC, DiL/PDCat, PNV...).

Este último aspecto es realmente novedoso, pues con ello se abría la posibilidad de romper con el tradicional bipartidismo gubernamental (la práctica alternancia de gobiernos de uno solo entre PSOE y PP) que había caracterizado al sistema de partidos del Estado español. No obstante, como veremos seguidamente, aunque tal posibilidad estuvo sobre la mesa y a través de diversas opciones, lo cierto es que en verdad no ocurrió.

\section{LAS POSIBILIDADES E INFRUCTUOSOS INTENTOS DE SUPERAR EL BIPARTIDISMO GUBERNAMENTAL}

Ya hemos seńalado que las generales de diciembre de 2015 dieron lugar a un sistema de multipartidismo parlamentario en el que no había mayorías absolutas ni mayorías simples holgadas (el PP, la fuerza mayoritaria obtuvo tan solo 123 escaños estando la mayoría absoluta en 176 escaños). De ahí surgió la necesidad de establecer coaliciones o pactos de gobierno que, sin embargo, siempre necesitaban del apoyo de tres o más fuerzas políticas, salvo la opción por una gran coalición entre PP y PSOE. Esta última posibilidad estuvo realmente en discusión durante los meses de marzo y abril de 2015, pero no logró obtener respaldo parlamentario ante la exigencia del PSOE de que el PP -implicado en múltiples casos de corrupción- no estuviera en el Gobierno (Clemente, 2016). No obstante, la primera opción a la hora de formar Gobierno fue la propuesta presentada - por sorpresa, en rueda

5 Sobre el debate y la posibilidad del sorpasso de Unidos Podemos al POSE en las elecciones generales de junio de 2016 véase, entre otros muchos, Romero (2016). Sobre la posterior posibilidad, en las generales de 2019, del sorpasso de Ciudadanos al PP véase, por ejemplo, García de Blas (2019). 
de prensa y al parecer sin conocimiento del PSOE (Rivero, 2016) - por Pablo Iglesias en nombre de Podemos y las confluencias afines. Fue este un hecho que sin duda significó un nuevo hito en la historia de la reciente democracia española y en el funcionamiento habitual del sistema de partidos. Hasta entonces el partido que ganaba las elecciones era el que tomaba la iniciativa para la conformación de acuerdos o coaliciones de gobierno. De hecho, tal iniciativa siempre correspondió a uno de los dos grandes partidos (UCD/PSOE o PSOE/PP). Pero ahora era otra formación política la que tomaba la iniciativa.

Presentada hacia finales de enero 2016 y pese a que el PP había sido el ganador de las elecciones (123 escaños), Podemos proponía un Gobierno de coalición presidido por Pedro Sánchez (PSOE, con 90 escaños), con la vicepresidencia de Pablo Iglesias (Podemos, confluencias e IU, con 71 escańos) y con reparto proporcional de ministerios que incluía a Izquierda Unida (Mármol, 2016). Sin embargo, finalizada la ronda de consultas y debido a la falta de acuerdos al respecto, el rey propuso como candidato a la presidencia del Gobierno a quien había ganado las elecciones, esto es, a Mariano Rajoy (PP). Pero este último, ante la falta de apoyos parlamentarios a su candidatura, rechazó someterse a la investidura (Piña, 2016). De ahí que se asistiera entonces a la primera derrota de la posibilidad de poner fin al bipartidismo gubernamental, esto es, a que por primera vez desde las generales de 1977 pudiera articularse en España un Gobierno de coalición en el que tuviera presencia otra (u otras) fuerzas políticas que acompañara al PP o al PSOE.

Poco después, tras nueva ronda de consultas, el rey propone a Pedro Sánchez (PSOE) como candidato a la presidencia. Sánchez acepta la propuesta con el aval de un acuerdo con Ciudadanos (Díaz, 2016) y el posible apoyo del PNV (Robles y Ruiz Sierra, 2016). Fue este un momento de especial trascendencia para Podemos y las fuerzas a la izquierda del PSOE: en primer lugar, por la negativa de Podemos a apoyar desde fuera un Gobierno del PSOE y Ciudadanos y, en segundo lugar, por su posterior decisión de conformar la coalición electoral Unidos Podemos, a la que las encuestas llegaron a colocar -ya hacia finales de abril de 2016 y en el contexto de posible repetición electoral- como segunda fuerza política y, por tanto, apuntando la posibilidad de un sorpasso al PSOE (El Pais, 2016). No obstante, a inicios de marzo de 2016 Pedro Sánchez se sometió al debate de investidura, si bien lo perdió con 131 votos a favor y 219 en contra (Calleja, 2016). Fue una nueva derrota de la opción por una cierta estabilidad institucional y, al tiempo, de otra posibilidad de poner fin al bipartidismo gubernamental.

En los convulsos y complejos meses posteriores continuaron los contactos entre las fuerzas políticas, permaneciendo vigente el acuerdo previo entre PSOE-Ciudadanos. Se discutían entonces al menos tres posibilidades: a) un pacto entre PSOE, Ciudadanos y Podemos, que fracasó por las sendas negativas de Ciudadanos y de Podemos; b) un pacto PP-PSOE-Ciudadanos, que tampoco obtuvo respaldo ni del PP ni del PSOE; y, finalmente, c) la ya citada opción de gran coalición entre PP y PSOE, que tampoco obtuvo respaldo. La situación de bloqueo interpartidista e institucional era ya más que evidente. Pero a ella subyacía una doble e importante novedad en el sistema español de partidos a la que cabría resumir bajo la idea de un nuevo «empate minoritario» entre los bloques de la izquierda y de la derecha: de un 
lado, los resultados electorales volvieron a traducirse en poco menos que un empate entre los bloques de la derecha (PP, Ciudadanos, Vox) y la izquierda (PSOE, UP) $y$, de otro, la suma de los escaños logrados por cada bloque de fuerzas estatales no alcanzaba la mayoría absoluta.

Finalmente, tras una tercera ronda de consultas, el rey decide no proponer candidato para la presidencia del Gobierno. Se disuelven por ello las Cortes y -por primera vez en la historia democrática reciente y en un contexto de inestabilidad y crisis institucional-culmina una de las legislaturas más cortas de la reciente democracia española y se convocan nuevas elecciones generales que se celebrarían finalmente el 26 de junio de 2016.

\section{NUEVO EMPATE MINORITARIO Y MOCIÓN DE CENSURA. LAS GENERALES DE JUNIO DE 2016}

Las elecciones de junio de 2016 volvieron a dejar un panorama partidista abiertamente complejo, pues los resultados electorales arrojan un nuevo empate minoritario entre el bloque de fuerzas estatales de la derecha (la suma de PP y Ciudadanos solo alcanzaba los 169 escaños) y el bloque de fuerzas estatales de la izquierda (la suma de PSOE y UP se quedaba en 156 escańos). El PP ganó las elecciones generales de 2016, si bien tan solo alcanzó una mayoría simple de 137 escaños. El PSOE retrocedió nuevamente, perdiendo cinco escaños y descendiendo hasta los 85 . Por su parte, también Ciudadanos experimentó una ligera bajada perdiendo 8 escaños y quedándose con 32. Por último, la coalición UP y sus aliados territoriales se queda lejos del anunciado sorpasso al PSOE, aunque obtiene los mismos resultados que en las generales de 2015 (71 escaños), pero pierde más de un millón de votos y afronta fuertes tensiones internas.

Conviene sin embargo detenerse en otras circunstancias y procesos postelectorales en tanto que tienen importantes efectos sobre la dinámica y la contienda política de entonces. Recordemos a este respecto que, por una parte, el primer debate de investidura a que se sometió Rajoy -avalado por un pacto de legislatura entre Ciudadanos y el PP (con el apoyo de Coalición Canaria) - se frustró por la falta de mayoría y por el famoso «no es no» de Pedro Sánchez a Rajoy, lo cual dejaba la investidura de Rajoy con más votos en contra que a favor; $y$, por otra, que en el segundo debate de investidura a que se sometió (finales de octubre de 2016), Rajoy solo logra ser investido gracias al apoyo del PP, Ciudadanos, Coalición Canaria, UPN y Foro Asturias y, sobre todo, gracias a la abstención de 68 diputados/as del PSOE tras el derrocamiento de Pedro Sánchez como secretario general del partido.

En este momento, no solo quedaba claramente refrendado el multipartidismo parlamentario. También lo quedaba el pluripartidismo gubernamental -incluso recurriendo a una interpretación estricta del criterio sartoriano de los que cuentanen tanto que ahora son al menos seis los partidos que tienen relevancia para formar Gobierno, aunque cabían otras opciones. No obstante, el Gobierno del PP no solo poseía una enorme fragilidad, sino que, al mismo tiempo, se ve abocado a afrontar la crisis catalana, el creciente descrédito de diferentes instituciones y de la clase 
política, las múltiples movilizaciones ciudadanas (pensionistas, feministas...) y, sobre todo, el proceso de corrupción sistémica que se atribuía al partido.

Junto a estos procesos, la convulsa vida interna del PSOE seguía lastrando el presente y futuro de un partido que se consideraba central para la articulación del Estado español y de su sistema de partidos. Especialmente relevante fue, en este periodo, la renuncia de Pedro Sánchez a su acta de diputado "para no traicionar ni a su palabra ni a su partido» (es decir, para mantener su «no es no» al PP y no verse obligado a aceptar la decisión del PSOE de abstenerse en la investidura de Rajoy), así como su propósito de «recorrer de nuevo todos los rincones de Espańa» para afrontar un nuevo proceso de primarias en las elecciones internas a secretario general del PSOE. Primarias que, de forma sorprendente y frente a los sectores oficialistas, volvió a ganar (Díaz y Marcos, 2017).

En medio de este y otros conflictos, y poco después de que la Audiencia Nacional considerara probado que el PP se había financiado ilegalmente (la trama Gürtel) y confirmara la existencia de una estructura de contabilidad paralela del partido desde 1989 (la famosa caja B), Pedro Sánchez -sin ocupar escaño en el Congreso- presentó a través del grupo parlamentario del PSOE una moción de censura al Gobierno de Rajoy en junio de 2018. En ella el líder del PSOE contaba con solo 85 escańos propios, pero también con el apoyo de UP, ERC, PNV, PDeCAT, Compromís, Bildu y Nueva Canarias. Por primera vez en la reciente historia de la democracia española, la moción de censura triunfa y, poco después, Sánchez es proclamado presidente del Gobierno. Tras ello, Mariano Rajoy presentó su dimisión como presidente del PP, siendo reemplazado - tras una tensa disputa interna- por Pablo Casado. En todo caso, es evidente que unos y otros acontecimientos muestran las fuertes tensiones y crisis internas a que estaban sometidos los dos grandes partidos del Estado español, al tiempo que apuntan al descontento que el electorado mostraba hacia ellos.

Sánchez, que había manifestado en la misma sesión de la moción de censura que -si era elegido presidente- convocaría elecciones cuanto antes, cambia posteriormente de posición y manifiesta su intención de agotar lo que quedaba de legislatura, esto es, de gobernar hasta junio de 2020 (Díaz, 2018). Pese a ello, el Congreso no aprueba los Presupuestos Generales del Estado para 2019 (Castro, 2019). La situación de bloqueo y debilidad del Gobierno es pues evidente y Sánchez se ve obligado a emplazar al país a unas nuevas elecciones anticipadas, que finalmente se convocan para el 28 de abril de 2019.

No obstante, antes de adentrarnos en los resultados de estas últimas elecciones y sus consecuencias sobre el sistema de partidos, conviene detenernos por un momento en algunas circunstancias de suma relevancia para comprender el tenso contexto en el que ocurren. Así, al margen fenómenos novedosos a los que seguidamente aludiré, creo pertinente mencionar, en primer lugar, la persistencia del conflicto catalán y la aplicación del artículo 155 a Cataluña y sus consecuencias (en especial, la suspensión de la autonomía catalana, la detención, encarcelamiento y enjuiciamiento de buena parte del Gobierno catalán y la intensísima polarización política al respecto a través de «la España de los balcones»); en segundo lugar, los resultados de las elecciones andaluzas del 2 de diciembre de 2018, que supusieron un 
auténtico terremoto político a causa de la fuerte irrupción en el Parlamento andaluz de una fuerza de ultraderecha (Vox) con 12 escaños. También por el importante descenso de los dos grandes partidos en Andalucía (el PSOE andaluz pierde nada menos que 14 escaños y el PP andaluz pierde 7) y, particularmente, por el hecho de que el PSOE -tras 36 años de Gobierno ininterrumpido- perdió el Gobierno de Andalucía, su feudo histórico por excelencia (con Susana Díaz -opositora interna de Pedro Sánchez- como la principal damnificada) (Sáiz, 2018); por último y, en tercer lugar, la fractura interna de Podemos. No cabe olvidar a este respecto que las diferencias políticas y estratégicas en el interior de Podemos - que ya fueron evidentes en Vistalegre II (febrero de 2017) - se traducen en múltiples problemas y diversas escisiones internas, en repetidos descensos electorales autonómicos y municipales y, finalmente, en una crisis interna de Podemos que se refleja, entre otras cosas, en el abandono de la organización de buena parte de sus fundadores (Luis Alegre, Íñigo Errejón, Carolina Bescansa, Ramón Espinar, etc.) (Espinar, 2019).

No obstante, más allá de estas circunstancias, parece evidente que el sistema de partidos del Estado español quedará caracterizado a partir de los resultados de tales elecciones por fenómenos como a) el crecimiento del pluralismo ideopolítico y de la fragmentación partidista; b) el retorno de los ejes izquierda-derecha y estatalismo-nacionalismo como base para una fuerte polarización del debate ideopolítico; c) la extendida conciencia acerca del fin del llamado bipartidismo imperfecto y la ausencia de partidos con mayorías amplias tanto en el espacio de la derecha como en el de la izquierda; d) la situación de empate minoritario entre uno y otro bloque ideopolítico y, en consecuencia, las dificultades de las fuerzas del tradicional bipartidismo gubernamental (PSOE y PP) para conformar gobiernos en tanto que siempre requería la presencia/apoyo de varios partidos; e) el decisivo papel de las fuerzas nacionalistas (de uno y otro signo ideopolítico) a la hora de resolver el empate entre los bloques de la derecha y la izquierda y formar gobierno; f) la acentuación -tras la aparición de Vox- de la dura disputa por (y en el interior de) el espacio electoral de la derecha (lo cual generará el recrudecimiento de los discursos racistas, xenófobos, sexistas, antigualitaristas, euroescépticos..., así como un notorio giro a la derecha del PP y de Ciudadanos) y el espacio de la izquierda (en este caso por mantener y conquistar el electorado progresista para sus diversas opciones); g) la cruda polarización o incluso crispación (Tezanos, 2019) política e ideológica tanto en torno al eje derecha/izquierda como sobre el eje estatalismo/nacionalismo; y, finalmente, h) la creciente dependencia del partido en el Gobierno respecto de minorías con capacidad de bloqueo y, como consecuencia de ello, la acentuación de las tendencias presidencialistas o, en fin, del recurso al gobierno por decreto. Pese a todo ello, debe destacarse que en esta compleja y convulsa situación el bipartidismo gubernamental se mantiene, pues el Gobierno en minoría que se forjó durante este periodo siguió siendo un Gobierno de un solo partido, en este caso del PSOE. 


\section{FIN DE LA EXCEPCIÓN ESPAÑOLA Y CORDONES SANITARIOS. LAS GENERALES DE ABRIL DE 2019}

En febrero de 2019 el Gobierno en minoría del PSOE presenta en el Congreso los Presupuestos Generales del Estado para 2019. Pero tales Presupuestos fueron derrotados con 191 votos a favor de las enmiendas de devolución (PP, Ciudadanos, PDeCAT, ERC, EH Bildu, Coalición Canaria y Foro Asturias), 158 votos en contra de tales enmiendas (PSOE y UP) y una abstención (NC). De esta forma, quedaba evidenciada la debilidad del Gobierno y la situación de bloqueo institucional. El PSOE se ve forzado así a convocar nuevas elecciones anticipadas, que finalmente se celebrarían el 28 de abril de 2019.

Los resultados de las generales de abril de 2019 generaron algunos cambios en el sistema de partidos, pero se tradujeron -entre otras cuestiones- en un nuevo empate minoritario entre los bloques de la izquierda y la derecha. En todo caso, puede decirse de forma sumaria que en ellas tuvo lugar a) la consolidación del fin de la excepción española a causa de la irrupción de la ultraderecha, representada por Vox, con 24 escaños en el Congreso de los Diputados; b) una cierta recuperación del PSOE, que fue el ganador de las elecciones (sube 38 escańos y alcanza los 123), aunque solo obtiene una mayoría simple muy lejana de la absoluta; c) un desastre electoral del PP, que pierde nada menos que 71 escańos y se queda con solo 66 (desde 1989, en que se refundó, había estado siempre por encima de los 100 escaños); d) un ascenso significativo de Ciudadanos, que obtiene 25 escaños más y alcanzó los 57, a tan solo 11 del sorpasso al PP; y, finalmente, e) una importante pérdida de escaños por parte de Unidas Podemos, que baja a 35 y que se suma a otros importantes descensos de varias confluencias en las que participa, quedando finalmente con un grupo confederal de 42 escaños (lejos de los 71 de junio de 2016).

Por otro lado, con respecto a las fuerzas políticas nacionalistas/regionalistas cabe destacar el ascenso de 3 escaños de ERC, que obtiene 12; el ligero retroceso de JxCat (antes DiL y PDCat), que pierde un escaño y se queda con 7; el tenue ascenso del PNV, que gana un escaño al obtener 6; el ascenso de EH Bildu, que obtiene 4 y asciende en 2 escaños; el suave incremento de CC-PNC, que sube 1 escaño al obtener 2; la aparición de Navarra Avanza, que obtiene 2 (aunque es una coalición entre UPN, PP y Ciudadanos); la presencia de Compromis con 1 (aunque en 2015 se había presentado bajo la coalición A la Valenciana-Podemos, IU-Compromís-, que había obtenido 9 escaños); y, por último, la aparición parlamentaria de Partido Regionalista de Cantabria, que obtiene 1 escaño. Por tanto, el peso de las fuerzas políticas nacionalistas/regionalistas ha aumentado significativamente, pasando de 25 escaños en 2016 a 35 en 2019.

De esta forma, el escenario resultante de las generales de abril de 2019 nos coloca ante un sistema de partidos en el que ahora son ya cinco los grandes partidos que tienen una presencia más que significativa en el sistema. Con todo, sigue siendo evidente -pese a cierta recuperación y ventaja relativa del PSOE respecto del resto de fuerzas políticas- la fragmentación y diversidad del sistema de partidos, así como la situación de bloqueo e inestabilidad institucional debido a las dificultades para articular mayorías de gobierno. A todo ello se suma un nuevo incremento 
de la polarización cuya máxima expresión acaso fuesen las líneas rojas o cordones sanitarios que se establecieron entre unas y otras fuerzas políticas. En este terreno, en el que la cuestión catalana sigue marcando significativamente las posiciones de los diferentes partidos, destacan a) la negativa de Ciudadanos a pactar con Unidas Podemos (a los que, en este momento, considera extremistas radicales y anticonstitucionalistas) y con el PSOE (al que tacha de anticonstitucionalista, vendido a los independentistas y a los extremistas de Podemos; b) la misma negativa de Ciudadanos a pactar con Vox, si bien luego admite diversos acuerdos de gobierno en diferentes comunidades autónomas; c) la negativa del PP a pactar con el PSOE (al que llega a acusar de felón, traidor...) o Unidas Podemos (al que considera igualmente extremista, radical o anticonstitucionalista). Pero también destaca la disputa del PSOE y de UP en torno al acceso de esta última coalición al Gobierno y, en definitiva, sobre la posibilidad de poner fin al bipartidismo gubernamental. No es necesario detenernos aquí sobre los pormenores de esta polémica, que tuvo derivaciones realmente sorprendentes como el veto del PSOE a que el líder de UP, Pablo Iglesias, formase parte del Gobierno (Hernández, 2019) o sus dudas respecto a la lealtad al Gobierno de los miembros de UP que formasen parte del mismo (Torres, 2019). Lo relevante a nuestros efectos es que, si bien en un primer momento el PSOE acepta la posibilidad de que UP acceda al Gobierno ocupando varios ministerios, lo cierto es que finalmente tal posibilidad se frustra, al parecer a causa de un desacuerdo entre PSOE y UP respecto a las competencias sobre políticas activas de empleo, que había reclamado el líder de UP para su formación. En suma, nos situamos así en un momento en el que, tras la preceptiva ronda de consultas del rey, Pedro Sánchez rechaza por falta de acuerdos la presentación de su candidatura y, nuevamente y por cuarta vez en menos de cuatro años (recuérdense las generales de diciembre de 2015, las de junio de 2016 y las de abril de 2019), se vuelven a convocar nuevas elecciones generales para noviembre de 2019. Con ello se abre un momento más de incertidumbre político-institucional cuyo aspecto más novedoso acaso sea el crecimiento del clima de desafección política ciudadana, de hartazgo e insatisfacción ciudadana con el sistema, los partidos y los líderes políticos. Tanto es así que combatir la fuerte tendencia a la abstención electoral se convierte en el principal objetivo de los partidos políticos.

\section{MULTIPARTIDISMO PARLAMENTARIO Y PLURALISMO GUBERNAMENTAL. LAS GENERALES DE NOVIEMBRE DE 2019}

Un breve repaso a los resultados de las generales de noviembre de 2019 nos muestra que, pese a que presentan ciertos elementos de continuidad con respecto a las generales anteriores, aportan también algunos cambios significativos en el sistema de partidos del Estado español. No obstante, siguen formando parte de un convulso ciclo político-electoral iniciado en 2015. Un ciclo marcado por la clara tendencia hacia el multipartidismo parlamentario y polarizado, por importantes grados de independencia o desalineamiento de los votantes respecto de los dos grandes partidos, por una notable volatilidad electoral, por sucesivos empates minoritarios 
entre los bloques de las derechas y de las izquierdas estatales y, finalmente, por las dificultades a la hora de formar y mantener el Gobierno.

Del lado de la continuidad se encuentra, en primer lugar, el nuevo empate minoritario entre los bloques de las izquierdas y las derechas estatales, aunque se han dado importantes cambios en el interior de cada bloque, en especial en el de las derechas. Así, en el bloque de las izquierdas asistimos a otra victoria del PSOE, aunque con solo 120 escaños. Es cierto que con tal triunfo aumenta ligeramente su ventaja respecto a UP, pero no es menos cierto pierde tres escańos y se queda de nuevo muy lejos de la mayoría absoluta. Podría decirse así que la estrategia electoral del PSOE, al parecer guiada por el deseo de ampliar su mayoría simple, había fracasado. Asistimos igualmente a un nuevo descenso de UP, que retrocede hasta los 35 escaños (antes tenía 42), y a la aparición de una nueva fuerza política, Más PaísEquo, que tan solo obtiene 3 escaños, aunque -frente a lo que inicialmente se sugería (Diariocrítico, 2019) - parece que poco afectó al descenso de UP.

Por su parte, en el bloque de las derechas cabe reseñar que el PP se mantiene como segunda fuerza política y recupera terreno con una significativa subida de 22 escaños que lo sitúa con 88 (antes 66). Destaca también el fuerte crecimiento de la ultraderecha representada por Vox, que obtiene 52 escaños (28 más que en las elecciones anteriores), consolidando nuevamente el fin de la excepción espańola y convirtiéndose en un partido homologado con sus socios de la ultraderecha europea. Y sobresale finalmente la imponente debacle de Ciudadanos, que, tras su errática y polarizadora estrategia política, así como tras su decidido giro a la derecha, se queda con solo 10 escaños. Lo realmente significativo es que pierde nada menos que 47 escaños, probablemente a causa de un importante y mayoritario trasvase de votos desde Ciudadanos al PP y a Vox.

De estos resultados electorales se desprende una segunda continuidad: la suma de PSOE, Unidas Podemos y Más País-Equo (158 escaños) en poco se diferencia de la suma entre PP, Vox y Ciudadanos (152, añadiendo los dos obtenidos por Navarra Suma). De hecho, en estas elecciones el insistente empate minoritario entre ambos bloques ideopolíticos fue incluso más evidente que en las pasadas elecciones. Pero este reiterado empate entre los dos bloques de fuerzas estatales sugiere al mismo tiempo varias hipótesis que pudieran abrir la puerta a una adecuada comprensión de la nueva dinámica del sistema de partidos: por un lado, todo apunta a la consolidación de un modelo de competencia política en el que la tradicional competitividad entre los dos grandes partidos ha sido sustituida por la lucha entre cinco o seis partidos estatales; por otro lado, parece que también se consolida un modelo de lucha política en el que sobresale tanto una competencia nada virtuosa entre los dos grandes bloques ideopolíticos cuanto también la batalla entre partidos de un mismo bloque ideopolítico. De hecho, la persistente polarización política y la interposición de cordones sanitarios o vetos hacia los partidos del otro bloque ideopolítico apuntan igualmente hacia esa posibilidad. No obstante, el último giro dado por Ciudadanos a raíz de la citada debacle electoral, la posterior dimisión de Albert Rivera y el nuevo liderazgo de Inés Arrimadas pudiera apuntar a un giro -aún por confirmar- hacia el centro que lo alejaría de dicha dinámica. Pero, por último, estos reiterados resultados sugieren también que la movilidad electoral o el 
cambio de preferencias electorales de la ciudadanía quizá haya tenido lugar -aunque no solo- más entre las fuerzas políticas de un mismo bloque ideopolítico que entre fuerzas de uno y otro bloque (Torcal, 2019).

La tercera de las continuidades residiría en que, una vez más, de los resultados electorales parecía abrirse la posibilidad de un nuevo bloqueo para la formación de Gobierno y hasta la posibilidad de una nueva repetición de las elecciones. De hecho, si bien de las generales de abril de 2019 se desprendían serias posibilidades -que finalmente no cuajaron- de sumar entre las izquierdas y formar Gobierno de coalición contando con la colaboración de varios partidos nacionalistas/regionalistas, de las generales de noviembre de 2019 -que, recordemos, se tradujeron en un ligero descenso de las izquierdas estatales y un igual aumento de las derechas estatales- se desprendía inicialmente que tal posibilidad era aún más incierta. La persistencia del bloqueo y la continuidad de la crisis política (Alabao, 2019), las dificultades para formar Gobierno y la posibilidad de unas nuevas elecciones generales constituían entonces algunos de los ejes y preocupaciones del debate político. Aun así y aunque parezca contradictorio, estos resultados reflejaron otra nueva continuidad con los de abril de 2019: la posibilidad de que las fuerzas nacionalistas/regionalistas pudieran deshacer el empate entre los bloques de las derechas y las izquierdas estatales.

No obstante, la pésima relación -y hasta los vetos- que las derechas estatales (PP, Ciudadanos y Vox) habían venido sosteniendo frente a la gran mayoría de los partidos nacionalistas apuntaba hacia una dinámica del sistema de partidos en la que el desempate entre los bloques ideopolíticos y la posibilidad de formar Gobierno solo podría venir del lado de un acuerdo progresista, esto es, entre las izquierdas estatales y algunas fuerzas nacionalistas/regionalistas de distinto signo ideopolítico. De ahí se desprendía una última continuidad con respecto a los resultados de las generales de abril de 2019: cerrada la posibilidad de la gran coalición a raíz de los mutuos vetos que se habían interpuesto el PP y el PSOE, quedaba igualmente descartada la posibilidad de que el bloque de las derechas pudiera formar Gobierno. Sí podía lograrlo el bloque de las izquierdas, aunque para ello tenía que contar con una compleja red de colaboraciones y acuerdos (coalición, acuerdo de legislatura, acuerdo de investidura, pactos específicos) con muy diversas fuerzas regionalistas/ nacionalistas. Esta circunstancia, que, insistimos, también existió tras las generales del pasado abril, ha generado no pocos debates, de una parte, en torno al cariz de las estrategias político-electorales del PP y Ciudadanos y, de otra, sobre las razones que impidieron el acuerdo progresista tras las generales de abril de 2019.

En el primer caso, lo que estaba en discusión fue, de un lado, las consecuencias y los resultados de la estrategia de polarización, confrontación y hasta crispación que las derechas estatales han sostenido y sostienen tanto frente a las izquierdas como contra los partidos nacionalistas (en especial a través del problema territorial y la cuestión catalana) y, de otro, la estrategia de complicidad y colaboración que el PP y Ciudadanos han mostrado hacia la ultraderecha representada por Vox. Estas dos estrategias tienen singular relevancia tanto para la dinámica del sistema de partidos como para la propia democracia, pues parece evidente que - de persistir- no solo perdurará una dinámica partidista de enfrentamiento y polarización. 
También se ocasionarán graves daños a la convivencia política y al propio sistema democrático. Es más, en un contexto multipartidista -salvo circunstancias excepcionales o cambios importantes en las preferencias electorales de la ciudadanía- supondrá serias dificultades para el acceso al poder y al Gobierno del PP y Ciudadanos o, acaso de mayor importancia, para alcanzar acuerdos acerca de los denominados grandes temas de Estado. Pero todo ello, conviene retenerlo, no hará más que alargar la sombra de inestabilidad y provisionalidad del sistema político y, sobre todo, de sus instituciones fundamentales.

No obstante, como decíamos más arriba, estas elecciones también han aportado varios e importantes cambios políticos. Uno de ellos es sin duda la realidad de un sistema de partidos mucho más plural, rico y complejo. Tanto es así que, considerando por separado las coaliciones conformadas por Podemos-IU y sus confluencias (ECP y Podemos-EU), así como por el PP y Ciudadanos (Navarra Suma) y Más País (EQUO-Compromís), mientras en las elecciones generales de abril de 2019 fueron quince las fuerzas políticas que obtuvieron representación parlamentaria, ahora nos encontramos con nada menos que veinte. La novedad reside en que, junto a las fuerzas nacionalistas/regionalistas que ya tenían representación (ERC, JxC, PNV, EH-Bildu, CC/NC, Navarra Suma, PRC, a las que podríamos añadir ECP y Podemos-EU), emergen ahora no solo una nueva fuerza política de carácter estatal (Más País-Equo), sino varios nuevos o viejos partidos de ámbito regional o nacionalista (CUP, BNG, Compromís, Teruel Existe). En todo caso, nuestro sistema de partidos queda ahora conformado por seis fuerzas políticas de ámbito estatal (tres en el bloque de la izquierda y tres en el de la derecha) y catorce de carácter nacionalista/regionalista de diverso signo ideopolítico.

Este último hecho alude, por una parte, a la realidad de una rica pluralidad basada en los polos izquierda/derecha y centralismo/nacionalismo, y en sus complejas combinaciones y modulaciones en la España actual. Pero alude también a la diversidad existente en el interior de cada uno de estos polos. De hecho, sugiere que convendría tomar buena nota de la configuración multipartidista y multipolar de un sistema de partidos en el que, como decíamos más arriba, conviven derechas estatalistas y nacionalistas con izquierdas estatalistas y nacionalistas. Y todo ello no refleja más que la realidad y persistencia del sano pluralismo ideológico inherente a toda sociedad democrática, al que en nuestro caso habría que añadir la igual permanencia de la cuestión territorial o del carácter plurinacional del Estado español.

Otro cambio significativo de estas elecciones es que han supuesto un avance en el número de escańos y en el peso político de las fuerzas nacionalistas. Esto sugiere que es posible que la estrategia recentralizadora de las derechas haya tenido como consecuencia su efecto contrario, esto es, el reforzamiento de las opciones nacionalistas/regionalistas. Pero también apunta a que las realidades y problemáticas de cada una de las regiones/nacionalidades no están encontrando adecuada respuesta por parte de las fuerzas estatales. Pero, sea como sea y sin incluir entre ellas a ECP y Podemos-EU, el sistema estatal de partidos se encuentra ahora con que mientras en las elecciones de abril de 2019 las fuerzas nacionalistas/regionalistas obtuvieron en conjunto 38 escaños y el 10,1\% de los sufragios, tras las últimas elecciones han alcanzado los 42 escaños y el 12\% de los votos (Lugilde, 2019). Ello ha sido posi- 
ble por la emergencia de nuevas fuerzas (Teruel Existe, BNG, CUP, Compromís), por la mejora de las posiciones de otras (JxC, HB-Bildu), por el mantenimiento de otras (PNV, CC/NC, PRC) o por el ligero descenso de ERC, que con sus 13 escańos sigue siendo, con diferencia, la mayor de las fuerzas nacionalistas.

Esta diversidad de fuerzas estatalistas y nacionalistas sugiere que, si bien en momentos anteriores a 2015 podría hablarse de un sistema pluripartidista, tras estas elecciones avanzamos decididamente hacia la consolidación de un modelo de multipartidismo parlamentario o, incluso, hacia un multipartidismo polarizado. Es cierto que la fuerte polarización e incluso crispación lleva a creer que el multipartidismo conduce inherentemente a la inestabilidad y el conflicto. Pero acaso estos problemas no sean tales y, sobre todo, no estén tan relacionados con el multipartidismo y la fragmentación del sistema de partidos cuanto con las estrategias de confrontación y polarización políticas. De hecho, incluso antes de las generales de abril de 2019, no faltaba quien señalara con acierto que «la experiencia europea muestra que las sociedades democráticas pueden convivir con la fragmentación, pero también que es más difícil de gestionar si viene acompañada de una polarización extrema. La estigmatización de los adversarios políticos como enemigos del país o que la campaña gire más en torno a los vetos y las políticas de alianzas de cada uno que sobre sus propuestas y prioridades son motivos para la preocupación» (Fernández-Albertos, 2019). En cualquier caso, la inquietud por el convulso ciclo político y electoral ha llevado a sostener que es necesaria una suerte de restauración del bipartidismo gubernamental, la recuperación de la vieja fórmula de la gran coalición, el establecimiento de sistemas electorales mayoritarios reforzados o, en fin, una vuelta a un nuevo consenso en el centro. Frente a tales deseos acaso sea mejor contemplar la posibilidad de que este ciclo político pueda continuar a través de un multipartidismo parlamentario capaz de poner fin al bloqueo y la inestabilidad institucional, así como de afrontar algunos de los importantes malestares sociales que padece la sociedad española.

Ha sido precisamente esta la novedad más significativa tras los últimos resultados electorales. El tan sorprendente como rápido preacuerdo al que llegaron el PSOE y UP para la formación de un Gobierno progresista de coalición, así como el apoyo directo o indirecto que obtuvo tal propuesta por parte de muy diversas fuerzas nacionalistas/regionalistas y la estabilidad del mismo desde entonces hasta el presente, permite albergar alguna esperanza en este sentido. Es cierto que ese mismo Gobierno se enfrenta hoy tanto a las dificultades derivadas de la aparición la pandemia de coronavirus covid-19 como, entre otros muchos desafíos y ataques, a la necesidad de tramitar y aprobar por fin unos nuevos presupuestos estatales. Pero, centrándonos en lo que aquí nos interesa, la continuidad de tal Gobierno de coalición aportaría cierta confirmación de que, en un sistema multipartidista como el actualmente existente en el Estado español, es posible preservar su rica pluralidad ideopolítica y mantener la estabilidad político-institucional, si bien conviene insistir en que -frente a lo que suele afirmar por parte del bloque de la derecha- la crisis de algunas de las instituciones fundamentales del Estado nada ha tenido que ver con el multipartidismo, sino, por el contrario, con otras prácticas tan poco edificantes como la corrupción, los vetos y cordones sanitarios, la polarización y la crispación 
política, etc. Supondría igualmente el reconocimiento de que -al igual que ocurre ya en muchas comunidades autónomas y en otros Estados de nuestro entorno- el viejo bipartidismo gubernamental puede haber tocado a fin o, cuando menos, que resulta inviable e incluso indeseable en sociedades realmente plurales y pluralistas. Pero también significaría un primer paso para la sustitución del bipartidismo gubernamental por el pluripartidismo gubernamental. El Gobierno de coalición que, a día de hoy, conforman el PSOE y UP tropieza sin duda con serias dificultades que no solo derivan de la aritmética parlamentaria. Provienen también del contexto de polarización y crispación, de la realidad del conflicto catalán, de la crisis de la monarquía, de los graves problemas sociales que soporta la ciudadanía o, en fin, de la nueva crisis (ya recesión) económica ocasionada por la pandemia que nos asola. En todo caso, de su éxito o fracaso depende la posibilidad de dar por culminado el convulso ciclo político-electoral que se inició en las generales de 2015 y de avanzar hacia la estabilidad y consolidación de un sistema de multipartidismo parlamentario y pluripartidismo gubernamental.

\section{CONCLUSIONES}

Como hemos ido señalando a lo largo de este trabajo, desde las generales de 1977 hasta el presente, el sistema de partidos del Estado español ha experimentado muy diversos cambios que permiten referirse al mismo como un sistema que, a través de diversos de ciclos políticos-electorales, ha transitado desde el pluripartidismo parlamentario de bipolaridad moderada (García Cotarelo y Bobillo, 1991) y bipartidismo gubernamental al multipartidismo parlamentario polarizado y pluripartidismo gubernamental. En ese tránsito ha quedado evidenciado que las diferencias entre los partidos tienen sus raíces tanto en razones ideológicas (el eje izquierda vs. derecha) como en fuentes étnico-culturales (el eje estatalismo/nacionalismo). Pero quisiera insistir aquí en la idea de que la inestabilidad del sistema se ha debido más a las diversas crisis socioeconómicas, a las crisis institucionales y a la corrupción, a los fuertes grados de polarización y enfrentamiento entre partidos y/o bloques ideopolíticos que a la propia fragmentación del mismo ${ }^{6}$.

En todo caso no quisiera concluir este trabajo sin señalar que en este último ciclo político 2015-2019 hemos asistido a importantes fluctuaciones en los partidos y en el sistema de partidos: a) a la debacle del PSOE y a su relativa recuperación; b) a la hecatombe del PP y a su igualmente débil recuperación; c) al fin del pluripartidismo limitado y la consolidación del multipartidismo parlamentario; d) al fin del consenso en el centro y a la emergencia de fuertes grados de polarización y cris-

${ }^{6}$ Conviene precisar aquí que -como señala Manuel Sánchez de Dios (2018: 121) - «si bien la polarización puede estar vinculada a la fragmentación, no existe una relación directa. Altos niveles de polarización se pueden encontrar tanto en sistemas muy fragmentados como poco fragmentados. Es, por tanto, una dimensión distinta de la fragmentación». 
pación política; e) a la fulgurante emergencia y a la relativa crisis de Podemos/UP; f) al rápido ascenso de Ciudadanos y a su profunda crisis actual; g) a la emergencia y consolidación de Vox, así como a su posible estancamiento y retroceso; h) a la débil emergencia de Más País y a su incierto futuro; i) a sucesivos empates minoritarios entre los bloques de las derechas y de las izquierdas estatales; $\mathrm{j}$ ) al fin del bipartidismo gubernamental y al inicio de un pluripartidismo gubernamental; y por último k), a la persistencia de unas fuerzas nacionalistas/regionalistas que no solo cuentan para formar gobiernos, sino que además han crecido en cuanto a representación e influencia política. En todo caso, si bien el sistema de partidos ha mostrado una amplia inestabilidad desde las generales de 2015 hasta las de noviembre de 2019 y si bien no cabe descartar posibles reajustes en su interior, estamos en un contexto en el que existen indicios que apuntan hacia el fortalecimiento y persistencia de un complejo y plural sistema de partidos marcado por el multipartidismo parlamentario y el pluripartidismo gubernamental, aunque nada permite sin embargo darlo por consolidado. 


\section{REFERENCIAS BIBLIOGRÁFICAS}

Alabao, N. (2019). «Persiste el bloqueo y persiste la crisis política», recuperado de https://www.ara. cat/es/opinion/nuria-alabao-persiste-bloqueo-cirisis-politica_0_2341565981.html.

Calleja, M. (2016). «El Congreso rechaza la investidura de Pedro Sánchez», recuperado de https:// www.abc.es/espana/abci-pedro-sanchez-enfrenta-segunda-votacion-investidura-sin-lograr-sumar-suficientes-apoyos-201603040902_dire.

Castro, I. (2019). «El Congreso tumba los Presupuestos y Sánchez comunicará su decisión sobre las elecciones el viernes», recuperado de https://www.eldiario.es/politica/Congreso-tumba-Presupuestos-Pedro-Sanchez_0_867563411.

Clemente, E. (2016). «Pedro Sánchez: "Descarto totalmente la gran coalición, el PP solo cambiará cuando pase a la oposición”", recuperado de https://www.lavozdegalicia.es/noticia/galicia/2016/03/10/descarto-total.

Diariocrítico. (2019). «Más País robaría cerca del 40\% de los votos a Unidas Podemos, pero no penalizaría al bloque de izquierdas», recuperado de https://www.diariocritico.com/nacional/ mas-madrid-robaria-votos-unidas-podemos-pero-no-penalizaria-bl.

DíAz, A. (2016). «Pedro Sánchez acepta las condiciones de Ciudadanos y anuncia un acuerdo», recuperado de https://elpais.com/politica/2016/02/23/actualidad/1456233618_836694.html.

DíAz, A. (2018). «Sánchez desvela su intención de agotar la legislatura», recuperado de https://elpais. com/politica/2018/06/18/actualidad/1529350124_259738.html.

Díaz, A. y Marcos, J. (2017). «Pedro Sánchez vuelve a ser el secretario general del PSOE», recuperado de https://elpais.com/politica/2017/05/21/actualidad/1495392291_548232.html.

Duverger, M. (1951). Los partidos politicos. México: FCE.

Encarnación, O. (2017). «The Spanish Exception. Why Spain Has Resisted Right-Wing Populism». Foreign Affairs, 20-07-2017, recuperado de https://www.foreignaffairs.com/articles/ spain/2017-07-20/spanish-exception.

Espinar, R. (2019). "Las cinco crisis de Podemos: nada grande puede hacerse sin grandeza», recuperado de https://www.eldiario.es/tribunaabierta/crisis-Podemos-grande-hacerse-grandeza_6_905069511.html.

Fernández-Albertos, J. (2019). "Convivir con el multipartidismo», recuperado de https:/elpais. com/elpais/2019/04/17/opinion/1555515578_826546.html.

García Cotarelo, R. y Bobillo, F. (1991). «El sistema de partidos», en Vidal-Beneyto J., ed., España a debate I. Madrid: Tecnos.

García de Blas, E. (2019). «Rivera se lo juega todo a conseguir el 'sorpasso' al PP», recuperado de https://elpais.com/politica/2019/02/23/actualidad/1550948268_130620.html.

GonZÁlez-Enríquez, C. (2017). «The Spanish Exception: Unemployment, inequality and immigration, but no right-wing populist parties». Real Instituto Elcano, Working Paper, recuperado de http://www.realinstitutoelcano.org/wps/wcm/.

Gunther, R., Sani, G. y Shabab, G. (1986). El sistema de partidos políticos en España: Génesis y evolución. Madrid: Siglo XXI/CIS.

Hernández, M. (2019). «Pedro Sánchez confirma su veto a Pablo Iglesias», recuperado de https:// www.elmundo.es/espana/2019/07/18/5d303febfc6c83dd678b45b9.html. 
LugiLdE, A. (2019). «El voto nacionalista alcanza máximos en Catalunya, se acerca en Euskadi y resurge en Galicia», recuperado de https://www.lavanguardia.com/politica/20191118/471700161340/ congreso-territorial-elecciones-generales-10n-nacionalistas-regiona.

MÁrmol, I. (2016). «Iglesias propone un Gobierno con Sánchez y se arroga “la retirada» de Rajoy”», recuperado de http://www.elperiodico.com/es/noticias/politica/iglesias-propone-gobierno-coalicion-sanchez-4837099.

Martínez Sospedra, M. (1992). «El sistema de partidos español: un caso de partido predominante». Cuadernos de la Cátedra Fadrique Furió Ceriol, 1: 77-92.

Mouffe, Ch. (2007). En torno a lo político. Buenos Aires, FCE.

EL PAÍs, (2016). «La alianza Podemos-IU superaría en votos al PSOE, según Metroscopia», recuperado de https://elpais.com/politica/2016/04/21/actualidad/1461258375_988530.html?rel=mas.

PIŃA, R. (2016). «Mariano Rajoy declina ser candidato a presidente, ¿y ahora qué pasa?», recuperado de https://www.elmundo.es/espana/2016/01/22/56a282ce46163f7d788b457c.html.

Ramírez, M. (1991). Sistema de partidos en España (1931-1990). Madrid, CEC.

Rivero, A. (2014). «Pablo Iglesias abre la Asamblea de Podemos: "El cielo no se toma por consenso: se toma por asalto"”, recuperado de https://www.eldiario.es/politica/Pablo-Iglesias-Asamblea-Podemos-toma_0_314968669.html.

Rivero, E. (2016). «Pablo Iglesias ofrece al PSOE y a IU un Gobierno de coalición con él como vicepresidente», recuperado de https://www.eldiario.es/politica/Pablo-Iglesias-ofrece-Gobierno-Sanchez-IU_0_476302566.html.

Robles, G. y Ruiz Sierra, J. (2016). «Sánchez espera al PNV mientras sube la presión por su pacto con Ciudadanos», recuperado de https://www.elperiodico.com/es/politica/20160225/ sanchez-espera-pnv-mientras-sube-presion-por-pacto-ciud.

Rodríguez Guerra, R. (2018). «Del psoecialismo electoral español. (Notas apresuradas en la evolución del PSOE)», recuperado de https://robertorodriguezguerra.files.wordpress. com/2018/01/del-psoecialismo-electoral-espac3blol.pdf.

Rodríguez Guerra, R. (2020). «Vicisitudes del sistema de partidos del Estado Español (1977-2011): ¿bipartidismo imperfecto, sistema de partido dominante, pluripartidismo limitado?». Laguna. Revista de Filosofia, 46: 9-26.

Romero, J.M. (2016). «El 'sorpasso' de Podemos al PSOE se afianza en los sondeos de los principales periódicos», recuperado de https://www.elconfidencial.com/elecciones-generales/2016-06-18/sorpasso-unidos-podemos-psoe-consolida-encuestas-principa.

SÁız, S. (2018). «El PSOE se hunde, la izquierda pierde la mayoría y Vox irrumpe con 12 diputados», recuperado de https://elpais.com/politica/2018/12/02/actualidad/1543774582_128933.html.

SÁnchez de Dios, M. (2018). «El cambio de los sistemas de partidos en el siglo XXI». Apuntes electorales, 58: 97-132.

Sánchez Medero, G. y Sánchez Medero, R. eds. (2015). Fundamentos de la ciencia política y de la administración. Madrid: Tecnos.

Sartori, G. (1989). Partidos y sistemas de partidos. Madrid: Alianza.

Tezanos, J.F. (2019). «Efectos políticos y sociales de la crispación». Temas para el debate, 296: 6-8, recuperado de https://www.fundacionsistema.com/wp-content/uploads/2018/12/ElPulso_T289.pdf. 
TorCal, M. (2019). «La derecha española: entre la irresponsabilidad democrática y el error estratégico», recuperado de https://ctxt.es/es/20191204/Firmas/29957/voto-ultraderecha-vox-PP-Ciudadanos-Inmigracion-Catalunya.

Torres, C. (2019). «Sánchez da un portazo a Iglesias», recuperado de https://www.elindependiente. com/politica/2019/07/18/ sanchez-da-portazo-iglesias-necesito-vicepresidente-defienda-la-democracia-espanola/.

Vilas Nogueira, J. (2003). «Los partidos políticos en España», en Del Águila, R. ed., Manual de ciencia politica. Madrid: Trotta. 



\section{EVALUADORES / AS}

Silvia Almenara Niebla (ULL)

Francisco Javier Amador Morera (ULL)

Alberto Javier BÁEz García (ULL)

Juan Manuel Cabrera Sánchez (ULL)

Ana Cano Ramírez (ULPGC)

Ramón Faustino Díaz Hernández (ULPGC)

Rosa María DíAz JimÉnez (UPO)

David Fuentefría Rodríguez (ULL)

Sara García Cuesta (ULL)

Verónica Moreira (UAB-Argentina)

Jesús Muyor Rodríguez (UAL)

Sonia Plasencia Carrillo (UlL)

Vanesa Rodríguez Breijo (ULL)

Sarai Rodríguez GonzÁlez (ULL)

Gloria Rojas Rivero (ULL) 
INFORME DEL PROCESO EDITORIAL DE LA REVISTA ATLÁNTIDA 11 (2020)

El equipo de dirección se reunió en las primeras quincenas de los meses de abril y junio y en la segunda quincena de septiembre de 2020 para tomar decisiones sobre el proceso editorial del número 11 de Atlántida.

\section{Estadística:}

N.o de trabajos recibidos en Atlántida: 12.

N. ${ }^{\circ}$ de trabajos aceptados para publicación: 9 (75\%). Rechazados: 3 (25\%). Media de revisores por artículo: 2 .

Media de tiempo entre envío y aceptación: 3 meses.

Media de tiempo entre aceptación y publicación: 2 meses.

Los revisores varían en cada número, de acuerdo con los temas presentados. 


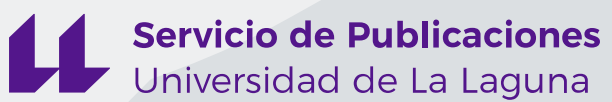

